\title{
WestVirginiaUniversity
}

THE RESEARCH REPOSITORY @ WVU

Graduate Theses, Dissertations, and Problem Reports

2006

\section{Effect of high salt intake on arteriolar responses to metabolic stimuli}

Paul J. Marvar

West Virginia University

Follow this and additional works at: https://researchrepository.wvu.edu/etd

\section{Recommended Citation}

Marvar, Paul J., "Effect of high salt intake on arteriolar responses to metabolic stimuli" (2006). Graduate Theses, Dissertations, and Problem Reports. 4246.

https://researchrepository.wvu.edu/etd/4246

This Dissertation is protected by copyright and/or related rights. It has been brought to you by the The Research Repository @ WVU with permission from the rights-holder(s). You are free to use this Dissertation in any way that is permitted by the copyright and related rights legislation that applies to your use. For other uses you must obtain permission from the rights-holder(s) directly, unless additional rights are indicated by a Creative Commons license in the record and/ or on the work itself. This Dissertation has been accepted for inclusion in WVU Graduate Theses, Dissertations, and Problem Reports collection by an authorized administrator of The Research Repository @ WVU.

For more information, please contact researchrepository@mail.wvu.edu. 
Effect of High Salt Intake on Arteriolar Responses to Metabolic Stimuli

\title{
Paul J. Marvar
}

Dissertation submitted to the School of Medicine at West Virginia University in partial fulfillment of the requirements for the degree of

\author{
Doctor of Philosophy \\ in \\ Physiology
}

\author{
Matthew A. Boegehold, Ph.D., Chairman \\ Mitchell S. Finkel, M.D. \\ Leah W. Hammer, Ph.D. \\ Pingnian He, M.D.,Ph.D. \\ Fred Minnear, Ph.D.
}

\section{Center for Interdisciplinary Research in Cardiovascular Sciences Department of Physiology \& Pharmacology}

\author{
Morgantown, West Virginia \\ 2006
}

Keywords: Microcirculation, Functional Hyperemia, Dietary Salt, Reactive Oxygen Species, Oxygen $\left(\mathrm{PO}_{2}\right)$ 


\section{ABSTRACT \\ Effect of high salt intake on arteriolar responses to metabolic stimuli}

\section{Paul J. Marvar}

Study I evaluated the possibility that a HS diet can reduce the arteriolar response to muscle contraction through reduced nitric oxide (NO) availability and increased reactive oxygen species (ROS) activity. Spinotrapezius muscle arterioles were examined in rats fed a normal salt (NS; $0.45 \%)$ or high salt (HS; 4\%) diets. Arteriolar diameter responses to an increase in metabolic demand were significantly less in HS rats and these HS rats exhibited increased presence of arteriolar ROS. The attenuated responses to muscle contraction in HS rats were not restored in the presence of ROS scavengers, and inhibition of NO synthesis had no effect in the HS rats.

Study II-III investigated potential mechanisms for the reduced functional dilation in HS fed rats. In study II, skeletal muscle contraction significantly increased the intensity of the hydrogen peroxide $\left(\mathrm{H}_{2} \mathrm{O}_{2}\right)$ fluorescent marker 2', 7'-dichlorofluorescein (DCFH). Arteriolar dilation and flow increases in response to muscle contraction were inhibited by the $\mathrm{H}_{2} \mathrm{O}_{2}$ scavenger catalase in both groups. Exogenous $\mathrm{H}_{2} \mathrm{O}_{2}$ elicited arteriolar dilation in both groups, but the magnitude of this dilation was significantly greater in the HS rats. The $\mathrm{K}^{+}$channel inhibitors glibenclamide and tetraethylammonium (TEA) chloride reduced arteriolar dilation to exogenous $\mathrm{H}_{2} \mathrm{O}_{2}$ in both groups and glibenclamide reduced the functional hyperemic response.

Study III examined the effect of HS diet on arteriolar responsiveness to oxygen. Elevated superfusate oxygen resulted in arteriolar constriction and decreased flow. These responses were less in HS rats. Inhibition of 20-HETE formation with N-methylsulfonyl12,12-dibromododec-11-enamide (DDMS) and 17-octadecynoic acid (17-ODYA ) reduced the oxygen-induced constriction in the NS rats, but had no effect in the HS rats.

Exogenous 20-HETE elicited a concentration-dependent constriction in the NS rats that was blocked by the $\mathrm{K}_{\mathrm{Ca}}$ channel inhibitor TEA and these effects were either reduced or absent in HS rats. Inhibition of ANG II-induced constriction by DDMS was significantly greater in NS than $\mathrm{HS}$ rats. These results suggest that $\mathrm{H}_{2} \mathrm{O}_{2}$ contributes to functional hyperemia but a HS diet does not effect this role, and that alterations in arteriolar oxygen sensitivity by a HS diet may contribute to the reduced functional dilation following HS intake. 


\section{PREFACE}

This dissertation will begin with a review of the literature that constitutes the scientific

foundation on which these studies are based. The three studies that constitute this

dissertation work will then be reported in manuscript form, followed by a general unified discussion of the findings. 


\section{ACKNOWLEDGEMENTS}

There are several people that I would like to thank for their contributions to this dissertation project and who have been instrumental in seeing me through my $\mathrm{PhD}$ studies. This dissertation and completion of my degree would not have been possible without the professional guidance of my advisor, Dr. Matthew A. Boegehold. Thanks Dr. B for your friendship, patience, availability, positive outlook and constant encouragement and support along the way. I am especially grateful for your extraordinary efforts in helping me meet my various deadlines during the final months leading up to the completion of this dissertation. I look forward to implementing the many scientific skills, qualities and attributes that I have learned under your guidance in my future career in biomedical research.

I would like to thank my committee members, Dr. Mitch Finkel, Dr. Leah Hammer, Dr. Ping He and Dr. Fred Minnear for all of their constructive comments, feedback, advice and especially for being so flexible with their time and availability. A special thanks to Leah for her remarkable editorial efforts and input in assisting in the completion of this dissertation.

To Tim and Leah; thank you for your friendship and mentoring over the years, I'm truly indebted to both of you for all that you've done in contributing to my graduate learning and overall tremendous experience inside and outside the lab. A special thanks to Kim Wix for all that she does to ensure that the laboratory is running smoothly and for making it an enjoyable and positive lab environment (eg: Grandma Gordon and the late Ali). In addition to the Boegehold Laboratory, there are many departmental faculty and staff whom I'm also indebted to for their friendship, kindness, and advice throughout my five years at WVU. I would especially like to recognize Dr. Stephen Alway, Chair of Exercise Physiology, for his helpfulness, guidance and efforts in getting me into the doctoral program and charting my initial academic path at WVU. Outside of WVU, I would be remiss if I did not thank my undergraduate Professor Michael Dolan for granting me the opportunity and initiating my interest in scientific research.

Thanks to the many friends that I've made in the doctoral program and to those whom I've spent more "extracurricular" time with (Jesse, Lori, Andrew, Parco, Jason, Brett, Dave) thanks for your friendship, all the good times we've shared together, and I look forward to keeping in contact in the years ahead. Very special thanks to Sarah for her constant encouragement, love and support throughout this process and beyond.

Last but certainly not least, I want to thank my family for their unyielding love, support, prayers and patience over the years. In particular my parents, Ron and Mary Jo, for instilling the values, faith and perseverance needed to achieve my academic goals, continued lifelong pursuits and future endeavors. Thanks Mom and Dad. 
TABLE OF CONTENTS

Ackecented

\section{Literature Review}

1. Metabolic Control of Arteriolar Tone..........................................1

A. Introduction...................................................

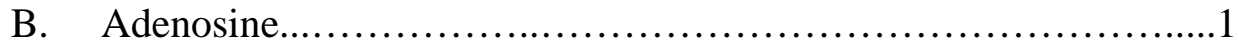

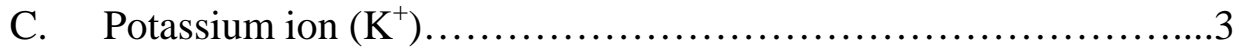

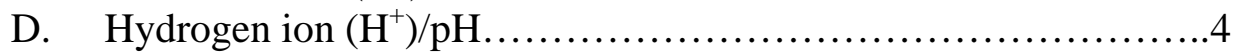

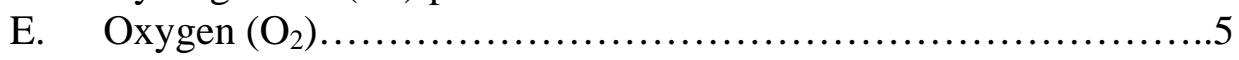

a. Cytochrome P450 metabolism and 20-HETE...............10

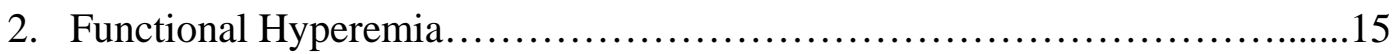

A. Historical Perspective ........................................15

B. Mechanisms..............................................

C. Endothelium-independent Control.............................17

D. Endothelium-dependent Control...............................18

a. Overview of endothelial factors in functional hyperemia.....18

b. Shear stress as a stimulus for endothelia NO and PG release during muscle contraction........................20

c. Reduced venular $\mathrm{PO}_{2}$ as a stimulus for endothelial $\mathrm{NO}$ and $\mathrm{PG}$ release............................................

d. Conducted vasodilation...................................23

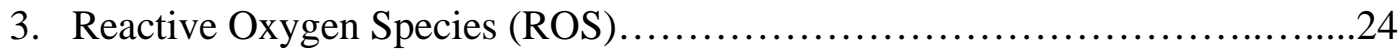

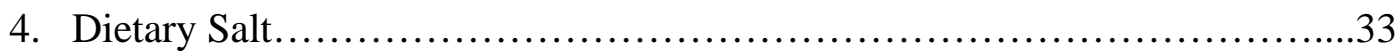

A. Physiological Regulation of Salt and Water Balance..................33

B. Salt-Sensitive Hypertension....................................34

C. Hypertension-Independent Effects.............................38

a. Structural Changes......................................... 38

b. Functional Changes..............................................

II. Purpose of this Dissertation Project. 
III. Study I: Reduced Arteriolar Responses to Skeletal Muscle Contraction After Ingestion of a High Salt Diet......................................45

IV. Study II: Hydrogen Peroxide-Dependent Arteriolar Dilation in Contracting Muscle of Rats Fed Normal and High Salt Diets....................8 80

V. Study III: The Role of 20-HETE in the Reduced Arteriolar Responses to Increased $\mathrm{PO}_{2}$ in Rats Fed a High Salt Diet.......................122

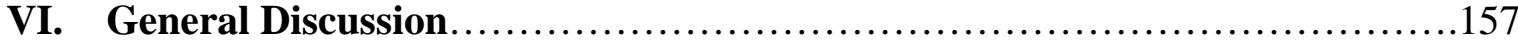

VII. References for Literature Review and General Discussion..................170

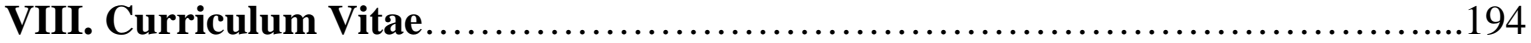




\section{LIST OF FIGURES}

\section{LITERATURE REVIEW}

Figure 1. Pathways for the metabolism for arachidonic acid..............10

Figure 2. Summary of the role of cytochrome $P-450$ metabolites of arachidonic acid (AA) in the control of vascular tone............12

Figure 3. Reactive Oxygen Species Sources and Pathways................25

Study I

Figure 1. Changes in arteriolar diameter and flow elicited by $0.5 \mathrm{~Hz}, 2 \mathrm{~Hz}$, and $4 \mathrm{~Hz}$ muscle contraction in rats fed NS and $\mathrm{HS}$ diets.

Figure 2. Effect of $\mathrm{N}^{\mathrm{G}}$-monomethyl L-arginine (L-NMMA) on resting arteriolar diameters and volume flows in rats fed NS and HS diets..........62

Figure 3. Effect of L-NMMA on arteriolar diameter and flow responses to $0.5 \mathrm{~Hz}, 2 \mathrm{~Hz}$, and $4 \mathrm{~Hz}$ muscle contraction in rats fed NS diet and HS diet.

Figure 4. Calculated arteriolar wall light absorption after exposure to $2 \%$ tetranitroblue tetrazolium (TNBT) in rats fed NS and HS diets. Nuclei in arteriolar walls exhibiting ethidium bromide fluorescence after exposure .64

Figure 5. Effect of 2,2,6,6-Tetramethylpiperidine-N-oxyl + catalase on arteriolar diameter and flow responses to $0.5 \mathrm{~Hz}, 2 \mathrm{~Hz}$, and $4 \mathrm{~Hz}$ muscle contraction in rats fed NS diet and HS diet. 65

Study II

Figure 1. Representative images of spinotrapezius muscle fibers following application of the fluorescence probe 2,7,dichlorodihydrofluorescein diacetate, before and immediately following muscle contraction at 4 $\mathrm{Hz}$ frequency...........................................96 
Figure 2. Changes in arteriolar diameter and flow elicited by $0.5 \mathrm{~Hz}, 2 \mathrm{~Hz}$, and $4 \mathrm{~Hz}$ muscle contraction in rats fed normal salt and high salt diets

Figure 3. Effect of catalase on arteriolar diameter and flow responses to $0.5 \mathrm{~Hz}, 2 \mathrm{~Hz}$, and $4 \mathrm{~Hz}$ muscle contraction in rats fed NS diet and $\mathrm{HS}$ diet. .98

Figure 4. Magnitude of the effect of catalase on arteriolar diameter responses and flow responses to $0.5 \mathrm{~Hz}, 2 \mathrm{~Hz}$, and $4 \mathrm{~Hz}$ muscle contraction in rats fed NS and HS diets.

Figure 5. Changes in arteriolar diameter with $\mathrm{H}_{2} \mathrm{O}_{2}$ application in rats fed NS and HS diets.... 100

Figure 6. Effect of glibenclamide and ODQ on arteriolar responses to pinacidil and sodium nitroprusside in rats fed NS diet.

Figure 7. Effect of glibenclamide on arteriolar diameter responses to exogenously applied $\mathrm{H}_{2} \mathrm{O}_{2}$ in rats fed NS and HS diets 102

Figure 8. Effect of glibenclamide on arteriolar diameter and flow responses to $4 \mathrm{~Hz}$ muscle contraction in rats fed NS and HS diets.

Figure 9. Effect of tetraethylammonium chloride on arteriolar diameter responses to exogenously applied $\mathrm{H}_{2} \mathrm{O}_{2}$ in rats fed NS and $\mathrm{HS}$ diets. 104

Figure 10. Effect of ODQ on arteriolar diameter responses to exogenously applied $\mathrm{H}_{2} \mathrm{O}_{2}$ in rats fed NS and $\mathrm{HS}$ diets

Study III

Figure 1. Changes in arteriolar diameter and flow to an increase in superfusate $\mathrm{O}_{2}$ concentration (10\%) in rats fed NS and HS diets

Figure 2. Effects of 17-ODYA and DDMS on arteriolar diameter and flow responses to an elevation in superfusate $\mathrm{O}_{2}$ concentration (10\%) in rats fed NS and HS diet. 138

Figure 3. Western blot expression of 51-kDa CYP450-4A protein in spinotrapezius muscle of (NS) and (HS) rats. 
Figure 4. Changes in arteriolar diameter with 20-HETE application in rats fed normal salt and high salt diets..........................140

Figure 5. Effect of TEA on arteriolar diameter responses to 20-HETE application in rats fed normal salt and high salt diets.........................141

Figure 6. Effect of DDMS on arteriolar diameter responses to ANG II application in rats fed normal salt and high salt diet.......................142

Figure 7. Effect of DDMS on arteriolar diameter responses to norepinephrine application in rats fed normal salt and high salt..................143 


\section{LIST OF TABLES}

Study $I$

Table 1 Profiles of all experimental animals at time of study.............59

Table 2 Arteriolar characteristics at time of study.....................60

Study II

Table 1 Profiles of all experimental animals at time of study..............93

Table 2 Arteriolar characteristics at time of study.....................94

Table 3 Effect of catalase on arteriolar responses to $1 \times 10^{-4} \mathrm{M} \mathrm{H}_{2} \mathrm{O}_{2}$ in both dietary groups.........................................95

Study III

Table 1 Profiles of all experimental animals at time of study............134

Table 2 Arteriolar characteristics at time of study......................135

Table 3 Effect of ODYA and DDMS on Resting Arteriolar

Diameter and Flow........................................... 136 


\section{GLOSSARY OF ABBREVIATIONS}

\begin{tabular}{|c|c|}
\hline AA & Arachidonic acid \\
\hline $\mathrm{ACE}$ & Angiotensin converting enzyme \\
\hline $\mathrm{ACh}$ & Acetylcholine \\
\hline ADMA & Asymmetric dimethylarginine \\
\hline AMP & Adenosine monophosphate \\
\hline ANG II & Angiotensin II \\
\hline ANP & Atrial natriuretic peptide \\
\hline $\mathrm{AT}_{1}$ Receptor & Angiotensin type 1 receptor \\
\hline ATP & Adensine 5 'triphosphate \\
\hline $\mathrm{BH}_{4}$ & Tetrahydrobiopterin \\
\hline $\mathrm{BK}_{\mathrm{Ca}}$ Channel & Large conductance, calcium-activated potassium channel \\
\hline $\mathrm{Ca}$ & Calcium \\
\hline $\mathrm{Ca}^{2+}$ & Calcium ion \\
\hline cAMP & 3',5'-cyclic adenosine monophosphate \\
\hline cGMP & 3'5'-cyclic guanosine monophosphate \\
\hline $\mathrm{Cl}^{-}$ & Chloride ion \\
\hline $\mathrm{CO}_{2}$ & Carbon dioxide \\
\hline $\operatorname{cox}$ & Cyclooxygenase \\
\hline CYP $4504 \mathrm{~A}$ & Cytochrome P450 4A $\omega$-hydroxylase \\
\hline CuZnSOD & Copper zinc superoxide dismutase \\
\hline
\end{tabular}




\begin{tabular}{|c|c|}
\hline Dahl-R rat & Dahl salt-resistant rat \\
\hline Dahl-S rat & Dahl salt-sensitive rat \\
\hline DCF & 2’7'-dichlorofluoroscein \\
\hline DCFH-DA & 2'7'-dichlorodihydrofluoroscein diacetate \\
\hline DDMS & Dibromo-dodecenyl-methylsulfimide \\
\hline DiHETE & Dihydroxyeicosatetraenoic acid \\
\hline ECF & Extracellular fluid \\
\hline ecSOD & Extracellular superoxide dismutase \\
\hline EDHF & Endothelium-derived hyperpolarizing factor \\
\hline EET & Epoxyeicosatrienoic acid \\
\hline eNOS & endothelial nitric oxide synthase \\
\hline Gs & Stimulatory G-protein \\
\hline $\mathrm{H}^{+}$ & Hydrogen ion \\
\hline 20-HETE & 20-Hydroxyeicosatetraenoic acid \\
\hline $\mathrm{H}_{2} \mathrm{O}_{2}$ & Hydrogen peroxide \\
\hline $\mathrm{HOCl}$ & Hypochlorous acid \\
\hline HS & High Salt \\
\hline iNOS & Inducible nitric oxide synthase \\
\hline $\mathrm{K}^{+}$ & Potassium ion \\
\hline $\mathrm{K}_{\mathrm{ATP}}$ channel & ATP-sensitive potassium channel \\
\hline $\mathrm{K}_{\mathrm{Ca}}$ channel & Calcium-activated potassium channel \\
\hline $\mathrm{K}_{\mathrm{ir}}$ channel & Inwardly rectifying postassium channel \\
\hline
\end{tabular}




\begin{tabular}{|c|c|}
\hline LDL & Low density lipoprotein \\
\hline L-NAME & $\mathrm{N}^{\mathrm{G}}$-nitro-L-arginine methyl ester \\
\hline MAPK & Mitogen activated protein kinase \\
\hline MLCK & Myosin light chain kinase \\
\hline MnSOD & Mitochondrial manganese superoxide dismutase \\
\hline $\mathrm{Na}^{+}$ & Sodium ion \\
\hline $\mathrm{NaCl}$ & Sodium chloride \\
\hline $\mathrm{NAD}(\mathrm{P}) \mathrm{H}$ & Nicotinamide adenine dinucleotide phosphate \\
\hline NO & Nitric oxide \\
\hline NOS & Nitric oxide synthase \\
\hline NS & Normal salt \\
\hline $\mathrm{O}_{2}$ & Oxygen \\
\hline $\mathrm{O}_{2}^{-}$ & Superoxide anion \\
\hline 17-ODYA & 17-octadecynoic acid \\
\hline $\mathrm{OH}^{-}$ & Hydroxyl anion \\
\hline $\mathrm{ONOO}^{-}$ & Peroxynitrite \\
\hline $\mathrm{PCO}_{2}$ & Partial pressure of carbon dioxide \\
\hline PG & Prostaglandin \\
\hline $\mathrm{PGE}_{2}$ & Prostaglandin E2 \\
\hline $\mathrm{PGI}_{2}$ & Prostacyclin \\
\hline PKA & Protein kinase A \\
\hline PKC & Protein kinase $\mathrm{C}$ \\
\hline
\end{tabular}




$\begin{array}{ll}\mathrm{PO}_{2} & \text { Partial pressure of oxygen } \\ \text { RAAS } & \text { Renin-angiotensin-aldosterone-system } \\ \text { RBC } & \text { Red blood cell } \\ \text { ROS } & \text { Reactive oxygen species } \\ \text { SOD } & \text { Superoxide dismutase } \\ \text { SNP } & \text { Sodium nitroprusside } \\ \text { TEA } & \text { Tetraethylammonia } \\ \text { Tempo } & \text { 2,2,6,6-tetramethylpiperidine-N-oxyl } \\ \text { VEGF } & \text { Vascular endothelial growth factor } \\ \text { VSM } & \text { Vascular smooth muscle } \\ \text { VSMC } & \text { Vascular smooth muscle cell } \\ \text { XO } & \text { Xanthine oxidase }\end{array}$




\section{LITERATURE REVIEW}

\section{Metabolic Control of Arteriolar Tone}

\section{A. Introduction:}

It is well known that muscle blood flow changes in proportion to the metabolic demands of the tissue. Muscle unloading, which leads to decreased metabolic demand, results in a reduction of resting blood flow (McDonald et al., 1992; Wang \& Prewitt, 1993), while in response to conditions of increased metabolic activity such as increased muscle contraction frequency (Mackie \& Terjung, 1983), increased running speed (Armstrong \& Laughlin, 1985) and increased muscle oxygen consumption (Mohrman \& Regal, 1988), many studies have shown that blood flow directly increases. The skeletal muscle microcirculation plays a key role in the regulation of blood flow during conditions of increased metabolic activity. For example, skeletal muscle arterioles dilate in a very localized manner in response to many of the metabolites that are released during exercise $(\mathrm{K}+$, adenosine, $\mathrm{H}+$, etc $)$ as well as to a reduction in tissue $\mathrm{PO}_{2}$. During skeletal muscle contraction, increased metabolite production during functional hyperemia is partially dependent on a fall in tissue $\mathrm{PO}_{2}$ levels and therefore the processes that regulate oxygen delivery to the tissue are critical to the study of mechanisms underlying functional hyperemia. Although metabolic control of vascular tone is a feature of many different vascular beds, this review of the literature will focus only on skeletal muscle.

\section{B. Adenosine}

Adenosine is a powerful endogenous vasodilator in the skeletal muscle vasculature that is considered to be an important mediator of metabolic vasodilation. Adenosine is a by- 
product of increased tissue metabolism and adenosine triphosphate (ATP) hydrolysis, and is mainly formed on the extracellular surface of the muscle cell plasma membrane from adenosine monophosphate (AMP) by the enzyme ecto-5' -nucleotidase (Boushel, 2003). Adenosine elicits vascular smooth muscle relaxation by increasing cyclic AMP with subsequent activation of protein kinase A (PKA) leading to myosin light chain kinase (MLCK) phosphorylation. An inhibitory site on MLCK is phosphorylated by PKA, thereby decreasing MLCK affinity for calcium-calmodulin kinase, a requirement for phosphorylation and vascular smooth muscle contraction (Adelstein et al., 1978)

During low intensity muscle contraction in humans, adenosine has been found to accumulate in the muscle interstitial space, and there is a strong correlation between interstitial adenosine concentrations and leg blood flow during exercise (Hellsten et al., 1998). Furthermore, following antagonism of the adenosine receptor with theophyline, exercise-induced increases in blood flow in the femoral artery of humans is reduced by $20 \%$ (Radegran \& Calbet, 2001). In animal preparations, such as the hamster cremaster muscle, adenosine has also been found to play an important role in functional vasodilation (Proctor \& Duling, 1982; Proctor, 1984; Murrant \& Sarelius, 2002). On the other hand, studies in the rat show that adenosine deaminase, which degrades endogenous adenosine, has no effect on hindlimb blood flow during treadmill running (Klabunde et al., 1988). In other animal species such as the dog, it was found that both adenosine receptor blockade and adenosine receptor desensitization do not alter blood flow (Koch et al., 1990).

These studies suggest that adenosine formation is increased during increased tissue metabolic activity, but its role in mediating the vasodilation and subsequent increase in blood flow varies from species to species and the type of vascular bed studied. Therefore the role 
of adenosine in mediating skeletal muscle dilation and hyperemia during increased tissue metabolic activity is currently unclear.

\section{Potassium Ion $\left(\mathrm{K}^{+}\right)$}

During skeletal muscle contractions, depolarization and excitation of the muscle fiber plasma membrane leads to the rapid diffusion of $\mathrm{K}^{+}$from the muscle fiber via voltagedependent $\mathrm{K}^{+}$channels (Clifford \& Hellsten, 2004). Sparks et al. (1980) suggested that extracellular $\mathrm{K}^{+}$may directly decrease $\mathrm{Na}^{+}$permeability of the vascular smooth muscle membrane thus reducing the movement of calcium into the cell, resulting in smooth muscle relaxation. These authors also suggested that extracellular $\mathrm{K}^{+}$causes a reduction in the amount of norepinephrine released from sympathetic nerves supplying the arterioles, which would lead to a decrease in neurogenic tone. More recent evidence suggests that the $\mathrm{K}^{+}$mediated vasodilation during muscle contraction is a result of activation of inwardly rectifying vascular smooth muscle potassium $\left(\mathrm{K}_{\mathrm{ir}}\right)$ channels (Jackson, 2000; Sobey \& Faraci, 2000). Overall, there is still an incomplete understanding regarding the specific mechanism by which elevated $\mathrm{K}^{+}$produces smooth muscle relaxation and vasodilation.

Potassium ion was first suggested to be a possible mediator of exercise-induced vasodilation when Dawes et al. (1941) observed that intra-arterial injection of $\mathrm{K}^{+}$causes vasodilation. Several studies have shown that during muscle contractions, venous blood potassium concentrations increase (Jackson, 2000; Radawski et al., 1975; Scott et al., 1970; Skinner, Jr. \& Costin, 1971), most likely due to potassium efflux from skeletal muscle cells during depolarization and excitation. Furthermore, in the interstitial space surrounding the vasculature, $\mathrm{K}^{+}$concentrations are found to be elevated following muscle contraction (Hnik 
et al., 1976; Juel et al., 2000). However, in the dog gastrocnemius muscle, increasing venous $\left[\mathrm{K}^{+}\right]$by intra-arterial infusion has no effect on resting blood flow, nor does it alter the relationship of blood flow and oxygen during exercise (Mohrman, 1982). These authors concluded that local $\left[\mathrm{K}^{+}\right]$does not play a significant role in exercise hyperemia.

Furthermore, in the rat spinotrapezius muscle Lash \& Bohlen (1987) measured periarteriolar $\left[\mathrm{K}^{+}\right]$as well as $\left[\mathrm{K}^{+}\right]$at the midpoint of capillary networks in the contracting rat spinotrapezius muscle. These authors did not find any significant changes in $\left[\mathrm{K}^{+}\right]$during muscle contraction and concluded that the arteriolar dilation and accompanying blood flow increase is dependent on factors other than $\mathrm{K}^{+}$. These studies show that in most muscles $\mathrm{K}^{+}$ levels increase and accumulate in the interstitial space during contraction. However, there is little or no evidence supporting an essential role for $\mathrm{K}^{+}$in the hyperemia which accompanies muscle contraction.

\section{Hydrogen ion $\left(\mathrm{H}^{+}\right) / \mathrm{pH}$}

During increased skeletal muscle activity, lactic acid can accumulate when the rate of glycolysis is increased to generate ATP. Accumulation of these by-products (lactic acid and $\mathrm{CO}_{2}$ ) of anaerobic metabolism can reduce cellular $\mathrm{pH}$, and subsequently interstitial $\mathrm{pH}$ due to $\mathrm{H}^{+}$efflux from the muscle cells. Changes in $\mathrm{pH}$ have been proposed to mediate changes in vascular tone which may have important implications in the regulation of local blood flow control. Earlier studies have shown that during very intense exercise, there is a drop in venous $\mathrm{pH}$, and that a reduction in $\mathrm{pH}$ of the arterial blood supplying skeletal muscle can reduce vascular resistance (Haddy \& Scott, 1975; Radawski et al., 1975). A later study conducted in the spinotrapezius muscle using ion-selective microelectrodes found that periarteriolar $\left[\mathrm{H}^{+}\right]$initially decreases during high frequency contractions $(8 \mathrm{~Hz})$ but during 
sustained muscle contraction, these $\mathrm{H}^{+}$levels return to resting levels. These authors suggested that physiological changes in periarteriolar $\left[\mathrm{H}^{+}\right]$are too small to substantially contribute to functional hyperemia (Lash \& Bohlen, 1987). In contrast, it has been suggested that a low intraluminal $\mathrm{pH}$ environment (increases in $\mathrm{H}^{+}$or $\mathrm{PCO}_{2}$ ) may facilitate the release of endothelial-derived factors or the release of vasodilator substances from red blood cells during increased tissue metabolic activity, thus contributing to the adjustment in arteriolar tone and blood flow (Ellsworth et al., 1999; Hester \& Hammer, 2002). These specific mechanisms will be discussed in more detail in a later section. In summary, it still remains unclear as to the overall role and functional importance of either intraluminal or extraluminal $\mathrm{H}^{+}$concentrations and $\mathrm{pH}$ in the hyperemic response during skeletal muscle contraction.

\section{E. Oxygen $\left(\mathrm{O}_{2}\right)$}

Local $\mathrm{O}_{2}$ levels are also an important determinant of arteriolar tone, and therefore tissue blood flow. Earlier studies have documented that skeletal muscle arterioles dilate in response to reduced blood or tissue $\mathrm{PO}_{2}$, and constrict in response to elevated $\mathrm{PO}_{2}$ (Duling, 1972;

Hutchins et al., 1974). More specifically, oxygen has been shown to be important in mechanisms of local blood flow control such as autoregulation (Granger et al., 1976; Sullivan \& Johnson, 1981), reactive hyperemia (Lombard \& Duling, 1981), and sympathetic escape (Boegehold \& Johnson, 1988) as well as during skeletal muscle contraction (Lash \& Bohlen, 1987).

The importance of oxygen in functional hyperemia was demonstrated in a study where venous $\mathrm{PO}_{2}$ was experimentally lowered prior to and during muscle contraction. This perturbation resulted in a greater increase in blood flow in order to maintain oxygen delivery to the contracting muscle (Granger et al., 1976). Other studies have clearly shown that 
during muscle contraction, there is a fall in local tissue $\mathrm{PO}_{2}$ levels and concurrent increases in arteriolar diameter (Boegehold \& Bohlen, 1988; Gorczynski \& Duling, 1978; Proctor et al., 1981), which is presumably due to increased tissue oxygen consumption. Additional studies, which will be discussed in more detail in a subsequent section, have shown and suggested that a fall in oxygen levels, which occurs during increased metabolic activity, can stimulate the release of vasodilator metabolites or endothelial factors which contribute to the arteriolar dilation and increased blood flow during skeletal muscle contraction (Bergfeld \& Forrester, 1992; Ellsworth et al., 1999; Hester \& Hammer, 2002). Therefore, understanding the mechanisms that influence oxygen delivery to skeletal muscle are essential to the understanding of functional hyperemia.

There has been much work aimed at defining the mechanisms by which arterioles constrict in response to an increase in oxygen availability. One of the initial questions that has been explored relates to the site of the putative oxygen sensor. Arteriolar constriction could be a result of either a direct effect of oxygen on a component of the arteriolar wall, such as the smooth muscle or endothelium, or an indirect effect mediated through attenuated parenchymal cell metabolism and/or inhibition of vasodilator metabolite production.

In an attempt to discern whether oxygen-induced arteriolar responses are due to a direct affect of oxygen on the arteriole itself or indirectly via surrounding parenchymal tissue, Duling, (1974) studied exteriorized superfused tissue preparations and compared arteriolar responses to a general increase in tissue oxygen availability (achieved by increasing superfusate oxygen content) with responses to direct application (via micropipettes) of a high-oxygen solution to the arteriolar wall. He found that compared to high oxygen superfusion delivery over the hamster cheek pouch, the arteriolar constrictions delivered with 
micropipettes to the arteriolar wall were much smaller and similar to the response with a very low oxygen solution. Based on these data it was concluded that the vasoconstriction associated with increased $\mathrm{PO}_{2}$ was not due to the direct effect of oxygen on the vascular smooth muscle cells but rather an indirect mechanism involving the surrounding parenchymal cells. However, results from Jackson and Duling (1983) in hamster cheek pouch arterioles suggest that oxygen exerts it effect partly by a direct mechanism and by an indirect effect through the surrounding parenchymal tissue (Jackson \& Duling, 1983). In order to better explain these discrepant findings and the lack of consistent arteriolar responses to direct application of high and low oxygen solutions to the arteriolar wall (Duling, 1974), Jackson et al. (1983) speculated that "oxygen sensors" are sparsely distributed on the surface of or within the arteriolar wall, and that these sensors may not have been adequately stimulated when $\mathrm{PO}_{2}$ was locally changed.

Subsequent studies have been conducted to further elucidate location and significance of an oxygen sensor within the vasculature. Some have suggested that the oxygen sensor is within the vascular endothelium (Busse et al., 1984; Pohl \& Busse, 1989; Sullivan \& Johnson, 1981). In examining this, Jackson (1987) used the hamster cheek pouch to study aparenchymal arteriolar segments. Arteriolar diameter responses were measured following local (periarteriolar microapplication of $\mathrm{PO}_{2}$ ) and global (superfusate $\mathrm{PO}_{2}$ ) changes in $\mathrm{PO}_{2}$. Contrary to what was predicted, local changes in $\mathrm{PO}_{2}$, achieved by application to the outside of occluded or unoccluded aparenchymal arterioles or by intraluminal perfusion of these vessels, had no consistent effect on arteriolar diameters. However, when the superfusate $\mathrm{PO}_{2}$ flowing over the entire tissue was changed, it not only affected the arteriole being studied but all other vessels in the tissue as well. These authors concluded that oxygen sensors are not 
located in endothelial cells but located sparsely along the vascular tree or in the surrounding parenchyma, and that these sensors can detect changes in $\mathrm{PO}_{2}$ and initiate a response that then gets conducted throughout the vasculature. Over the years, microvascular oxygen sensing research has given rise to many different theories and proposed models. It can be concluded from these many years of research that there is not a single "oxygen sensor" in the vasculature, but rather, depending on the vascular bed studied, it can involve a variety of oxygen-dependent enzyme systems (nicotinamide adenine dinucleotide phosphate $(\mathrm{NAD}(\mathrm{P}) \mathrm{H})$ oxidases, cytochrome P450 enzymes, nitric oxide synthase (NOS)) or, as some have suggested, the red blood cells themselves can serve as an oxygen sensor (Goligorsky, 2000; Nase et al., 2003; Wolin et al., 1999; Ellsworth et al., 1995).

There has been much interest in the possible role of metabolites of arachidonic acid in vascular oxygen sensing (Busse et al., 1984; Kalsner, 1978; Roberts et al., 1981). Several lines of evidence suggest that prostaglandins are involved in vascular responses to changes in $\mathrm{PO}_{2}$ (Afonso et al., 1974; Hintze \& Kaley, 1977; Wei et al., 1980). Messina et al. (1994) found that constriction of rat cremaster arterioles in response to increased oxygen tension is reduced following removal of the endothelium or inhibition of cyclooxygenase (COX; one of the enzymes in the arachidonic acid pathway responsible for prostaglandin production) with indomethacin. These authors concluded that cremaster arterioles constrict in response to increased oxygen by a decreased synthesis of endothelium-derived vasodilator prostaglandins. In contrast, inhibition of prostaglandin formation with $\mathrm{COX}$ inhibitors has no effect on arteriolar oxygen reactivity in hamster cheek pouch and hamster or rat cremaster muscle (Jackson, 1986). 
In additional studies, Jackson obtained evidence of a role for lipooxygenase or cytochrome $\mathrm{P} 450$ products of arachidonic acid metabolism in arteriolar oxygen sensing in the hamster cheek pouch (Jackson, 1988; Jackson, 1989; Jackson, 1991). More recently, the enzyme CYP450 4A $\omega$-hydroxylase has been identified as an important oxygen sensor due to its ability to generate the vasoconstrictor metabolite 20-hydroxyeicosatetraenoic acid (20HETE) (Harder et al., 1996). In two different microvascular beds, these authors demonstrated the presence and activity of CYP450 4A $\omega$-hydroxylase and 20-HETE formation in both the vasculature and parenchyma. They also showed that the rate of 20HETE formation is linearly dependent on $\mathrm{PO}_{2}$ over its normal physiological range. These data strongly suggest that increased oxygen availability causes vasoconstriction as a result of an increased production of 20-HETE via increased P450-4A $\omega$-hydroxylase activity and that decreased oxygen availability reduces 20-HETE production. An overview of the synthesis and production of 20-HETE and it's possible role in the regulation of vascular tone and local blood flow can be found in the next section.

Studies on the roles of nitric oxide (NO) in oxygen sensing in skeletal muscle have yielded conflicting results. In spinotrapezius muscle arterioles, it was found that inhibition of NOS reduced the arteriolar constriction to increased $\mathrm{O}_{2}$, suggesting that NO must be present for these arterioles to exhibit normal $\mathrm{O}_{2}$ responsiveness (Pries et al., 1995). In contrast, Jackson (1991) found that NO does not mediate arteriolar reactivity to increased oxygen in the hamster cheek pouch.

Overall, the evidence presented above for prostaglandins and NO in oxygen sensing is controversial. The reason for the differences in these studies has not been determined but 
may very well be due to differences in vascular beds, the specific region of the vasculature studied or the type of oxygen conditions used.

\section{a. Cytochrome P450 metabolism and 20-HETE:}

Arachidonic acid (AA) makes up part of the membrane phospholipid pool and is released following activation of phospholipase $A_{2}$ by various agonists, such as norepinephrine, angiotensin II, and bradykinin (Kroetz \& Xu, 2005). It has been known for many years that COX and lipoxygenase enzymes metabolize AA to 5-,12-and 15 hydroxyeicosatetraenoic acid (HETE), prostaglandins, thromboxane, and leukotrienes (Figure 1).

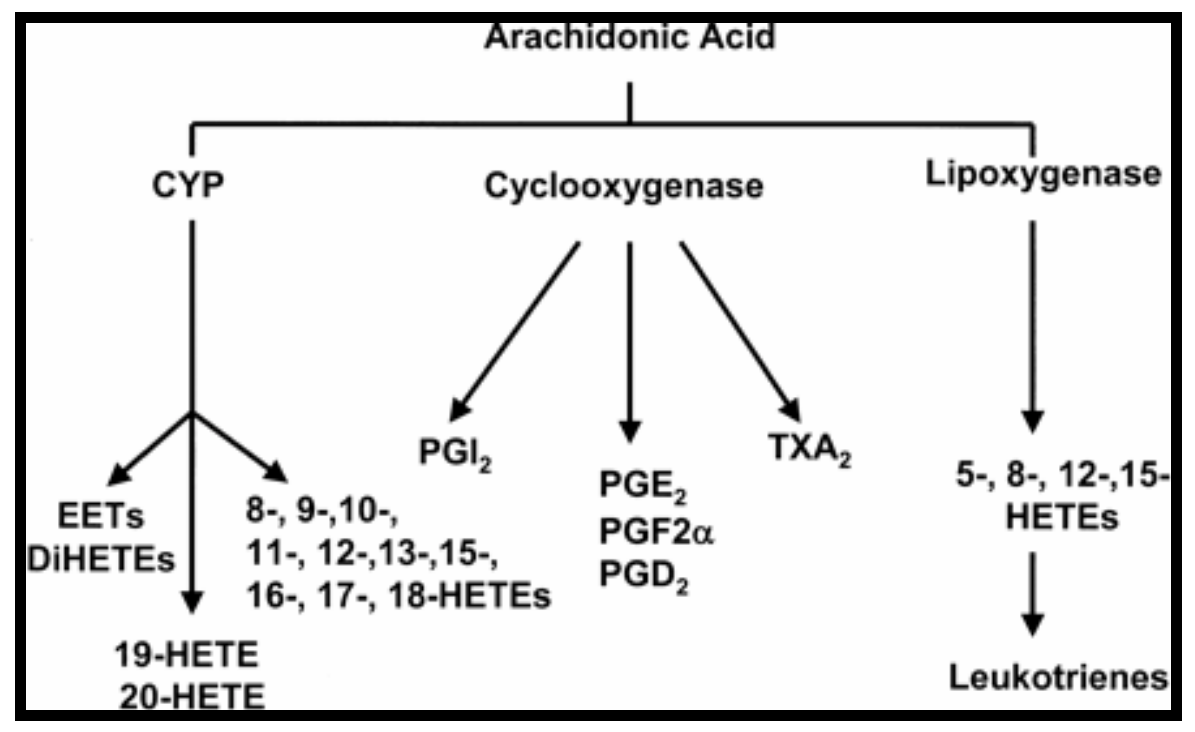

Figure 1. Pathways for the metabolism of arachidonic acid. Arachidonic acid is metabolized via the cyclooxygenase, lipoxygenase, and cytochrome p-450 (CYP) enzymes to prostaglandins (PGs), prostacyclin $\left(\mathrm{PGI}_{2}\right)$, thromboxane $\mathrm{A}_{2}\left(\mathrm{TxA}_{2}\right)$, or a series of hydroxyeicosatetraenoic acids (HETEs), epoxyeicosatrienoic acids (EETS), and dihydroxyeicosatrienoic acids (DiHETEs).

From Roman, R.J. (2004) P-450 Metabolites of arachidonic acid in the control of cardiovascular function, Physiol Rev, 82, 131-185.

These metabolic products are known to modulate renal and pulmonary function, vascular tone and inflammatory responses (Harder et al., 1998; Makita et al., 1996; McGiff \& Quilley, 
1999). Subsequently, it has been discovered that AA is metabolized to epoxyeicosatrienoic acids (EETS) and dihydroxyeicosatetraenoic (DiHETEs) via CYP450 enzymes in the liver and kidney (Morrison \& Pascoe, 1981). Following this major discovery it was later learned that AA metabolism via CYP 450 leads to the formation of 19-and 20hydroxyeicosatetraenoic acids (19-and 20-HETE) in other extra-hepatic tissues such as the heart, brain, and peripheral vasculature (Capdevila et al., 2000; Roman, 2002). Despite these discoveries over 20 years ago, it has not been until this past decade that a real interest has emerged in the role of CYP-450 metabolites as important mediators in the control of renal and vascular function.

20-HETE is a potent endogenous vasoconstrictor produced by $\omega$-hydroxylation of AA, catalyzed by the enzymes of the CYP450 4A families (Harder et al., 1995). 20-HETE is produced in vascular smooth muscle cells in the renal cortex and in other blood vessels, including cat cerebral microvessels, rat renal microvessels, rat cerebral arterioles, rat mesenteric resistance arteries and dog renal arteries. 20-HETE constricts arterioles in many different vascular beds, including renal (Alonso-Galicia et al., 1999; Imig et al., 1996), cerebral (Gebremedhin et al., 2000), mesenteric (Wang et al., 2001) and skeletal muscle (Harder et al., 1996), and can play an important physiological role in the local regulation of tissue blood flow (Roman, 2002). 20-HETE constricts blood vessels by inhibiting the activity of large conductance, calcium-activated potassium $\left(\mathrm{BK}_{\mathrm{Ca}}\right)$ channels, resulting in depolarization of the vascular smooth muscle cell membrane (Zou et al., 1996), which leads to increased calcium entry through the L-type calcium channels (Gebremedhin et al., 1998) (Figure 2). 


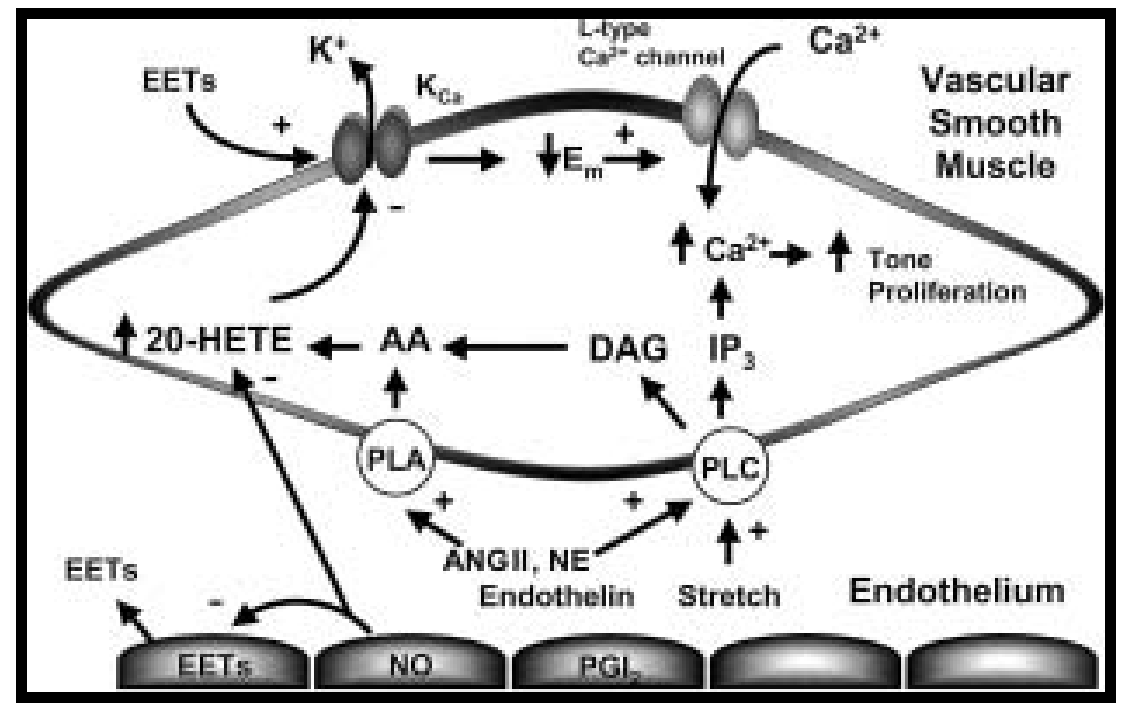

Figure 2. Summary of the role of cytochrome $P-450$ metabolites of arachidonic acid (AA) in the control of vascular tone. Membrane stretch and vasoactive agents [angiotensin II (ANG II), norepinephrine (NE)] activate phospholipase C (PLC) to release inositol trisphosphate $\left(\mathrm{IP}_{3}\right)$ and diacylglycerol (DAG). $\mathrm{IP}_{3}$ triggers the release of intracellular $\mathrm{Ca}^{2+}$ from the endoplasmic reticulum. Elevations in intracellular $\mathrm{Ca}^{2+}$ concentration activate $\mathrm{Ca}^{2+}$-sensitive phospholipase $\mathrm{A}_{2}$ (PLA) and diacylglycerol (DAG) lipase to release AA and stimulate the formation of 20-hydroxyeicosatetraenoic acid (20HETE). 20-HETE blocks the large-conductance, calcium-activated potassium $\left(\mathrm{K}_{\mathrm{Ca}}\right)$ channel in vascular smooth muscle (VSM) cells, leading to a fall in membrane potential $\left(E_{\mathrm{m}}\right)$, which enhances $\mathrm{Ca}^{2+}$ influx via L-type, voltage-sensitive $\mathrm{Ca}^{2+}$ channels.

Epoxyeicosatrienoic acids (EETs) are produced by the endothelium and are potent vasodilators that hyperpolarize VSM cells by increasing the activity of the $\mathrm{K}_{\mathrm{Ca}}$ channel. Acetylcholine and bradykinin stimulate the release of EETs from the endothelium, and they serve as endothelial-derived hyperpolarizing factor (EDHF) in some vascular beds.

From Roman, R.J. (2004) P-450 Metabolites of arachidonic acid in the control of cardiovascular function, Physiol Rev, 82, 131-185.

The vasoconstrictor response to 20-HETE has also been associated with the activation of protein kinase C (Lange et al., 1997), Rho kinase and the mitogen activated protein kinase (MAPK) pathway, having effects on cell growth and increased sensitivity of the contractile mechanism to calcium. Inhibitors of protein kinase $\mathrm{C}$ (PKC) block the effects of 20-HETE on calcium-sensitive potassium $\left(\mathrm{K}_{\mathrm{Ca}}\right)$ channel activity and vascular tone in cat cerebral arteries (Lange et al., 1997). 
The biological significance of 20-HETE is an area of ongoing investigation. Much of the early work has been conducted in the kidney, where 20-HETE-synthesizing enzymes are highly expressed in the proximal tubule, preglomerular arterioles and the thick ascending loop of Henle, and may play a role in salt and water homeostasis (Miyata \& Roman, 2005). 20-HETE has been found to potentiate the constrictor response to angiotensin II (ANG II) and various studies have shown that ANG II stimulates the release of 20-HETE in rat renal preglomerular vessels (Carroll et al., 1996). Similarly, in isolated rat kidney, 20-HETE production is stimulated in response to the vasoconstrictor endothelin-1. 20-HETE inhibits sodium reabsorbtion in the proximal tubule by reducing sodium-potassium-ATPase activity (Nowicki et al., 1997; Ominato et al., 1996), and also inhibits $\mathrm{Na}^{+}-\mathrm{K}^{+}-2 \mathrm{Cl}^{-}$co-transport in the thick ascending limb of Henle (Escalante et al., 1991; Ito \& Roman, 1999).

20-HETE has been shown to have an important role in various mechanisms that are essential to local blood flow control, such as the myogenic activation of cerebral (Harder et al., 1994) and renal (Imig et al., 1994) arteries and arterioles. Following inhibition of 20HETE, myogenic responses and blood flow autoregulation are impaired in cerebral and renal vascular beds (Harder et al., 1997). It has been more recently determined that the myogenic activation of skeletal muscle arterioles is impaired in the presence of the 20-HETE inhibitors 17-octadecynoic acid (17-ODYA) or dibromo-dodecenyl-methylsulfimide (DDMS) (Frisbee et al., 2001b). This latter study also showed that during inhibition of 20-HETE with 17ODYA, addition of the $\mathrm{K}_{\mathrm{Ca}}$ channel blocker tetraethylammonium (TEA) restored the myogenic activity to control levels. These data suggest that 20-HETE contributes to myogenic activity in various vascular beds through its inhibitory effect on vascular smooth muscle $\mathrm{K}_{\mathrm{Ca}}$ channels in response to an increase in transmural pressure. 
As discussed earlier, the oxygen-sensing mechanism of blood vessels is not completely understood. However, there is considerable evidence that supports a role for 20HETE in this process (Harder et al., 1996; Kunert et al., 2001; Zhu et al., 2000). Because CYP450-4A is present in striated muscle fibers as well as in vascular smooth muscle, the 20HETE that mediates arteriolar $\mathrm{O}_{2}$ responsiveness may originate from either the surrounding parenchymal tissue or the vessel wall itself (Kunert et al., 2001). In vivo studies in rat cremaster and hamster cremaster and retractor muscles have shown that blocking 20-HETE formation with 17-ODYA or DDMS significantly reduces the constriction of arterioles to a hyperoxic challenge (Frisbee et al., 2000; Harder et al., 1996; Kunert et al., 2001). Harder et al. (1996) concluded that the endogenous production of 20-HETE is dependent on a concentration of $\mathrm{O}_{2}$ that falls within the normal physiological range for blood and tissue $\mathrm{PO}_{2}$, and suggested that increased $\mathrm{O}_{2}$ availability leads to vasoconstriction as a result of an increased production of 20-HETE. There is also evidence to suggest that 20-HETE contributes to the vascular response to hypoxic conditions. Frisbee et al. (2001) showed that inhibition of 20-HETE with 17-ODYA or DDMS significantly reduces the dilation of rat gracilis muscle arterioles to hypoxia. Other studies suggest that NO mediates hypoxic dilation through indirect inhibition of 20-HETE production (Kerkhof et al., 1999). In summary, the oxygen sensing mechanism(s) that contribute to the metabolic regulation of local blood flow are not completely understood, but there is considerable evidence that supports a role for 20- HETE in this process. An example of local blood flow regulation that is thought to be predominately due to metabolic mechanisms is functional hyperemia. 


\section{Functional Hyperemia}

\section{A. Historical Perspective}

Since the early studies by Gaskell (1877), it has been known that blood flow increases during elevated skeletal muscle activity. Following these initial observations, it was later shown in a classic study by Krogh (1929) that the number of capillaries per unit of cross sectional area of muscle is much larger in active than in resting tissue. Further studies revealed a direct relationship between increasing strength of muscle contraction and hyperemia (Kramer et al., 1938; Dornhorst et al., 1949). These studies provided the framework for a landmark study conducted in the isolated cat hindlimb, which showed that the hyperemic response was attributed to dilation of resistance vessels and an increase in capillary filtration coefficient, a value that represents the number of perfused capillaries (Kjellmer, 1964). Therefore it has been known for some time that during increased skeletal muscle activity, such as that occurring with exercise, there is a dilation of resistance vessels to increase total blood flow, as well as redistribution of that blood flow through an increased number of capillaries (due more specifically to dilation of distal arterioles). These data highlight the interrelated nature of blood flow, capillary function and tissue metabolic rate in the essential function of matching a tissue's nutrient demand to its metabolic requirement.

The first study to use intravital microscopy to directly observe the relationship between contracting skeletal muscle and microvascular blood flow was conducted by Gorczynski et al. (1978). These authors used the cremaster muscle of the hamster to examine the time course and magnitude of arteriolar dilation during stimulation of single muscle fibers, small bundles of adjacent muscle fibers, or the whole muscle. This experimental design allowed for some assessment of the relationship between the number of active muscle 
fibers and the pattern of vascular response. In all three stimulation protocols used, arteriolar dilation was dependent on the frequency of muscle stimulation. Also, at any given contraction frequency, the magnitude of arteriolar dilation increased in proportion to the amount of tissue stimulated, thus clearly demonstrating a relationship between tissue metabolic activity and blood flow. These results were supported in a subsequent study using the rat spinotrapezius muscle, where it was found that arterioles that crossed or ran alongside the activated fibers dilated in response to muscle contraction (Marshall \& Tandon, 1984).

\section{B. Mechanisms}

Currently, the mechanism(s) responsible for the arteriolar dilation that links increased metabolic demand to increased blood flow are complex and incompletely understood. A variety of mechanisms and related vasoactive factors that are both endothelium-independent and -dependent are thought to contribute to functional hyperemia. As mentioned under "Metabolic Control of Arteriolar Tone", vasodilator metabolites whose interstitial concentrations typically increase with muscle contraction (adenosine, $\mathrm{K}^{+}$, and $\mathrm{H}^{+}$) could theoretically trigger endothelium-independent relaxation of vascular smooth muscle, thereby contributing to the arteriolar dilation associated with this contraction. Whether or not any particular metabolite actually contributes to the dilation, as well as the magnitude of this contribution, was discussed earlier in this section.

The importance of reduced oxygen levels in contributing to this arteriolar dilation, which was only briefly discussed previously, will be covered here in more detail, first as an endothelium-independent stimulus for dilation, and then as a possible mediator of endothelium-dependent mechanisms that could contribute to dilation. 


\section{Endothelium-Independent Control}

The role of oxygen as an important mediator in functional hyperemia has been extensively studied. During increased skeletal muscle contraction, tissue oxygen consumption increases thus decreasing local tissue oxygen tension, which in turn, either directly or indirectly (via metabolic by-products) leads to smooth muscle relaxation and vasodilation.

Various studies have been conducted to better understand a direct role of oxygen in the functional hyperemic response. Early studies in a variety of vascular preparations show that during exercise, venous blood $\mathrm{Po}_{2}$ decreases (Scott et al., 1970; Skinner, Jr. \& Costin, 1971; Tominaga et al., 1973). However, at the time it was unknown whether this reduction in venous blood $\mathrm{Po}_{2}$ was required and/or contributed to the contraction-induced dilation of the arterioles. The potential roles of changes in venular $\mathrm{PO}_{2}$ in functional hyperemia will be discussed in Section ii.

Using the hamster cremaster muscle, Gorczynski et al. (1978) was one of the first to examine the relationships between tissue $\mathrm{PO}_{2}$, arteriolar $\mathrm{PO}_{2}$ and functional hyperemia. These authors showed that arteriolar dilation during muscle contraction occurs without altering periarteriolar $\mathrm{PO}_{2}$. However, tissue $\mathrm{PO}_{2}$ was reduced during the contraction period and was correlated with changes in arteriolar diameter. Interestingly though, the arteriolar diameter returned to resting levels sooner than the tissue $\mathrm{PO}_{2}$ levels which would suggest that oxygen does not have a direct effect on the arteriolar diameter during muscle contraction. Consistent with Gorczynski et al. (1978), it was later determined that periarteriolar $\mathrm{PO}_{2}$ does not change and actually may increase during skeletal muscle contraction (Lash \& Bohlen, 1987). In several other studies, tissue $\mathrm{PO}_{2}$ was found to initially fall, but quickly return to 
basal levels during muscle contraction while vasodilation is maintained during this period (Boegehold \& Bohlen, 1988; Lash \& Bohlen, 1987; Proctor et al., 1981). All of these studies demonstrate a discordance in the temporal relationship between tissue $\mathrm{PO}_{2}$ and arteriolar dilation during muscle contraction, suggesting that if reduced $\mathrm{PO}_{2}$ is contributing to the dilation, it is not due to a direct effect of changes in the $\mathrm{PO}_{2}$ of surrounding parenchymal cells.

\section{Endothelium-Dependent Control}

\section{a. Overview of endothelial factors in functional hyperemia}

The vascular endothelium releases vasodilator substances in response to a variety of signals. The two most well studied vasodilator substances are prostacyclin $\left(\mathrm{PGI}_{2}\right)$ and NO, yet their roles in functional hyperemia are still not well understood. In hamster cremaster muscle, inhibition of NOS reduces dilation of arterioles in response to field stimulation (Hester et al., 1993) or local stimulation of muscle fiber bundles (Murrant \& Sarelius, 2002). There is also supporting evidence that NO plays an important role in functional hyperemia in other vascular beds, including rat hindquarter muscles (Hirai et al., 1994; Musch et al., 2001), and mouse cremaster muscle (Lau et al., 2000). In contrast to these studies, there are also several reports that do not support a role for NO in functional hyperemia. For example, using intravital microscopy in the rabbit tenuissimus muscle microvasculature, Persson et al. (1990) reported that NOS inhibition has no effect on the hyperemic response to muscle contraction, suggesting that NO does not play a role in functional hyperemia in this preparation. Similarly, in arterioles of rat spinotrapezius muscle (Boegehold, 1996) and in the hindlimb of exercising dogs (O'Leary et al., 1994) inhibition of NO does not alter the 
functional hyperemic response. Furthermore, there is some evidence suggesting that the decreased hyperemic response to muscle contraction or exercise in the presence of a NOS inhibitor may be largely attributed to the effect of NOS inhibition on resting vascular tone (O'Leary et al., 1994; Saito et al., 1994).

In addition to NO, the vasodilatory COX metabolites of arachidonic acid metabolism, $\mathrm{PGI}_{2}$ and $\mathrm{PGE}_{2}$, are also released from the vascular endothelium (Kilbom \& Wennmalm, 1976; Koller \& Kaley, 1990; Koller et al., 1994), and may contribute to the vasodilation and increase in blood flow during muscle contraction. However, similar to investigations involving NO, many studies have examined the role of COX metabolites in functional hyperemia, but the results of these studies are inconsistent. For example, studies from the Hester laboratory demonstrate that inhibition of $\mathrm{COX}$ with indomethacin can significantly reduce the functional hyperemic response in the hamster cremaster muscle (Hammer et al., 2001; McKay et al., 1998). In other studies, indomethacin has no effect on the arteriolar diameter or blood flow response to muscle contraction in arterioles of the rat spinotrapezius muscle (Hammer \& Boegehold, 2005). Studies in humans and dogs have yielded equally conflicting data, with some studies demonstrating a role for prostaglandins in functional hyperemia (Messina et al., 1976; Wilson \& Kapoor, 1993) while others have not (Shoemaker et al., 1996; Young \& Sparks, 1980). Overall, the divergent results in these studies examining the roles of NO and PGs in functional hyperemia make interpretation difficult. One possible explanation for these conflicting results is that endothelium-mediated responses involve redundant mechanisms. For example, the combined inhibition of NO and PGs reduces muscle blood flow during dynamic exercise in humans (Boushel et al., 2002), whereas in other studies, inhibition of only one of these vasodilators may not have an effect 
due to the compensatory signaling of the other endothelium-mediated vasodilator pathway. In further support of this concept, combined inhibition of NOS and cytochrome P450 2C9 has been shown to reduce the exercise-induced hyperemic response in humans, whereas when investigated independently neither NOS nor cytochrome P450 2C9 inhibition has an effect on functional hyperemia (Hillig et al., 2003). Therefore, if one is investigating whether an individual pathway contributes to functional hyperemia, a lack of an effect of one pathway does not necessarily mean that the pathway does not contribute to functional hyperemia, but rather it may mean that the other redundant system(s) is compensating for the loss of this one pathway (Laughlin \& Korzick, 2001). In order to have a more complete understanding of functional hyperemia, additional research aimed at uncovering some of these redundant endothelial and smooth muscle control mechanisms is necessary.

\section{b. Shear stress as a stimulus for endothelial NO and PG release during muscle contraction}

Endothelial production of both NO and PG's can occur in response to an increase in blood flow which creates an increase in shear stress along the vascular wall with subsequent vasodilation (Koller et al., 1994; Koller et al., 1995; Koller \& Huang, 1999; Boegehold, 1995). This endothelium-dependent control mechanism is referred to as flow-induced dilation and has been shown to be involved in the regulation of cardiac and skeletal muscle blood flow (Holtz et al., 1983; Sun et al., 1995). However, most studies examining flowinduced dilation are conducted in isolated vessels, and so there has yet to be an in vivo study that critically evaluates and compares contraction-dependent changes in flow and shear stress with direct $\mathrm{NO}$ and PG measurements. 


\section{c. Reduced venular $\mathrm{PO}_{2}$ as a stimulus for endothelial NO and PG release}

Many studies show that NO and PGs are released from the vascular endothelium in response to a fall in tissue $\mathrm{PO}_{2}$ (Fredricks et al., 1994; Kerkhof et al., 1999; Messina et al., 1992; Pries et al., 1995; Sun et al., 1995; Frisbee et al., 2001c; Frisbee \& Lombard, 2002). As discussed earlier, studies indicate that it is unlikely that tissue and or periarteriolar $\mathrm{PO}_{2}$ are the stimuli for mediating the release of endothelium-dependent vasoactive factors in response to muscle contraction. In contrast Lash and Bohlen (1987) showed that large sustained decreases in perivenular $\mathrm{PO}_{2}$ occur during contraction of rat skeletal muscle. These results support earlier studies showing that venous $\mathrm{PO}_{2}$ decreases during exercise (Scott et al., 1970; Skinner, Jr. \& Costin, 1971; Tominaga et al., 1973). It is possible that this decrease in venular $\mathrm{PO}_{2}$ may be an important stimulus for the release of endothelium-derived vasodilators during increased metabolism of skeletal muscle.

A novel concept that may provide a link between the tissues metabolic status and the vascular response is that red blood cells (RBC) may act as oxygen sensors (Ellsworth et al., 1995). Red blood cells contain millimolar amounts of ATP (Miseta et al., 1993) and exposure of human and hamster RBCs to a low physiological $\mathrm{PO}_{2}$ can result in ATP release (Bergfeld \& Forrester, 1992; Ellsworth et al., 1995). Subsequently it has been shown that cerebral arterioles isolated from rats dilate in response to low extraluminal oxygen only when perfused with RBCs (Dietrich et al., 2000). An increase in ATP in the vessel effluent accompanied this dilation, lending support to the idea that ATP released from RBCs under hypoxic conditions may be an important mechanism of vascular control. It is well established that through activation of purinergic receptors (Abbracchio \& Burnstock, 1994), 
ATP can act as a vasoactive molecule and contribute to the regulation of blood flow. The vascular actions of ATP are well characterized and are reviewed elsewhere (Ralevic \& Burnstock, 1998). McCullough et al. (1997) and Hammer et al. (2001a) used in vivo microscopy to demonstrate that intraluminal venular application of ATP results in a significant increase in arteriolar diameter. Together with the results from Deitrich et al. (2000), these studies provide strong evidence of a relationship between $\mathrm{Po}_{2}, \mathrm{RBCs}$, venular ATP concentration and arteriolar dilation.

Despite these data, the mechanism(s) responsible for the ATP-mediated vasodilatory response is less clear, with evidence of roles for both NO and COX metabolites. Studies conducted in the Hester laboratory have shown obligatory roles for the venular endothelium (Saito et al., 1994) and COX products during functional hyperemia (McKay et al., 1998; Nuttle et al., 1999). Evidence of a role for the diffusion of vasoactive venular products to the adjacent arterioles which may be important in the control of blood flow is reviewed elsewhere (Hester \& Hammer, 2002). Additionally, the arteriolar response to venular administration of ATP was also shown to be dependent on an intact venular endothelium and COX (Hammer et al., 2001).

The collective data from Hester's laboratory have led to the hypothesis that during muscle contraction, decreased venular $\mathrm{PO}_{2}$ (and/or decrease $\mathrm{pH}$ ) stimulates ATP release from RBCs. This ATP then binds to receptors on the venular endothelium, stimulating the release of a cyclooxygenase product (possibly $\mathrm{PGI}_{2}$ ). This COX metabolite then diffuses to and dilates the adjacent arterioles. (Collins et al., 1998) also showed that intravenular administration of ATP resulted in dilation of upstream arterioles. However, in contrast to the study by Hammer et al. (2001a), these authors provide evidence of a conducted response 
(discussed below) which is dependent on NO. Thus, despite the differences between this study and Hammer et al. (2001a), these studies all provide indirect evidence for an ATPdependent mechanism coupling venular $\mathrm{Po}_{2}$ to endothelial release of vasodilators which may be important during functional hyperemia.

\section{d. Conducted vasodilation}

One means for coordinating the responses of individual blood vessels within a network is propagated or conducted vasodilation. This concept is based on the original observation by Duling and Berne (1970), that local application of acetycholine to a hamster cheek pouch arteriole resulted in increases in diameter that were propagated bi-directionally along the arteriole to upstream and downstream vessels. Subsequent studies have shown that this conducted vasodilation is an important mechanism in local blood flow control (Kurjiaka \& Segal, 1995; Segal, 1991) and that muscle fiber activation by itself can elicit conducted vasodilation along arterioles (Berg et al., 1997) into feed arteries (Welsh \& Segal, 1997).

Because $30-50 \%$ of total vascular resistance lies within the feed arteries located upstream and outside of the skeletal muscle microcirculation (Lash, 1994), it was proposed by Segal and Duling (1986) that in order for adequate blood flow perfusion to occur these vessels must dilate during skeletal muscle contraction. In support of this hypothesis, in both the cremaster and gracilis muscles of the hamster it has been shown that these feed arteries significantly increase in diameter, thus reducing the inflow resistance and contributing to the hyperemic response during contractions (Segal \& Duling, 1986; Segal \& Duling, 1987). In addition, work by other laboratories provide data in support of a conducted vasodilatory response during increased tissue metabolic activity (Murrant \& Sarelius, 2000). Currently, 
the mechanism by which this response occurs is believed to be a result of a conducted electrical signal that spreads through gap junctions between smooth muscle and endothelial cells (Emerson \& Segal, 2000; Welsh \& Segal, 1998).

In summary, there is not one specific factor that contributes to the functional hyperemic response. Rather, it involves a complex coordination of redundant endotheliumdependent and independent mechanisms that ultimately serve to provide the tissue with the required nutrients for a given level of tissue metabolic activity.

\section{Reactive oxygen species (ROS)}

As previously discussed, oxygen can have both direct and indirect effects on vascular function. In addition, derivatives of the one electron reduction of oxygen, widely known as ROS, have been known to play a central role in many disease processes. However, within the last decade ROS have also emerged as important signaling molecules in normal vascular function.

ROS is a general term for a family of short-lived molecules that result from the metabolism of oxygen. The high reactivity of these molecules is a result of an unpaired electron that exists in their outer shells around the nucleus. Any molecule with an unpaired electron will attempt to donate or obtain another electron to gain stability. Due to their chemical nature, ROS are capable of independent existence and therefore are more commonly known as free radicals. Examples of ROS include: hydroxyl anion $\left(\mathrm{OH}^{-}\right)$, superoxide anion $\left(\mathrm{O}_{2}{ }^{-}\right)$, hydrogen peroxide $\left(\mathrm{H}_{2} \mathrm{O}_{2}\right)$, and hypochlorous acid $(\mathrm{HOCl})$. In the cardiovascular system nearly every cell type is capable of producing ROS and more recently, it has been found that during increased metabolic activity, skeletal muscle cells can also generate ROS 
(Pattwell et al., 2004). There are a variety of sources that contribute to the one-electron reduction of oxygen leading to the production of ROS (Figure 3).

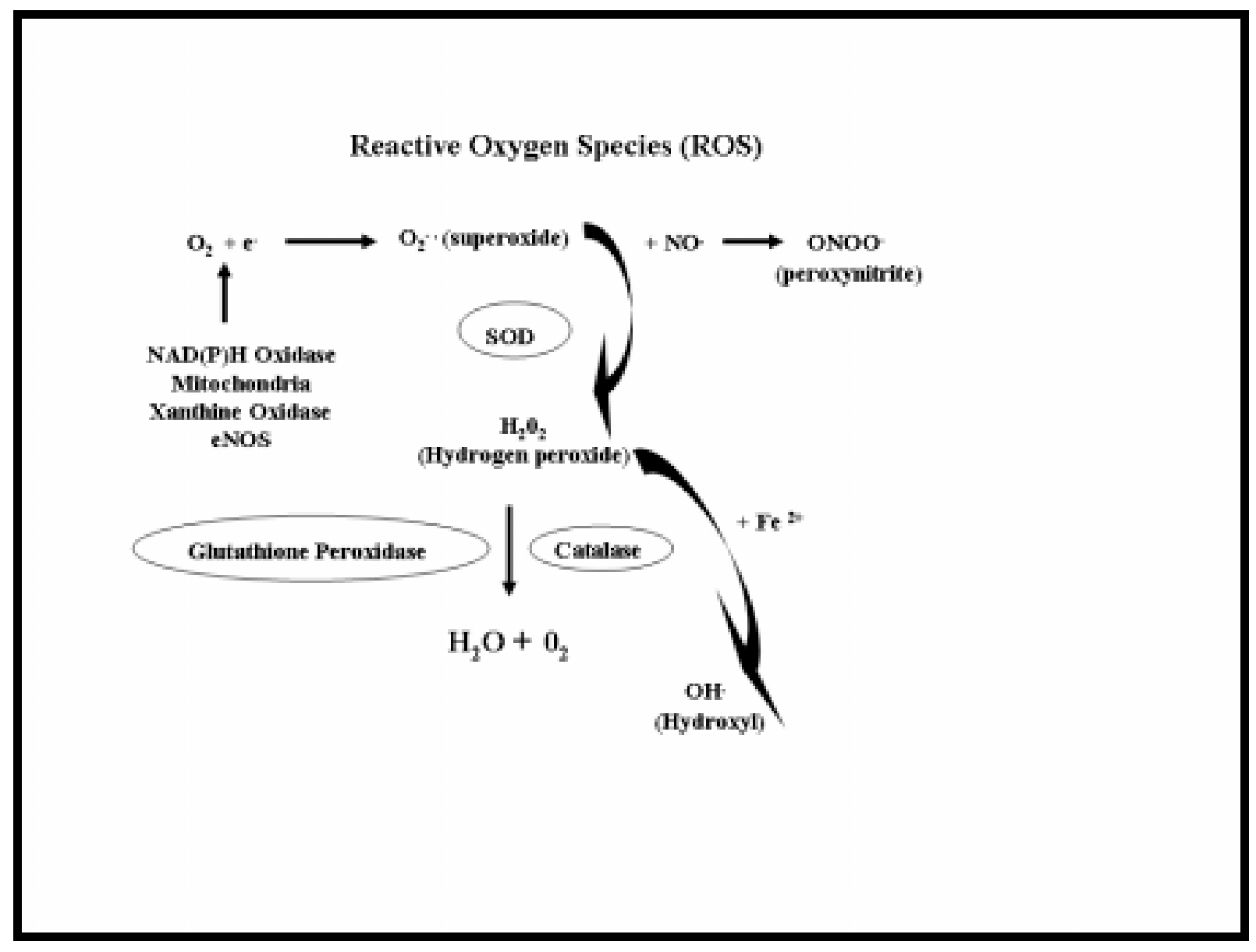

Figure 3. Reactive oxygen species sources and pathways

In the cardiovascular system, the most common are $\mathrm{NAD}(\mathrm{P}) \mathrm{H}$ oxidase, xanthine oxidase (XO), eNOS and the mitochondria. During increased metabolic activity, both NAD(P)H oxidase and $\mathrm{XO}$ serve as electron donors to oxygen, with subsequent formation of $\mathrm{O}_{2}^{-}$. Endothelial nitric oxide synthase, the enzyme responsible for the generation of NO, requires the essential co-factor, tetrahydrobiopterin $\left(\mathrm{BH}_{4}\right)$ (Rathaus \& Bernheim, 2002), which is important for maintaining the stability of the NOS dimer and for allowing electron transfer from the heme core of the enzyme to L-arginine (Hevel \& Marletta, 1992; Mayer \& Werner, 
1995). However, during conditions of reduced $\mathrm{BH}_{4}$ or L-arginine levels, this electron transfer is redirected to molecular $\mathrm{O}_{2}$ rather than L-arginine and results in the generation of $\mathrm{O}_{2}{ }^{-}$instead of NO, a condition known as eNOS uncoupling (Cosentino et al., 2001; VasquezVivar et al., 1998). This uncoupling of eNOS can also occur in the presence of increased asymmetric dimethylarginine (ADMA), an endogenous eNOS inhibitor (Sydow \& Munzel, 2003) and under conditions of reduced intracellular pH (Gorren et al., 1998). Recent findings indicate that reduced $\mathrm{BH}_{4}$ availability is responsible for vascular $\mathrm{O}_{2}^{-}$production in various cardiovascular related diseases such as diabetes (Bagi \& Koller, 2003) and atherosclerosis (Jiang et al., 2000).

The more common ROS known to have pathological and physiological effects on vascular structure and function include $\mathrm{O}_{2}^{-}, \mathrm{OH}^{-}, \mathrm{H}_{2} \mathrm{O}_{2}$, and peroxynitrite $\left(\mathrm{ONOO}^{-}\right)$. In order to minimize some of the harmful effects of ROS (lipid peroxidation, protein nitration, oxidation of LDL, DNA damage, apoptosis), the body is equipped with a number of natural cellular antioxidant defense mechanisms. For example, there are non-enzymatic antioxidants taken in by diet (eg. vitamins $\mathrm{C}$ and E) as well as specific intracellular and extracellular enzymatic antioxidants such as superoxide dismutase (SOD) and catalase (Rathaus \& Bernheim, 2002). The enzymatic reduction of $\mathrm{O}_{2}{ }^{-}$into $\mathrm{H}_{2} \mathrm{O}_{2}$ is catalyzed by the enzyme SOD, of which several forms exist (copper zinc SOD (CuZnSOD), mitochondrial manganese SOD (MnSOD and extracellular SOD (ecSOD) . In addition, $\mathrm{H}_{2} \mathrm{O}_{2}$ can be further metabolized into water and oxygen by catalase or glutathione peroxidase (Halliwell \& Gutterman, 1989). Through these actions, antioxidant enzymes are able to balance and maintain normal cellular homeostasis. However in various disease states this balance is disrupted and ROS formation can exceed the cellular antioxidant defenses resulting in a state of oxidative stress. 
It is well established that oxidative stress is involved in the development of many cardiovascular related diseases such as hypertension, atherosclerosis, diabetes, heart failure, and obesity (Griendling \& FitzGerald, 2003; Wolin, 1996). One of the primary mechanisms for the deleterious effects of ROS in the vasculature is the inactivation or reduction in the bioavailability of $\mathrm{NO}$ by $\mathrm{O}_{2}^{-}$. A reduction in the bioavailability of $\mathrm{NO}$ is a key contributing factor to endothelial dysfunction which is present in many forms of cardiovascular diseases (Harrison \& Cai, 2003). Elevated $\mathrm{O}_{2}^{-}$levels are present within vascular cells (smooth muscle, endothelial) in several forms of hypertension, atherosclerosis and diabetes (Griendling \& FitzGerald, 2003) and studies have shown that scavengers of $\mathrm{O}_{2}^{-}$such as SOD, can increase NO production and improve endothelial function (Laursen et al., 1997; Mugge et al., 1991). $\mathrm{H}_{2} \mathrm{O}_{2}$ levels have also been found to be increased in various cardiovascular diseases such as hypertension and diabetes (Kobayashi \& Kamata, 2002; Lacy et al., 2000) and increased vascular formation of $\mathrm{H}_{2} \mathrm{O}_{2}$ can lead to morphological and functional changes in vascular smooth muscle cells (Ardanaz \& Pagano, 2006). These are just some examples of how ROS are involved in cardiovascular disease and current research is focused on better understanding the molecular and cellular mechanisms. In addition to the role of ROS in the disease process, there is a growing body of literature showing that ROS are important second messenger molecules that participate in various signal transduction and transcriptional regulatory processes that are essential to normal cardiovascular function (Droge, 2002; Wolin, 2000).

Several lines of evidence suggest that ROS are important in the acute control of vascular tone and tissue blood flow (Oltman et al., 2003; Wolin, 1996; Wolin et al., 2005). The role of ROS in the regulation of vascular tone was first observed in the cerebral 
circulation, in which arteriolar dilation to sodium arachidonate or bradykinin was markedly inhibited in the presence of exogenously applied SOD and catalase, suggesting that either endogenous $\mathrm{O}_{2}{ }^{-}$or $\mathrm{H}_{2} \mathrm{O}_{2}$ contribute to these dilations (Kontos et al., 1983). Subsequent studies have also shown a role for ROS in regulating vascular tone in non-cerebral vessels, such as the coronary circulation (Oltman et al., 2003), intestinal arterioles (Hatoum et al., 2005), pulmonary circulation (Mohazzab \& Wolin, 1994; Omar et al., 1993), and skeletal muscle arterioles (Cseko et al., 2004). In many of these studies it is suggested that the primary ROS responsible for mediating changes in vascular tone is endothelium-derived $\mathrm{H}_{2} \mathrm{O}_{2}$, however very few of these studies (other than coronary circulation) actually demonstrate a physiological role for $\mathrm{H}_{2} \mathrm{O}_{2}$ in regulating vascular tone and blood flow. Hydrogen peroxide is a highly stable, membrane permeable molecule that is thought to have various autocrine and paracrine effects (Ardanaz \& Pagano, 2006). Hydrogen peroxide usually acts as a vasodilator, and can be important in local blood flow control such as during flow-induced dilation and reactive hyperemia in the coronary vasculature (Koller \& Bagi, 2004; Miura et al., 2003). Despite the numerous papers that have been published in recent years, the role of $\mathrm{H}_{2} \mathrm{O}_{2}$ in the regulation of vascular function is not completely understood.

Exogenous $\mathrm{H}_{2} \mathrm{O}_{2}$ has been shown to elicit vasoconstriction in the rat aorta (Rodriguez-Martinez et al., 1998), rat superior mesenteric artery (Gao \& Lee, 2001), and pulmonary artery (Jin \& Rhoades, 1997), but in most vessel types, $\mathrm{H}_{2} \mathrm{O}_{2}$ is a vasodilator. For example, $\mathrm{H}_{2} \mathrm{O}_{2}$ dilates human, mouse, rat and rabbit mesenteric arteries (Fujimoto et al., 2001; Gao et al., 2003; Lucchesi et al., 2005; Matoba et al., 2000; Matoba et al., 2002), porcine and human coronary arteries and arterioles (Barlow \& White, 1998; Sato et al., 
2003), canine cerebral arterioles (Iida \& Katusic, 2000), and bovine pulmonary arteries

(Burke \& Wolin, 1987). Vasodilation in response to $\mathrm{H}_{2} \mathrm{O}_{2}$ is consistent with strong evidence suggesting that $\mathrm{H}_{2} \mathrm{O}_{2}$ is an endothelium-derived hyperpolarizing factor (EDHF) (Matoba et al., 2000). $\mathrm{H}_{2} \mathrm{O}_{2}$-induced vasoconstriction, when present, may be a result of differences in species, the type of vascular bed studied and or the concentration of $\mathrm{H}_{2} \mathrm{O}_{2}$ used.

Interestingly, it was recently reported that depending on the concentration used, $\mathrm{H}_{2} \mathrm{O}_{2}$ can elicit a biphasic response, causing both a contraction and dilation of the vessel (Cseko et al., 2004; Gao et al., 2003). For example, in isolated gracilis arterioles it was determined that at its lower concentrations $\left(10^{-6}-3 \times 10^{-5} \mathrm{M}\right)$ exogenous $\mathrm{H}_{2} \mathrm{O}_{2}$ elicited only constrictions while at higher concentrations $\left(6 \times 10^{-5}-2 \times 10^{-4} \mathrm{M}\right)$ there was an initial constriction followed by vasodilation of the arteriole. Gao et al., (2003) also observed a biphasic response to $\mathrm{H}_{2} \mathrm{O}_{2}$ in rat mesenteric arteries, however, these authors observed constriction at their higher concentrations and a biphasic effect at lower concentrations. It should be noted that both of these studies were conducted on isolated vessel segments. Given that the $\mathrm{H}_{2} \mathrm{O}_{2}$ scavenging enzymes catalase and glutathione peroxidase are expressed throughout both the vasculature and surrounding parenchymal tissue (Harrison, 1997; Radak et al., 2001), it is possible that these biphasic effects are a result of altered $\mathrm{H}_{2} \mathrm{O}_{2}$ breakdown that is specific to in vitro vessel preparations. In summary, the above studies clearly suggest a role for $\mathrm{H}_{2} \mathrm{O}_{2}$ in the regulation of vascular tone. To more clearly define this role and how it may be altered during cardiovascular disease, there has been much work focused on elucidating the mechanism(s) of $\mathrm{H}_{2} \mathrm{O}_{2}$-mediated changes in vascular tone.

There are both direct and indirect mechanisms by which $\mathrm{H}_{2} \mathrm{O}_{2}$ relaxes or constricts vascular smooth muscle, and these mechanisms can vary depending on the type of vessel 
studied and/or the conditions under which it is studied. $\mathrm{H}_{2} \mathrm{O}_{2}$ can increase intracellular calcium levels (Yang et al., 1999) and calcium-dependent $\mathrm{H}_{2} \mathrm{O}_{2}$-induced vasoconstriction has been demonstrated in the rat aorta and dog basilar artery (Yang et al., 1999; Yang et al., 1998). Once activated, $\mathrm{Ca}^{2+}$-dependent pathways lead to increased intracellular $\mathrm{Ca}^{2+}$ through voltage-gated $\mathrm{Ca}^{2+}$ channels as well as $\mathrm{Ca}^{2+}$ release from the sarcoplasmic reticulum. This increase in intracellular $\mathrm{Ca}^{2+}$ levels leads to $\mathrm{Ca}^{2+}$-calmodulin binding and activation of MLCK with subsequent myosin light chain phosphorylation and vasoconstriction (Ardanaz \& Pagano, 2006). These data represent the general mechanism by which $\mathrm{H}_{2} \mathrm{O}_{2}$-mediated vasoconstriction is thought to occur. In comparison to $\mathrm{H}_{2} \mathrm{O}_{2}$ - mediated vasoconstriction, the mechanism(s) which mediate $\mathrm{H}_{2} \mathrm{O}_{2}$-mediated vasodilation have been more widely studied and characterized.

There is considerable evidence that $\mathrm{H}_{2} \mathrm{O}_{2}$-mediated vasodilation occurs via activation of diverse membrane $\mathrm{K}^{+}$channels (Barlow \& White, 1998; Barlow et al., 2000; Lacza et al., 2002; Matoba et al., 2000) leading to hyperpolarization of the vascular smooth muscle. In membrane patch clamp studies, $\mathrm{H}_{2} \mathrm{O}_{2}$ has been shown to directly hyperpolarize vascular smooth muscle cells (Ichinari et al., 1996; Kourie, 1998), and this has been supported by in vivo studies using pharmacological inhibitors. For example, in rat cerebral arterioles, $\mathrm{H}_{2} \mathrm{O}_{2}$ induced dilation can be inhibited by the large conductance, $\mathrm{Ca}$-activated $\mathrm{K}^{+}\left(\mathrm{BK}_{\mathrm{Ca}}\right)$ channel inhibitors TEA and iberiotoxin, suggesting that $\mathrm{H}_{2} \mathrm{O}_{2}$-induced dilation is mediated via the $\mathrm{BK}_{\mathrm{Ca}}$ channel (Sobey et al., 1997). This has also been demonstrated in the coronary circulation (Miura et al., 2003; Thengchaisri \& Kuo, 2003), cerebral circulation (Sobey et al., 1997) and skeletal muscle arterioles (Cseko et al., 2004). While $\mathrm{BK}_{\mathrm{Ca}}$ channels appears to be important in $\mathrm{H}_{2} \mathrm{O}_{2}$-induced dilation, there is also evidence that shows that ATP-sensitive 
potassium $\left(\mathrm{K}_{\text {ATP }}\right.$ ) channels play a role in $\mathrm{H}_{2} \mathrm{O}_{2}$ - induced dilation of cerebral arterioles (Lacza et al., 2002; Wei et al., 1996) and skeletal muscle arterioles (Cseko et al., 2004).

The data clearly demonstrate that $\mathrm{H}_{2} \mathrm{O}_{2}$-induced dilation is a $\mathrm{K}^{+}$channel-mediated event, and it is currently thought that $\mathrm{H}_{2} \mathrm{O}_{2}$ hyperpolarizes the vascular smooth muscle membrane via $\mathrm{K}^{+}$channels by either directly altering a specific protein component of the $\mathrm{K}^{+}$ channel (e.g. by an effect on methionine groups) and/or by enhancing the open-state probability of the channel (Gutterman et al., 2005; Liu \& Gutterman, 2002). In addition to having direct effects on $\mathrm{K}^{+}$channel function, there is also evidence that $\mathrm{H}_{2} \mathrm{O}_{2}$ can relax vascular smooth muscle indirectly through its metabolism by catalase and subsequent stimulation of soluble guanylate cyclase, which increases cytosolic cyclic guanosine monophosphate (cGMP) (Burke-Wolin et al., 1991; Burke \& Wolin, 1987). $\mathrm{H}_{2} \mathrm{O}_{2}$ can also increase NO production in endothelial cells via activation of phosphatidylinositol 3-kinase (PI3 kinase), leading to a $\mathrm{Ca}^{2+}$-independent activation of eNOS through the phosphorylation of its Ser 1177/1179 residues (Cai et al., 2003; Thomas et al., 2002). Through $\mathrm{K}^{+}$channel activation, both increases in cGMP and NO can lead to hyperpolarization and relaxation of vascular smooth muscle (Feletou \& Vanhoutte, 2000), thus providing two alternative mechanisms by which $\mathrm{H}_{2} \mathrm{O}_{2}$ may indirectly activate $\mathrm{K}^{+}$channels. Given that the activity of the $\mathrm{K}_{\mathrm{ATP}}$ channel is based on the ratio of intracellular ATP/ADP, this channel may be important in metabolic vascular control mechanisms such as the blood flow response to skeletal muscle contraction.

Several papers have reported that ROS production increases during skeletal muscle contractions. For example, using skeletal muscle fiber bundles and the ROS fluorochrome probe 2',7'-dichlorofluoroscein (DCFH), it was demonstrated that submaximal tetanic 
contractions of diaphragm muscle fibers significantly increased DCFH emission intensity, thus suggesting that cytosolic ROS production increases in contracting muscle fibers (Reid et al., 1992a). These authors concluded that $\mathrm{O}_{2}{ }^{-}$and $\mathrm{H}_{2} \mathrm{O}_{2}$ were responsible for the DCFH oxidation. In a companion paper using a cytochrome c reduction assay (for $\mathrm{O}_{2}{ }^{-}$production ) plus the $\mathrm{O}_{2}^{-}$scavenging enzyme SOD, these same authors went on to show that contracting muscle increases $\mathrm{O}_{2}{ }^{-}$release into the extracellular space (Reid et al., 1992b). In addition, using in vivo (mouse hindlimb muscle stimulation) and in vitro (mouse skeletal muscle myotubes) techniques, it was demonstrated that $\mathrm{O}_{2}{ }^{-}$production is increased following muscle contraction (McArdle et al., 2001). Using a more specific technique for the detection of $\mathrm{H}_{2} \mathrm{O}_{2}$ these same authors subsequently showed that $\mathrm{H}_{2} \mathrm{O}_{2}$ is the primary ROS formed in the extracellular space during muscle contraction (Silveira et al., 2003).

To examine the particular source of ROS from contracting skeletal muscle, more recent data has been conducted using knockout mice heterozygous for MnSOD. These mice exhibit a 50\% reduction in MnSOD activity in all tissues (McArdle et al., 2004). These authors found that $\mathrm{OH}^{-}$concentrations increase in the extracellular space during intense isometric contractions of wild type mice only and that this $\mathrm{OH}^{-}$radical is derived from the iron-catalyzed degradation of $\mathrm{H}_{2} \mathrm{O}_{2}$ generated from MnSOD activity, thus suggesting that the mitochondria can serve as an important source for $\mathrm{H}_{2} \mathrm{O}_{2}$ production in skeletal muscle. In summary, these data clearly demonstrate both in vivo and in vitro, that $\mathrm{H}_{2} \mathrm{O}_{2}$ is released during skeletal muscle contraction. Currently the role and function of this increased $\mathrm{H}_{2} \mathrm{O}_{2}$ during skeletal muscle contraction is not well understood. However given that $\mathrm{H}_{2} \mathrm{O}_{2}$ is a highly stable and diffusible molecule it is possible that it may also exert various paracrine effects on the skeletal muscle vasculature contributing to functional hyperemia. 


\section{Dietary Salt}

\section{A. Physiological Regulation of Salt and Water Balance}

The normal physiological response to increased dietary salt intake involves multiple mechanisms to compensate for the initial changes in water and $\mathrm{Na}^{+}$balance. Sodium is the predominant cation in the extracellular fluid (ECF), and is directly proportional to the plasma volume of the body. In order to maintain normal fluid balance, the ECF volume must be maintained within narrow limits. In response to high salt intake, there is an initial expansion of plasma volume (increased ECF) which increases the blood volume, thereby increasing the venous return to the heart and cardiac output. Subsequent activation of low and highpressure baroreceptors lead to a reflex reduction in total peripheral resistance, a decrease in circulating hormones (ANG II and aldosterone) that inhibit sodium reabsorption in the kidneys and decreases in renal autonomic nervous activity (Ganguli et al., 1979; Greene et al., 1990; Hansen-Smith et al., 1996; Widimsky et al., 1991). These compensatory mechanisms allow for the return of normal $\mathrm{Na}^{+}$levels and blood volume within 3-4 days and the maintenance of normal mean arterial pressure (Cowley, Jr. et al., 1983; Cowley, Jr., 1991; Nakamura \& Cowley, Jr., 1989)

The kidneys are primarily responsible for these compensatory adjustments in maintaining fluid balance following high salt intake. For example, an increase in plasma volume is detected by the kidneys through an increase in renal perfusion pressure. This leads to increased sodium excretion by the kidneys, thus aiding in returning the sodium levels (and therefore plasma volume) to normal, a mechanism referred to as pressure natriuresis (Guyton, 1987). Other renal compensatory mechanisms following high salt intake involve hormonal 
changes that function to inhibit $\mathrm{Na}^{+}$and water tubular reabsorption. These include increases in atrial natriuretic peptide (ANP), decreased renin release and circulating ANG II levels, and decreased circulating aldosterone levels (Allen et al., 1997; Hansen-Smith et al., 1996; Rapp, 1982; Widimsky et al., 1991).

The most important and well known hormonal system in the regulation of $\mathrm{Na}^{+}$ balance is the renin-angiotensin-aldosterone system (RAAS). Following an increased salt load, the macula densa cells in the short segment of the thick ascending limb sense this increase in sodium chloride $(\mathrm{NaCl})$ in the tubular fluid and inhibit the amount of renin secreted. In contrast, when $\mathrm{Na}^{+}$levels fall, the granular cells of the juxtaglomerular apparatus secrete renin into the blood. Renin functions as a proteolytic enzyme and acts on angiotensinogen, which is produced in the liver. Angiotensinogen is cleaved by renin, yielding angiotensin I which is then converted to ANG II by angiotensin converting enzyme (ACE). Some of the important physiological functions of ANG II include stimulation of aldosterone secretion, arteriolar constriction, and stimulation of vasopressin. Overall, the effects of $\mathrm{ANG}$ II favor $\mathrm{NaCl}$ retention and increased arterial blood pressure.

Vasopressin is an important hormone that is not only regulated by ANG II but can also be released in response to increased plasma osmolality, such as following a high salt diet. This increase in plasma osmolality is sensed by osmoreceptor cells located in the supraoptic and paraventricular nuclei of the anterior hypothalamus. Once released, vasopressin binds to the $V_{2}$ vasopressin receptor which is coupled to a stimulatory $G$ protein $\left(\mathrm{G}_{\mathrm{s}}\right)$ in the principal collecting ducts which stimulates increased permeability of the luminal membrane to water by increasing the number of water channels (aquoporins) in the membrane (Berne and Levy, 1998). The end result is that increased vasopressin levels 
promote water retention, thus buffering increased plasma osmolality and contributing to arterial pressure homeostasis.

NO also contributes significantly to the renal compensatory adjustments in response to high salt intake. High salt intake triggers increased production of NO in the kidney (Deng et al., 1994; Shultz \& Tolins, 1993). This serves to inhibit sodium reabsorption, as well as inhibition of renin release (Schnackenberg et al., 1997), thus promoting sodium excretion and the maintenance of normal sodium balance. The importance of NO is highlighted by studies that show that inhibition of NO production in salt-fed animals results in decreased sodium excretion and increased blood pressure (Shultz \& Tolins, 1993; Tolins \& Shultz, 1994).

Sympathetic nerve activity to the kidneys also decreases which contributes to inhibition of sodium reabsorption and increased sodium excretion (Osborn, 1991), thus maintaining normal plasma osmolality. In addition, secondary to increased cardiac output and increased baroreceptor activity (during initial days of HS intake), peripheral sympathetic nerve activity is also reduced thus maintaining normal total peripheral resistance (Ganguli et al., 1979).

In summary, changes in salt intake result in various compensatory mechanisms. Of particular importance is RAAS as rats fed a high salt diet have increased vasopressin levels (Matsuguchi et al., 1981), decreased plasma ANP and aldosterone levels (Widimsky et al., 1991), and suppressed renin release (Hernandez et al., 1992). The overall result is a reduction in plasma ANG II levels (Hansen-Smith et al., 1996) leading to the normalization of plasma sodium levels. 


\section{B. Salt-Sensitive Hypertension}

It is estimated that in the United States alone, approximately $20 \%$ of the population or 50 million individuals, have hypertension (Blaustein et al., 2006) and these numbers are on the rise (Fields et al., 2004). Anywhere from 30-50\% of these hypertensive people are considered to be salt-sensitive, in that their blood pressure will rise further with a high salt diet and can be lowered with salt restriction. With the goal of being able to better understand the hemodynamic and functional consequences of this form of hypertension, Lewis Dahl and colleagues developed a salt-sensitive strain of rats (Dahl et al., 1962). Since its inception, the Dahl rat model has provided important information regarding the physiological changes that occur, specifically in the resistance vasculature, with salt-sensitive hypertension. This form of hypertension, as with most forms, is characterized by a chronic elevation in total peripheral resistance with normal or even reduced cardiac output (Boegehold, 1991).

Using intravital microscopy, Boegehold (1991) showed that there is an exaggerated pressure drop across the small arteries and large arterioles in the spinotrapezius muscle of Dahl salt-sensitive (Dahl-S) rats, indicating that these segments contribute to the increase in vascular resistance in this muscle. Additional studies showed that a reduction in resting arteriolar diameters contributes to this increased vascular resistance (Boegehold \& Kotchen, 1990; Hillig et al., 2003). A factor that is thought to contribute to this reduction is loss of basal levels of endothelium-derived NO (Boegehold, 1992). Whole animal studies have also found suppressed NO activity in the hypertensive Dahl-S rat (Chen \& Sanders, 1993; Matsuoka et al., 1997) as well as reduced inducible nitric oxide synthase (iNOS) activity (Tan et al., 2000). A reduction in NO levels in salt-sensitive hypertension may not only 
effect resting arteriolar tone, but it may also affect the kidneys ability to excrete the excess sodium, which would lead to increased blood volume and overall increase in arterial pressure (Hu \& Manning, Jr., 1995; Miyata \& Cowley, Jr., 1999). Given that oxidative stress plays a key role in the development of hypertension, it is possible that the increased presence of ROS in the Dahl-S rat (Swei et al., 1997; Swei et al., 1999) can contribute to the accelerated breakdown of NO and therefore possibly contribute to the loss of NO and development of hypertension in this rat model.

Impaired renal function has been a central focus for the progression of salt- sensitive hypertension. Studies have shown that a transplanted kidney from a Dahl-salt resistant (Dahl-R) rat into a Dahl-S rat will lead to a decrease in blood pressure in the Dahl-S rat (Dahl et al., 1972; Dahl et al., 1974; Morgan et al., 1990). In addition, Dahl-S rats exhibit low plasma renin activity, and so a recent genetic model was developed by substituting chromosome 13 (carries functioning renin gene) from the Brown Norway rat into the Dahl-S rat (SS.BN13) (Cowley, Jr. et al., 2001), thus correcting the RAAS in the Dahl-S rat. Interestingly, unlike vasodilator mechanisms which are impaired in Dahl-S rats (discussed below), vasodilator mechanisms are normal in both cremaster arterioles and cerebral arteries in these genetically modified rats (Drenjancevic-Peric et al., 2003; Drenjancevic-Peric et al., 2005). These data highlight the overall importance of renal function in salt-sensitive hypertension.

In addition to the work focused on understanding the underlying mechanisms that contribute to increased total peripheral resistance in the Dahl-S rat, there is also evidence to show that mechanisms of local blood flow control are impaired in these rats. For example, metabolic control mechanisms such as the ability of the arterioles to sense oxygen changes, 
as well as the myogenic activity of renal arteries, and endothelium- dependent responses have all been shown to be impaired in hypertensive Dahl-S rats (Boegehold, 1992; Frisbee et al., 2001d; Rafi \& Boegehold, 1993; Takenaka et al., 1992). These data provide evidence that both structural and functional changes are present in this salt-sensitive model of hypertension. However, recent work has shown similar microvascular dysfunction in animals fed a high salt diet that have a normal blood pressure (normotensive), suggesting that it is the high salt per se which is responsible for altered vascular function, rather than the hypertension.

\section{Dietary Salt and the Vasculature: Hypertension-Independent effects}

\section{a. Structural Changes}

Consumption of a high salt diet can result in a variety of microvascular impairments that are independent of a change in blood pressure. The ability to study the effects of salt on normotensive animals provides a unique model that allows one to directly examine the effects of salt and how it may contribute to the microvascular dysfunction associated with salt-sensitive hypertension. It also provides for an opportunity to study potential risks associated with a high salt consumption in normotensive indviduals. In normotensive rats fed a high salt diet a number of investigators have reported microvascular structural changes that could directly affect mechanisms of local blood flow control.

Following a high salt diet for just 3 days, Hansen-Smith et al. (1996) determined that there are significant reductions in microvessel density (rarefaction) in the cremaster muscle of the rat. Ultrastructural characterization of these microvessels revealed loss of basement membranes and dissociation and thickening of endothelial and smooth muscle cells, all of 
which contributed to the overall loss of vessel integrity. Microvascular rarefaction has also been previously reported in the cremaster muscle of normotensive rats fed a high salt diet for 4 weeks (Greene et al., 1990; Hansen-Smith et al., 1990), however this rarefaction has not been shown to occur in the spinotrapezius muscle (Boegehold, 1993a). More recently it has also been shown that normotensive rats fed a high salt diet for 3 or 6 months show increased vascular remodeling and increased wall to lumen ratio in mesenteric resistance arterioles, as well as reduced wall-to-lumen ratios in renal cortical resistance arteries (Simon et al., 2003).

In normotensive rats, a high salt diet has also been demonstrated to reduce passive arteriolar diameters in a variety of vascular beds (Boegehold, 1993; Frisbee \& Lombard, 1998; Frisbee \& Lombard, 1999a; Nurkiewicz \& Boegehold, 2000) and this is thought to be due to changes in vessel wall structure from eutrophic (unchanged medial wall mass) or hypotrophic (decreased medial wall mass) remodeling. A high salt diet is associated with reduced circulating levels of ANG II (Hansen-Smith et al., 1996; Hernandez et al., 1992). ANG II is a critical hormone for normal vessel growth and arteriolar wall structure (Wang \& Prewitt, 1990) and so it is possible that these changes in microvessel structure are due to a reduction in ANG II levels. Angiogenesis is the physiological process involving the growth of new blood vessels and it was recently demonstrated that the angiogenic response to chronic muscle stimulation is completely inhibited in normotensive rats following high salt intake and suppression of ANG II contributes to this effect (Petersen et al., 2006).

\section{b. Functional Changes}

The myogenic response, which is important in local blood flow control (Johnson, 1989), is attenuated in rat renal afferent arterioles (Takenaka et al., 1992) and skeletal muscle arterioles following high salt intake (Nurkiewicz \& Boegehold, 1998; Nurkiewicz \& 
Boegehold, 1999; Nurkiewicz \& Boegehold, 2000). Reduced circulating ANG II, as well as increased local bradykinin levels, was found to contribute to this salt-induced attenuation of the myogenic response (Nurkiewicz \& Boegehold, 2000). In contrast, it has been reported that the myogenic responsiveness of isolated rat gracilis feed arteries is unaffected by high salt intake (Weber et al., 1999). These divergent results may be due to differences in rat strain, experimental preparation, and/or vessel characteristics.

It is well established that in the absence of an increase in blood pressure, a high salt diet affects endothelium-dependent and endothelium-independent arteriolar behavior. For example, in 1993, Boegehold reported that high salt intake impairs the arteriolar dilation to acetylcholine (ACh) in the spinotrapezius muscle of normotensive Dahl-R rats. In the same rat strain, it has been reported that high salt intake can attenuate flow- mediated dilation of skeletal muscle arterioles (Boegehold, 1995) as well as cerebral arteriole collateral dilation following a decrease in cerebral blood flow (Coyle, 1988). Gracilis muscle feed arteries from normotensive Sprague-Dawley rats fed a high salt diet exhibited reduced dilation to ACh, hypoxia, and the prostacyclin analog iloprost, which acts directly on the smooth muscle (Liu et al., 1997). Additional studies on arterioles from other vascular beds, such as the rat cerebral cortex (Liu et al., 1999) and cremaster muscle (Frisbee \& Lombard, 1998; Frisbee \& Lombard, 1999a) have also revealed reduced dilatory responses in normotensive rats fed high salt. These earlier studies provided the impetus to elucidate some of the underlying mechanisms and specific signaling pathways through which a high salt diet leads to functional alterations in the resistance vasculature.

Since the discovery of NO (Furchgott \& Zawadzki, 1980; Ignarro et al., 1987), ACh as well as L-arginine analogs such as $\mathrm{N}^{\mathrm{G}}$-nitro-L-arginine-methyl ester (L-NAME), have 
been commonly used to examine NO-dependent mechanisms in the resistance vasculature. Boegehold (1993) was the first to report that independent of an increase in blood pressure, dietary salt can reduce the steady-state influence of NO on arteriolar tone. In spinotrapezius muscle arterioles, NO mediates approximately two-thirds of flow-dependant dilation and the impairment of this response following high salt intake has been shown to be due to a loss of its NO-mediated component (Boegehold, 1995). Additionally, in this and other studies (Lenda et al., 2000; Liu et al., 1999), the vascular smooth muscle responsiveness to the NO donor sodium nitroprusside (SNP) is normal. This suggests that the reduced influence of NO cannot be due to altered VSM sensitivity to NO, but may result from a reduction in the amount of NO available and/or the level of activation of eNOS.

Reduced NO bioavailability has been attributed to an increase in production of the free radical $\mathrm{O}_{2}^{-}$in both hypertensive (Landmesser et al., 2006; Somers et al., 2000) and normotensive rat models (Zhu et al., 2006) and several reports show that in normotensive rats fed a high salt diet there are increased levels of ROS in the vascular wall (Kitiyakara et al., 2003; Lenda et al., 2000; Zhu et al., 2004). Excess $\mathrm{O}_{2}{ }^{-}$production can lead to accelerated breakdown of $\mathrm{NO}$, thus decreasing its bioavailability. In addition, the interaction of $\mathrm{O}_{2}{ }^{-}$and NO forms $\mathrm{ONOO}^{-}$, which degrades $\mathrm{BH}_{4}$ and can therefore lead to eNOS uncoupling which would in turn accentuate $\mathrm{O}_{2}{ }^{-}$formation and reduce $\mathrm{NO}$ availability. In the spinotrapezius muscle, Lenda et al. (2000) found that reduced arteriolar responses to ACh in high salt-fed normotensive rats could be returned to normal following the application of the ROS scavengers 2,2,6,6-tetramethylpiperidine-N-oxyl (Tempo) + catalase. These data suggest that the increased ROS in high salt rats contribute to the reduced arteriolar responses to ACh, most likely by limiting the bioavailability of $\mathrm{NO}$ through increased $\mathrm{O}_{2}^{-}$production. 
Additional studies have shown that arteriolar wall NAD(P)H oxidase and $\mathrm{XO}$ activities are increased in these salt-fed animals (Lenda \& Boegehold, 2002b) and these changes are accompanied by a reduction in the basal activity of CuZnSOD (Lenda \& Boegehold, 2002a). In agreement with this concept, recent data from aortic endothelial cells show that eNOSgenerated NO is reduced due to increased $\mathrm{O}_{2}^{-}$in normotensive high salt-fed rats ( $\mathrm{Zhu}$ et al., 2004). A follow-up study by these same authors, showed impaired endothelium-dependent relaxation in aortic segments from normotensive high salt-fed rats (Zhu et al., 2006). Taken together, these data provide convincing evidence that high salt intake leads to oxidative stress in the vascular wall, thus contributing to reduced endothelium-dependent responses via the inactivation of NO.

Studies focusing on other mechanisms of local blood flow control suggest that there may be alternative mechanisms responsible for the impaired dilator responses in other vascular beds of high salt-fed rats. For example, gracilis muscle arterioles exhibit an impaired dilator response to hypoxia (Frisbee et al., 2001d) that is due to reduced vascular smooth muscle sensitivity to $\mathrm{PGI}_{2}$ (Frisbee \& Lombard, 1999b; Frisbee et al., 2001e). This impaired dilator response will not develop if the normal salt-induced reduction in circulating ANG II is prevented by chronic infusion of ANG II at sub-pressor levels (Hernandez et al., 1992; Weber \& Lombard, 2000). This protective effect of ANG II was subsequently found to be mediated through the $\mathrm{AT}_{1}$ receptor (Weber \& Lombard, 2001). In further examining this signaling pathway, Frisbee et al. (2001) showed that the impaired dilation to hypoxia may be due to a compromised ability of $\mathrm{PGI}_{2}$ to cause intracellular generation of cAMP via adenylyl cyclase, occuring at the coupling between the $\mathrm{PGI}_{2}$ receptor and the $\mathrm{G}_{\mathrm{s}}$ protein complex. Subsequent studies have also demonstrated that low dose infusion of ANG II 
restores the impaired relaxation to reduced $\mathrm{PO}_{2}$ and iloprost in cerebral arteries of high salt rats (Lombard et al., 2003) and more recently, in vascular smooth cells (VSMCs) (Zhu et al., 2004). The study using isolated VSMCs from arteries of high salt-fed rats, provides further mechanistic insight by showing that the ability of VSMC to properly regulate $\mathrm{Ca}^{2+}$ in response to $\mathrm{PGI}_{2}$ is defective (Zhu et al., 2006)

In addition to impaired mechanisms of vasodilation in normotensive high salt rats, there is also evidence of altered arteriolar responses to constrictor stimuli in rat cremaster and mesenteric vessels (Wang et al., 2005; Weber et al., 1999). Recent data have shown that 20HETE is a potent vasoconstrictor in a variety of vascular beds (as previously discussed) and can mediate arteriolar constriction to increased $\mathrm{PO}_{2}$, ANG II, and norepinephrine (Frisbee et al., 2001a; Wang et al., 2005). Wang et al., (2005) was the first to report in normotensive rats that high salt intake can influence the role of 20-HETE in the constrictor response to norepinephrine as well as to the arteriolar response to reduced oxygen availability in the mesentery. These authors found that the impaired arteriolar responses were due to increased expression of CYP450 $\omega$-hydroxylase and increased production of 20-HETE levels. These data provide additional new evidence for another mechanism that can contribute to changes in local blood flow regulation in normotensive animals on a high salt diet, however whether such an effect occurs in the skeletal muscle vasculature has not been determined. 


\section{PURPOSE OF THIS DISSERTATION PROJECT}

Consumption of a high salt diet can lead to significant microvascular changes without affecting blood pressure. For example, in skeletal muscle arterioles of rats fed high salt, NO dependent dilation, as well as myogenic activity and hypoxic dilation, are impaired.

Furthermore, increased ROS are present in the arteriolar wall following a high salt diet, and can contribute to the dysfunction in some of these important mechanisms of microvascular blood flow control. These salt-dependent changes in resistance vessel function may have a profound impact on the regulation of blood flow in response to conditions of increased tissue metabolic demand and/or changes in oxygen availability.

An increase in tissue metabolic demand is accompanied by an increase in blood flow (functional hyperemia), which is essential for meeting the nutrient requirements of the tissue. This is a complex and incompletely understood process that involves multiple mechanisms of local blood flow control. For example, the direct and indirect effects of oxygen on vascular tone are thought to play a key role in mediating functional hyperemia. In addition, other oxygen linked molecules, such as ROS, have been shown to contribute to the regulation of vascular tone.

Independent of increased arterial pressure, it is unknown whether mechanisms of metabolic vascular blood flow control are affected by a high salt diet, and the role of increased ROS in this process has not been fully defined. Therefore, the purpose of this project is to better understand the impact of high salt intake on functional hyperemia, oxygen-dependent control of arteriolar tone and, to further define the role(s) of reactive oxygen species in some of these processes. 
Study I: Reduced Arteriolar Responses to Skeletal Muscle Contraction After Ingestion of a High Salt Diet 


\section{SUMMARY}

In skeletal muscle arterioles of rats fed a very high (7\%) salt diet, the bioavailability of endothelium-derived nitric oxide (NO) is reduced through scavenging by reactive oxygen species (ROS). Because arteriolar NO can play an important role in some forms of local blood flow control, we investigated whether arteriolar responses to increased tissue metabolism become compromised in skeletal muscle of salt-fed rats. Consumption of a high salt $(4 \%, \mathrm{HS})$ diet for 4 weeks had no effect on arteriolar diameters, volume flow or shear stress in resting spinotrapezius muscle. Arteriolar responses to a modest elevation in metabolic demand (0.5 $\mathrm{Hz}$ contraction) were not different from those in rats fed a normal (NS) diet, but diameter responses to a greater elevation in metabolic demand (4 Hz contraction) were significantly less in HS rats than NS rats. In both groups, the NO synthase inhibitor $\mathrm{N}^{\mathrm{G}}$-monomethyl-Larginine reduced resting arteriolar diameters and flow by a similar amount, and had little or no effect on arteriolar diameter or flow responses to muscle contraction. Arterioles in HS rats exhibited an increase in overall oxidant activity (determined by tetranitroblue tetrazolium reduction) but not in superoxide activity (determined by dihydroethidine oxidation).

Treatment with ROS scavengers (2,2,6,6-Tetramethylpiperidine-N-oxyl and catalase) did not normalize the reduced arteriolar responses to muscle contraction in HS rats. These findings suggest that oxidant stress in the arteriolar network of salt-fed rats is not due to increased superoxide anion, and that neither this oxidant stress nor reduced NO availability can account for the blunted active arteriolar dilation in rats fed a $4 \%$ salt diet. 


\section{INTRODUCTION}

The exacerbation of hypertension by dietary salt is accompanied by functional changes in the microcirculation of skeletal muscle, including increased arteriolar responsiveness to both $\mathrm{O}_{2}$ and myogenic stimuli [1-3], and a loss of the influence of endothelial nitric oxide (NO) on resting arteriolar tone [4]. High salt intake can also trigger microvascular changes in the absence of increased arterial pressure. For example, in the spinotrapezius muscle of normotensive rats fed a high salt diet, there is a reduction in arteriolar responsiveness to myogenic stimuli $[3,5,6]$ and to stimuli that normally elicit dilation through increased endothelial NO release [7-10], as well as a loss of NO's influence on resting arteriolar tone [11]. High salt intake has also been found to impair the hypoxic dilation of gracilis muscle feed arteries in normotensive rats [12-15].

The impact of these salt-dependent changes in resistance vessel function on local blood flow regulation remains unclear. The arteriolar dilation that links increased metabolic demand to increased tissue blood flow (active hyperemia) is a complex and incompletely understood process involving both endothelium-independent and endothelium-dependent mechanisms. Depending on a vessel's location within the network, this dilation may be triggered by a fall in tissue $\mathrm{O}_{2}$ levels and increased cellular metabolite production [16,17], a reduction in luminal pressure (leading to myogenic relaxation) [18,19], and/or an increase in hemodynamic shear stress [20-22]. These individual vasomotor adjustments are coordinated into an integrated network response through longitudinal conduction of electrical signals among cells in the vascular wall $[23,24]$. Since high salt intake can alter arteriolar responsiveness to one or more of these potential stimuli, consumption of a high salt diet may ultimately compromise the arteriolar dilation and hyperemia that accompany muscle contraction. To evaluate this 
possibility, we investigated the changes in arteriolar diameter and blood flow induced by different levels of contraction in the spinotrapezius muscle of normotensive rats fed normal $(0.45 \%)$ or high $(4 \%)$ salt diets for 4 weeks. Most of our previous studies on the microvascular changes associated with high salt intake have been conducted on rats fed a 7\% salt diet [3-11]. For the current study, we chose to use a $4 \%$ salt diet, which allows a more direct comparison with other studies on salt-dependent changes in microvascular function [12-15, 36]. Since scavenging of endothelium-derived NO by reactive oxygen species (ROS) has also consistently been found in this vascular bed after high salt intake [8-10], a second aim of this study was to determine if ROS and/or reduced NO bioavailability could contribute to any salt-linked deficit in the hyperemic response to muscle contraction. 


\section{METHODS}

Weanling male Sprague-Dawley rats (Harlan Sprague Dawley, Indianapolis, IN, USA) were placed on a whole-grain diet containing either $0.45 \% \mathrm{NaCl}$ (normal salt, NS) or 4\% $\mathrm{NaCl}$ (high salt, HS) by weight (NS diet= TD88311, HS diet= TD92034; Teklad, Madison, WI, USA). All rats were studied 4-5 weeks after being placed on their respective diets, and were 7-8 weeks old at this time.

\section{Surgical Preparation and Intravital Microscopy}

All surgical and experimental procedures were approved by the West Virginia University Animal Care and Use Committee. Each rat was anesthetized with sodium thiopental $(100 \mathrm{mg} / \mathrm{kg}$, i.p. $)$ and placed on a heating pad to maintain a $37^{\circ} \mathrm{C}$ rectal temperature. The trachea was intubated to ensure a patent airway and the right carotid artery was cannulated to measure arterial pressure. The right spinotrapezius muscle was exteriorized for microscopic observation as previously described [7], leaving its innervation and all feed vessels completely intact. Throughout the surgery and subsequent experimental period, the muscle was continuously superfused with an electrolyte solution $(119 \mathrm{mM} \mathrm{NaCl}$, $25 \mathrm{mM} \mathrm{NaHCO}_{3}, 6 \mathrm{mM} \mathrm{KCl}$ and $3.6 \mathrm{mM} \mathrm{CaCl}_{2}$ ) warmed to $35^{\circ} \mathrm{C}$ and equilibrated with $95 \%$ $\mathrm{N}_{2}-5 \% \mathrm{CO}_{2}(\mathrm{pH}=7.35-7.40)$. Superfusate flow rate was maintained at $4-6 \mathrm{ml} / \mathrm{min}$ to minimize equilibration with atmospheric $\mathrm{O}_{2}[25]$.

The animal preparation was transferred to the stage of an Olympus BX50WI intravital microscope (Hyde Park, NY, USA) fitted with a CCD video camera (Dage-MTI, Michigan City, IN, USA). Video images were displayed on a Sony high-resolution video monitor and videotaped for off-line analysis. Observations were made with an Olympus 20X water 
immersion objective (final video image magnification $=1460 \mathrm{X}$ ). Arteriolar centerline red blood cell velocities were measured on-line with an optical Doppler velocimeter (Cardiovascular Research Institute, Texas A\&M University, USA), and arteriolar inner diameters were measured off-line during videotape replay with a video caliper (Cardiovascular Research Institute).

\section{Muscle Contraction}

To increase tissue metabolic activity, muscle contraction was elicited by small wire electrodes inserted into the rostral and caudal edges of the muscle. Square-wave stimulating pulses of $0.2 \mathrm{~ms}$ duration and 3-6 volts in amplitude were used, with stimulus voltage adjusted for each animal to produce the greatest tissue movement with contraction. The stimulus pulse duration and voltage used in these experiments are below the thresholds for direct excitation of vascular smooth muscle or autonomic neurons [26], and this has been confirmed in rat spinotrapezius muscle using the same stimulation paradigm described here [17]. Because tissue movement precludes the measurement of any hemodynamic variable during the actual contraction period, arteriolar diameter and red cell velocity were measured during the first 5 seconds after cessation of contraction. Because there is minimal recovery of arteriolar diameters or flow during this period $[1,25]$, these values should closely reflect the steady-state values reached during contraction. 


\section{Experimental Protocols}

Protocol 1: Arteriolar responses to increased metabolic activity. In rat spinotrapezius muscle, the central "arcade bridge" arteriole gives rise to a network of interconnected arcade arterioles that extends throughout the muscle [27]. After exteriorization of the spinotrapezius muscle and a 30-minute post-surgical equilibration period, an arcade arteriole was chosen for study. After a 1-minute control period, the muscle was stimulated to repeatedly contract for 1 minute at a frequency of $0.5,2$ or $4 \mathrm{~Hz}$ (frequency randomly chosen), followed by a 5-minute recovery period. This sequence was repeated 2 more times for stimulation at the remaining frequencies, so that arteriolar responses to all 3 levels of increased tissue metabolism could be assessed.

In one subset of rats, to determine if NO release contributes to these arteriolar responses, the nitric oxide synthase (NOS) inhibitor $\mathrm{N}^{\mathrm{G}}$-monomethyl-L-arginine (L-NMMA, Sigma-Aldrich Corp., St. Louis, MO, USA) was then infused via syringe pump into the superfusate delivery line to produce an L-NMMA concentration of $10^{-4} \mathrm{M}$ in the solution bathing the muscle. A 10-minute exposure to L-NMMA at this concentration reduces the dilation of spinotrapezius muscle arterioles to acetylcholine by 50-70\%, which represents most if not all of the NO-dependent portion of the response [7,28]. After this equilibration period, arteriolar responses to muscle contraction at all 3 frequencies were reassessed, with L-NMMA superfusion continued throughout to ensure maximal NOS inhibition.

In a second subset of rats, we evaluated the possible contribution of ROS to any dietrelated differences in arteriolar responsiveness to muscle contraction. Arteriolar diameter and flow changes with contraction were evaluated before and then during exposure to 2,2,6,6-Tetramethylpiperidine-N-oxyl (TEMPO, Sigma-Aldrich , $1 \times 10^{-4} \mathrm{M}$ in superfusate) 
+ catalase (CAT, Sigma-Aldrich, $50 \mathrm{U} / \mathrm{ml}$ in superfusate). TEMPO belongs to a family of a nitroxide spin labels that act as membrane-permeable SOD mimics [29], and we have previously verified that in rat spinotrapezius muscle, these superfusate concentrations of TEMPO + CAT are sufficient to effectively scavenge ROS in the immediate vicinity of the arteriolar wall [8].

At the end of each experiment, $1 \times 10^{-3} \mathrm{M}$ adenosine (Sigma-Aldrich) was added to the superfusate to abolish microvascular tone, and passive arteriolar diameter was measured in order to express each response to muscle contraction as percent of maximum dilation (see below).

Protocol 2: In vivo measurement of microvascular wall oxidant activity. Steady-state arteriolar wall levels of superoxide anion $\left(\mathrm{O}_{2}^{-}\right)$or its reactive metabolites were assessed by the tetranitroblue tetrazolium (TNBT) reduction assay and by the dihydroethidine (DHE) oxidation assay, as adapted for use with in vivo microscopy [8-10, 30].

The TNBT reduction assay was used to provide a general index of microvascular oxidant activity. The exteriorized muscle was continuously superfused with a $2 \%$ TNBT solution for 60 minutes, then fixed in situ with $10 \%$ formalin and excised. The muscle was then progressively dehydrated with ethanol and cleared with methyl salicylate so vessels could be more easily visualized with brightfield microscopy. Images of arcade arterioles were captured, digitized and analyzed with a MetaMorph 6.01 imaging system (Universal Imaging Corporation, Downingtown, PA, USA). Using a 1 x $5 \mu \mathrm{m}$ photometric window, measurements of average pixel intensity were made at a series of sites along each vessel wall, and in a corresponding series of extravascular regions immediately adjacent to those sites. Normalizing each wall measurement to that of a nearby extravascular site allowed for the 
control of any site-to-site or muscle-to-muscle variations in background intensity. To assess arteriolar wall levels of formazan (the dark reduction product of TNBT, and therefore an index of oxidant activity), the pixel intensity measurements were used to calculate microvascular wall light absorption $(A): A=-\ln \left(I_{w} / I_{o}\right)$, where $I_{w}$ is the vessel intensity and $I_{o}$ is the intensity for the adjacent extravascular region. We have previously verified that the amount of formazan formed during TNBT exposure is proportional to the level of oxidant activity, and that calculated light absorption is linearly related to the amount of formazan present [9].

DHE was introduced into the spinotrapezius muscle microcirculation by intra-arterial infusion. Because it is not oxidized by $\mathrm{H}_{2} \mathrm{O}_{2}, \mathrm{HOCl}, \mathrm{ONOO}^{-}$or $\mathrm{O}_{2}, \mathrm{DHE}$ is considered to be relatively specific for the detection of $\mathrm{O}_{2}^{-}$[31-33]. DHE easily permeates cell membranes, and, when oxidized by $\mathrm{O}_{2}^{-}$, it is converted to fluorescent ethidium bromide that intercalates into nuclear DNA [31,32]. A polyethylene cannula containing $2 \mathrm{ml}$ of $10^{-3} \mathrm{M} \mathrm{DHE}$ in physiological electrolyte solution was advanced down the right common carotid artery to its junction with the right subclavian artery, so that the DHE solution could be slowly infused into the subclavian artery close to its bifurcation into the right axillary and right mammary arteries. Branches of these arteries directly feed the spinotrapezius muscle [34]. After preparation of the muscle for in vivo microscopy, a region containing clearly visible arcade arterioles was selected, and then DHE was infused into the vascular bed in complete darkness to prevent its photo-destruction. In a series of pilot experiments, we found that with this route of administration, endothelial and smooth muscle cell nuclei in the arteriolar wall exhibit maximum ethidium bromide fluorescence 10 minutes after DHE infusion. After this 10-minute period, the tissue was briefly (1-2 s) epi-illuminated with a mercury lamp, using 
appropriate excitation and emission filters for ethidium bromide fluorescence (480-550 nm bandpass, $590 \mathrm{~nm}$ barrier). During this illumination, Metamorph 6.01 was used to acquire, digitize and store arteriolar images for subsequent analysis. In some preparations, vascular $\mathrm{O}_{2}{ }^{-}$generation was experimentally enhanced to provide a positive control for ethidium bromide fluorescence. This was achieved by adding xanthine (XAN, Sigma-Aldrich, 1x10-4 M) + xanthine oxidase (XO, ICN Biomedicals Inc., Aurora, Ohio, $0.015 \mathrm{U} / \mathrm{ml}$ ), in combination with the SOD inhibitor diethyldithiocarbamate (DETCA, Sigma-Aldrich, 5 x $10^{-}$

${ }^{3}$ ) to the superfusate, and, after 20 minutes, acquiring images for fluorescence measurement. To quantify the level of ethidium bromide fluorescence in each microvessel, clearly visible fluorescent nuclei were identified and counted, with the data expressed as the number of fluorescent nuclei per $100 \mu \mathrm{m}$ vessel length [30].

\section{Data and Statistical Analysis}

Arteriolar diameter $(\mathrm{D}, \mu \mathrm{m})$ and centerline red cell velocity $\left(\mathrm{V}_{\mathrm{cl}}, \mathrm{mm} / \mathrm{s}\right)$ were sampled at 5-second intervals during control and post-contraction periods. Diameter responses to muscle contraction were expressed in absolute terms $\left(D_{s s}-D_{c}\right)$, where $D_{s s}$ is steady-state diameter immediately after contraction and $\mathrm{D}_{\mathrm{c}}$ is pre-contraction control diameter, and as percent of maximum response for that vessel: \% Maximum Response $=\left[\left(D_{s s}-D_{c}\right) /\left(D_{\text {pass }}-\right.\right.$ $\left.D_{c}\right)$ ] x 100 , where $D_{\text {pass }}$ is passive diameter. Mean red cell velocity $\left(V_{\text {mean }}\right)$ was calculated as $\mathrm{V}_{\mathrm{cl}} / 1.6$, where 1.6 is the ratio of centerline red cell velocity to mean velocity for vessels $>10$ $\mu \mathrm{m}$ in diameter [35]. Paired values of $\mathrm{D}$ and $\mathrm{V}_{\text {mean }}$ were used to calculate arteriolar volume flow $(\mathrm{Q}, \mathrm{nl} / \mathrm{s})$ and wall shear rate $\left(\mathrm{WSR}, \mathrm{s}^{-1}\right): \mathrm{Q}=\mathrm{V}_{\text {mean }} \times\left(\pi \times \mathrm{D}^{2} / 4\right)$, and WSR $=8 \mathrm{x}$ 
$\left(\mathrm{V}_{\text {mean }} / \mathrm{D}\right)$. Wall shear rate was used as an index of wall shear stress, and its calculation assumes a parabolic velocity profile.

All data are reported as means \pm SE. Statistical analysis was performed by commercially available software (Sigmastat, SPSS Inc., Chicago, IL, USA). One-way repeated measures ANOVA was used to determine the effect of treatment within a group. Two-way repeated measures ANOVA was used to determine the effects of diet, treatment and diet-treatment interactions on measured variables. For all ANOVA procedures, the Student-Newman-Keuls method for post hoc analysis was used to isolate pairwise differences among specific groups. Significance was assessed at the $95 \%$ confidence level $(\mathrm{P}<0.05)$ for all tests. 


\section{RESULTS}

The general characteristics of all rats used in this study (Protocols 1 and 2) are shown in Table 1. At the time of study, the body weight and mean arterial pressure of rats fed high salt were not significantly different from those of rats fed the normal diet. Table 2 displays the characteristics of all arterioles studied by in vivo microscopy in Protocol 1. Under control conditions, there were no significant differences between dietary groups in resting arteriolar diameter, volume flow or wall shear rate, or in passive arteriolar diameter measured after abolition of vascular tone with adenosine.

In both groups, muscle contraction at each frequency elicited a significant increase in arteriolar diameters (Figure 1). The average increases in diameter, whether expressed in absolute terms or as percent of the maximum dilator response, tended to be less in HS rats than in NS rats, with the differences reaching statistical significance at $4 \mathrm{~Hz}$ contraction. In both groups, there were similar increases in arteriolar volume flow during muscle contraction at all frequencies. Calculated arteriolar wall shear rate decreased significantly at all contraction frequencies in NS rats (changes from control of $-212 \pm 107,-397 \pm 166$ and -551 $\pm 217 \mathrm{~s}^{-1}$ at $0.5 \mathrm{~Hz}, 2 \mathrm{~Hz}$ and $4 \mathrm{~Hz}$, respectively), but did not significantly change with contraction in HS rats $\left(-146 \pm 220,-12 \pm 206\right.$ and $-47 \pm 310 \mathrm{~s}^{-1}$ at $0.5 \mathrm{~Hz}, 2 \mathrm{~Hz}$ and $4 \mathrm{~Hz}$, respectively).

As shown in Figure 2, exposure to the NOS inhibitor L-NMMA significantly reduced arteriolar diameter and volume flow in resting muscle of both NS and HS rats, and these reductions were of similar magnitudes in the two dietary groups. In NS rats, L-NMMA had no effect on the magnitude of arteriolar dilation in response to $0.5 \mathrm{~Hz}$ or $2 \mathrm{~Hz}$ contraction, but it did significantly reduce the dilation in response to $4 \mathrm{~Hz}$ contraction (Figure 3, left 
panels). However, L-NMMA had no effect on the increase in flow that accompanied muscle contraction at any frequency in NS rats. In the HS rats, L-NMMA had no significant effect on the changes in diameter or flow that accompanied muscle contraction at any frequency (Figure 3, right panels).

In preparations exposed to TNBT, calculated arteriolar wall light absorption in HS rats $(0.192 \pm 0.025$, dimensionless units $)$ was significantly greater than that in NS rats $(0.113$ \pm 0.026 ) (Figure 4, top panel). Since these absorption values are linearly related to formazan content, and therefore local oxidant activity [9], we infer from this finding that under resting conditions, overall oxidant activity is significantly higher in the walls of HS arterioles than in those of NS arterioles. However, in preparations exposed to dihydroethidine (bottom panel), there was no difference between HS and NS rats in the level of ethidium bromide fluorescence in arteriolar walls $(1.60 \pm 0.30$ vs. $1.81 \pm 0.25$ fluorescent nuclei/100 $\mu \mathrm{m}$ vessel length, respectively), suggesting that steady-state levels of $\mathrm{O}_{2}^{-}$are comparable in these 2 groups. Exposure of muscle in HS rats to XAN/XO + DETCA significantly increased ethidium bromide fluorescence above the steady-state value for either group $(2.99 \pm 0.22$ fluorescent nuclei/100 $\mu \mathrm{m}$ vessel length).

In NS rats, exposure to the ROS scavengers TEMPO + CAT had no effect on resting arteriolar diameters or flows (data not shown). However, TEMPO + CAT tended to decrease the magnitude of arteriolar dilation in response to muscle contraction at all frequencies, with this effect reaching statistical significance at $4 \mathrm{~Hz}$ contraction (Figure 5, left panels). In this group, TEMPO + CAT also tended to reduce the flow changes accompanying muscle contraction, but this effect was not statistically significant at any frequency. In the HS rats, TEMPO + CAT also had no effect on resting arteriolar diameters or flows, and also tended to 
reduce arteriolar diameter and flow responses to muscle contraction at each frequency, although none of these differences were significant (right panels). 
Table 1: Profiles of all experimental animals at time of study.

\begin{tabular}{lccr}
\multicolumn{1}{c}{ Dietary Group } & N & Weight $(\mathrm{g})$ & $\begin{array}{r}\text { Mean Arterial } \\
\text { Pressure (mm }\end{array}$ \\
\hline Normal Salt & 22 & $299 \pm 5$ & $101 \pm 2$ \\
High Salt & 24 & $293 \pm 5$ & $103 \pm 3$
\end{tabular}

$\mathrm{N}$, number of animals. Values are given as mean $\pm \mathrm{SE}$. 
Table 2: Arteriolar characteristics at time of study.

\begin{tabular}{lcccc} 
Dietary Group & $\begin{array}{c}\text { Resting } \\
\text { Diameter } \\
(\mu \mathrm{m})\end{array}$ & $\begin{array}{c}\text { Passive } \\
\text { Diameter } \\
(\mu \mathrm{m})\end{array}$ & $\begin{array}{c}\text { Resting } \\
\text { Volume Flow } \\
(\mathrm{nl} / \mathrm{s})\end{array}$ & $\begin{array}{c}\text { Resting Wall } \\
\text { Shear Rate } \\
\left(\mathrm{s}^{-1}\right)\end{array}$ \\
\hline Normal Salt & $18.2 \pm 0.8$ & $58.6 \pm 3.3$ & $1.5 \pm 0.3$ & $1877 \pm 237$ \\
High Salt & $19.0 \pm 1.3$ & $55.0 \pm 4.1$ & $1.3 \pm 0.3$ & $1793 \pm 232$
\end{tabular}

Values are given as mean \pm SE. Within each group, values for resting diameter and passive diameter are paired (Normal Salt: $\mathrm{n}=24$ vessels; High Salt: $\mathrm{n}=25$ vessels), and values for resting volume flow and resting wall shear rate are paired (Normal Salt: $\mathrm{n}=19$ vessels; High Salt: $\mathrm{n}=18$ vessels). 

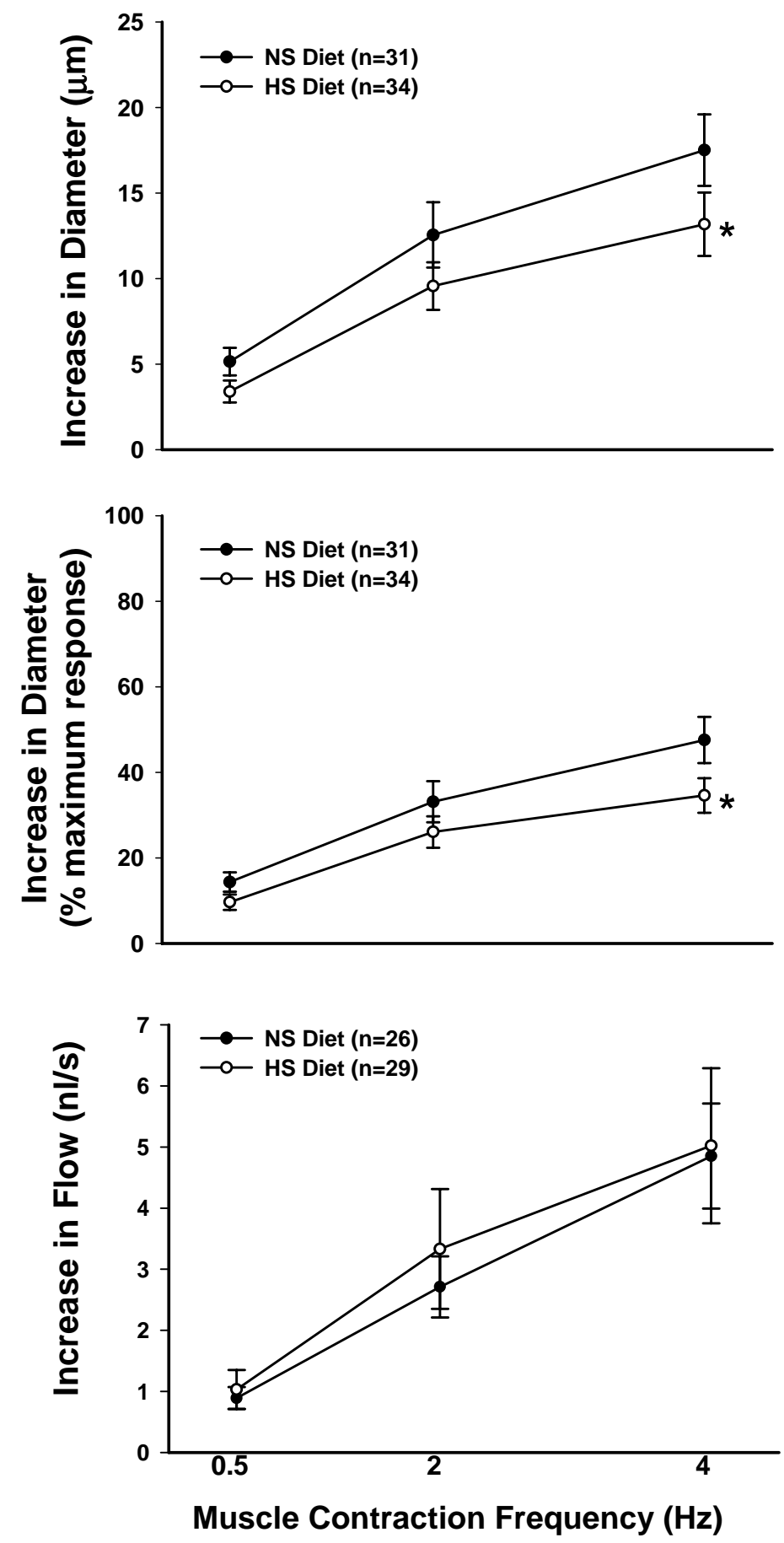

Figure 1. Changes in arteriolar diameter and flow elicited by $0.5 \mathrm{~Hz}, 2 \mathrm{~Hz}$, and $4 \mathrm{~Hz}$ muscle contraction in rats fed NS and HS diets. Diameter responses are expressed in absolute terms (top panel) or relative to each vessel's maximum capacity for dilation (middle panel). $\mathrm{n}=$ number of vessels studied. $* \mathrm{P}<0.05$ vs. NS. 


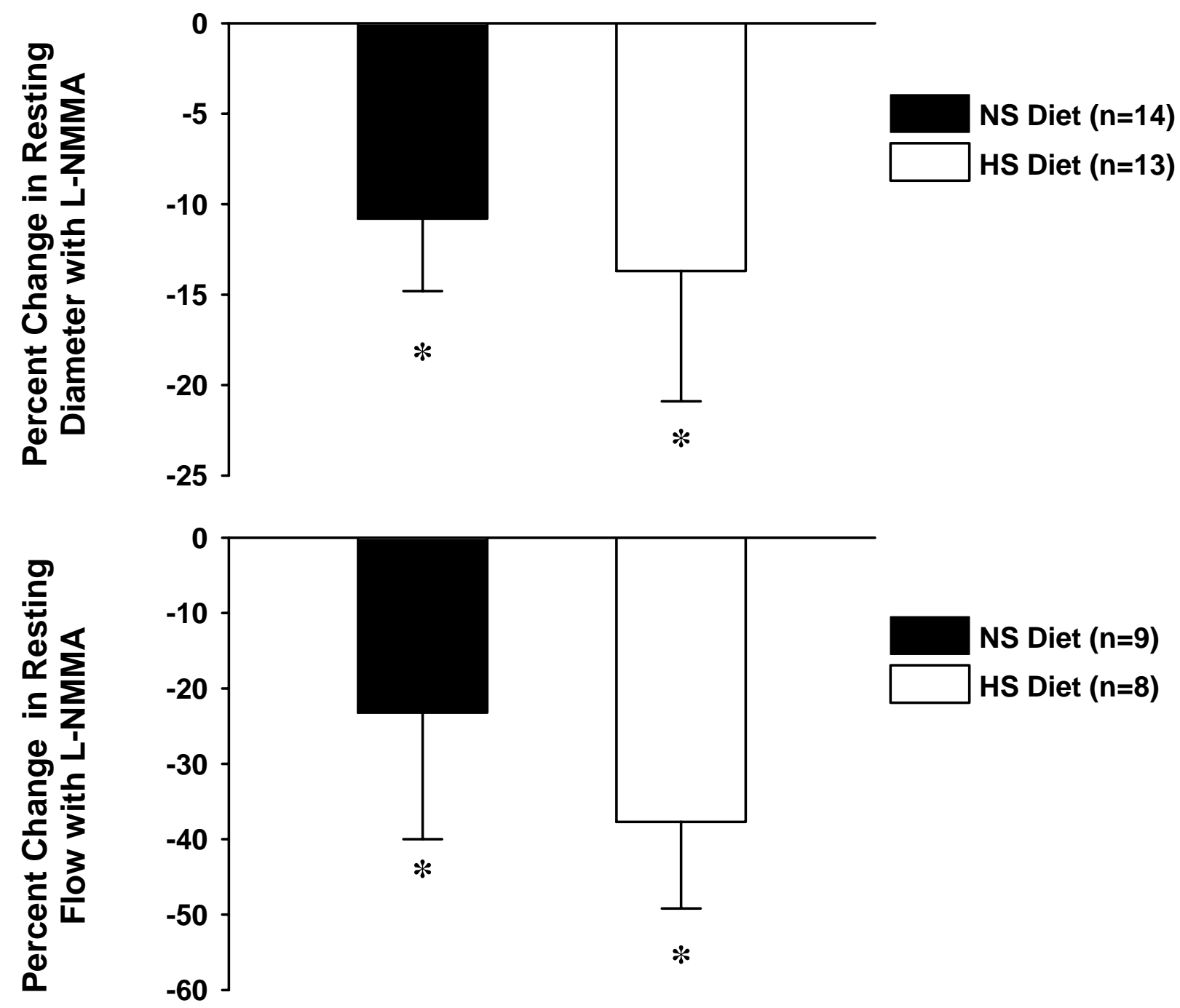

Figure 2. Effect of $\mathrm{N}^{\mathrm{G}}$-monomethyl L-arginine (L-NMMA) on resting arteriolar diameters (top) and volume flows (bottom) in rats fed NS and HS diets. $\mathrm{n}=$ number of vessels studied. * $\mathrm{P}<0.05$ vs. 0 
NS Diet

HS Diet
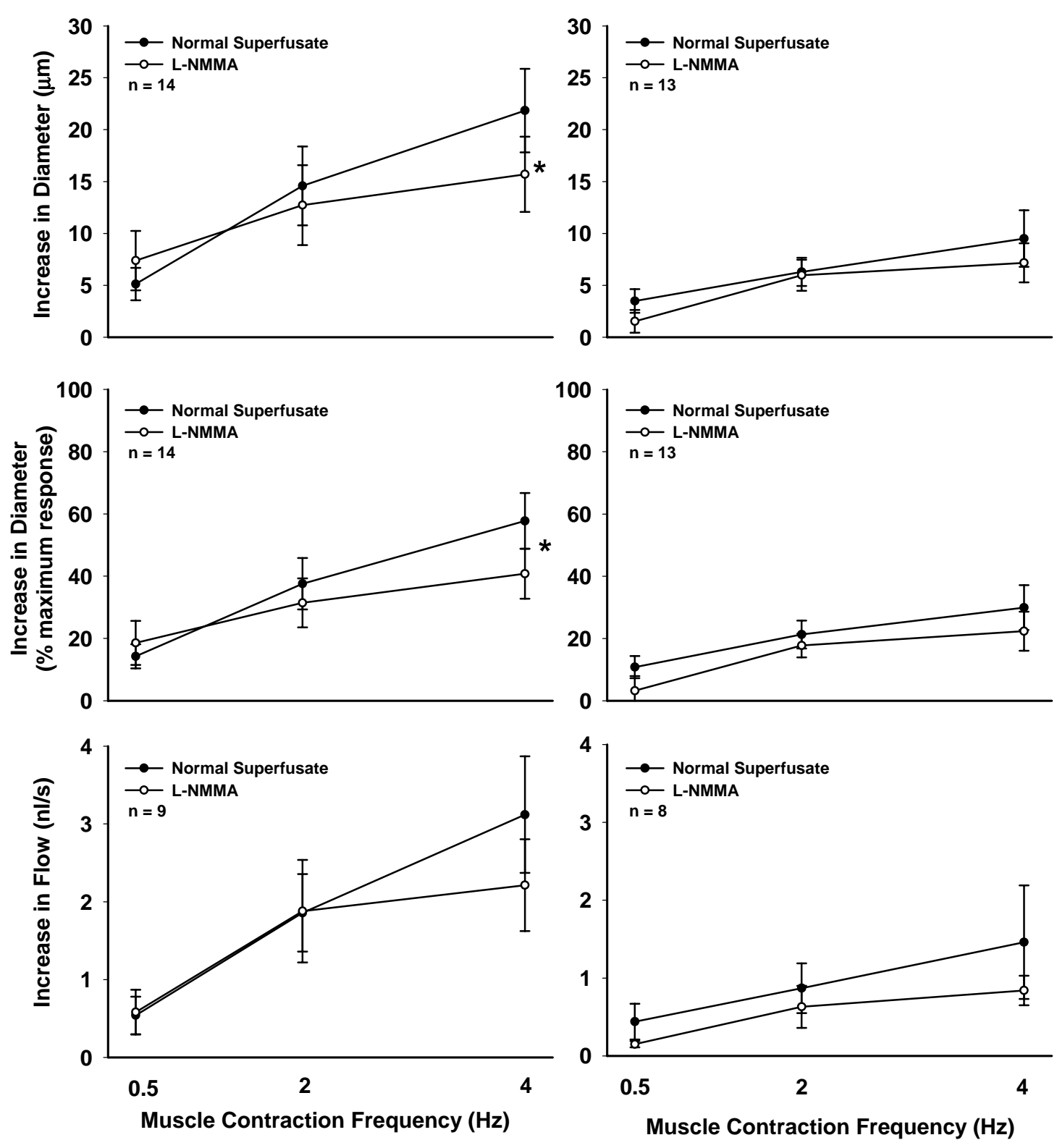

Figure 3. Effect of L-NMMA on arteriolar diameter and flow responses to $0.5 \mathrm{~Hz}, 2 \mathrm{~Hz}$, and $4 \mathrm{~Hz}$ muscle contraction in rats fed NS diet (left panels) and HS diet (right panels). Diameter responses are expressed in absolute terms (top panels) or relative to each vessel's maximum capacity for dilation (middle panels). $\mathrm{n}=$ number of vessels studied. $* \mathrm{P}<0.05$ vs. Normal Superfusate. 

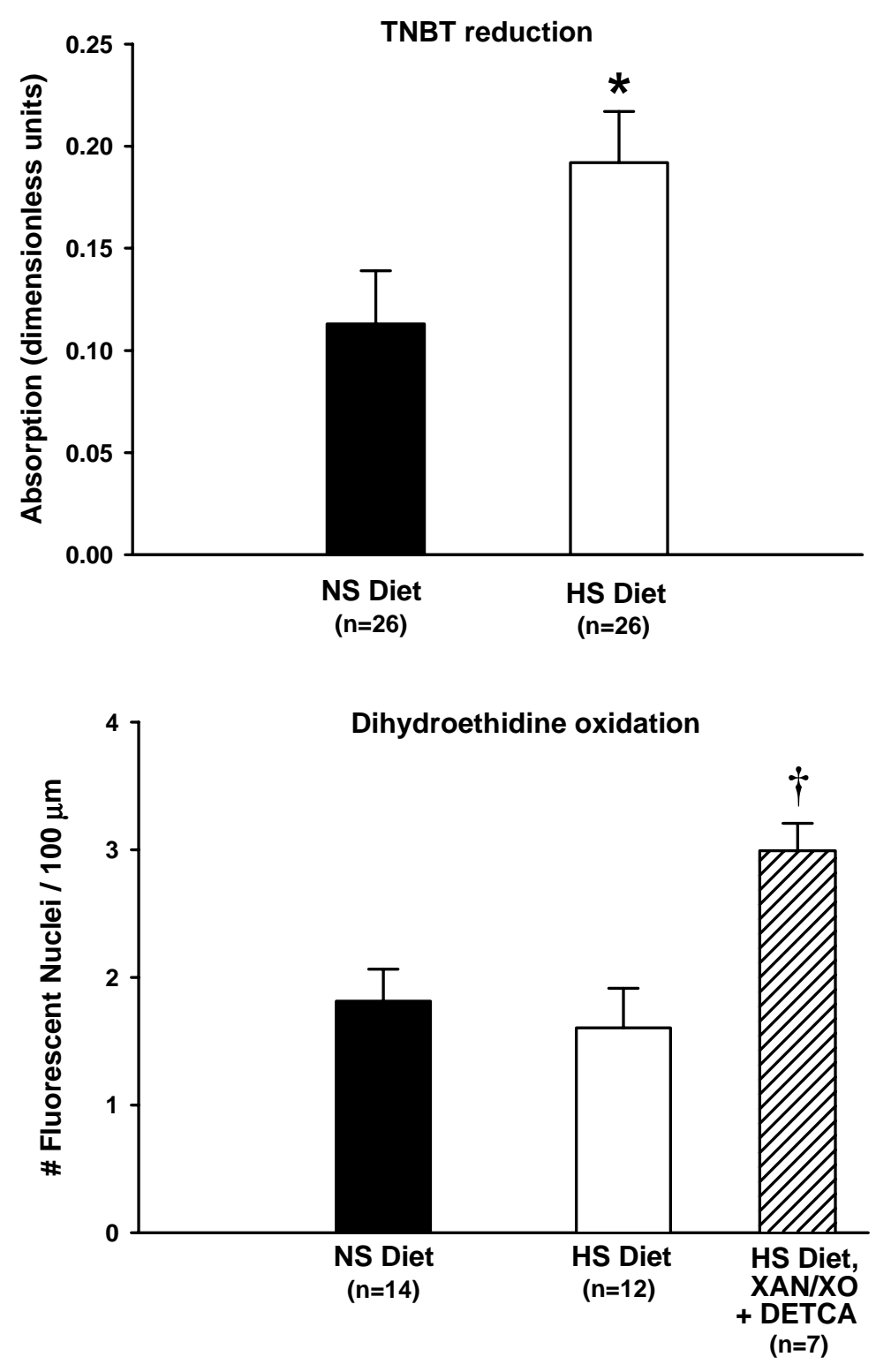

Figure 4. Top panel: Calculated arteriolar wall light absorption after exposure to $2 \%$ tetranitroblue tetrazolium (TNBT) in rats fed NS and HS diets. Bottom panel: Number of nuclei in arteriolar walls, normalized to segment length, exhibiting ethidium bromide fluorescence after exposure to intravascular dihydroethidine in rats fed NS diet and HS diet under control conditions, and in rats fed HS diet during treatment with xanthine / xanthine oxidase + diethyldithiocarbamate $(\mathrm{XAN} / \mathrm{XO}+$ DETCA $) . \mathrm{n}=$ number of vessels studied. $\dagger$ $\mathrm{P}<0.05$ vs. control for either dietary group. 
NS Diet
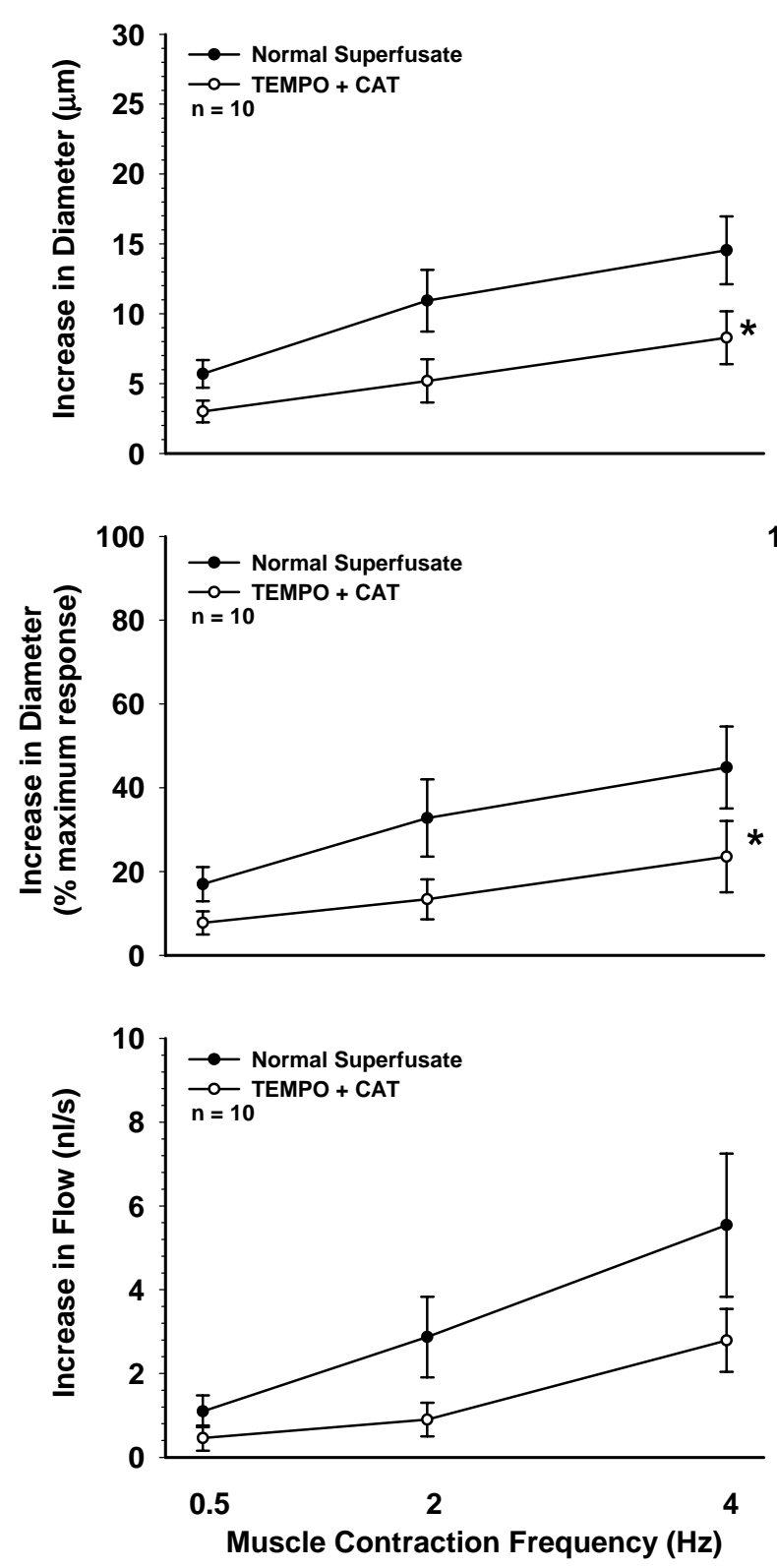

HS Diet
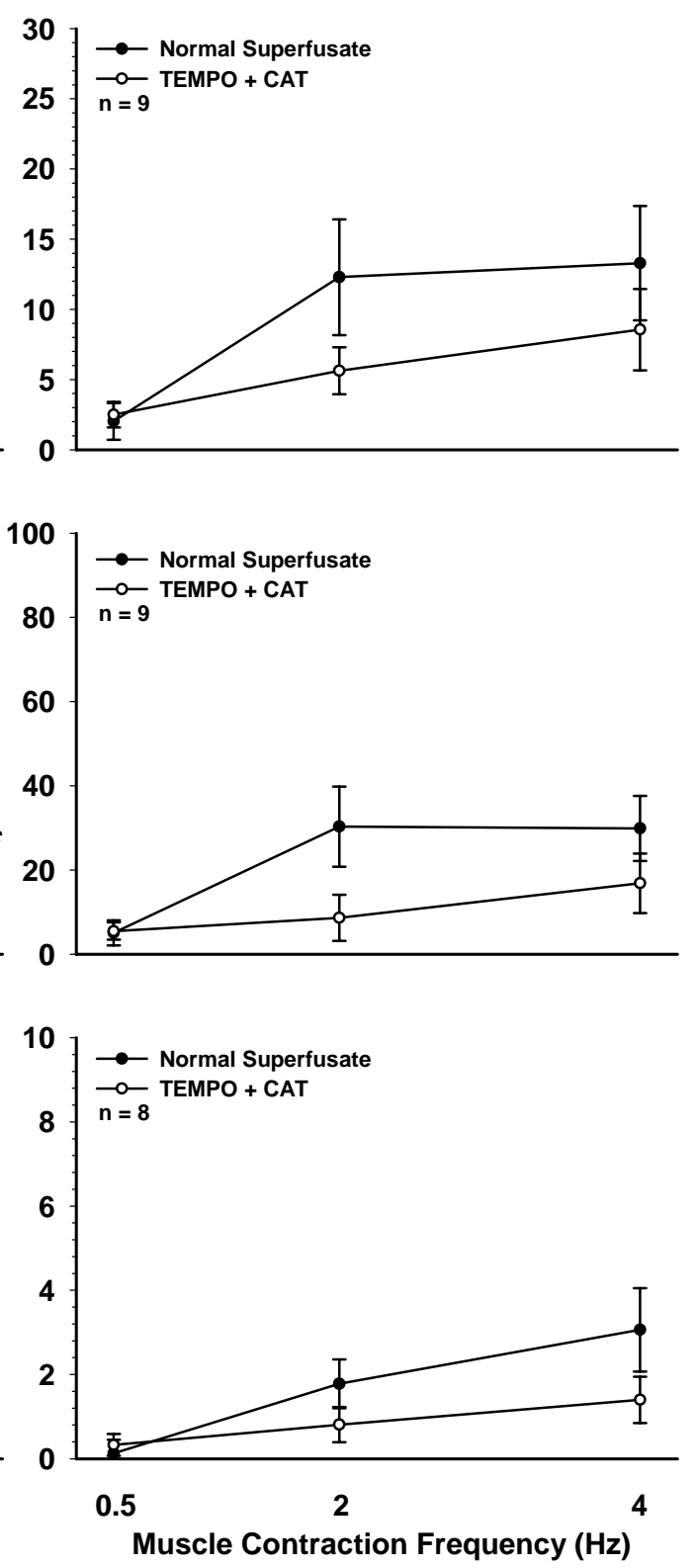

Figure 5. Effect of 2,2,6,6-Tetramethylpiperidine-N-oxyl + catalase (TEMPO + CAT) on arteriolar diameter and flow responses to $0.5 \mathrm{~Hz}, 2 \mathrm{~Hz}$, and $4 \mathrm{~Hz}$ muscle contraction in rats fed NS diet (left panels) and HS diet (right panels). Diameter responses are expressed in absolute terms (top panels) or relative to each vessel's maximum capacity for dilation (middle panels). $\mathrm{n}=$ number of vessels studied. $* \mathrm{P}<0.05$ vs. Normal Superfusate. 


\section{Discussion}

There are four major findings in this study: (1) High salt intake leads to a blunting of the arteriolar dilation that accompanies muscle contraction at relatively high frequencies. (2) In rats fed a normal diet, NOS inhibition modestly reduces arteriolar dilation during muscle contraction at high frequencies, but has no effect on the flow increase at any contraction frequency. In rats fed high salt, NOS inhibition has no effect on arteriolar diameter or flow responses to muscle contraction at any frequency. (3) Under normal, steady-state conditions, arterioles in rats fed high salt exhibit greater overall oxidant activity than those in rats fed normal diet, but this is not due to accumulation of $\mathrm{O}_{2}^{-}$in the arteriolar wall. (4) Scavengers of ROS tend to reduce the arteriolar dilation and hyperemia during muscle contraction in both dietary groups. These findings suggest that, regardless of dietary salt intake, there is little or no contribution of NO to the dilation of these arterioles during muscle contraction, and that reduced arteriolar responses to muscle contraction in rats fed high salt cannot be attributed to the activity of $\mathrm{O}_{2}{ }^{-}$and/or a decrease in $\mathrm{NO}$ availability.

Consumption of a high salt diet leads to changes in some aspects of microvascular function that may be essential for matching blood flow to increased tissue metabolic demand. For example, high salt intake impairs the dilation of skeletal muscle resistance arteries in response to a reduction in $\mathrm{PO}_{2}$, apparently by limiting the production of vascular smooth muscle cAMP that is normally triggered by endothelial prostacyclin release [12-15]. This disruption in smooth muscle signaling may ultimately be due to the decrease in circulating angiotensin II (Ang II) that accompanies high salt consumption [13,14], although structural limitations imposed by vascular wall remodeling may also contribute to the impaired dilation [36]. Active hyperemia may also depend in part on the myogenic relaxation of proximal 
arterioles as intravascular pressure falls with downstream arteriolar dilation $[18,19]$, and we have reported that consumption of a $7 \%$ salt diet decreases the responsiveness of rat spinotrapezius muscle arterioles to myogenic stimuli due to decreased circulating Ang II and increased local bradykinin levels [3,5,6]. Finally, shear stress-dependent NO release can also contribute to the dilation of proximal arterioles during larger increases in metabolic demand [22], and we have found that consumption of a 7\% salt diet decreases arteriolar responsiveness to shear stress due to a selective loss of NO activity [7]. This salt-induced attenuation of arteriolar responsiveness to pressure and shear stress has been documented in other vascular beds as well [37-39]. Based on the above findings, we postulated in this study that active hyperemia would be compromised in the contracting spinotrapezius muscle of rats fed high salt.

Our laboratory has also previously documented that in spinotrapezius muscle of rats fed a 7\% salt diet, microvascular NO activity is lost due to accelerated NO breakdown by ROS within the arteriolar wall [8]. Our more recent findings indicate that this accumulation of ROS is due to reduced $\mathrm{Cu} / \mathrm{Zn}$ SOD activity in combination with increased $\mathrm{NAD}(\mathrm{P}) \mathrm{H}$ oxidase and xanthine oxidase activity $[9,10]$, implicating $\mathrm{O}_{2}{ }^{-}$as the molecule that is most likely responsible for the decrease in microvascular NO. The current study was also designed to determine if this increased oxidant activity and decreased NO availability could contribute to reduced arteriolar dilation during muscle contraction.

As predicted, we found that the arteriolar dilation elicited by muscle contraction is reduced in rats fed high salt (Figure 1). However, this reduction is relatively modest, and the fact that increases in blood flow with muscle contraction were not compromised in HS rats indicates that this reduced dilation may have been offset by increased dilation at some other 
level of the arteriolar network. Therefore, despite the considerable changes in arteriolar function that are associated with high salt intake, the overall capacity of the striated muscle resistance vasculature to support active hyperemia is preserved in rats fed high salt diets. Our findings also suggest that the blunted dilation of arcade arterioles in HS rats is most likely not due to reduced NO availability. In fact, L-NMMA had similar effects on resting arteriolar diameter and blood flow in both dietary groups (Figure 2), suggesting NO's basal influence on arteriolar tone was not reduced by the high salt diet used in this study. This contrasts with our earlier finding that the continuous influence of $\mathrm{NO}$ on resting arteriolar tone is lost in rats fed a 7\% salt diet for 4 weeks [11]. In the current study, our data suggest that NO contributes to active arteriolar dilation in NS rats only at the highest frequency of contraction (4 Hz), and that after NOS inhibition, this dilation is still greater than that seen in HS rats under normal conditions (Figure 3). Therefore, even a complete absence of NO could not fully explain the extent to which these arteriolar responses are reduced in the HS rats studied here.

Ingestion of a $4 \%$ salt diet for only 3 days was found to eliminate the increase in vascular wall NO levels and dilation of rat cerebral arteries during ACh exposure, but this is due to disruption of the ACh signaling pathway proximal to NOS activation, rather than formation of ROS in the vascular wall [40]. The same short-term ingestion of a $4 \%$ salt diet also does not lead to increased resting $\mathrm{O}_{2}^{-}$levels in the thoracic aorta [41]. The current finding of increased arteriolar formazan staining after TNBT exposure in rats fed high salt for 4 weeks (Figure 4, top) confirms our earlier findings [8-10], and we have previously reported that exposure of the muscle to TEMPO + CAT prevents this increase in arteriolar formazan staining [8]. Therefore, the current study verifies that, in contrast to a short-term high salt diet, a prolonged period of high salt intake does lead to accumulation of ROS in the walls of 
striated muscle arterioles. Our earlier studies suggested that $\mathrm{O}_{2}{ }^{-}$may be the specific $\mathrm{O}_{2}$ metabolite responsible for the loss of microvascular NO activity in rats fed 7\% salt [8-10]. However, in the current study, arterioles in both dietary groups exhibited similar levels of ethidium bromide fluorescence (Figure 4), which is considered to be fairly reliable for the specific detection of $\mathrm{O}_{2}^{-}$[31-33]. We could easily detect increased arteriolar fluorescence levels in rats exposed to XAN/XO + DETCA (Figure 4), which rules out the possibility that dye saturation or some other technical limitation simply prevented us from detecting a difference between the NS and HS rats under control conditions. Therefore, we conclude that ROS other than $\mathrm{O}_{2}{ }^{-}$are increased in the arterioles of rats fed $4 \%$ salt, which is also consistent with the fact that there is no diet-related difference in arteriolar responses to L-NMMA (Figure 2), indicating that tonic NO availability is not reduced in the rats fed $4 \%$ salt.

The identity of the oxidant molecules accumulating in the arteriolar walls of rats fed $4 \%$ salt is not clear. It is possible that arteriolar oxidant activity could be increased without elevated $\mathrm{O}_{2}{ }^{-}$levels if catalase activity were decreased, leading to the accumulation of $\mathrm{H}_{2} \mathrm{O}_{2}$ in the arteriolar wall [42]. However, regardless of the particular oxidant(s) present, they apparently don't contribute to the reduced arteriolar responses to muscle contraction in the HS rats studied here, because TEMPO + CAT tended to reduce, rather than increase, the arteriolar dilation in contracting muscle of these rats (Figure 5). The mechanism(s) by which high salt intake reduces arteriolar dilation in contracting muscle therefore remains open to speculation. As mentioned earlier, a decreased responsiveness to hypoxia [12-15] or myogenic stimuli $[3,5,6]$ may be involved, but further studies are required to definitively test these possibilities. As also shown in Figure 5, TEMPO + CAT had no effect on resting arteriolar diameter, but did reduce the arteriolar dilation during $4 \mathrm{~Hz}$ contraction in NS rats, suggesting that one or 
more reactive oxygen metabolites may be playing a physiological role as a contributor to the active dilation of striated muscle arterioles. To our knowledge, this possibility hasn't been critically tested in the rat, but there is indirect evidence to support this hypothesis. The formation of $\mathrm{O}_{2}{ }^{-}$and its metabolic byproducts is increased during contraction in rat striated muscle cells $[43,44]$, and at high levels of contraction, large amounts of $\mathrm{H}_{2} \mathrm{O}_{2}$ are released by these cells into the extracellular space [44]. In addition to its oxidant properties, $\mathrm{H}_{2} \mathrm{O}_{2}$ also exerts a direct relaxing effect on arteriolar smooth muscle $[45,46]$.

In this study, calculated arteriolar wall shear rate was used as an index of shear stress. Because shear rate is equal to shear stress divided by blood viscosity, any change in shear rate will be proportional to the change in shear stress if viscosity does not change. This assumption seems reasonable because shear rates in the arterioles studied here are well above the range over which this variable can influence apparent blood viscosity [35]. Our findings suggest that in NS rats, shear stress in the arcade arterioles actually declines as blood flow increases. Therefore, although mean blood velocity often increased with muscle contraction (data not shown), this was offset by a proportionately greater increase in arteriolar diameter. This is consistent with a report that arteriolar shear rates either decrease or remain constant in contracting hamster cremaster muscle [47], and suggests that a shear-dependent increase in the release of endothelial factors does not contribute to the dilation of these vessels. However, we cannot rule out the possibility that this mechanism may be operative at other levels of the arteriolar network [22]. In HS rats, the changes in mean blood velocity that accompanied muscle contraction were similar to those seen in NS rats, but wall shear rates did not fall, presumably because the arterioles did not dilate as much as those in NS rats (Figure 1). 
In conclusion, our results indicate that reduced arteriolar dilation during muscle contraction in rats fed high salt is not due to decreased NO bioavailability and/or increased arteriolar wall ROS levels. Given that active hyperemia is a complex response regulated by multiple physiological factors, it is possible that the high salt intake may instead be reducing the local influence of tissue-derived metabolic factors that more readily contribute to the coupling of tissue blood flow to metabolic demand, or reducing arteriolar responsiveness to hypoxic or myogenic stimuli. Future investigation of these possibilities should provide further insight into the mechanism(s) underlying the functional changes that occur in the resistance vessels following the consumption of high dietary salt. 


\section{REFERENCES}

1. Rafi JA, Boegehold MA: Microvascular responses to oxygen and muscle contraction in hypertensive Dahl rats. Int J Microcirc Clin Exp 1993; 13: 83-97.

2. Drenjancevic-Peric I, Frisbee JC, Lombard JH: Skeletal muscle arteriolar reactivity in SS.BN13 consomic rats and Dahl salt-sensitive rats. Hypertension 2003; 41: 1012-1015.

3. Nurkiewicz TR, Boegehold MA: High dietary salt alters arteriolar myogenic responsiveness in normotensive and hypertensive rats. Am J Physiol 1998; 275: H2095H2104.

4. Boegehold MA: Reduced influence of nitric oxide on arteriolar tone in hypertensive Dahl rats. Hypertension 1992; 19: 290-295.

5. Nurkiewicz TR, Boegehold MA: Limitation of arteriolar myogenic activity by local nitric oxide: segment-specific effect of dietary salt. Am J Physiol 1999; 277: H1946-H1955.

6. Nurkiewicz TR, Boegehold MA: Reinforcement of arteriolar myogenic activity by endogenous ANG II: susceptibility to dietary salt. Am J Physiol 2000; 279: H269-H278. 
7. Boegehold MA: Flow-dependent arteriolar dilation in normotensive rats fed low- or highsalt diets. Am J Physiol 1995; 269: H1407-H1414

8. Lenda DM, Sauls BA, Boegehold MA: Reactive oxygen species may contribute to reduced endothelium-dependent dilation in rats fed high salt. Am J Physiol 2000; 279: H7-H14.

9. Lenda DM, Boegehold MA: Effect of a high salt diet on microvascular antioxidant enzymes. J Vasc Res 2002; 39: 41-50.

10. Lenda DM, Boegehold MA: Effect of a high salt diet on oxidant enzyme activity in skeletal muscle microcirculation. Am J Physiol 2002; 282: H395-H402.

11. Boegehold MA: Effect of dietary salt on arteriolar nitric oxide in striated muscle of normotensive rats. Am J Physiol 1993; 264: H1810-H1816.

12. Liu Y, Fredricks KT, Roman RJ, Lombard JH: Response of resistance arteries to reduced $\mathrm{PO}_{2}$ and vasodilators during hypertension and elevated salt intake. Am J Physiol 1997; 273: H869-H877.

13. Weber DS, Lombard JH: Elevated salt intake impairs dilation of rat skeletal muscle resistance arteries via ANG II suppression. Am J Physiol 2000; 278: H500-H506. 
14. Weber DS, Lombard JH: Angiotensin II $\mathrm{AT}_{1}$ receptors preserve vasodilator reactivity in skeletal muscle resistance arteries. Am J Physiol 2001; 280: H2196-H2202

15. Frisbee JC, Sylvester FA, Lombard JH: High-salt diet impairs hypoxia-induced cAMP production and hyperpolarization in rat skeletal muscle arteries. Am J Physiol 2001; 281: H1808-H1815.

16. Sparks HV Jr.: Effect of local metabolic factors on vascular smooth muscle; in Bohr DF, Somlyo AP, Sparks HV Jr. (eds): Handbook of Physiology. The Cardiovascular System, Vol II. Vascular Smooth Muscle. Bethesda, MD, American Physiological Society, 1980, pp 475-513.

17. Lash JM, Bohlen HG: Perivascular and tissue $\mathrm{PO}_{2}$ in contracting rat spinotrapezius muscle. Am J Physiol 1987; 252: H1192-H1202.

18. Kuo L, Chilian WM, Davis MJ: Interaction of pressure- and flow-induced responses in porcine coronary resistance vessels. Am J Physiol 1991; 261: H1706-H1715.

19. Kuo L, Davis MJ, Chilian WM: Longitudinal gradients for endothelium-dependent and independent vascular responses in the coronary microcirculation. Circulation 1995; 92: 518525.

20. Bohlen HG, Lash JM: Intestinal absorption of sodium and nitric oxide-dependent vasodilation interact to dominate resting vascular resistance. Circ Res 1996; 78: 231-237. 
21. Bohlen HG, Nase GP: Dependence of intestinal arteriolar regulation on flow-mediated nitric oxide formation. Am J Physiol 2000; 279: H2249-H2258.

22. Pohl U, de Wit C, Gloe T: Large arterioles in the control of blood flow: role of endotheliumdependent dilation. Acta Physiol Scand 2000; 168: 505-510.

23. Welsh DG, Segal SS: Endothelial and smooth muscle cell conduction in arterioles controlling blood flow. Am J Physiol 1998; 274: H178-H186.

24. Emerson GG, Segal SS: Electrical coupling between endothelial cells and smooth muscle cells in hamster feed arteries. Role in vasomotor control. Circ Res 2000; 87: 474-479.

25. Boegehold MA, Bohlen HG: Arteriolar diameter and tissue oxygen tension during muscle contraction in hypertensive rats. Hypertension 1988; 12: 184-191.

26. Honig CR: Contributions of nerves and metabolites to exercise vasodilation: a unifying hypothesis. Am J Physiol 1979; 236: H705-H719.

27. Linderman JR, Boegehold MA: Arteriolar network growth in rat striated muscle during juvenile maturation. Int J Microcirc Clin Exp 1996; 16: 232-239. 
28. Linderman JR, Boegehold MA: Growth-related changes in the influence of nitric oxide on arteriolar tone. Am J Physiol 1999; 277: H1570-H1578.

29. Fuchs J, Groth N, Herrling T, Zimmer G: Electron paramagnetic resonance studies on nitroxide radical 2,2,5,5- tetramethyl-4-piperidin-1-oxyl (TEMPO) redox reactions in human skin. Free Radic.Biol.Med. 1997; 22: 967-976.

30. Suzuki H, Swei A, Zweifach BW, Schmid-Schönbein GW: In vivo evidence for microvascular oxidative stress in spontaneously hypertensive rats. Hydroethidine microfluorography. Hypertension 1995; 25: 1083-1089.

31. Morgan AR, Evans DH, Lee JS, Pulleyblank DE: Review: ethidium fluorescence assay. Part II. Enzymatic studies and DNA-protein interactions. Nucleic Acids Res 1979; 7: 57194.

32. Benov L, Sztejnberg L, Fridovich I: Critical evaluation of the use of hydroethidine as a measure of superoxide anion radical. Free Radic Biol Med 1998; 25: 826-831.

33. Bindokas VP, Jordan J, Lee CC, Miller RJ: Superoxide production in rat hippocampal neurons: selective imaging with hydroethidine. J Neurosci 1989; 16: 1324-1326. 
34. Schmid-Schonbein GW, Firestone G, Zweifach BW: Network anatomy of arteries feeding the spinotrapezius muscle in normotensive and hypertensive rats. Blood Vessels 1986; 23: 3449.

35. Zweifach BW, Lipowsky HH: Pressure-flow relations in blood and lymph microcirculation; in Renkin EM, Michel CC (eds): Handbook of Physiology. The Cardiovascular System, Vol IV. Microcirculation, Pt 1. Bethesda, MD, American Physiological Society, 1984, pp 251-308.

36. Frisbee JC, Lombard JH: Chronic elevations in salt intake and reduced renal mass hypertension compromise mechanisms of arteriolar dilation. Microvasc Res 1998; 56: 218-227.

37. Coyle P: High $\mathrm{NaCl}$ predisposes Dahl rats to cerebral infarction after middle cerebral artery occlusion. Hypertension 1988; 12: 96-101.

38. Takenaka T, Forster H, De Micheli A, Epstein M: Impaired myogenic responsiveness of renal microvessels in Dahl salt-sensitive rats. Circ Res 1992; 71: 471-480.

39. Matrougui K, Loufrani L, Levy BI, Henrion D: High $\mathrm{NaCl}$ intake decreases both flowinduced dilation and pressure-induced myogenic tone in resistance arteries from normotensive rats: involvement of cyclooxygenase-2. Pharmacol Toxicol 2001; 4: 183-187. 
40. Sylvester FA, Stepp DW, Frisbee JC, Lombard JH: High-salt diet depresses acetylcholine reactivity proximal to NOS activation in cerebral arteries. Am J Physiol 2002; 283: H353H363.

41. Zhu J, Mori T, Huang T, Lombard JH: Effect of high-salt diet on NO release and superoxide production in rat aorta. Am J Physiol 2004; 286: H575-H583.

42. Wolin MS: Reactive oxygen species and vascular signal transduction mechanisms. Microcirculation 1996; 3: 1-17.

43. Nethery D, Stofan D, Callahan L, DiMarco A, Supinski G: Formation of reactive oxygen species by the contracting diaphragm is $\mathrm{PLA}_{2}$ dependent. J Appl Physiol 1999; 87: 792-800.

44. Silveira LR, Pereira-da-Silva L, Juel C, Hellsten Y: Formation of hydrogen peroxide and nitric oxide in rat skeletal muscle cells during contractions. Free Rad Biol Med 2003; 35: 455-464.

45. Chen Y-L, Wolin MS, Messina EJ: Evidence for cGMP mediation of skeletal muscle arteriolar dilation to lactate. J Appl Physiol 1996; 81: 349-354.

46. Wolin MS, Rodenburg JM, Messina EJ, Kaley G: Similarities in the pharmacological modulation of reactive hyperemia and vasodilation to hydrogen peroxide in rat skeletal 
muscle arterioles: effects of probes for endothelium-derived mediators. J Pharmacol Exp Ther 1990; 253:508-12.

47. Hester RL, Duling BR: Red cell velocity during functional hyperemia: implications for rheology and oxygen transport. Am J Physiol 1988; 255: H236-H244. 
Study II: Hydrogen Peroxide-Dependent Arteriolar Dilation in Contracting Muscle of Rats Fed Normal and High Salt Diets 


\section{SUMMARY}

We previously reported that high salt intake decreases arteriolar dilation during skeletal muscle contraction. Because hydrogen peroxide $\left(\mathrm{H}_{2} \mathrm{O}_{2}\right)$ can reduce microvascular tone and is released from contracting skeletal muscle cells, the purpose of this study was to assess the contribution of $\mathrm{H}_{2} \mathrm{O}_{2}$ to muscle functional hyperemia in rats fed a normal salt $(0.45 \%$, NS) or high salt (4\% HS) diet for 4 weeks. Contraction of the exteriorized spinotrapezius muscle significantly increased 2',7'-dichlorofluorescein (DCF) fluorescence intensity, which was preventable by addition of catalase. During $0.5 \mathrm{~Hz}$ and $2.0 \mathrm{~Hz}$ muscle contraction, the $\mathrm{H}_{2} \mathrm{O}_{2}$ scavenger catalase significantly inhibited the arteriolar dilation and flow increases in NS and HS rats. Exogenously applied $\mathrm{H}_{2} \mathrm{O}_{2}$ elicited arteriolar dilation in both groups, but the magnitude of this dilation was significantly greater in the HS rats. Inhibition of guanylate cyclase with $1 \mathrm{H}-[1,2,4$,$] -oxadiazole-[4,3-a]quinoxalin-1-one (ODQ) had no consistent effect$ on arteriolar responses to $\mathrm{H}_{2} \mathrm{O}_{2}$ in either group, whereas the $\mathrm{K}^{+}$channel inhibitors glibenclamide and tetraethylammonium chloride (TEA) reduced arteriolar dilation to exogenous $\mathrm{H}_{2} \mathrm{O}_{2}$ in both groups and glibenclamide reduced the functional hyperemic response. We conclude that locally produced $\mathrm{H}_{2} \mathrm{O}_{2}$ contributes to arteriolar dilation in contracting skeletal muscle, and that the effect of $\mathrm{H}_{2} \mathrm{O}_{2}$ on arteriolar tone depends in large part on $\mathrm{K}^{+}$channel activation. Increased dietary salt intake does not reduce the contribution of $\mathrm{H}_{2} \mathrm{O}_{2}$ to this dilation, or alter the mechanism through which $\mathrm{H}_{2} \mathrm{O}_{2}$ relaxes vascular smooth muscle. 


\section{INTRODUCTION}

High levels of reactive oxygen species (ROS) can contribute to the pathogenesis of various cardiovascular diseases $(17,31)$, but there is growing evidence to suggest that at lower levels, ROS are important intra- and extracellular signaling molecules that can play a key role in normal physiological processes $(12,52)$. For example, endothelium-derived hydrogen peroxide $\left(\mathrm{H}_{2} \mathrm{O}_{2}\right)$ appears to play an important role in mediating flow-induced dilation, autoregulation, and reactive hyperemia in the coronary vasculature $(20,36,53)$. Exogenous $\mathrm{H}_{2} \mathrm{O}_{2}$ can also dilate other vessels, including rat aorta (54), mouse and human mesenteric arteries $(33,34)$, canine and feline cerebral arteries $(19,51)$, human coronary arterioles (36), and rat gracilis muscle arterioles (11). Other studies have demonstrated that $\mathrm{H}_{2} \mathrm{O}_{2}$ can be released from the endothelium in response to application of the $\mathrm{Ca}^{2+}$ ionophore A23187, bradykinin, or acetycholine $(9,21,53)$. However, there have been few in vivo studies in vascular beds other than the coronary circulation that actually demonstrate a physiological role for $\mathrm{H}_{2} \mathrm{O}_{2}$ in regulating vascular tone and blood flow.

Intracellular ROS levels have been found to increase in contracting skeletal muscle cells $(42,47)$, and at low levels, these ROS are necessary for normal force generation (44). However, ROS generated within contracting fibers could also have significant paracrine effects. For example, $\mathrm{H}_{2} \mathrm{O}_{2}$ generated intracellularly from superoxide anion $\left(\mathrm{O}_{2}{ }^{-}\right)$, is readily released into the extracellular space during moderate to intense muscle contraction $(35,47)$. Because it is uncharged, relatively stable and freely diffusible (44), $\mathrm{H}_{2} \mathrm{O}_{2}$ could exert an effect on the tone of nearby arterioles. The first aim of this study was to assess this possibility by using in vivo microscopy to determine whether $\mathrm{H}_{2} \mathrm{O}_{2}$ contributes to skeletal 
muscle functional hyperemia, an important response that matches tissue nutrient delivery to increased metabolic demand.

Several studies have documented that consumption of a high salt (HS) diet can lead to microvascular changes in the absence of hypertension. For example, in the spinotrapezius muscle of normotensive rats fed a HS diet, there is a reduction in arteriolar responsiveness to myogenic stimuli $(39,40)$, and to stimuli that normally elicit dilation through increased endothelial nitric oxide (NO) release $(4,25,27)$. Increased microvascular ROS generation, in combination with reduced $\mathrm{Cu} / \mathrm{Zn}$ superoxide dismutase (SOD) activity, is at least partially responsible for the impairment of these endothelium-dependent responses following a HS diet $(25,27)$. We have recently shown that a HS diet also attenuates the arteriolar dilation that accompanies skeletal muscle contraction (32). In that study we found that ROS scavengers did not restore normal arteriolar dilation during muscle contraction in the HS rats, and actually reduced this dilation in rats fed a normal diet. These findings suggest a possible role for ROS in mediating functional hyperemia, and also indicate that increased oxidant activity in arterioles of salt-fed rats is not responsible for the attenuated dilation during contraction. The second aim of the current study was to determine whether dietary salt alters the role of $\mathrm{H}_{2} \mathrm{O}_{2}$ in functional hyperemia. 


\section{Methods}

Weanling male Sprague-Dawley rats (Harlan Sprague Dawley, Indianapolis, IN, USA) were placed on a whole-grain diet containing either $0.45 \% \mathrm{NaCl}$ (normal salt, $\mathrm{NS}$ ) or 4\% NaCl (high salt, HS) by weight (NS diet= TD88311, HS diet= TD92034; Teklad, Madison, WI, USA). All rats were studied 4-5 weeks after being placed on their respective diets, and were 7-8 weeks old at this time. Each of the protocols described below was performed on rats from both dietary groups.

\section{Surgical Preparation and Intravital Microscopy}

All surgical and experimental procedures were approved by the West Virginia University Animal Care and Use Committee. Each rat was anesthetized with sodium thiopental $\left(100 \mathrm{mg} / \mathrm{kg}\right.$, i.p.) and placed on a heating pad to maintain a $37^{\circ} \mathrm{C}$ rectal temperature. The trachea was intubated to ensure a patent airway and the right carotid artery was cannulated to measure arterial pressure. The right spinotrapezius muscle was exteriorized for microscopic observation as previously described (4), leaving its innervation and all feed vessels completely intact. Throughout the surgery and subsequent experimental period, the muscle was continuously superfused with an electrolyte solution $(119 \mathrm{mM} \mathrm{NaCl}$, $25 \mathrm{mM} \mathrm{NaHCO} 3,6 \mathrm{mM} \mathrm{KCl}$ and $3.6 \mathrm{mM} \mathrm{CaCl}_{2}$ ) warmed to $35^{\circ} \mathrm{C}$ and equilibrated with $95 \%$ $\mathrm{N}_{2}-5 \% \mathrm{CO}_{2}(\mathrm{pH}=7.35-7.40)$. Superfusate flow rate was maintained at $4-6 \mathrm{ml} / \mathrm{min}$ to minimize equilibration with atmospheric $\mathrm{O}_{2}(5)$.

The animal preparation was transferred to the stage of an Olympus BX50WI intravital microscope (Hyde Park, NY, USA) fitted with a CCD video camera (Dage-MTI, Michigan 
City, IN, USA). Video images were displayed on a Sony high-resolution video monitor and videotaped for off-line analysis. Observations were made with an Olympus 20X water immersion objective (final video image magnification $=1460 \mathrm{X}$ ). Arteriolar centerline red blood cell velocities were measured on-line with an optical doppler velocimeter (Cardiovascular Research Institute, Texas A\&M University, USA), and arteriolar inner diameters were measured off-line during videotape replay with a video caliper (Cardiovascular Research Institute).

\section{Muscle Contraction}

To increase tissue metabolic activity, muscle contraction was elicited by small wire electrodes inserted into the rostral and caudal edges of the muscle. Square-wave stimulating pulses of 0.2 ms duration and 3-6 volts in amplitude were used, with voltage adjusted for each animal to produce the greatest tissue movement with contraction indicating maximum recruitment of muscle fibers. The pulse duration and voltages used in these experiments are below the thresholds for direct excitation of vascular smooth muscle or autonomic neurons (5), and this has been confirmed in rat spinotrapezius muscle using the same stimulation paradigm as in this study (23). Because tissue movement precludes the measurement of any hemodynamic variable during the actual contraction period, arteriolar diameter and red cell velocity were measured during the first 5 seconds after cessation of contraction. There is minimal recovery of arteriolar diameters or flow during this period $(5,43)$, so these values should closely reflect the steady-state values reached during contraction. 


\section{Experimental Protocols}

Protocol 1: Assessment of tissue $\mathrm{H}_{2} \mathrm{O}_{2}$ during muscle contraction.

The fluorescent probe 2,7' dichlorodihydrofluorescein diacetate (DCFH-DA) was used to detect intracellular $\mathrm{H}_{2} \mathrm{O}_{2}$ formation during skeletal muscle contraction $(36,47)$. Nonfluorescent DCFH-DA freely enters cells and is de-acetated to DCFH, which is then oxidized by $\mathrm{H}_{2} \mathrm{O}_{2}$ to form 2,7' dichlorofluorescein (DCF), a green fluorescent compound that can be detected using the appropriate excitation and emission filters (48). In preparation for these experiments, we conducted a series of pilot studies to determine the optimal contraction frequency and duration for DCFH-DA detection, as well as the number of tissue illuminations we could make without significant photo-bleaching of the fluorochrome.

After preparation of the muscle for in vivo microscopy, a region containing clearly visible arcade arterioles (see below) was selected, and 10 $\mu \mathrm{M}$ DCFH-DA was added to the muscle superfusate. After equilibration with the DCFH-DA for 30 minutes, the resting muscle was briefly (1-2 s) epi-illuminated with a mercury lamp using the appropriate excitation and emission filters for detection of DCF fluorescence (460-490 nm excitation, 515-550 nm barrier). The muscle was then stimulated to contract at a frequency of $4 \mathrm{~Hz}$ for 5 minutes, and a second DCF fluorescence image was captured immediately following this contraction period. To avoid photo-bleaching of DCF, the tissue was only illuminated these two times after its addition to the superfusate. However, prior to DCFH-DA superfusion, a preliminary illumination was made for determination of tissue background autofluorescence, which was then subtracted from the subsequent images to determine DCF- specific fluorescence. 
Metamorph 6.01 software was used to acquire, digitize and store images for subsequent analysis. The DCF fluorescence signal intensities from regions that ranged between 10-100 $\mu \mathrm{m}$ from the arteriolar wall were averaged and normalized to control (pre-contraction). To confirm that DCF fluorescence is primarily an indicator of $\mathrm{H}_{2} \mathrm{O}_{2}$ activity under our experimental conditions, the above protocol was repeated in the presence of the $\mathrm{H}_{2} \mathrm{O}_{2}$ scavenger catalase (at 50 $\mathrm{U} / \mathrm{ml}$ ), which at this superfusate concentration has been previously shown to decrease arteriolar oxidant activity in this preparation (27).

Protocol 2: Arteriolar responses to increased metabolic activity. In rat spinotrapezius muscle, the central "arcade bridge" arteriole gives rise to a network of interconnected arcade arterioles that extends throughout the muscle (28). After exteriorization of the spinotrapezius muscle and a 30-minute post-surgical equilibration period, one to three arcade arterioles were chosen for study. After a 1-minute control period, the muscle was stimulated to repeatedly contract for 1 minute at a frequency of $0.5,2$ or $4 \mathrm{~Hz}$ (random frequency selection), followed by a 5-minute recovery period. This sequence was repeated two more times for stimulation at the remaining frequencies, so that the arteriolar diameter and flow increases to all three levels of increased tissue metabolism were measured. Then, to assess the contribution of $\mathrm{H}_{2} \mathrm{O}_{2}$ to these responses, the $\mathrm{H}_{2} \mathrm{O}_{2}$ scavenger catalase (at $50 \mathrm{U} / \mathrm{ml}$ ) was added to the superfusate and the stimulation protocol was repeated after a 30-minute equilibration period with catalase superfusion continued throughout to ensure maximum scavenging of $\mathrm{H}_{2} \mathrm{O}_{2}$.

Because any $\mathrm{H}_{2} \mathrm{O}_{2}$ released during contraction would be expected to dilate arterioles at least partially through activation of smooth muscle $\mathrm{K}_{\mathrm{ATP}}$ channels (11), we added the $\mathrm{K}_{\mathrm{ATP}}$ channel inhibitor glibenclamide at $1 \times 10^{-5} \mathrm{M}$ (30-minute equilibration period) to the 
superfusate in other animals. In these experiments, the effect of glibenclamide was only assessed on arteriolar responses to $4 \mathrm{~Hz}$ contraction. Also, the $\mathrm{K}_{\mathrm{ATP}}$ channel opener pinacidil $\left(1 \times 10^{-6} \mathrm{M}\right)$ was used to confirm that the concentration of glibenclamide used in these studies was effective in blocking the $\mathrm{K}_{\mathrm{ATP}}$ channel.

Protocol 3: Arteriolar responses to exogenously applied $\mathrm{H}_{2} \mathrm{O}_{2}$. These experiments were conducted to assess vascular responsiveness to $\mathrm{H}_{2} \mathrm{O}_{2}$ in both dietary groups, and to more broadly investigate the mechanism(s) by which $\mathrm{H}_{2} \mathrm{O}_{2}$ reduces arteriolar tone in this muscle. Arteriolar diameter was measured before and after $\mathrm{H}_{2} \mathrm{O}_{2}$ was added to the superfusate at $1 \mathrm{x}$ $10^{-5}, 5 \times 10^{-5}$ or $1 \times 10^{-4} \mathrm{M}$. Each application of $\mathrm{H}_{2} \mathrm{O}_{2}$ was followed by a washout period to allow for restoration of normal arteriolar tone. After the series of applications was completed, responses to the same concentrations of $\mathrm{H}_{2} \mathrm{O}_{2}$ were then reexamined in the presence of catalase, glibenclamide, the selective guanylate cyclase inhibitor $1 \mathrm{H}-[1,2,4$,$] -oxadiazole-$ [4,3-a]quinoxalin-1-one (ODQ, $1 \times 10^{-5} \mathrm{M}$ ) or the large-conductance $\mathrm{Ca}^{2+}$ activated potassium channel $\left(\mathrm{K}_{\mathrm{Ca}}\right)$ inhibitor tetraethylammonium chloride (TEA, $\left.1 \times 10^{-3} \mathrm{M}\right)$.

In Protocols 2 and 3, $1 \times 10^{-3} \mathrm{M}$ adenosine was added to the superfusate at the end of each experiment to abolish microvascular tone for measurement of passive arteriolar diameter. All agents were purchased from Sigma-Aldrich (St. Louis MO).

\section{Data and Statistical Analysis}

Metamorph 6.01 software was used for the DCF image analysis. First, immediately after contraction, we identified DCF fluorescence signals in skeletal muscle fibers adjacent to one or more arcade arterioles. After measuring the fluorescence intensity for each of these 
positively identified fluorescent regions, we measured fluorescence intensity for the same regions on the pre-contraction image. The post-contraction values were then averaged and normalized to their respective pre-contraction values.

Arteriolar diameter $(\mathrm{D}, \mu \mathrm{m})$ and centerline red cell velocity $\left(\mathrm{V}_{\mathrm{cl}}, \mathrm{mm} / \mathrm{s}\right)$ were sampled at 5-second intervals during control and post-contraction periods. Diameter responses to muscle contraction were expressed in absolute terms $\left(D_{s s}-D_{c}\right)$, where $D_{s s}$ is steady-state diameter immediately after contraction and $\mathrm{D}_{\mathrm{c}}$ is pre-contraction control diameter. Resting vascular tone $(R V T)$ was also calculated for each vessel: $R V T=\left[\left(D_{\text {pass }}-D_{c}\right) / D_{\text {pass }}\right] \times 100$, where $\mathrm{D}_{\text {pass }}$ is passive diameter under adenosine. Mean red cell velocity $\left(\mathrm{V}_{\text {mean }}\right)$ was calculated as $\mathrm{V}_{\mathrm{cl}} / 1.6$, where 1.6 is the ratio of centerline red cell velocity to mean velocity for vessels $>10 \mu \mathrm{m}$ in diameter (55). Paired values of $\mathrm{D}$ and $\mathrm{V}_{\text {mean }}$ were used to calculate arteriolar volume flow $(\mathrm{Q}, \mathrm{nl} / \mathrm{s})$, where $\mathrm{Q}=\mathrm{V}_{\text {mean }}\left[\pi\left(\mathrm{D}^{2} / 4\right]\right.$.

All data are reported as means \pm SE. Statistical analysis was performed by commercially available software (Sigmastat, SPSS Inc., Chicago, IL). One-way repeated measures ANOVA was used to determine the effect of treatment within a group and Student's $t$-test for statistical comparisons between groups. Two-way repeated measures ANOVA was used to determine the effects of diet, treatment and diet-treatment interactions on measured variables. For all ANOVA procedures, the Student-Newman-Keuls method for post hoc analysis was used to isolate pairwise differences among specific groups.

Significance was assessed at the $95 \%$ confidence level $(\mathrm{P}<0.05)$ for all tests. 


\section{Results}

The general characteristics of all rats used in this study (Protocols 1-3) are shown in Table 1. At the time of study, the body weight and mean arterial pressure of rats fed high salt were not significantly different from those of rats fed the normal diet. Table 2 displays the characteristics of all arterioles studied by in vivo microscopy in Protocol 2. As compared to the rats fed normal diet, rats fed high salt displayed a significant decrease in passive arteriolar diameter. Resting arteriolar diameter and volume flow were also slightly decreased in the high salt group, but calculated vascular tone was not different between the two groups.

In preparation for using the $\mathrm{H}_{2} \mathrm{O}_{2}$ scavenger catalase, we first assessed its effect on arteriolar responses to a high concentration of exogenously applied $\mathrm{H}_{2} \mathrm{O}_{2}$. These results, shown in Table 3, illustrate that the concentration of catalase we used was sufficient to effectively scavenge $\mathrm{H}_{2} \mathrm{O}_{2}$ in both dietary groups. These data also indicate that the exogenously-applied catalase had no effect on resting arteriolar diameter in either group.

In rats fed normal diet, $4 \mathrm{~Hz}$ contraction of muscle exposed to DCFH-DA produced significant increases in DCF fluorescence intensity that were associated with the muscle fibers (Fig. 1A,C). However, in the presence of catalase, this $4 \mathrm{~Hz}$ contraction did not lead to increased DCF fluorescence (Fig. 1B,C). In both dietary groups, muscle contraction at each frequency elicited a significant increase in arteriolar diameter (Fig. 2A). However, the average increase in diameter was less in HS rats than in NS rats, with the differences reaching statistical significance at $2 \mathrm{~Hz}$ and $4 \mathrm{~Hz}$ contractions. In contrast, there were no differences between groups in the arteriolar flow increase with contraction at any frequency (Fig. 2B). 
As shown in Figure 3A and B, catalase significantly reduced the increases in arteriolar diameter and flow during muscle contraction at each frequency in NS rats, suggesting an important role for $\mathrm{H}_{2} \mathrm{O}_{2}$ in functional hyperemia. In the $\mathrm{HS}$ rats (Fig. 3C and D), catalase significantly reduced the increases in diameter at $0.5 \mathrm{~Hz}$ and $2 \mathrm{~Hz}$ contractions, and significantly reduced the flow increase at $0.5,2.0$ and $4 \mathrm{~Hz}$ contractions. As shown in Figure 4, the magnitude of the effect of catalase on the arteriolar dilations and flow responses to 0.5 and $2.0 \mathrm{~Hz}$ contractions were similar in NS and HS rats. In contrast, catalase had a significantly smaller effect on arteriolar dilation to $4 \mathrm{~Hz}$ contraction in $\mathrm{HS}$ rats than in NS rats, although its effect on the accompanying flow increase was not significantly smaller in HS rats.

Arteriolar responses to exogenous $\mathrm{H}_{2} \mathrm{O}_{2}$ in each group are shown in Figure $5 . \mathrm{H}_{2} \mathrm{O}_{2}$ at superfusate concentrations of $5 \times 10^{-5} \mathrm{M}$ and $1 \times 10^{-4} \mathrm{M}$ produced arteriolar dilation in both NS and HS rats, but the magnitude of this dilation was significantly greater in the HS group. $\mathrm{H}_{2} \mathrm{O}_{2}$ at a concentration of $1 \times 10^{-5} \mathrm{M}$ dilated arterioles in $\mathrm{HS}$ rats only.

At a superfusate concentration of $1 \times 10^{-5} \mathrm{M}$, glibenclamide effectively inhibited arteriolar $\mathrm{K}_{\mathrm{ATP}}$ channel activity, as judged by complete abolition of arteriolar responses to the $\mathrm{K}_{\mathrm{ATP}}$ channel opener pinacidil (Fig. 6). This concentration of glibenclamide also significantly reduced arteriolar responses to exogenous $\mathrm{H}_{2} \mathrm{O}_{2}$ in both groups (Fig. 7), and virtually abolished arteriolar dilation and hyperemia during $4 \mathrm{~Hz}$ contraction in both groups as well (Fig. 8).

Tetraethylammonium chloride at a concentration previously shown to inhibit largeconductance $\mathrm{K}_{\mathrm{Ca}}$ channels (38), also reduced arteriolar responses to exogenous $\mathrm{H}_{2} \mathrm{O}_{2}$ in both dietary groups (Fig. 9). 
At a superfusate concentration of $1 \times 10^{-5} \mathrm{M}$, ODQ completely abolished arteriolar responses to exogenous sodium nitroprusside (Fig. 6), indicating complete inhibition of soluble guanylate cyclase. However, this concentration of ODQ had no consistent effect on arteriolar responses to exogenous $\mathrm{H}_{2} \mathrm{O}_{2}$ in either group (Fig. 10). 
Table 1: Profiles of all experimental animals at time of study

\begin{tabular}{llll}
\hline \hline Dietary Group & $\mathrm{N}$ & $\begin{array}{l}\text { Weight } \\
(\mathrm{g})\end{array}$ & $\begin{array}{l}\text { Mean Arterial } \\
\text { Pressure }(\mathrm{mm} \mathrm{Hg})\end{array}$ \\
\hline Normal Salt & 40 & $285 \pm 3$ & $122 \pm 2$ \\
High Salt & 44 & $289 \pm 4$ & $121 \pm 2$ \\
\hline
\end{tabular}

$\mathrm{N}$, number of animals. Values are given as mean $\pm \mathrm{SE}$. 
Table 2: Arteriolar characteristics at time of study

\begin{tabular}{lcclc}
\hline \hline $\begin{array}{l}\text { Dietary } \\
\text { Group }\end{array}$ & $\begin{array}{l}\text { Resting } \\
\text { Diameter }\end{array}$ & $\begin{array}{l}\text { Passive } \\
\text { Diameter } \\
(\mu \mathrm{m})\end{array}$ & $\begin{array}{l}\text { Vascular Tone } \\
(\% \text { of } \\
\text { Maximum })\end{array}$ & $\begin{array}{c}\text { Resting Volume } \\
\text { Flow } \\
(\mathrm{nl} / \mathrm{s})\end{array}$ \\
\hline & & & & \\
Normal Salt & $16.8 \pm 0.3$ & $59.7 \pm 1.6$ & $71.7 \pm 1.0$ & $1.4 \pm 0.1$ \\
High Salt & $15.8 \pm 0.3^{*}$ & $54.9 \pm 1.6^{*}$ & $71.2 \pm 0.7$ & $1.0 \pm 0.1^{*}$ \\
\hline
\end{tabular}

Values are given as mean \pm SE. Within each group, values for resting diameter

(Normal Salt: $n=101$ vessels; High Salt: $n=99$ vessels), passive diameter and vascular tone (Normal Salt: $n=94$ vessels; High Salt: $n=96$ vessels). For resting volume flow $n=36$ vessels for Normal Salt and 41 vessels for High Salt. *p<0.05 vs Normal Salt. 
Table 3. Effect of catalase on arteriolar responses to $1 \times 10^{-4} \mathrm{M} \mathrm{H}_{2} \mathrm{O}_{2}$ in both dietary groups

\begin{tabular}{|c|c|c|c|c|c|}
\hline & \multicolumn{3}{|c|}{ Normal Superfusate } & \multicolumn{2}{|c|}{$\underline{\text { Catalase }(50 \mathrm{U} / \mathrm{ml})}$} \\
\hline & $\mathrm{n}$ & Control & $\mathrm{H}_{2} \mathrm{O}_{2}$ & Control & $\overline{\mathrm{H}_{2}} \mathrm{O}_{2}$ \\
\hline & \multicolumn{3}{|c|}{ Arteriolar diameter $(\mu \mathrm{m})$} & \multicolumn{2}{|c|}{ Arteriolar diameter $(\mu \mathrm{m})$} \\
\hline Normal Salt & 8 & $14.1 \pm 1.8$ & $42.7 \pm 6.8^{*}$ & $13.5 \pm 1.5$ & $13.6 \pm 1.6$ \\
\hline High Salt & 7 & $14.7 \pm 1.3$ & $43.3 \pm 5.6^{*}$ & $16.4 \pm 2.0$ & $21.4 \pm 4.3$ \\
\hline
\end{tabular}

$\mathrm{n}=$ number of vessels. Values are given as mean \pm SE. $* \mathrm{p}<0.05$ vs Control 

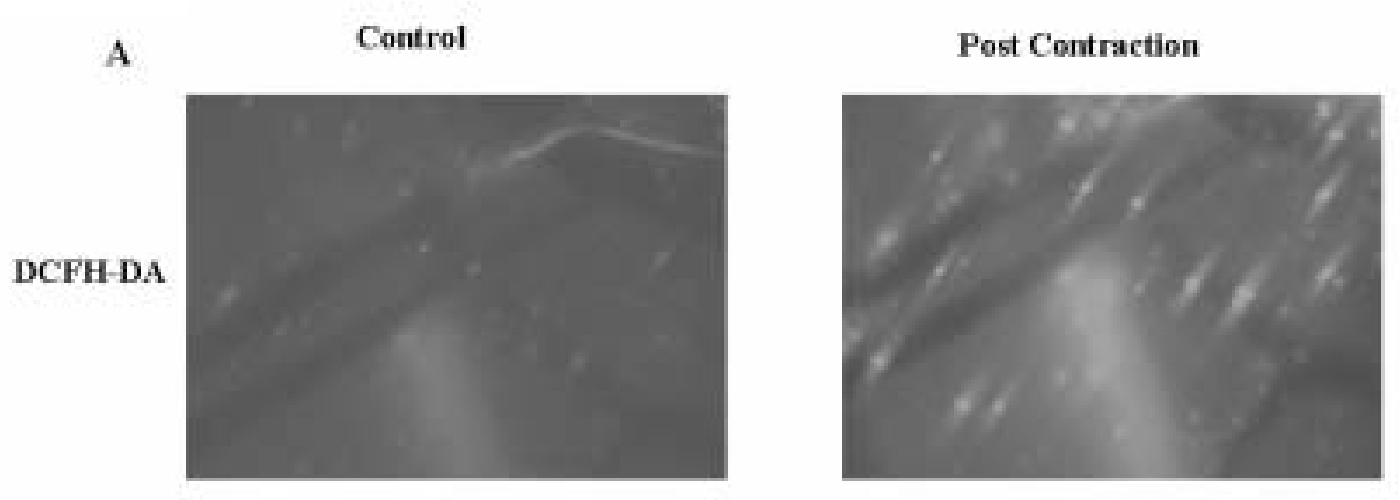

B
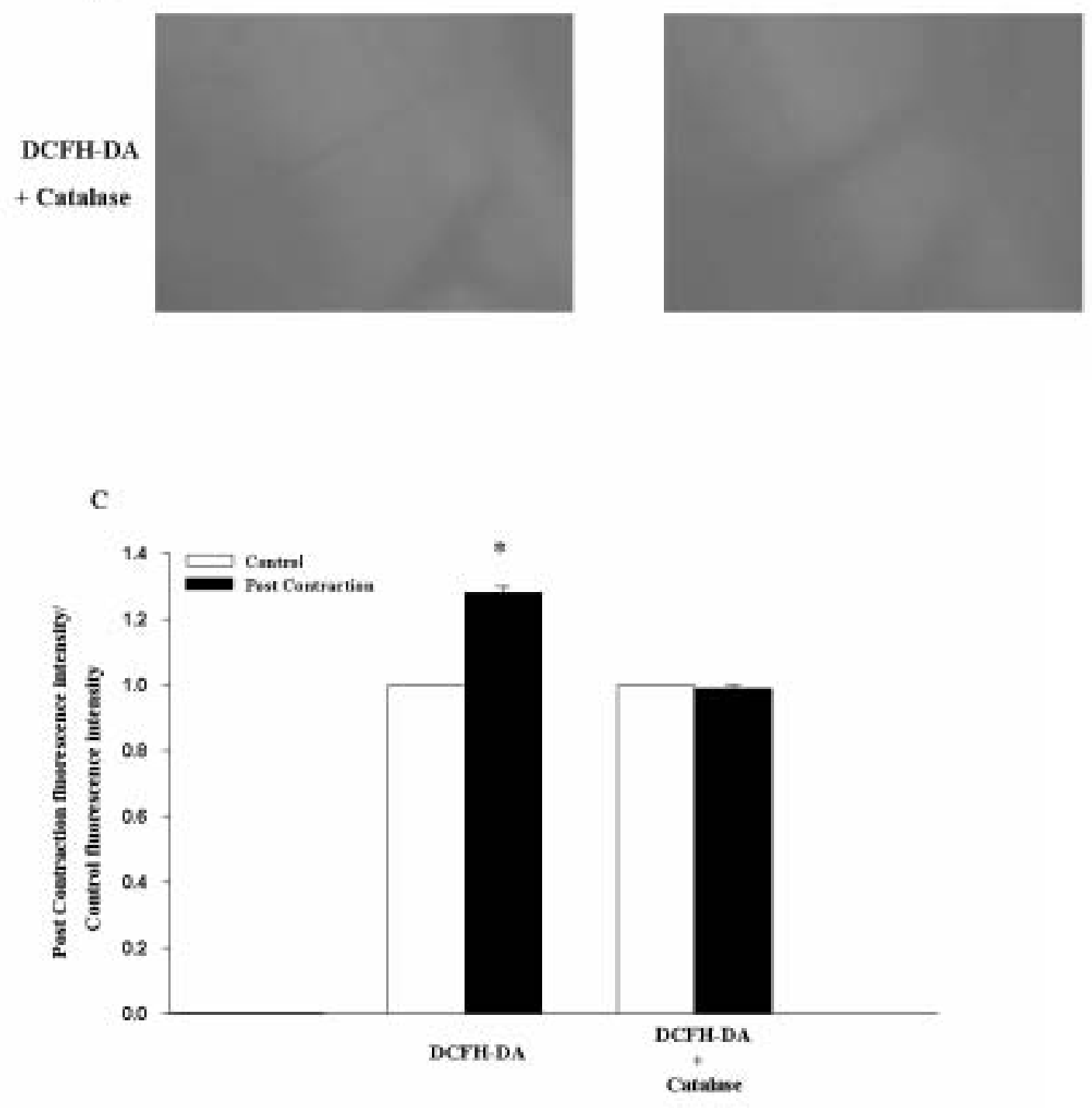

Figure 1. (A) Representative images of spinotrapezius muscle fibers following application of the fluorescence probe 2,7,-dichlorodihydrofluorescein diacetate (DCFHDA; $10 \mu \mathrm{M}$ ), before (Control) and immediately following muscle contraction at $4 \mathrm{~Hz}$ frequency. (B) Control and post contraction images following DCFH-DA application in the presence of catalase $(50 \mathrm{U} / \mathrm{ml})$. (C) Mean values for all images analyzed $(\mathrm{N}=3)$, normalized to control. $* \mathrm{p}<0.05$ vs Control. 
A

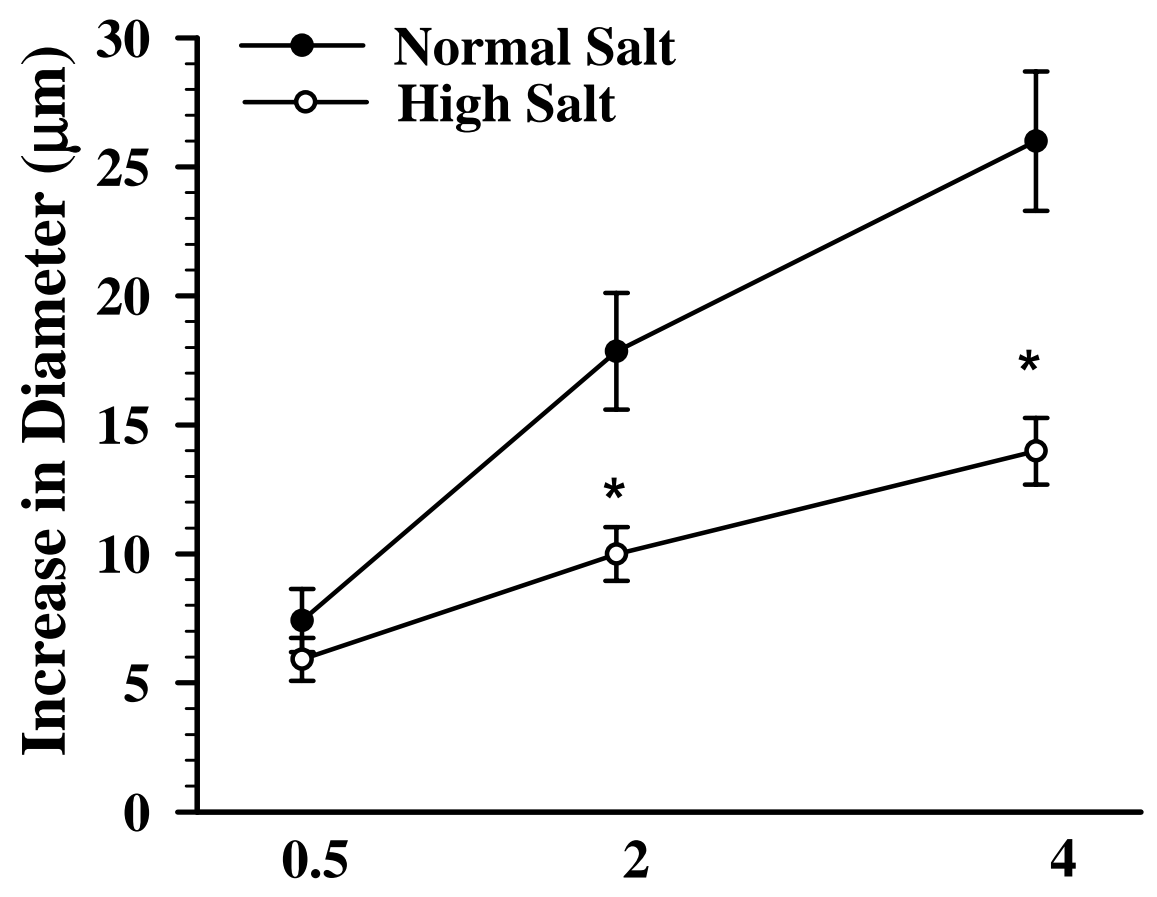

B

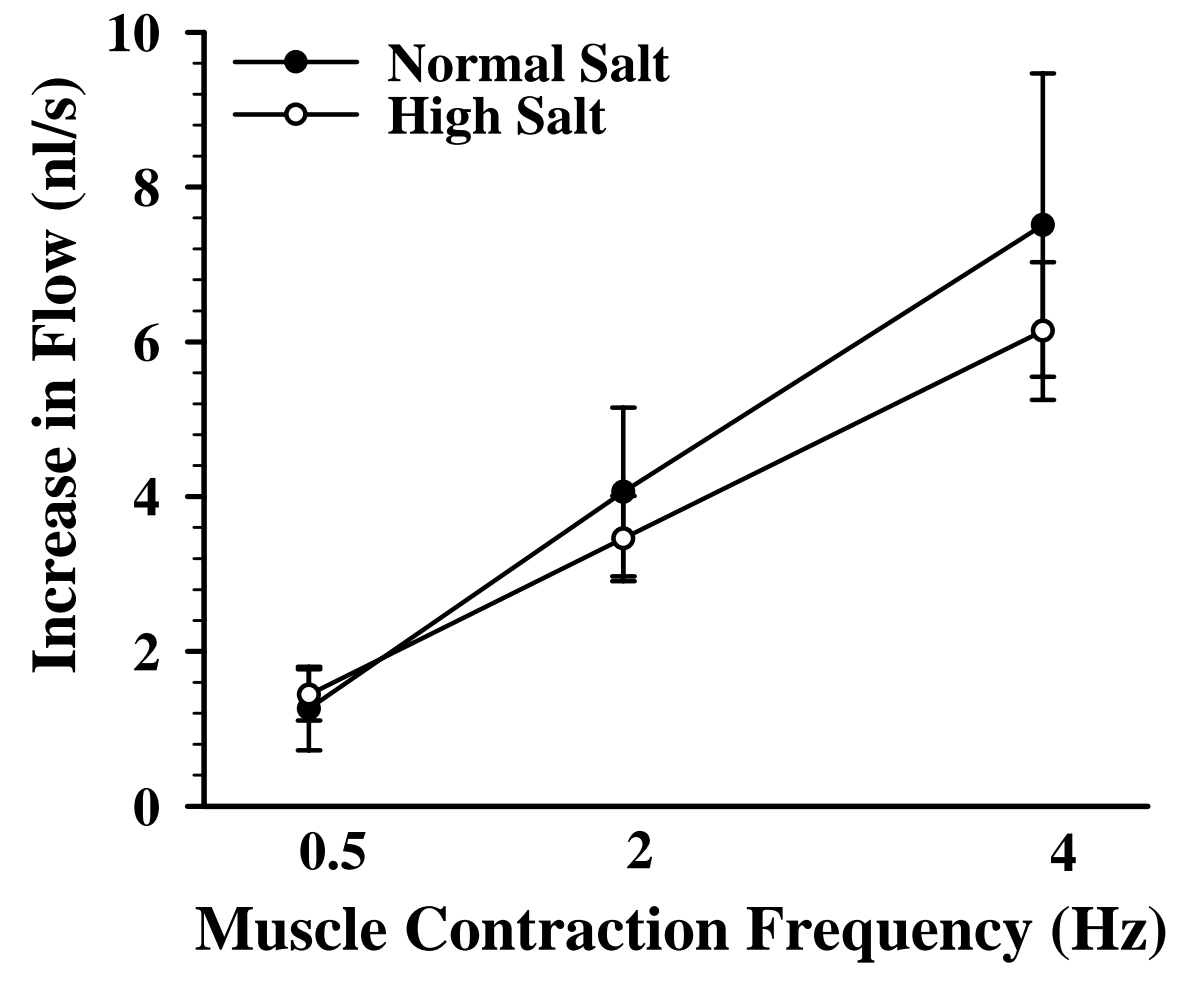

Figure 2. Changes in arteriolar diameter and flow elicited by $0.5 \mathrm{~Hz}, 2 \mathrm{~Hz}$, and $4 \mathrm{~Hz}$ muscle contraction in rats fed NS (normal salt) and HS (high salt) diets. Diameter responses are expressed in absolute terms. (A) NS: $\mathrm{n}=25$; HS: $\mathrm{n}=$ 26. (B) NS: $n=20$; HS: $n=26 . n=$ number of vessels. ${ }^{*} p<0.05$ vs. NS. 


\section{Normal Salt}

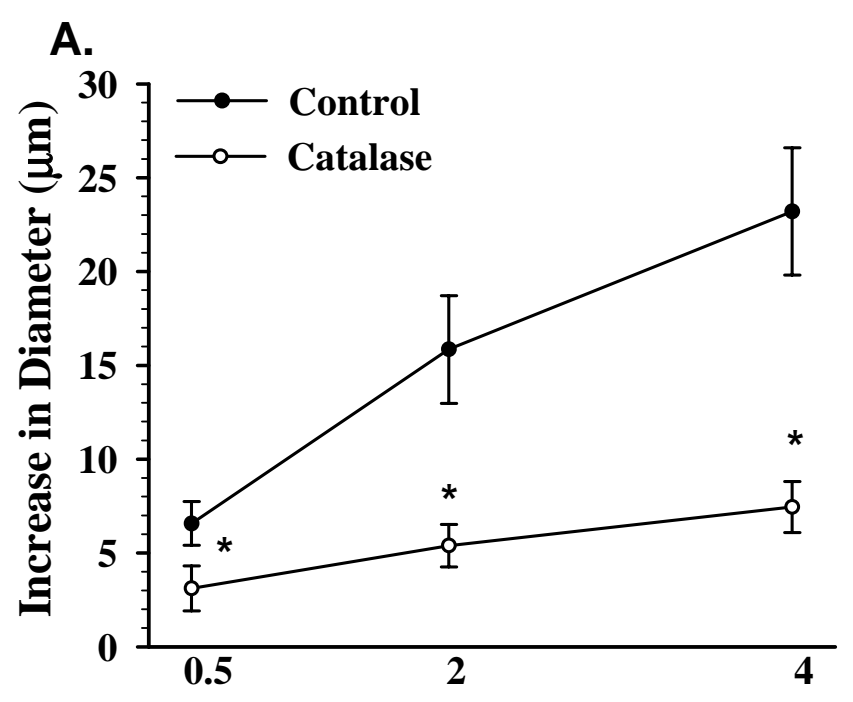

\section{High Salt}

C.

30

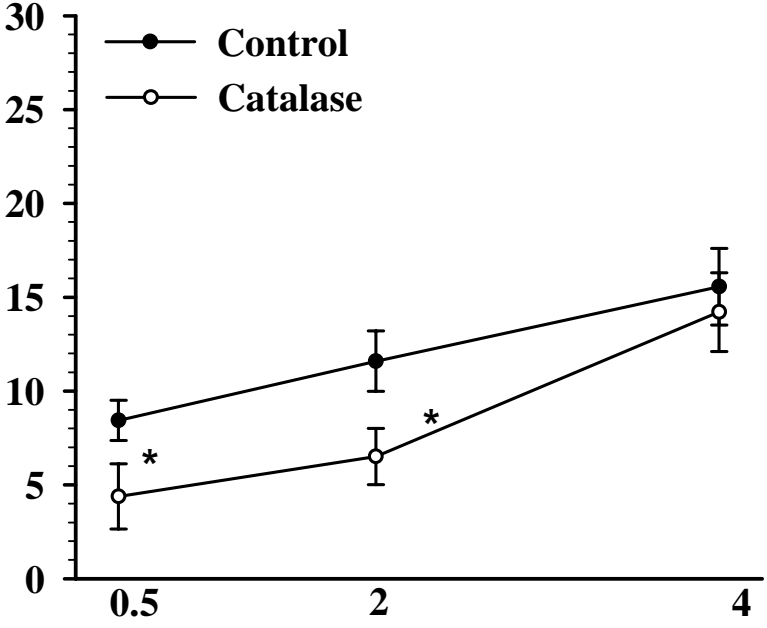

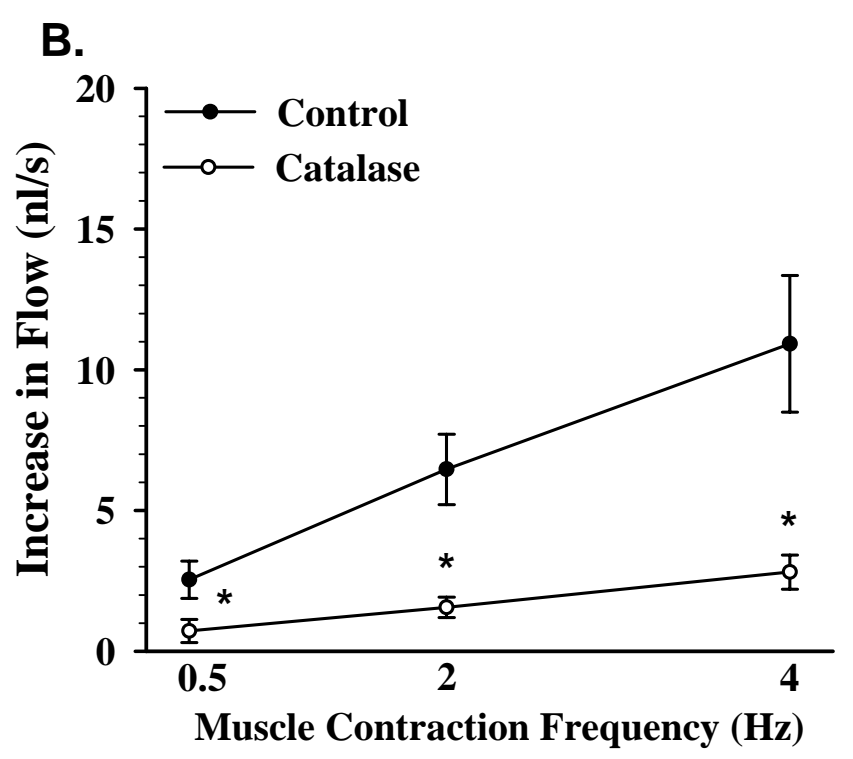

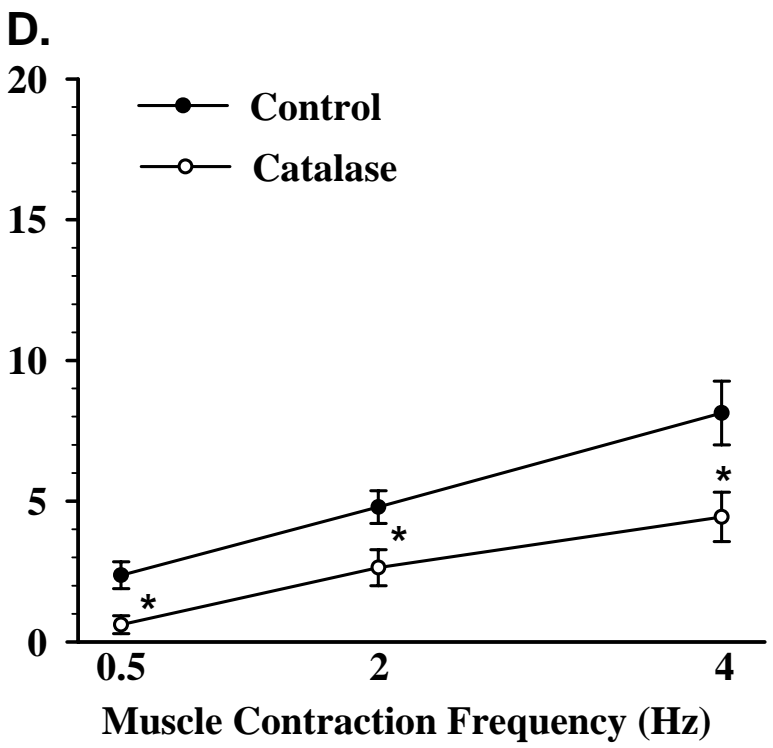

Figure 3. Effect of catalase on arteriolar diameter and flow responses to $0.5 \mathrm{~Hz}, 2 \mathrm{~Hz}$, and $4 \mathrm{~Hz}$ muscle contraction in rats fed NS diet (A and B) and HS diet (C and D). Diameter responses are expressed in absolute terms. A and B: $n=12 ; C$ and $D: n=12 . n=$ number of vessels. $* \mathrm{p}<0.05$ vs. Control. 


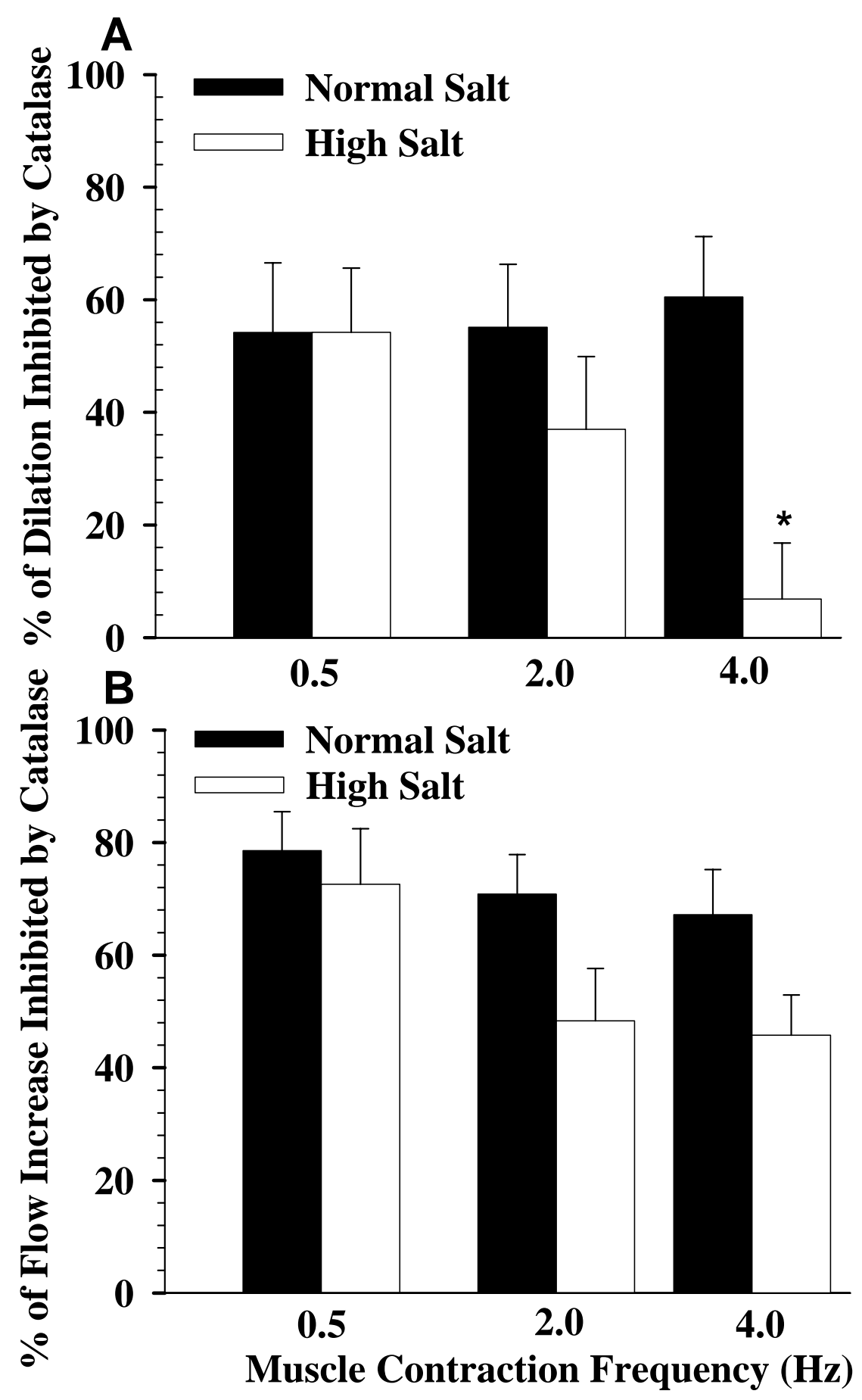

Figure 4. Magnitude of the effect of catalase on arteriolar diameter responses (A) and flow responses (B) to $0.5 \mathrm{~Hz}, 2 \mathrm{~Hz}$, and $4 \mathrm{~Hz}$ muscle contraction in rats fed NS and HS diets. Data are expressed as percent inhibition by catalase. NS: $n=12$; HS: $n=14 . n=$ number of vessels. $* \mathrm{p}<0.05$ vs. NS. 


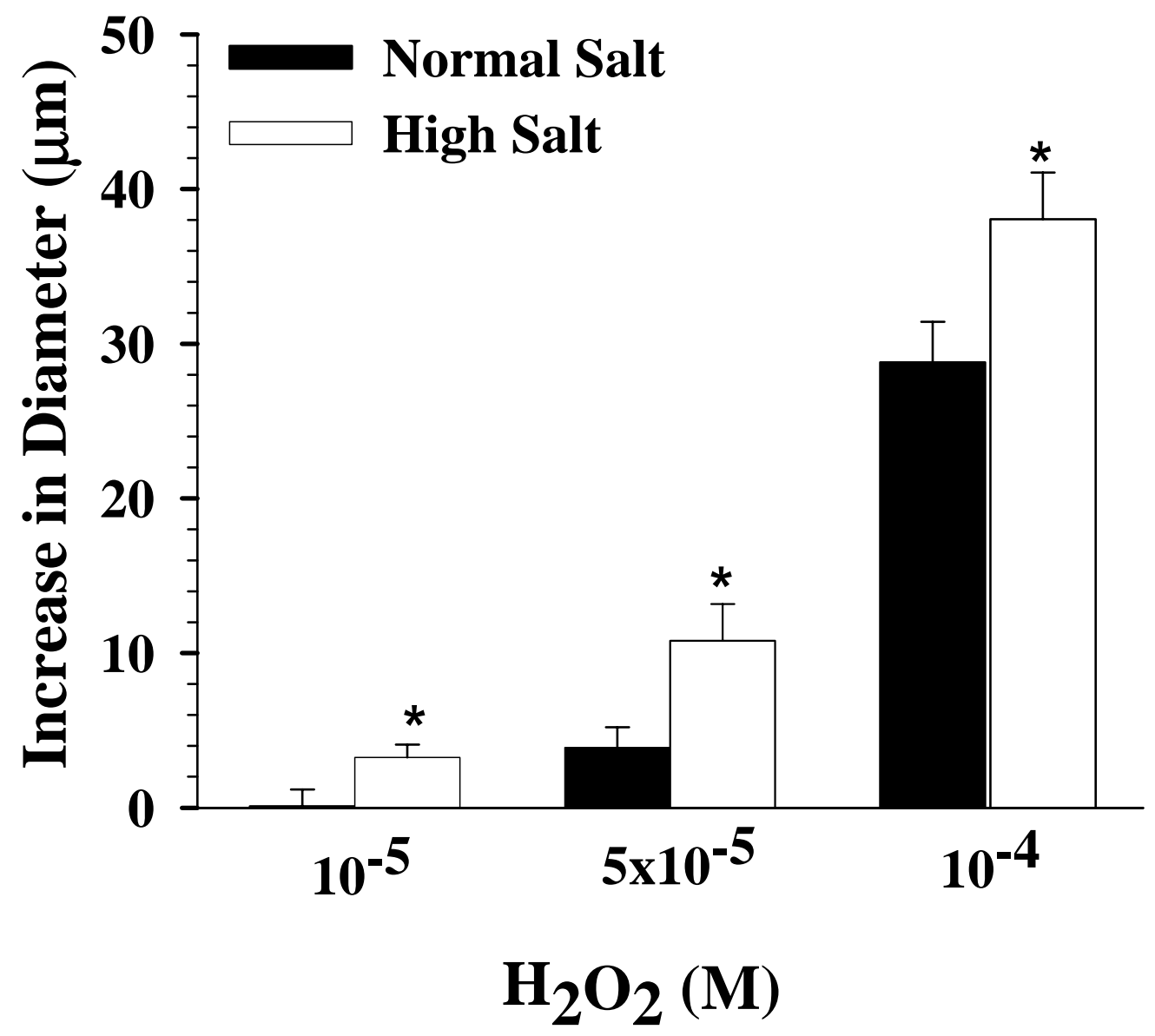

Figure 5. Changes in arteriolar diameter with $\mathrm{H}_{2} \mathrm{O}_{2}$ application in rats fed NS and $\mathrm{HS}$ diets. NS: $\mathrm{n}=24$ for $1 \times 10^{-5} \mathrm{M}$ and $5 \times 10^{-5} \mathrm{M}$, and $\mathrm{n}=26$ for $1 \times 10^{-4} \mathrm{M}$. HS: $\mathrm{n}=23$ for $1 \times 10^{-5} \mathrm{M}$ and $5 \times 10^{-5} \mathrm{M}$, and $\mathrm{n}=24$ for $1 \times 10^{-4} \mathrm{M} . \mathrm{n}=$ number of vessels. $* \mathrm{p}<0.05$ vs. NS. 


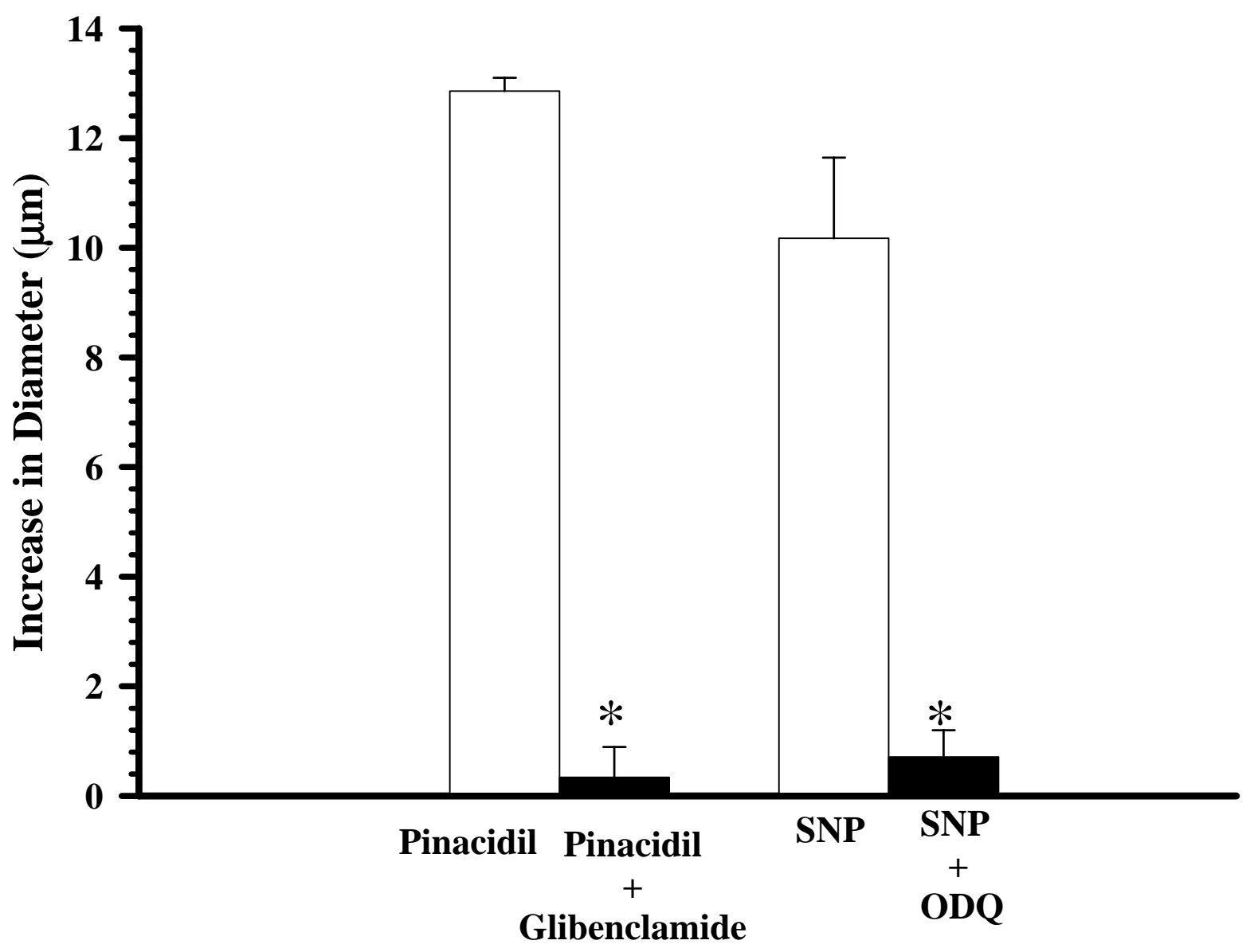

Figure 6. Effect of glibenclamide $\left(1 \times 10^{-5} \mathrm{M}\right)$ and ODQ $\left(1 \times 10^{-5} \mathrm{M}\right)$ on arteriolar responses to pinacidil $\left(1 \times 10^{-6} \mathrm{M}\right)$ and sodium nitroprusside (SNP, $\left.1 \times 10^{-7} \mathrm{M}\right)$, respectively in rats fed NS diet. $* \mathrm{p}<0.05$ vs. pinacidil or SNP. 


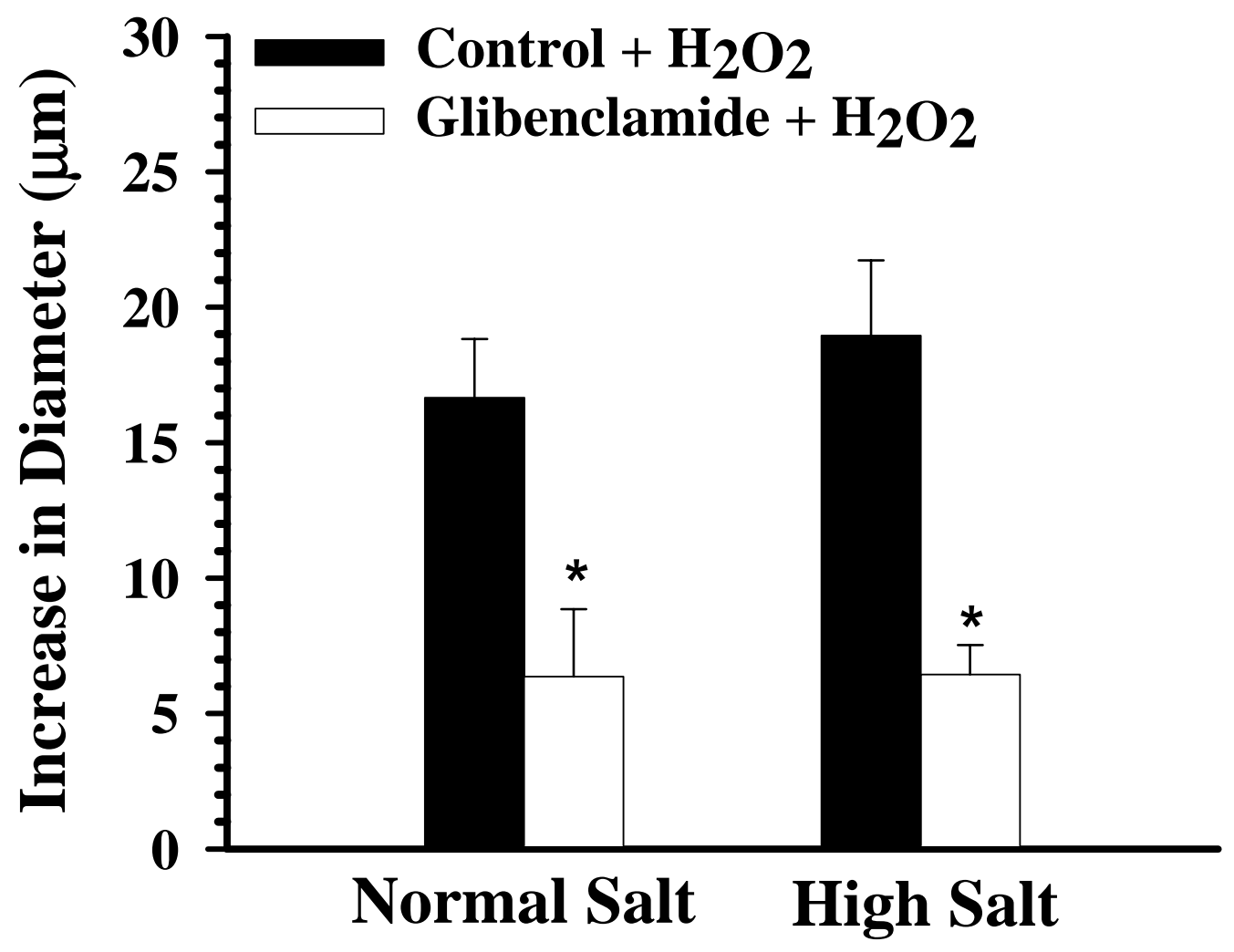

Figure 7. Effect of glibenclamide on arteriolar diameter responses to exogenously applied $\mathrm{H}_{2} \mathrm{O}_{2}\left(5 \times 10^{-5} \mathrm{M}\right)$ in rats fed NS and HS diets. NS: $\mathrm{n}=9 ; \mathrm{HS}: \mathrm{n}=9$. $\mathrm{n}=$ number of vessels. ${ }^{*} \mathrm{p}<0.05$ vs. Control $+\mathrm{H}_{2} \mathrm{O}_{2}$. 

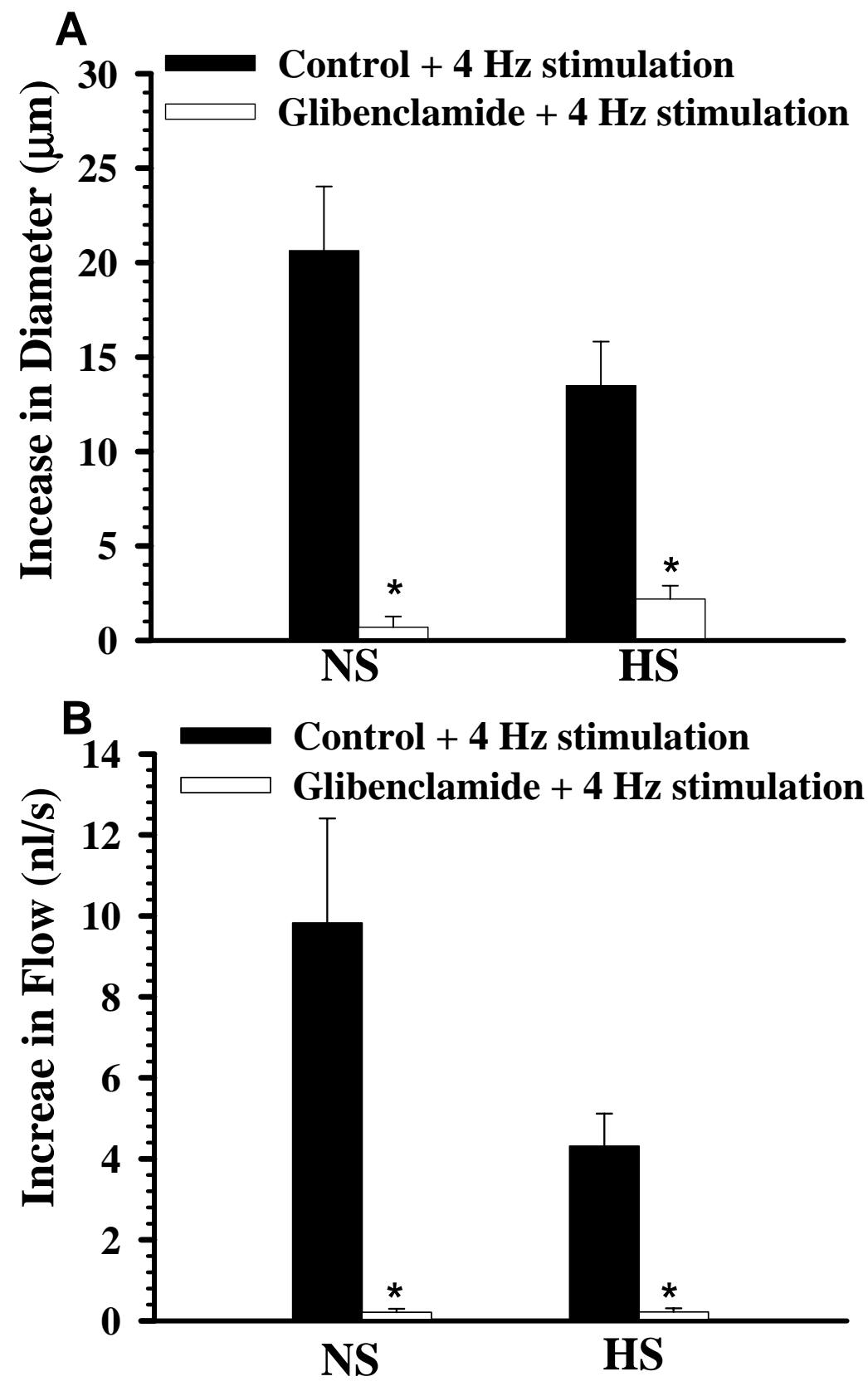

Figure 8. Effect of glibenclamide on arteriolar diameter (A) and flow (B) responses to 4 $\mathrm{Hz}$ muscle contraction in rats fed NS and HS diets. Diameter responses are expressed in absolute terms. NS: $\mathrm{n}=15$; HS: $\mathrm{n}=15 . \mathrm{n}=$ number of vessels. ${ }^{*} \mathrm{p}<0.05$ vs. Control +4 $\mathrm{Hz}$ stimulation. 


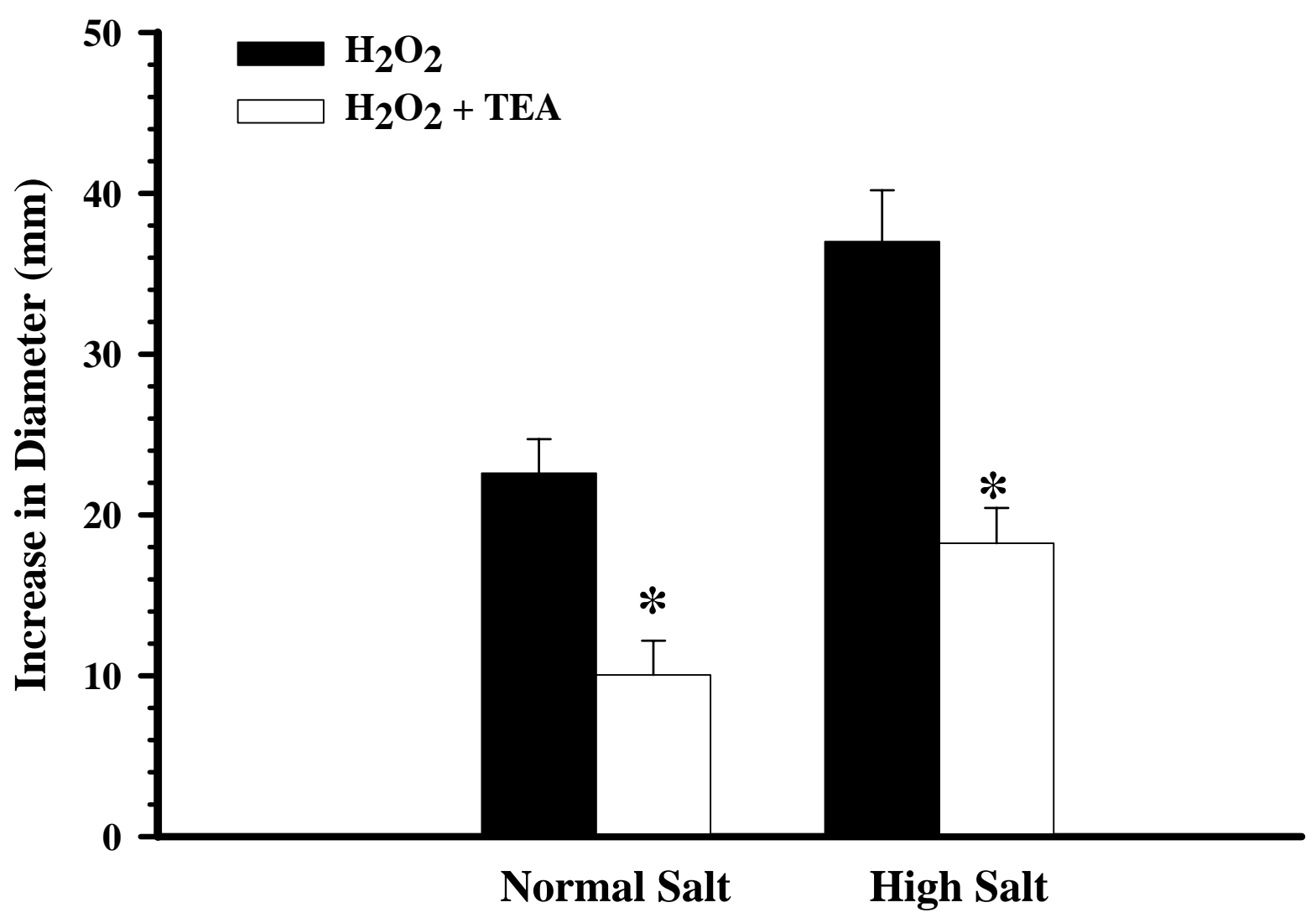

Figure 9. Effect of tetraethylammonium chloride (TEA) on arteriolar diameter responses to exogenously applied $\mathrm{H}_{2} \mathrm{O}_{2}\left(5 \times 10^{-5} \mathrm{M}\right)$ in rats fed NS and $\mathrm{HS}$ diets. NS: $\mathrm{n}=5 ; \mathrm{HS}: \mathrm{n}$ $=5 . \mathrm{n}=$ number of vessels. $* \mathrm{p}<0.05$ vs. $\mathrm{H}_{2} \mathrm{O}_{2}$. 

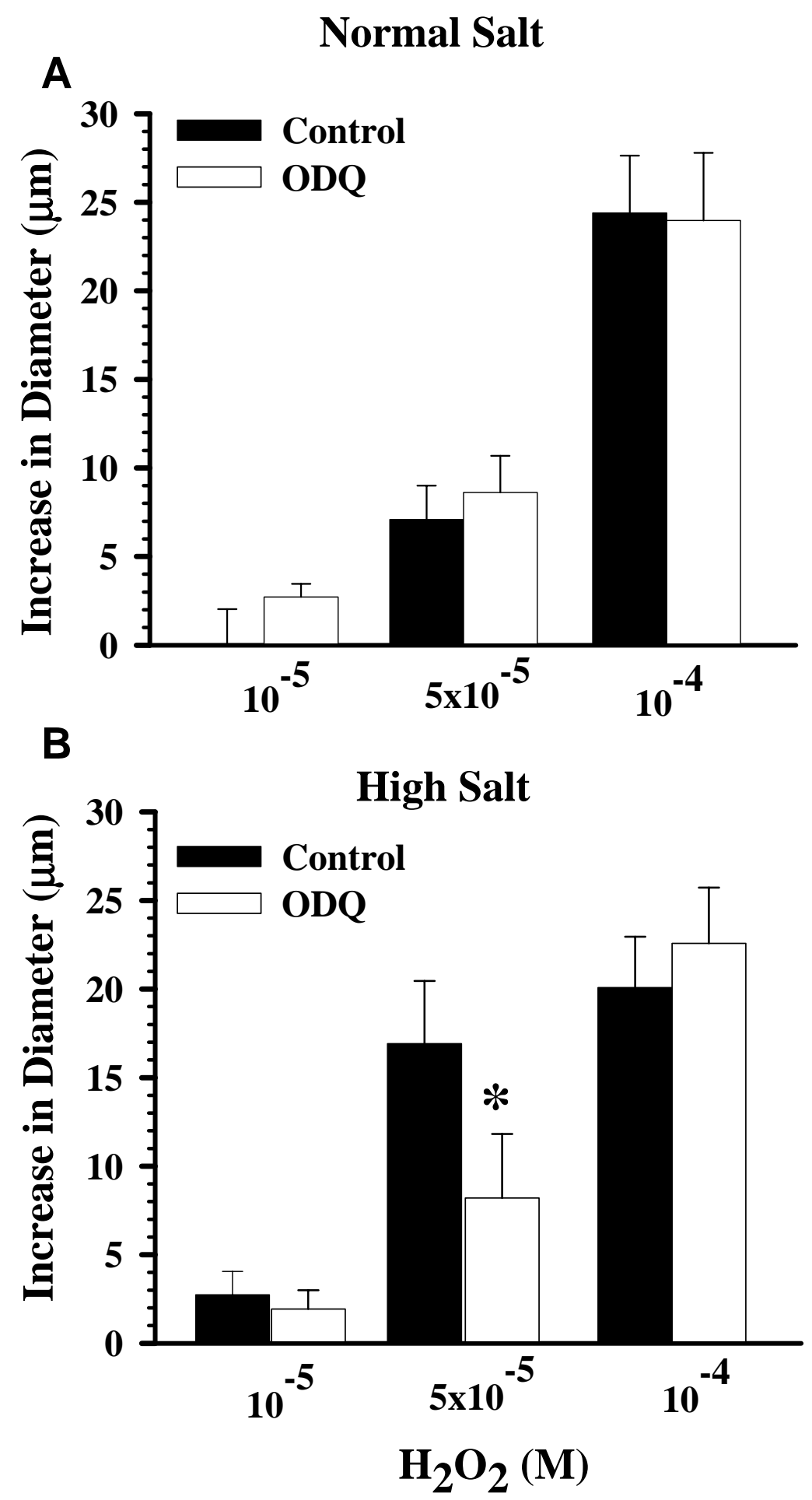

Figure 10. Effect of ODQ on arteriolar diameter responses to exogenously applied $\mathrm{H}_{2} \mathrm{O}_{2}$ in rats fed NS (A) and HS (B) diets. NS: $\mathrm{n}=12$ for $1 \times 10^{-5}$ and $5 \times 10^{-5} \mathrm{M}$, and $\mathrm{n}=9$ for $1 \times 10^{-4}$ M. HS: $n=9$ for $1 \times 10^{-5} \mathrm{M}, \mathrm{n}=12$ for $5 \times 10^{-5} \mathrm{M}$ and $\mathrm{n}=9$ for $1 \times 10^{-4} \mathrm{M} . \mathrm{n}=$ number of vessels. $* \mathrm{p}<0.05$ vs. Control. 


\section{DISCUSSION}

This study confirms our recent findings (32) that arteriolar responses to muscle contraction are reduced after ingestion of a high salt diet. The major new findings from this study are: (1) Hydrogen peroxide production is increased within contracting skeletal muscle fibers in NS rats and the $\mathrm{H}_{2} \mathrm{O}_{2}$ scavenger catalase significantly reduces the arteriolar dilation and hyperemia that accompany muscle contraction in both dietary groups. (2) Exogenous $\mathrm{H}_{2} \mathrm{O}_{2}$ elicits concentration-dependent dilations of skeletal muscle arterioles in both groups, with arterioles in HS rats showing greater responsiveness to $\mathrm{H}_{2} \mathrm{O}_{2}$. (3) The $\mathrm{K}_{\text {ATP }}$ and $\mathrm{K}_{\mathrm{Ca}}$ channel inhibitors glibenclamide and TEA reduce the arteriolar dilation to exogenous $\mathrm{H}_{2} \mathrm{O}_{2}$ by similar amounts in both dietary groups. (4) The arteriolar dilation and flow increases that accompany muscle contraction are also nearly abolished by glibenclamide in both groups. These findings suggest that locally produced $\mathrm{H}_{2} \mathrm{O}_{2}$ contributes to arteriolar dilation and hyperemia during muscle contraction, and that the reduction of arteriolar dilation associated with high salt intake cannot be due to a decrease in this role of $\mathrm{H}_{2} \mathrm{O}_{2}$. Despite increased arteriolar responsiveness to $\mathrm{H}_{2} \mathrm{O}_{2}$ in saltfed rats, the primary mechanism by which $\mathrm{H}_{2} \mathrm{O}_{2}$ triggers arteriolar dilation in this vascular bed $\left(\mathrm{K}^{+}\right.$channel activation presumably leading to vascular smooth muscle hyperpolarization) is unaffected by high salt intake.

It has become increasingly clear that ROS serve as important signaling molecules that can regulate normal vascular function. For example, arachidonic acid-induced dilation of isolated porcine coronary arterioles is attenuated by SOD and catalase, suggesting that cyclooxygenase-derived ROS could, at least theoretically, play a role in the regulation of coronary blood flow (41). In isolated human coronary arterioles, 
catalase inhibits flow-induced dilation and shear stress increases $\mathrm{H}_{2} \mathrm{O}_{2}$ production (36), suggesting that flow-dependent shear stress can relax arteriolar smooth muscle, at least partially, via endothelial $\mathrm{H}_{2} \mathrm{O}_{2}$ release. Other studies in the intact circulation or on isolated arterioles provide more direct evidence that $\mathrm{H}_{2} \mathrm{O}_{2}$ contributes to autoregulation and to reactive hyperemia in the coronary circulation (20,53). Additional physiological roles for $\mathrm{H}_{2} \mathrm{O}_{2}$ have been purported in the regulation of pulmonary $(7,37)$ and cerebral vascular resistance $(21,51)$, but the role of $\mathrm{H}_{2} \mathrm{O}_{2}$ in regulating skeletal muscle blood flow has been less well studied. Cseko et al. have reported that $\mathrm{H}_{2} \mathrm{O}_{2}$ can dilate isolated rat gracilis muscle arterioles by a combination of mechanisms, and have speculated that $\mathrm{H}_{2} \mathrm{O}_{2}$ may be an important modulator of myogenic tone in these vessels (11).

In this study we sought to investigate a possible role of $\mathrm{H}_{2} \mathrm{O}_{2}$ in skeletal muscle hyperemia, a complex and incompletely understood process that can involve metabolic, myogenic, and endothelium-dependent mechanisms to varying degrees (24). Moderateto-intense contraction of muscle fibers leads to intracellular formation of $\mathrm{O}_{2}{ }^{-}$, most likely due to increased mitochondrial respiration (44). Mitochondrial and cytosolic SOD then quickly dismutate the $\mathrm{O}_{2}{ }^{-}$to $\mathrm{H}_{2} \mathrm{O}_{2}$, which can diffuse across the plasma membrane and into the extracellular space $(35,47)$. In addition, some $\mathrm{H}_{2} \mathrm{O}_{2}$ may be generated extracellularly from $\mathrm{O}_{2}^{-}$of unclear origin (10). Because of its relative stability, this $\mathrm{H}_{2} \mathrm{O}_{2}$ could act as an inter-cellular messenger by diffusing to nearby arterioles and contributing to their dilation and the subsequent flow increase.

We have recently found that in rat spinotrapezius muscle arcade arterioles, the hyperemic response to muscle contraction is attenuated by simultaneous exposure to the SOD mimetic 2,2,6,6-Tetramethylpiperidine-N-oxyl (Tempo) and catalase, suggesting 
that ROS may play an important role in the regulation of blood flow during skeletal muscle contraction (32). Our current evidence that $\mathrm{H}_{2} \mathrm{O}_{2}$, formed within contracting muscle fibers, is the particular species involved in this setting comes from a combination of observations. First, immediately after contraction, muscle fibers show increased DCF fluorescence (Fig. 1), which signifies the oxidation of DCFH that was trapped within the cells after enzymatic removal of the acetate group from the DCFH-DA (48). Second, in the presence of exogenous catalase, this increase in DCF fluorescence is completely prevented, and both the arteriolar dilation and hyperemia associated with contraction is markedly reduced (Figs 1,3 and 4). To our knowledge, this is the first study to report a role for $\mathrm{H}_{2} \mathrm{O}_{2}$ in functional hyperemia during skeletal muscle contractions.

High salt intake can produce microvascular structural and functional changes in the absence of increased arterial pressure $(3,4,16,29,39)$. In this study, passive arteriolar diameters were reduced in rats fed high salt (Table 2), which is consistent with previous studies $(13,39)$ and which may reflect arteriolar wall remodeling due to the salt-induced suppression of circulating angiotensin II levels $(16,18)$. Although we have consistently found that arteriolar dilation during muscle contraction is impaired in normotensive rats fed a HS diet, this was not associated with a reduced hyperemic response, in either this (Fig.2) or our previous study (32). A significant fraction of total spinotrapezius muscle vascular resistance is attributable to arterioles distal to the arcade arterioles studied here, and to the small feed arteries upstream from the arcade arterioles (55). It is possible that vessels in one or both of these other locations are dilating to a larger extent than in rats fed normal diet, effectively compensating for the reduced arcade dilation and therefore resulting in an appropriate hyperemic response. The small feed arteries would be 
especially good candidates for such a compensatory response; these vessels account for $30-40 \%$ of total network vascular resistance in resting spinotrapezius muscle, and they are responsible for as much as $40 \%$ of the total resistance decrease during muscle contraction (22).

The mechanism(s) by which $\mathrm{H}_{2} \mathrm{O}_{2}$ relaxes vascular smooth muscle may vary depending on vessel type. For example, $\mathrm{H}_{2} \mathrm{O}_{2}$ increases $\mathrm{NO}$ production in endothelial cells from bovine aortas via PI 3-kinase/Akt-dependent phosphorylation of endothelial nitric oxide synthase (eNOS) (8), raising the possibility of an endothelium-dependent mechanism of vasodilation in vivo. Consistent with this, there is evidence to suggest that the stimulation of soluble guanylate cyclase underlies $\mathrm{H}_{2} \mathrm{O}_{2}$-induced dilation of bovine pulmonary arteries and arterioles $(6,37)$. However, guanylate cyclase-cGMP signaling has not been found to mediate $\mathrm{H}_{2} \mathrm{O}_{2}$-induced arteriolar dilation in coronary and cerebral vascular beds $(36,50,51)$, and our findings that guanylate cyclase inhibition with ODQ has no effect on arteriolar responses in this study (Fig.10) suggests that this mechanism is also not operative in spinotrapezius muscle arterioles.

In contrast, there is considerable evidence that $\mathrm{H}_{2} \mathrm{O}_{2}$ hyperpolarizes vascular smooth muscle by activating diverse membrane potassium channels $(1,2,21,34) . \mathrm{K}_{\mathrm{ATP}}$ channels play a role in $\mathrm{H}_{2} \mathrm{O}_{2}$ - induced dilation of cerebral arterioles $(21,51)$ and gracilis muscle arterioles (11), whereas $\mathrm{K}_{\mathrm{Ca}}$ channels contribute to $\mathrm{H}_{2} \mathrm{O}_{2}$-induced dilation of coronary and gracilis muscle arterioles $(11,36,46)$. In the present study, glibenclamide and TEA greatly reduced the arteriolar dilation to exogenous $\mathrm{H}_{2} \mathrm{O}_{2}$ (Figs. 7 and 9), suggesting that in rat spinotrapezius muscle, $\mathrm{H}_{2} \mathrm{O}_{2}$ elicits smooth muscle relaxation primarily through a mechanism involving activation of both $\mathrm{K}_{\mathrm{ATP}}$ and $\mathrm{K}_{\mathrm{Ca}}$ channels. Our 
finding that these inhibitors were equally effective in both dietary groups are consistent with an earlier study showing that ingestion of a high salt diet does not interfere with $\mathrm{K}_{\mathrm{ATP}}$ channel function (30). Despite the roughly similar contributions of $\mathrm{K}_{\mathrm{ATP}}$ and $\mathrm{K}_{\mathrm{Ca}}$ channels to $\mathrm{H}_{2} \mathrm{O}_{2}$-induced dilation in both groups, the overall dilator responses to $\mathrm{H}_{2} \mathrm{O}_{2}$ were greater in HS rats than in NS rats (Fig. 5). The net hyperpolarization of vascular smooth muscle upon activation of these channels may have been greater in HS rats, although our findings provide no real insight into this possibility.

Glibenclamide effectively blocks functional hyperemia in hamster cremaster muscle $(15,45)$, and we found that this agent almost abolished the arteriolar dilation and hyperemia during spinotrapezius muscle contraction in both groups (Fig. 8). During increases in local metabolism (i.e., muscle contraction), the intracellular ATP/ADP ratio in vascular smooth muscle decreases, thus increasing the open-state probability of the $\mathrm{K}_{\mathrm{ATP}}$ channels, resulting in vascular smooth muscle hyperpolarization and vasodilation (14). The spinotrapezius muscle contains a large proportion of muscle fibers with high ATPase activity (49), which may also explain why $\mathrm{K}_{\mathrm{ATP}}$ channels mediate such a large portion of the vascular response to muscle contraction in this vascular bed (Fig. 8).

In conclusion, the present study points to $\mathrm{H}_{2} \mathrm{O}_{2}$ as a critical vasodilator metabolite during muscle contraction, adding to the growing body of literature that demonstrates important roles for $\mathrm{H}_{2} \mathrm{O}_{2}$ in the regulation of normal vascular events. In this study, dietary salt does not appear to impair this role; rather, the HS rats exhibited enhanced arteriolar responsiveness to exogenously applied $\mathrm{H}_{2} \mathrm{O}_{2}$. This may reflect a secondary adaptation to the altered oxidant and antioxidant enzyme activities that this laboratory has previously reported in HS fed rats (25-27,32). During muscle contraction, local oxygen 
availability can be an important local regulator of arteriolar tone (23), and it is possible that the altered arteriolar wall redox activity shown previously in HS rats may be a consequence of local oxygen metabolism. Future studies are planned to determine whether such an effect may be linked to the reduced arteriolar dilation to skeletal muscle contraction following HS intake. 


\section{REFRENCES}

1. Barlow RS, EI Mowafy AM and White RE. $\mathrm{H}_{2} \mathrm{O}_{2}$ opens $\mathrm{BK}_{\mathrm{Ca}}$ channels via the PLA(2)-arachidonic acid signaling cascade in coronary artery smooth muscle. Am J Physiol Heart Circ Physiol 279: H475-H483, 2000.

2. Barlow RS and White RE. Hydrogen peroxide relaxes porcine coronary arteries by stimulating $\mathrm{BK}_{\mathrm{Ca}}$ channel activity. Am J Physiol 275: H1283-H1289, 1998.

3. Boegehold MA. Effect of dietary salt on arteriolar nitric oxide in striated muscle of normotensive rats. Am J Physiol 264: H1810-H1816, 1993.

4. Boegehold MA. Flow-dependent arteriolar dilation in normotensive rats fed lowor high-salt diets. Am J Physiol 269: H1407-H1414, 1995.

5. Boegehold MA and Bohlen HG. Arteriolar diameter and tissue oxygen tension during muscle contraction in hypertensive rats. Hypertension 12: 184-191, 1988.

6. Burke TM and Wolin MS. Hydrogen peroxide elicits pulmonary arterial relaxation and guanylate cyclase activation. Am J Physiol 252: H721-H732, 1987. 
7. Burke-Wolin TM and Wolin MS. Inhibition of cGMP-associated pulmonary arterial relaxation to $\mathrm{H}_{2} \mathrm{O}_{2}$ and $\mathrm{O}_{2}$ by ethanol. Am J Physiol 258: H1267-H1273, 1990.

\section{Cai H, Li Z, Davis ME, Kanner W, Harrison DG and Dudley SC, Jr. Akt-} dependent phosphorylation of serine 1179 and mitogen-activated protein kinase kinase/extracellular signal-regulated kinase 1/2 cooperatively mediate activation of the endothelial nitric-oxide synthase by hydrogen peroxide. Mol Pharmacol 63: 325-331, 2003.

\section{Chaytor AT, Edwards DH, Bakker LM and Griffith TM. Distinct} hyperpolarizing and relaxant roles for gap junctions and endothelium-derived $\mathrm{H}_{2} \mathrm{O}_{2}$ in NO-independent relaxations of rabbit arteries. Proc Natl Acad Sci U S A 100: 15212-15217, 2003.

10. Close GL, Ashton T, McArdle A and Jackson MJ. Microdialysis studies of extracellular reactive oxygen species in skeletal muscle: Factors influencing the reduction of cytochrome $\mathrm{c}$ and hydroxylation of salicylate. Free Radic Biol Med 39: 1460-1467, 2005.

11. Cseko C, Bagi $\mathbf{Z}$ and Koller A. Biphasic effect of hydrogen peroxide on skeletal muscle arteriolar tone via activation of endothelial and smooth muscle signaling pathways. J Appl Physiol 97: 1130-1137, 2004. 
12. Droge W. Free radicals in the physiological control of cell function. Physiol Rev 82: 47-95, 2002.

13. Frisbee JC and Lombard JH. Chronic elevations in salt intake and reduced renal mass hypertension compromise mechanisms of arteriolar dilation. Microvasc Res 56: 218-227, 1998.

14. Gutterman DD, Miura H and Liu Y. Redox modulation of vascular tone: focus of potassium channel mechanisms of dilation. Arterioscler Thromb Vasc Biol 25: 671-678, 2005.

15. Hammer LW, Ligon AL and Hester RL. Differential inhibition of functional dilation of small arterioles by indomethacin and glibenclamide. Hypertension 37: 599-603, 2001.

16. Hansen-Smith FM, Morris LW, Greene AS and Lombard JH. Rapid microvessel rarefaction with elevated salt intake and reduced renal mass hypertension in rats. Circ Res 79: 324-330, 1996.

17. Harrison DG. Endothelial function and oxidant stress. Clin Cardiol 20: II-7, 1997. 
18. Hernandez I, Cowley AW, Jr., Lombard JH and Greene AS. Salt intake and angiotensin II alter microvessel density in the cremaster muscle of normal rats. Am J Physiol 263: H664-H667, 1992.

19. Iida $Y$ and Katusic ZS. Mechanisms of cerebral arterial relaxations to hydrogen peroxide. Stroke 31: 2224-2230, 2000.

20. Koller A and Bagi Z $\mathbf{Z}$. Nitric oxide and $\mathrm{H}_{2} \mathrm{O}_{2}$ contribute to reactive dilation of isolated coronary arterioles. Am J Physiol Heart Circ Physiol 287: H2461-H2467, 2004.

21. Lacza Z, Puskar M, Kis B, Perciaccante JV, Miller AW and Busija DW. Hydrogen peroxide acts as an EDHF in the piglet pial vasculature in response to bradykinin. Am J Physiol Heart Circ Physiol 283: H406-H411, 2002.

22. Lash JM. Contribution of arterial feed vessels to skeletal muscle functional hyperemia. J Appl Physiol 76: 1512-1519, 1994.

23. Lash JM and Bohlen HG. Perivascular and tissue $\mathrm{PO}_{2}$ in contracting rat spinotrapezius muscle. Am J Physiol 252: H1192-H1202, 1987.

24. Laughlin MH, Korthuis RJ, Dunker DJ and Bache RJ. Control of blood flow to cardiac and skeletal muscle during exercise. In: Handbook of Physiology. 
Exercise: Regulation and Integration of Multiple Systems, Oxford University Press , 1996, p. 705-769.

25. Lenda DM and Boegehold MA. Effect of a high salt diet on microvascular antioxidant enzymes. J Vasc Res 39: 41-50, 2002.

26. Lenda DM and Boegehold MA. Effect of a high-salt diet on oxidant enzyme activity in skeletal muscle microcirculation. Am J Physiol Heart Circ Physiol 282: H395-H402, 2002.

27. Lenda DM, Sauls BA and Boegehold MA. Reactive oxygen species may contribute to reduced endothelium-dependent dilation in rats fed high salt. Am J Physiol Heart Circ Physiol 279: H7-H14, 2000.

28. Linderman JR and Boegehold MA. Arteriolar network growth in rat striated muscle during juvenile maturation. Int J Microcirc Clin Exp 16: 232-239, 1996.

29. Liu Y, Fredricks KT, Roman RJ and Lombard JH. Response of resistance arteries to reduced $\mathrm{PO}_{2}$ and vasodilators during hypertension and elevated salt intake. Am J Physiol 273: H869-H877, 1997.

30. Lombard JH, Sylvester FA, Phillips SA and Frisbee JC. High-salt diet impairs vascular relaxation mechanisms in rat middle cerebral arteries. Am J Physiol Heart Circ Physiol 284: H1124-H1133, 2003. 
31. Madamanchi NR, Vendrov A and Runge MS. Oxidative stress and vascular disease. Arterioscler Thromb Vasc Biol 25: 29-38, 2005.

32. Marvar PJ, Nurkiewicz TR and Boegehold MA. Reduced arteriolar responses to skeletal muscle contraction after ingestion of a high salt diet. $J$ Vasc Res 42: 226-236, 2005.

33. Matoba T, Shimokawa H, Kubota H, Morikawa K, Fujiki T, Kunihiro I, Mukai Y, Hirakawa Y and Takeshita A. Hydrogen peroxide is an endotheliumderived hyperpolarizing factor in human mesenteric arteries. Biochem Biophys Res Commun 290: 909-913, 2002.

34. Matoba T, Shimokawa H, Nakashima M, Hirakawa Y, Mukai Y, Hirano K, Kanaide $\mathbf{H}$ and Takeshita A. Hydrogen peroxide is an endothelium-derived hyperpolarizing factor in mice. J Clin Invest 106: 1521-1530, 2000.

35. McArdle F, Pattwell DM, Vasilaki A, McArdle A and Jackson MJ. Intracellular generation of reactive oxygen species by contracting skeletal muscle cells. Free Radic Biol Med 39: 651-657, 2005.

36. Miura H, Bosnjak JJ, Ning G, Saito T, Miura M and Gutterman DD. Role for hydrogen peroxide in flow-induced dilation of human coronary arterioles. Circ Res 92: e31-e40, 2003. 
37. Monaco JA and Burke-Wolin T. $\mathrm{NO}$ and $\mathrm{H}_{2} \mathrm{O}_{2}$ mechanisms of guanylate cyclase activation in oxygen-dependent responses of rat pulmonary circulation. Am J Physiol 268: L546-L550, 1995.

38. Nelson MT and Quayle JM. Physiological roles and properties of potassium channels in arterial smooth muscle. Am J Physiol 268: C799-C822, 1995.

39. Nurkiewicz TR and Boegehold MA. High dietary salt alters arteriolar myogenic responsiveness in normotensive and hypertensive rats. Am J Physiol 275: H2095H2104, 1998.

40. Nurkiewicz TR and Boegehold MA. Limitation of arteriolar myogenic activity by local nitric oxide: segment-specific effect of dietary salt. Am J Physiol 277: H1946-H1955, 1999.

41. Oltman CL, Kane NL, Miller FJ, Jr., Spector AA, Weintraub NL and Dellsperger KC. Reactive oxygen species mediate arachidonic acid-induced dilation in porcine coronary microvessels. Am J Physiol Heart Circ Physiol 285: H2309-H2315, 2003.

42. Pattwell DM, McArdle A, Morgan JE, Patridge TA and Jackson MJ. Release of reactive oxygen and nitrogen species from contracting skeletal muscle cells. Free Radic Biol Med 37: 1064-1072, 2004. 
43. Rafi JA and Boegehold MA. Microvascular responses to oxygen and muscle contraction in hypertensive Dahl rats. Int J Microcirc Clin Exp 13: 83-97, 1993.

44. Reid MB. Invited Review: redox modulation of skeletal muscle contraction: what we know and what we don't. J Appl Physiol 90: 724-731, 2001.

45. Saito Y, McKay M, Eraslan A and Hester RL. Functional hyperemia in striated muscle is reduced following blockade of ATP-sensitive potassium channels. Am J Physiol 270: H1649-H1654, 1996.

46. Sato A, Sakuma I and Gutterman DD. Mechanism of dilation to reactive oxygen species in human coronary arterioles. Am J Physiol Heart Circ Physiol 285: H2345-H2354, 2003.

47. Silveira LR, Pereira-Da-Silva L, Juel C and Hellsten Y. Formation of hydrogen peroxide and nitric oxide in rat skeletal muscle cells during contractions. Free Radic Biol Med 35: 455-464, 2003.

48. Tarpey MM and Fridovich I. Methods of detection of vascular reactive species: nitric oxide, superoxide, hydrogen peroxide, and peroxynitrite. Circ Res 89: 224236, 2001. 
49. Taylor K and Calvey TN. Histochemical characteristics and contractile properties of the spinotrapezius muscle in the rat and the mouse. J Anat 123: 67$76,1977$.

50. Thengchaisri $\mathbf{N}$ and Kuo L. Hydrogen peroxide induces endothelium-dependent and -independent coronary arteriolar dilation: role of cyclooxygenase and potassium channels. Am J Physiol Heart Circ Physiol 285: H2255-H2263, 2003.

51. Wei EP, Kontos HA and Beckman JS. Mechanisms of cerebral vasodilation by superoxide, hydrogen peroxide, and peroxynitrite. Am J Physiol 271: H1262H1266, 1996.

52. Wolin MS. Interactions of oxidants with vascular signaling systems. Arterioscler Thromb Vasc Biol 20: 1430-1442, 2000.

\section{Yada T, Shimokawa H, Hiramatsu O, Kajita T, Shigeto F, Goto M,} Ogasawara Y and Kajiya F. Hydrogen peroxide, an endogenous endotheliumderived hyperpolarizing factor, plays an important role in coronary autoregulation in vivo. Circulation 107: 1040-1045, 2003.

54. Yang Z, Zhang A, Altura BT and Altura BM. Hydrogen peroxide-induced endothelium-dependent relaxation of rat aorta involvement of $\mathrm{Ca}^{2+}$ and other cellular metabolites. Gen Pharmacol 33: 325-336, 1999. 
55. Zweifach BW and Lipowsky HH. Pressure-flow relations in blood and lymph microcirculation. In: Handbook of Physiology, The Cardiovascular System: Microcirculation, edited by Renkin EM and Michel CC. Bethesda, MD: American Physiological Society, 1984, p. 251-308. 
Study III: The Role of 20-HETE in the Reduced Arteriolar Responses to Increased Oxygen Availability in Rats Fed High Salt 


\section{SUMMARY}

The arteriolar dilation that accompanies skeletal muscle contraction is reduced in normotensive rats fed a high salt diet. Variations in oxygen availability during skeletal muscle contraction can influence vascular tone, and such oxygen-induced changes in vascular tone are mediated in part by the vasoconstrictor 20-hydroxyeicosatetraenoic acid (20-HETE). The purpose of this study was to examine the effects of dietary salt on the arteriolar responsiveness to oxygen, and the role of 20-HETE in these responses. Rats were fed either a normal salt (NS, $0.45 \%$ ) or high salt (HS, $4 \%$ ) diet for $4-5$ weeks. In response to an elevation in superfusate oxygen concentration, the constriction and reduction in blood flow through arterioles in the exteriorized spinotrapezius muscle were less in HS rats than NS rats. Inhibition of 20-HETE formation with N-methylsulfonyl12,12-dibromododec-11-enamide (DDMS) or 17-octadecynoic acid (17-ODYA ) reduced the oxygen-induced constriction in NS rats, but not in the HS rats. Exogenous 20-HETE elicited a concentration-dependent constriction that was blocked by the $\mathrm{K}_{\mathrm{Ca}}$ channel inhibitor tetraethylammoniumchloride (TEA) in NS rats, and a smaller constriction that was insensitive to TEA in HS rats. In NS rats, arteriolar responsiveness to angiotensin II was similar in both groups, but was more sensitive to inhibition with DDMS in NS rats. Norepinephrine-induced arteriolar constriction was similar and insensitive to DDMS in both groups. We conclude that 20-HETE contributes to oxygen-induced arteriolar constriction via inhibition of $\mathrm{K}_{\mathrm{Ca}}$ channels, and that a high salt diet impairs the arteriolar response to increased oxygen availability due to a loss of this 20-HETE component. 


\section{INTRODUCTION}

Oxygen is an important regulator of tissue blood flow and vascular resistance.

Gracilis muscle feed arteries from rats fed high salt for as little as 3 days consistently show an impaired dilator response to reduced oxygen levels $(37,38)$. In contrast, the influence of oxygen on the tone of smaller arterioles within the rat cremaster muscle is unchanged by 3 days of high salt intake (8). This suggests that either a longer period of high salt intake is required to alter the oxygen responsiveness of more distal skeletal muscle resistance vessels, or that there is a fundamental difference between extraparenchymal arteries and arterioles in the susceptibility of oxygen-sensitive tone to dietary salt. The first aim of this study was to distinguish between these possibilities by determining if more prolonged ingestion of a high salt diet leads to a change in the relationship between oxygen availability and arteriolar tone in rat skeletal muscle.

The mechanisms through which oxygen can influence the tone of skeletal muscle resistance vessels have long been of interest to those studying the local regulation of blood flow (7,17). Mounting evidence indicates that the enzyme cytochrome P450 4A (CYP450 4A) $\omega$-hydroxylase, which is present in skeletal muscle arterioles as well as in the surrounding muscle fibers (19), can play a pivotal role in arteriolar responses to increased or decreased oxygen availability. In response to an elevation or reduction in $\mathrm{PO}_{2}$, this enzyme can either increase or decrease production of the vasoconstrictor 20hydroxyeicosatetraenoic acid (20-HETE) $(15,26)$. Studies have documented the contribution of 20-HETE to oxygen-induced constriction of hamster retractor muscle arterioles (26), rat and hamster cremaster muscle arterioles $(8,11,15,19,26)$, as well as isolated rat gracilis muscle feed arteries (9). Other findings suggest a role for 20-HETE 
in the oxygen-dependent control of arteriolar tone in non-muscle vascular beds as well $(15,39)$. Recent findings indicate that both the expression of CYP450 4A and production of 20-HETE are increased in mesenteric resistance arteries of rats fed a high salt diet, and that these vessels exhibit an impaired responsiveness to changes in oxygen availability (35). However, given the functional differences that can exist among resistance vessels in different vascular beds $(10,31)$, these results cannot be automatically extrapolated to skeletal muscle. Therefore, a second aim of this study was to assess whether high salt intake alters the specific contribution of the CYP450 4A /20-HETE pathway to oxygendependent changes in the tone of skeletal muscle arterioles. 


\section{METHODS}

Weanling male Sprague-Dawley rats (Harlan Sprague Dawley, Indianapolis, IN) were placed on a whole-grain diet containing either $0.45 \% \mathrm{NaCl}$ (normal salt, $\mathrm{NS}$ ) or 4 $\% \mathrm{NaCl}$ (high salt, HS) by weight (NS diet= TD88311, HS diet= TD92034; Teklad, Madison, WI). All rats were studied 4-5 weeks after being placed on their respective diets, and were 7-8 weeks old at this time. Each of the protocols described below was performed on rats from both dietary groups.

\section{Surgical Preparation and Intravital Microscopy}

All surgical and experimental procedures were approved by the West Virginia University Animal Care and Use Committee. Each rat was anesthetized with sodium thiopental $(100 \mathrm{mg} / \mathrm{kg}$, i.p. $)$ and placed on a heating pad to maintain a $37^{\circ} \mathrm{C}$ rectal temperature. The trachea was intubated to ensure a patent airway and the right carotid artery was cannulated to measure arterial pressure. The right spinotrapezius muscle was exteriorized for microscopic observation as previously described (4), leaving its innervation and all feed vessels completely intact. Throughout the surgery and subsequent experimental period, the muscle was continuously superfused with an electrolyte solution (119 mM NaCl, $25 \mathrm{mM} \mathrm{NaHCO}$, $6 \mathrm{mM} \mathrm{KCl}$ and $3.6 \mathrm{mM} \mathrm{CaCl}_{2}$ ) warmed to $35^{\circ} \mathrm{C}$ and equilibrated with $95 \% \mathrm{~N}_{2}-5 \% \mathrm{CO}_{2}(\mathrm{pH}=7.35-7.40)$. Superfusate flow rate was maintained at 4-6 $\mathrm{ml} / \mathrm{min}$ to minimize equilibration with atmospheric $\mathrm{O}_{2}$ (5).

The animal preparation was transferred to the stage of an Olympus BX50WI intravital microscope (Hyde Park, NY) fitted with a CCD video camera (Dage-MTI, 
Michigan City, IN). Video images were displayed on a Sony high-resolution video monitor and videotaped for off-line analysis. Observations were made with an Olympus $20 \mathrm{X}$ water immersion objective (final video image magnification $=1460 \mathrm{X}$ ). Arteriolar centerline red blood cell velocities were measured on-line with an optical doppler velocimeter (Cardiovascular Research Institute, Texas A\&M University), and arteriolar inner diameters were measured off-line during videotape replay with a video caliper (Cardiovascular Research Institute).

Inhibition of Cytochrome P-450 4A $\omega$-Hydroxylase

To evaluate the role of CYP450 4A enzymes in regulating vascular tone, we used (1) 17-octadecynoic acid (17-ODYA, Sigma Chemical, St. Louis, MO), a suicide substrate inhibitor of CYP450 4A $\omega$-hydroxylases $(15,41)$ which also blocks the epoxygenase pathway (41), and (2) the more specific inhibitor of CYP-450 4A $\omega$ hydroxylase, N-methylsulfonyl-12,12-dibromododec-11-enamide (DDMS) (1). In the first set of experiments, 17-ODYA $\left(1 \times 10^{-5} \mathrm{M}\right)$ was topically applied to the muscle for 30 minutes while the superfusion was stopped. In other experiments, a $5 \times 10^{-5} \mathrm{M}$ solution of DDMS was topically applied to the muscle (with superfusion stopped) for 30 minutes, followed by continuous superfusion of the muscle with a $1 \times 10^{-6} \mathrm{M}$ solution of DDMS throughout the experimental period. These inhibitors have been shown to be effective in other in vivo studies examining the role of 20-HETE in skeletal muscle microvascular control (25). 


\section{Application of Exogenous Vasoconstrictors}

To determine whether the sensitivity of spinotrapezius muscle arterioles to 20HETE is different between dietary groups, increasing concentrations of 20-HETE (1 x 10-

${ }^{9} \mathrm{M}$, to $5 \times 10^{-8} \mathrm{M}$, Sigma) were added directly to the muscle superfusate. Prior to application of 20-HETE, the muscle was superfused with $1 \times 10^{-5} \mathrm{M}$ 17-ODYA to inhibit endogenous 20-HETE formation, and the lipoxygenase inhibitor baicalein $\left(1 \times 10^{-5} \mathrm{M}\right.$, Sigma) plus the cyclooxygenase inhibitor indomethacin $\left(1 \times 10^{-6} \mathrm{M}\right.$, Sigma) to prevent the metabolism of exogenous 20-HETE to other products (25). Previous studies suggest that angiotensin II (ANG II) and norepinephrine (NE) may elicit vasoconstriction in part through 20-HETE production $(2,16,18)$. Therefore, we also assessed arteriolar responsiveness to ANG II $\left(1 \times 10^{-9} \mathrm{M}, 1 \times 10^{-8} \mathrm{M}\right.$, Sigma $)$ and NE $\left(1 \times 10^{-7} \mathrm{M}, 1 \times 10^{-8}\right.$ M, Sigma), before and after inhibition of 20-HETE formation with DDMS.

\section{$\underline{\text { Inhibition of } \mathrm{K}_{\mathrm{Ca}} \text { channels }}$}

Because 20-HETE causes vasoconstriction in part by inhibiting the opening of large-conductance $\mathrm{Ca}^{2+}$-activated potassium $\left(\mathrm{K}_{\mathrm{Ca}}\right.$ ) channels $(40)$, the effect of tetraethylammoniumchloride (TEA $1 \mathrm{mM}$, Sigma) on arteriolar responses to exogenous 20-HETE $\left(1 \times 10^{-8} \mathrm{M}\right)$ were also determined. At a concentration of $1 \mathrm{mM}$, TEA has been shown to selectively block $\mathrm{K}_{\mathrm{Ca}}$ channels, without effects on other potassium channels (30). 


\section{Western Analysis for Cytochrome P450 4A $\omega$-Hydroxylase}

Western blots were performed to measure the expression of CYP450 4A $\omega$ hydroxylase in isolated microvessels and whole spinotrapezius muscle from each dietary group. After induction of sodium thiopental anesthesia, the right and left spinotrapezius muscles were removed, rinsed in electrolyte solution $\left(4^{\circ} \mathrm{C}\right)$, and immediately frozen in liquid nitrogen. In another group of rats, the right and left spinotrapezius muscles were removed, rinsed in electrolyte solution $\left(4^{\circ} \mathrm{C}\right)$ and pinned out in a silastic-coated petri dish filled with $100 \%$ methanol at $4^{\circ} \mathrm{C}$. In these rats, arcade arterioles were excised from the surrounding parenchyma and immediately frozen in liquid nitrogen. Whole skeletal muscle from the first group and isolated arterioles from the second group were homogenized on ice using the homogenization buffer T-PER ${ }^{\mathrm{TM}}$ (Pierce, Rockford, IL) and then centrifuged at $10,000 \mathrm{RPM}$ for $5 \mathrm{~min}$ at $4^{\circ} \mathrm{C}$, and the supernatant was stored at $80^{\circ} \mathrm{C}$ until use. 1 microgram of vessel protein (measured with a Bio-Rad protein assay kit) from each dietary group was separated on a NuPage 4-12\% Bis-Tris polyacrylamide gel (Invitrogen, San Diego CA) and transferred to a nitrocellulose membrane. The membrane was probed with rabbit polyclonal antibody for CYP450 4A (1:1,500; Affinity Bioreagents, Golden, CO), and then incubated with horseradish peroxidaseconjugated goat anti-rabbit IgG F(ab')2 (1:3,000; Santa Cruz, CA). After treatment with SuperSignal $^{\circledR}$ (Pierce), membranes were exposed to autoradiography film. X-ray images were digitally captured, and optical density measurements were made. To ensure equal protein loading, glyceraldehyde 3-phosphate dehydrogenase (GAPDH) was measured as a loading control protein. 


\section{Experimental Protocols}

1. Assessement of arteriolar responses to increased oxygen availability, exogenous 20HETE, ANG II and NE:

In rat spinotrapezius muscle, there is a network of interconnected arcade arterioles that extends throughout the muscle (22). After exteriorization of the spinotrapezius muscle and a 30-minute post-surgical equilibration period, one to three arcade arterioles were chosen for study and baseline measurements of resting arteriolar diameter and flow were determined. Then, to assess responsiveness to elevated $\mathrm{PO}_{2}$, the superfusate was switched from the $0 \%$ oxygen solution (equilibrated with $95 \% \mathrm{~N}_{2}, 5 \% \mathrm{Co}_{2}$ ) to a $10 \%$ oxygen solution (equilibrated with $85 \% \mathrm{~N}_{2}, 5 \% \mathrm{Co}_{2}$ ) and after a 10-minute equilibration period, arteriolar diameters and blood flows were re-measured. In a separate experiments, arteriolar responsiveness to exogenous 20-HETE, ANG II or NE were determined (see above), with arteriolar diameters measured at rest and following a 10- minute equilibration period for each of the vasoconstrictors used.

\section{Assessement of the role of CYP450 $4 a \omega$-hydroxylase or $K_{C a}$ channels in arteriolar} responses to oxygen, 20-HETE, ANG II and NE

To determine the role of 20-HETE in oxygen-induced arteriolar constriction, we assessed arteriolar diameter and flow responses to $10 \%$ oxygen, as described above, before and after treatment with DDMS or 17-ODYA. The contribution of $\mathrm{K}_{\mathrm{Ca}}$ channels to the effects of 20-HETE on arteriolar diameter was assessed in a third group of experiments. In these studies, arteriolar diameters were measured at rest and after exogenous 20-HETE 
application, and then these measurements were repeated following addition of TEA to the superfusate. To assess the role of 20-HETE in the vasoconstrictor effects of ANG II and $\mathrm{NE}$, arteriolar diameters were measured before and after either ANG II $\left(1 \times 10^{-9}-1 \times 10^{-8}\right.$ $\mathrm{M})$ or NE $\left(1 \times 10^{-6}-1 \times 10^{-5} \mathrm{M}\right)$ was added to the bath. Following a washout period to allow for restoration of normal arteriolar tone, responses to the same concentrations of ANG II and NE were re-examined in the presence of DDMS.

At the end of all in vivo experiments, $1 \times 10^{-4} \mathrm{M}$ adenosine was added to the superfusate to abolish microvascular tone for measurement of passive arteriolar diameter.

\section{$\underline{\text { Data and Statistical Analysis }}$}

Arteriolar diameter $(\mathrm{D}, \mu \mathrm{m})$ and centerline red cell velocity $\left(\mathrm{V}_{\mathrm{cl}}, \mathrm{mm} / \mathrm{s}\right)$ were measured. Mean red cell velocity $\left(\mathrm{V}_{\text {mean }}\right)$ was calculated as $\mathrm{V}_{\mathrm{cl}} / 1.6$, where 1.6 is the ratio of centerline red cell velocity to mean velocity for vessels $>10 \mu \mathrm{m}$ in diameter (42) . Paired values of $\mathrm{D}$ and $\mathrm{V}_{\text {mean }}$ were used to calculate arteriolar volume flow $(\mathrm{Q}, \mathrm{nl} / \mathrm{s})$, where $Q=V_{\text {mean }}\left[\pi\left(D^{2} / 4\right]\right.$

All data are reported as means \pm SE. Statistical analysis was performed by commercially available software (Sigmastat, SPSS Inc., Chicago, IL). Two-way repeated measures ANOVA was used to determine the effects of diet, treatment and diet-treatment interactions on measured variables and Student's $t$-test were used for statistical comparisons between groups. For all ANOVA procedures, the Student-Newman-Keuls method for post hoc analysis was used to isolate pairwise differences among specific groups. Significance was assessed at the $95 \%$ confidence level $(\mathrm{P}<0.05)$ for all tests. 


\section{RESULTS}

The general characteristics of all rats used in this study are shown in Table 1. At the time of study, the body weight and mean arterial pressure of rats fed high salt were not significantly different from those of rats fed the normal diet. Table 2 displays the characteristics of all arterioles studied by in vivo microscopy in Protocols 1 and 2. Under control conditions, there were no significant differences between dietary groups in resting arteriolar diameter, volume flow or calculated vascular tone, or in passive arteriolar diameter measured after abolition of vascular tone with adenosine. Table 3 displays the effects of 17-ODYA and DDMS on resting arteriolar diameter and flow. Neither of these inhibitors had a significant effect on resting arteriolar diameter or flow in either group.

Arteriolar responses to an increase in oxygen availability are presented in Figure 1. An elevation in superfusate $\mathrm{PO}_{2}$ resulted in arteriolar constriction and a reduction in blood flow in both dietary groups. However, compared to the NS rats, these responses were significantly attenuated in the HS rats. The effects of inhibiting 20-HETE formation with 17-ODYA or DDMS on the responses to increased superfusate $\mathrm{PO}_{2}$ are illustrated in Figure 2. Despite having no effect on resting arteriolar tone, 17-ODYA and DDMS markedly decreased the oxygen-induced constriction and flow reduction in NS rats (Top panels). In contrast, neither of these inhibitors had an effect on arteriolar responses to increased superfusate $\mathrm{PO}_{2}$ in $\mathrm{HS}$ rats.

A representative CYP450 4A $\omega$-hydroxylase Western blot from spinotrapezius muscle protein is shown in Figure 3. Protein expression was detected at the 51-kDa band, which corresponds to the CYP450 4A protein. Densitometric analysis revealed no 
difference between dietary groups in the expression of CYP450 4A protein in whole muscle (Figure 3).

Figure 4 illustrates arteriolar diameter changes in response to various concentrations of exogenous 20-HETE. Exogenous 20-HETE elicited arteriolar constriction in both groups, but the magnitude of these responses was significantly less in rats fed high salt.

Under control conditions, resting arteriolar diameters were significantly reduced by the $\mathrm{K}_{\mathrm{Ca}}$ channel inhibitor TEA in both dietary groups (NS, pre-TEA: $21.0 \pm 0.5 \mu \mathrm{m}$, post-TEA: $15.6 \pm 1.4 \mu \mathrm{m} ; \mathrm{p}<0.05)(\mathrm{HS}$, pre-TEA: $20.5 \pm 0.5 \mu \mathrm{m}$, post-TEA: $14.7 \pm$ $1.2 \mu \mathrm{m} ; \mathrm{p}<0.05)$. The effects of TEA on arteriolar responses to exogenous 20-HETE are shown in Figure 5. TEA greatly reduced responses to $1 \times 10^{-8} \mathrm{M}$ 20-HETE in the NS rats, but had no effect on these responses in the HS rats.

There was no significant difference in arteriolar responsiveness to ANG II between the dietary groups (Figure 6). In the presence of DDMS, these responses were consistently decreased in the normal salt group. The effect of DDMS on these responses was markedly less in the HS group, with a significant inhibition observed only at the lower concentration of ANG II.

At the higher concentration, arteriolar responsiveness to NE was greater in $\mathrm{HS}$ rats than in NS rats (Figure 7), but inhibition of 20-HETE formation with DDMS had no significant effect on these responses in either group, with the exception of a modest reduction in responses to the higher concentration of $\mathrm{NE}$ in the $\mathrm{HS}$ rats. 
Table 1: Profiles of all experimental animals at time of study

\begin{tabular}{|c|c|c|c|}
\hline $\begin{array}{l}\text { etary } \\
\text { oup }\end{array}$ & $\mathrm{N}$ & $\begin{array}{l}\text { Weight } \\
\text { (g) }\end{array}$ & $\begin{array}{l}\text { Mean Arterial } \\
\text { Pressure }(\mathrm{mm} \mathrm{Hg})\end{array}$ \\
\hline
\end{tabular}

$\begin{array}{llll}\text { Normal Salt } & 35 & 291 \pm 4 & 121 \pm 3\end{array}$

$\begin{array}{llll}\text { High Salt } \quad 34 & 292 \pm 4 & 124 \pm 3\end{array}$

$\mathrm{N}$, number of animals. Values are given as mean \pm SE. 
Table 2: Arteriolar characteristics at time of study

\begin{tabular}{lllll}
\hline \hline Dietary Group & $\begin{array}{l}\text { Resting } \\
\text { Diameter } \\
(\mu \mathrm{m})\end{array}$ & $\begin{array}{l}\text { Passive } \\
\text { Diameter } \\
(\mu \mathrm{m})\end{array}$ & $\begin{array}{l}\text { Vascular Tone } \\
(\% \text { of } \\
\text { Maximum })\end{array}$ & $\begin{array}{c}\text { Resting Volume Flow } \\
(\mathrm{n} 1 / \mathrm{s})\end{array}$ \\
\hline Normal Salt & $20.4 \pm 0.5$ & $60.1 \pm 2.5$ & $64.1 \pm 1.6$ & $1.9 \pm 0.2$ \\
High Salt & $20.0 \pm 0.4$ & $54.4 \pm 2.1$ & $60.9 \pm 1.9$ & $1.9 \pm 0.2$ \\
& & & & \\
\hline
\end{tabular}

Values are given as mean \pm SE. For Normal Salt Group, $n=93$ vessels for Resting Diameter, 62 vessels for Passive Diameter and Vascular Tone, and 65 vessels for Resting Volume Flow. For High Salt Group, $\mathrm{n}=100$ vessels for Resting Diameter, 61 vessels for Passive Diameter and Vascular Tone, and 59 vessels for Resting Volume Flow. 
Table 3: Effect of ODYA and DDMS on Resting Arteriolar Diameter and Flow $\underline{\text { Diameter }(\mu \mathrm{m})} \quad \underline{\text { Flow }(\mathrm{nl} / \mathrm{s})}$

\begin{tabular}{ccccc} 
& Normal Salt & High Salt & Normal Salt & High Salt \\
\hline Control & $22.6 \pm 1.4$ & $18.6 \pm 1.0$ & $1.8 \pm 0.3$ & $1.8 \pm 0.2$ \\
$\begin{array}{c}\text { ODYA } \\
(10 \mu \mathrm{M})\end{array}$ & $22.2 \pm 1.4$ & $20.6 \pm 1.5$ & $2.0 \pm 0.4$ & $2.4 \pm 0.2$ \\
\hline Control & $17.9 \pm 0.2$ & $16.0 \pm 0.3$ & $1.2 \pm 0.1$ & $1.2 \pm 0.3$ \\
$\begin{array}{c}\text { DDMS } \\
(50 \mu \mathrm{M})\end{array}$ & $17.5 \pm 0.8$ & $16.9 \pm 1.0$ & $1.1 \pm 0.2$ & $1.0 \pm 0.2$
\end{tabular}

Values are given as mean \pm SE. For ODYA effect, $n=16$ vessels for Normal Salt group and 9 vessels for High Salt group. For DDMS effect, $\mathrm{n}=9$ vessels for Normal Salt group and 7 vessels for High Salt group. 


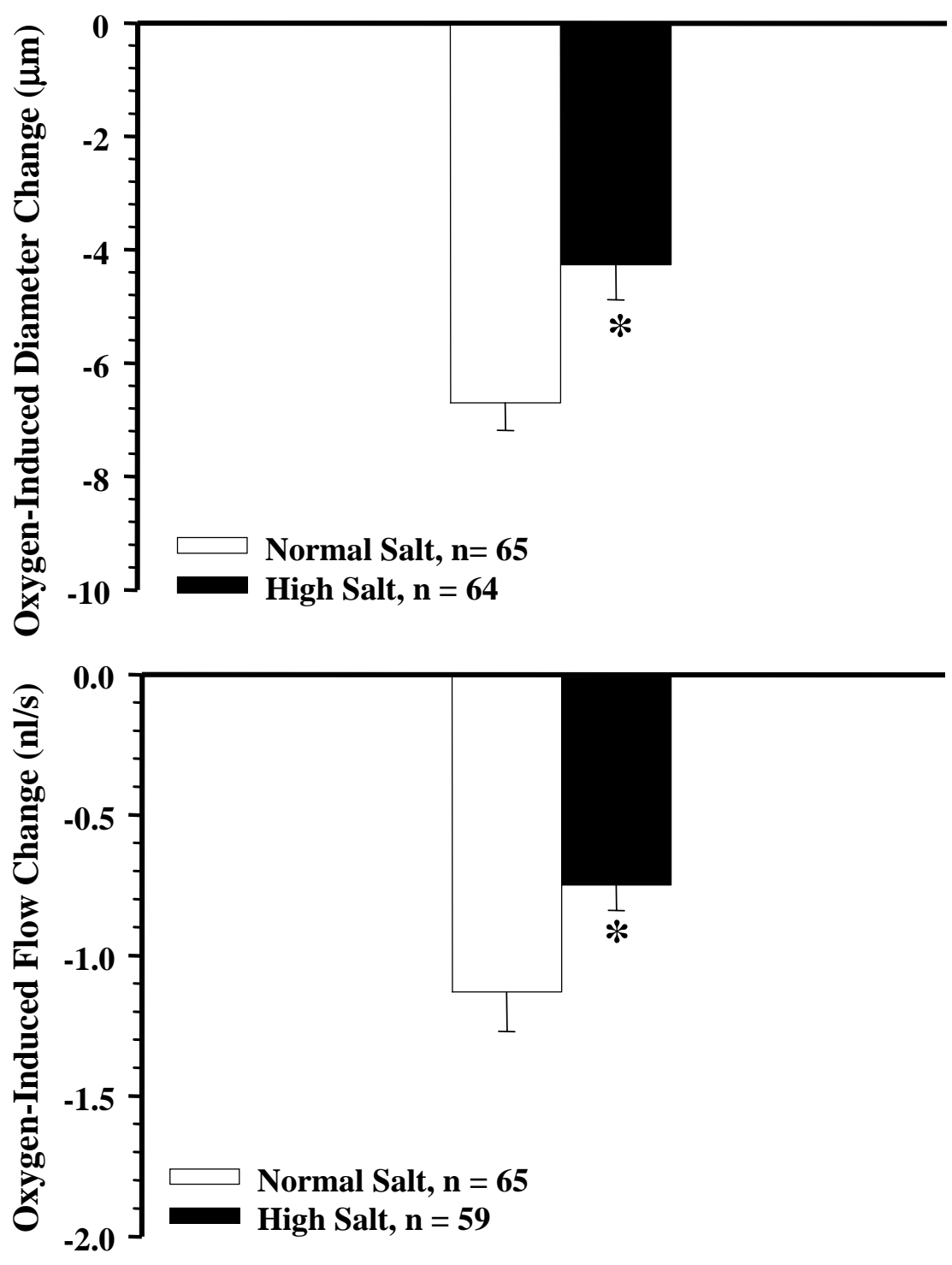

Figure 1. Changes in arteriolar diameter (Top) and flow (Bottom) to an increase in superfusate $\mathrm{O}_{2}$ concentration (10\%) in rats fed normal salt and high salt diets. $\mathrm{n}=$ number of vessels. $* \mathrm{p}<0.05$ vs. Normal Salt. 


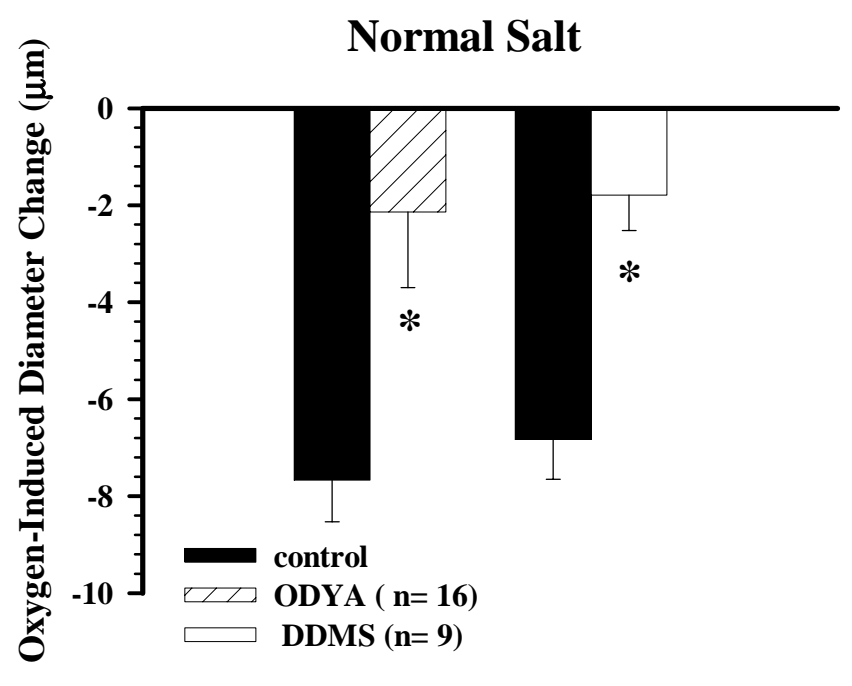

Normal Salt

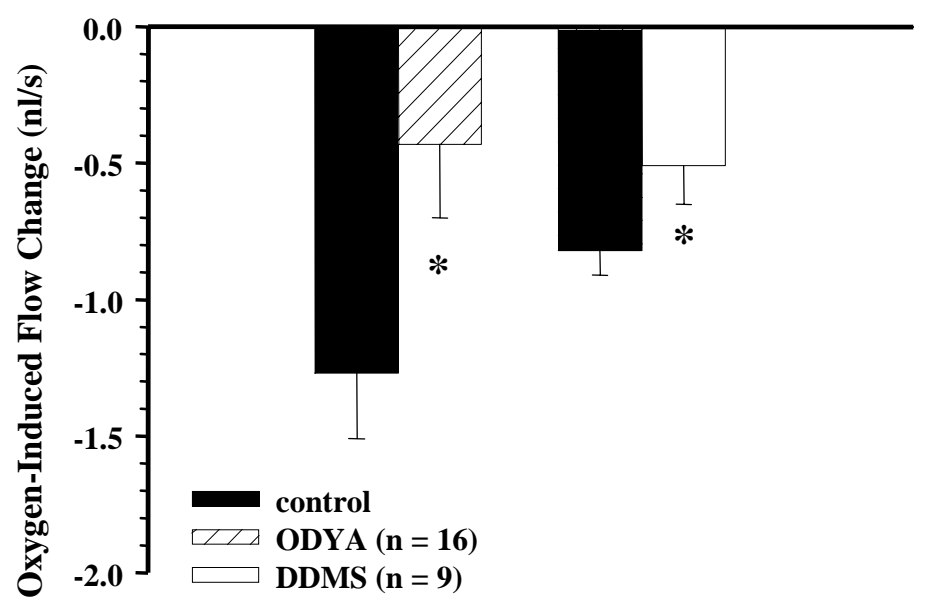

High Salt

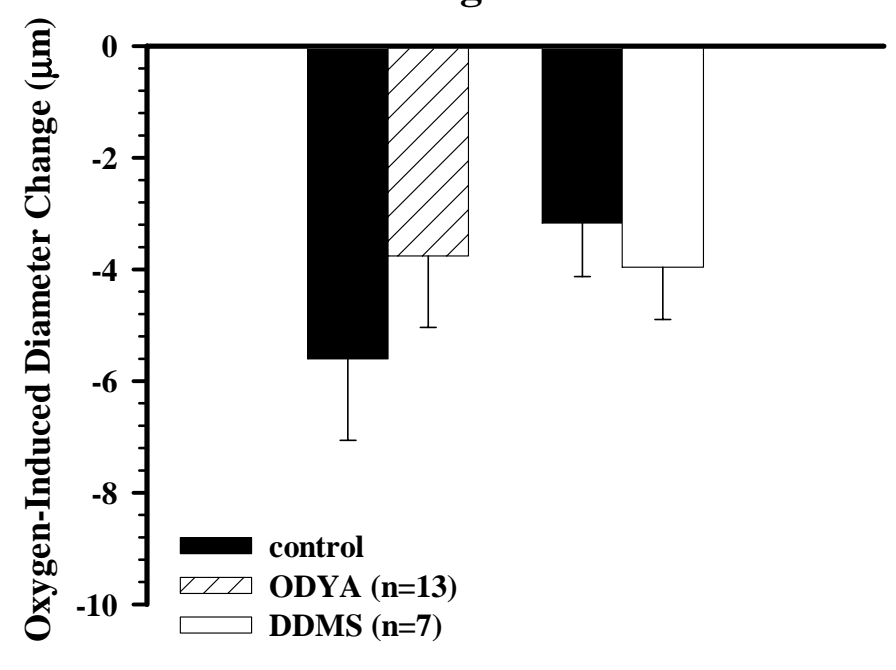

High Salt

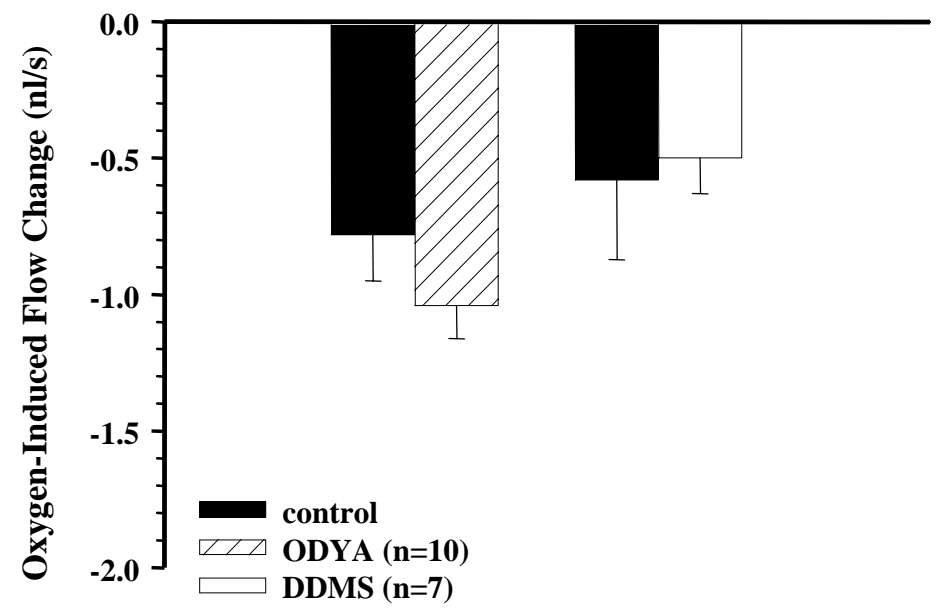

Figure 2. Effects of 17-ODYA and DDMS on arteriolar diameter and flow responses to an elevation in superfusate $\mathrm{O}_{2}$ concentration (10\%) in rats fed normal salt (top panels) and high salt (bottom panels) diet. $\mathrm{n}=$ number of vessels. ${ }^{*} \mathrm{p}<0.05$ vs. Control. 


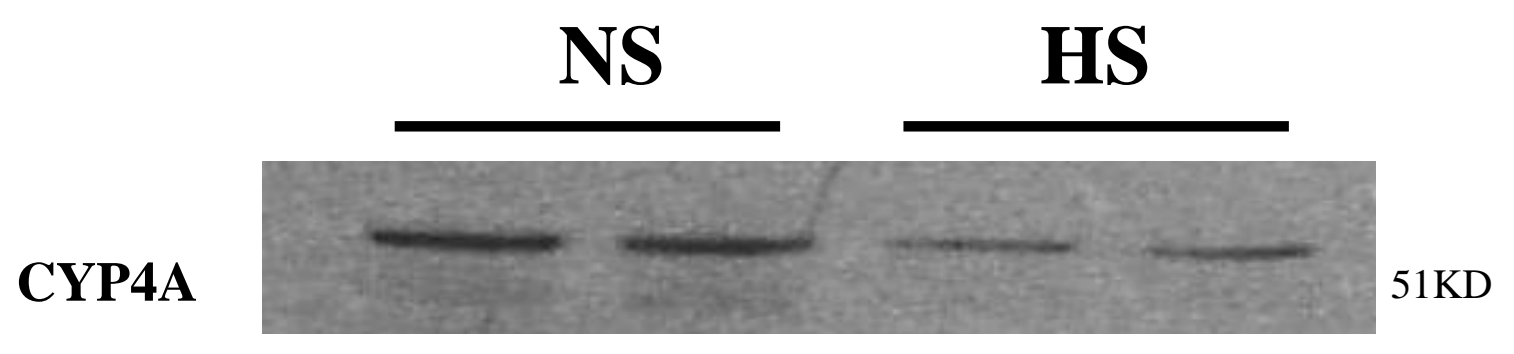

GAPDH

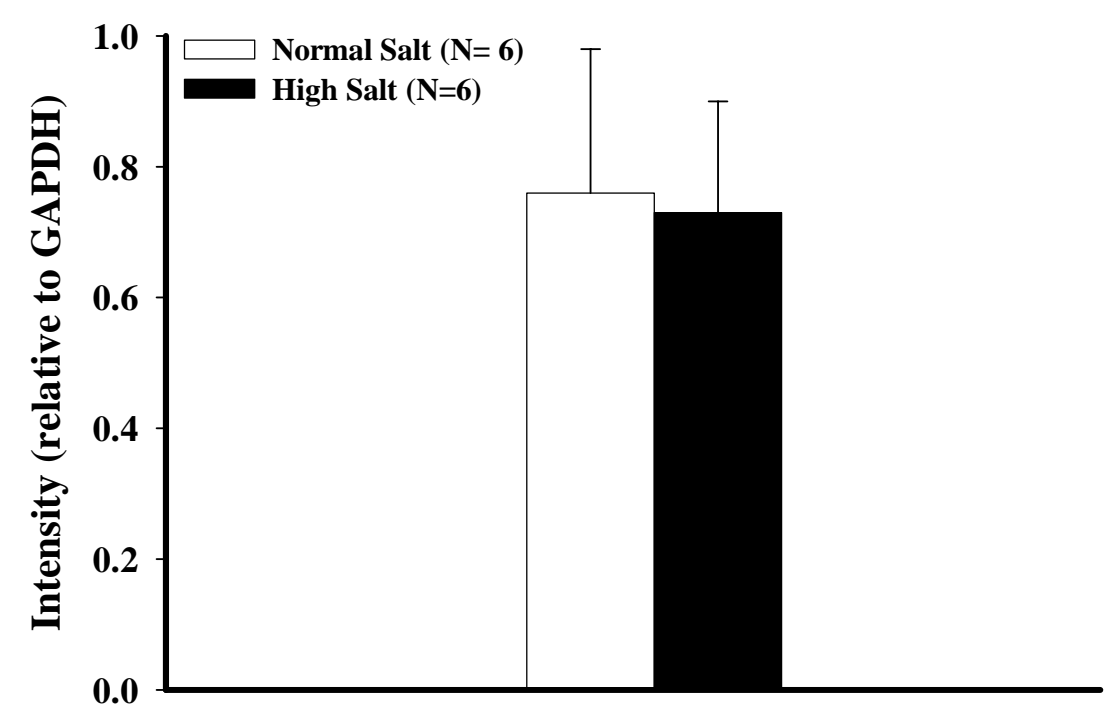

Figure 3. Western Blot expression of 51-kDa CYP450 4A protein in spinotrapezius muscle of Normal Salt (NS) and High Salt (HS) rats (top). Densitometric CYP450 4A band intensity is expressed as a percentage of the loading control protein (GAPDH) (bottom). $\mathrm{N}=$ number of rats. 


\section{0-HETE Concentration (M)}

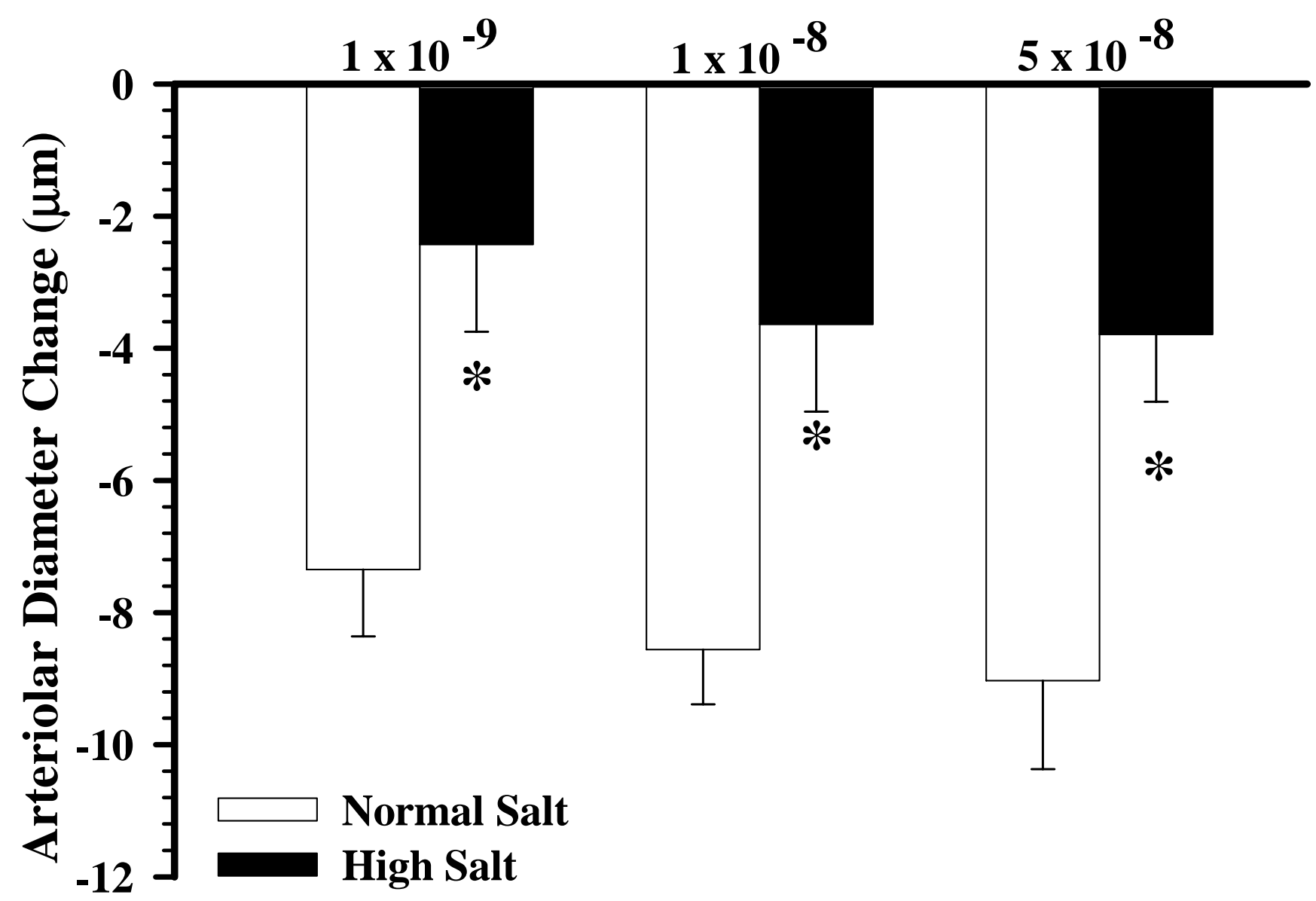

Figure 4. Changes in arteriolar diameter with 20-HETE application in rats fed normal salt and high salt diets. Normal Salt: $\mathrm{n}=8$ for $1 \times 10^{-9} \mathrm{M}$ and $1 \times 10^{-8} \mathrm{M}, \mathrm{n}=9$ for $5 \times 10^{-8} \mathrm{M}$. High Salt: $\mathrm{n}=8$ for $1 \times 10^{-9} \mathrm{M}$ and $1 \times 10^{-8} \mathrm{M}$, and $\mathrm{n}=10$ for $5 \times 10^{-8} \mathrm{M}$. $\mathrm{n}=$ number of vessels. 
Normal Salt High Salt

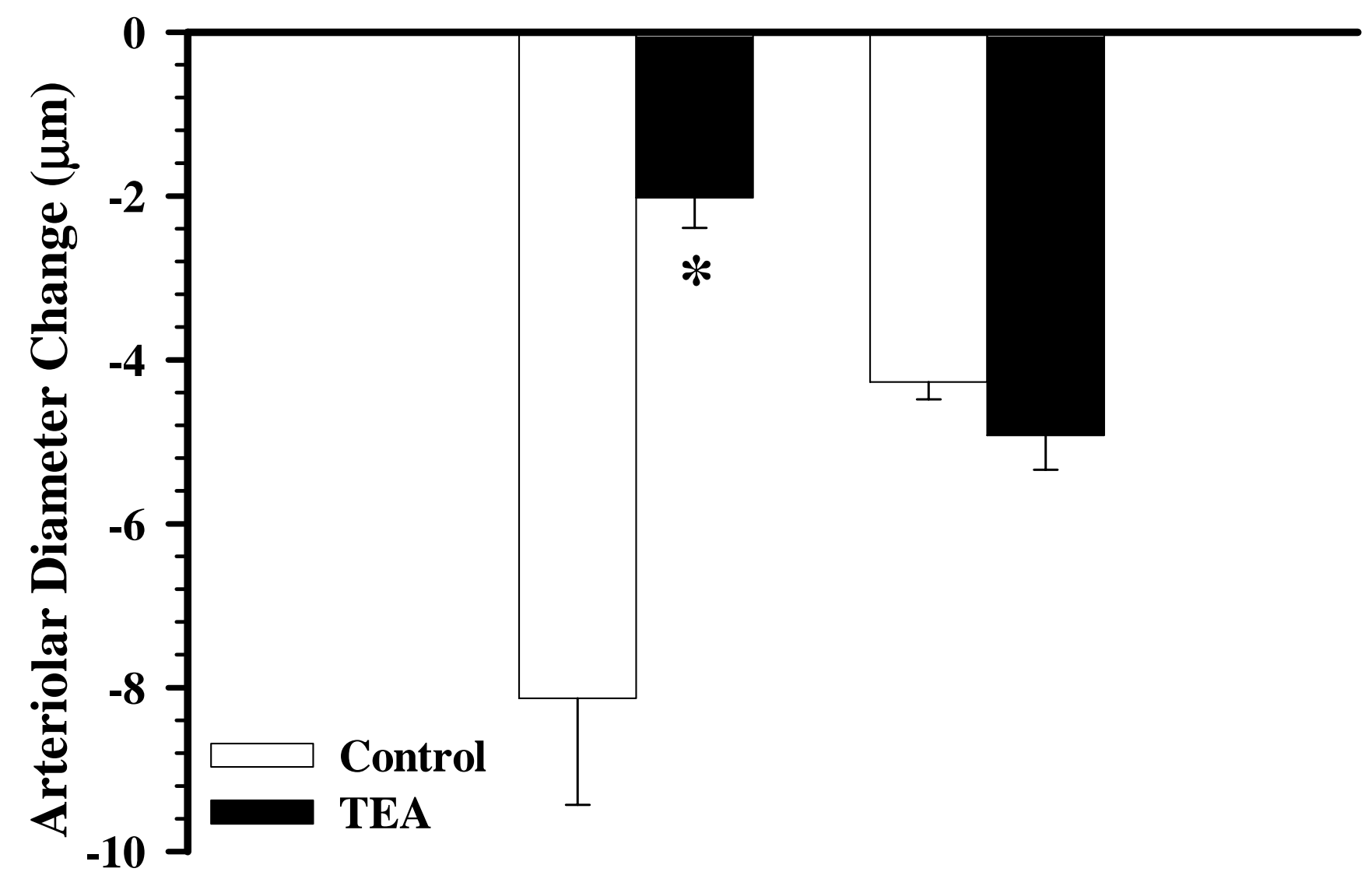

Figure 5. Effect of TEA on arteriolar responses to $1 \times 10^{-8} \mathrm{M}$ 20-HETE in rats fed normal salt and high salt diets. $\mathrm{n}=4$ vessels for rats fed each diet. $* \mathrm{p}<0.05$ vs. Control. 


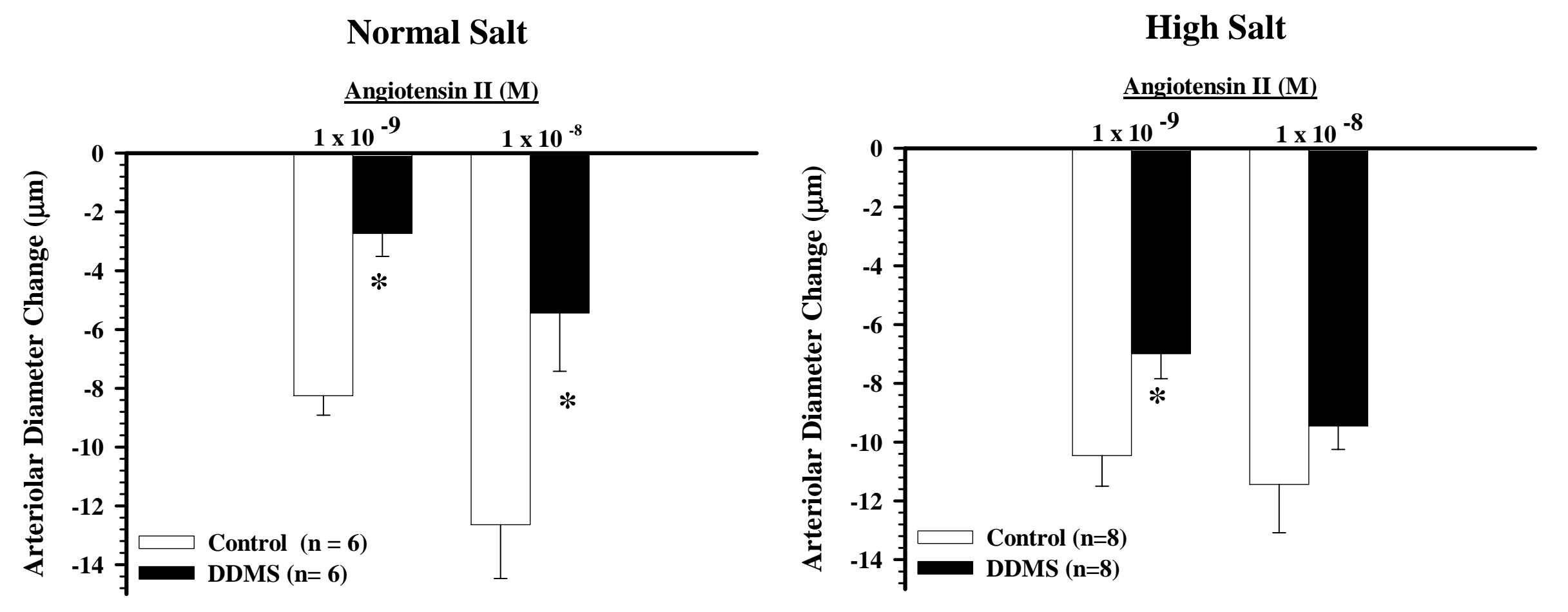

Figure 6. Effect of DDMS on arteriolar responses to angiotensin II in rats fed normal salt (left panel) and high salt (right panel) diet. $\mathrm{n}=$ number of vessels. $* \mathrm{p}<0.05$ vs. Control. 
Normal Salt

Norepinephrine (M)

$1 \times 10^{-6} \quad 1 \times 10^{-5}$

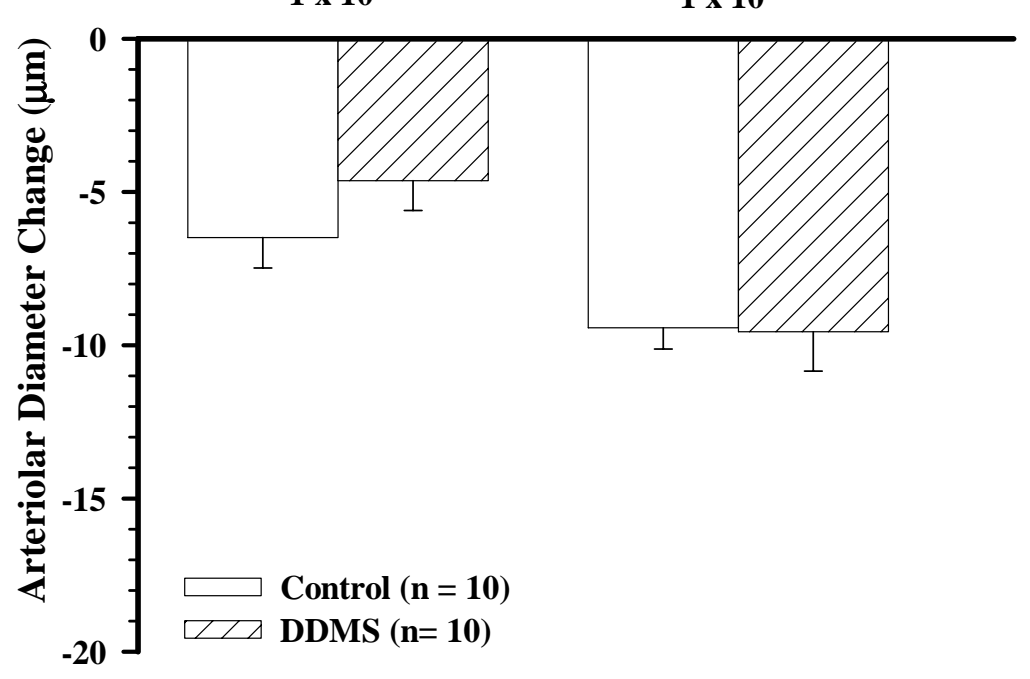

High Salt

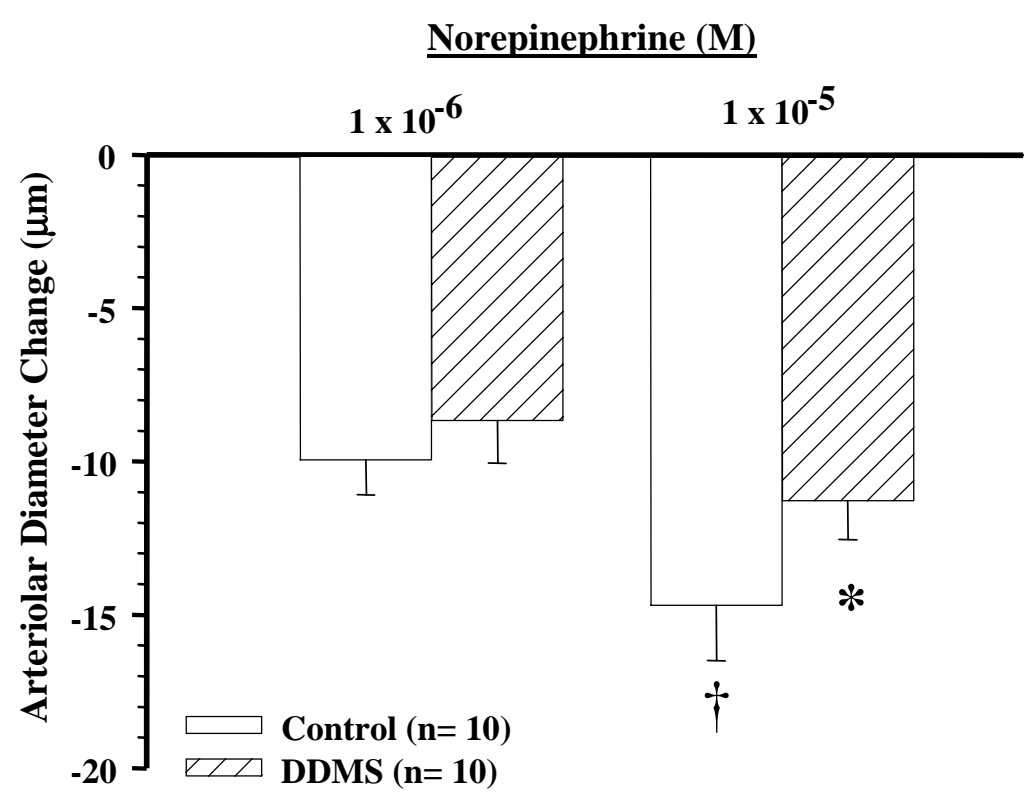

Figure 7. Effect of DDMS on arteriolar responses to norepinephrine in rats fed normal salt (left panel) and high salt (right panel) diet. $\mathrm{n}=$ number of vessels. $* \mathrm{p}<0.05$ vs. Control; $\dagger \mathrm{p}<0.05$ vs. Normal Salt. 


\section{DISCUSSION}

The major findings in this study are as follows: (1) Long-term (4-weeks) ingestion of a high salt diet attenuates the arteriolar constriction and blood flow reduction that occurs in response to increased oxygen levels in skeletal muscle. (2) Inhibition of CYP450 4A $\omega$-hydroxylase reduces these responses to oxygen in rats fed a normal diet, but not in rats fed a high salt diet. (3) Arteriolar responsiveness to exogenous 20-HETE is reduced and insensitive to $\mathrm{K}_{\mathrm{Ca}}$ channel inhibition in rats fed high salt. (4) Arteriolar responsiveness to ANG II is similar in rats fed normal and high salt diets, but CYP450 4A $\omega$-hydroxylase inhibition is less effective in reducing these responses in rats fed high salt. These findings suggest that independent of a change in blood pressure, a high salt diet impairs arteriolar responses to an increase in oxygen availability, and that this is due to a reduction in the contribution of 20-HETE to arteriolar constriction.

In a recent study, we have reported that ingestion of a high salt diet leads to a blunting of the proximal arteriolar dilation that accompanies contraction of rat spinotrapezius muscle (29). We have also recently obtained evidence that $\mathrm{H}_{2} \mathrm{O}_{2}$ released from the contracting muscle fibers, is one of the key vasoactive metabolites that contributes to this arteriolar dilation (28). However, because this contribution of $\mathrm{H}_{2} \mathrm{O}_{2}$ to the arteriolar dilation is not diminished by high salt intake, another mechanism unrelated to $\mathrm{H}_{2} \mathrm{O}_{2}$ must be responsible for the salt-dependent decrease in functional arteriolar dilation. A reduction in local oxygen levels can also contribute to the arteriolar dilation associated with muscle contraction $(5,13,32)$, either directly if arteriolar wall $\mathrm{PO}_{2}$ declines during muscle contraction, or indirectly via vasoactive mediators produced in response to a $\mathrm{PO}_{2}$ reduction in nearby parenchymal cells or closely paired venules 
$(21,33)$. Because the salt-induced blunting of functional dilation could reflect altered arteriolar responsiveness to such changes in local oxygen, one aim of this study was to examine the effects of a high salt diet on arteriolar oxygen responsiveness. Short-term and long-term high salt intake (from 3 days to as long as 8 weeks) has been found to impair the hypoxic dilation of small gracilis muscle feed arteries in normotensive rats $(12,24,37)$, and in the current study we have found that 4 weeks of high salt intake also impairs the constriction of spinotrapezius muscle arterioles in response to increased oxygen levels (Figure 1).

In the exteriorized rat spinotrapezius muscle, an increase in superfusate oxygen content from $0 \%$ to $10 \%$ increases arcade arteriole wall $\mathrm{PO}_{2}$ from $42 \pm 8 \mathrm{mmHg}$ to $66 \pm 6$ $\mathrm{mmHg}$, values that are considered to be within the normal physiological range (21). In the current study, the same increase in superfusate oxygen content decreased arcade arteriole diameter and volume flow in rats fed both diets, but these responses were significantly less in rats fed the high salt diet (Fig 1). These data are consistent with the hypothesis that reduced arteriolar dilation during skeletal muscle contraction in rats fed high salt is due in part to reduced responsiveness to changes in oxygen availability (29). In contrast, Frisbee et al. (2000) found that the oxygen-induced arteriolar constriction is similar in skeletal muscle (cremaster) of rats fed $4 \%$ and $0.4 \%$ salt for 3 days. The current findings indicate that in contrast to the larger upstream arterioles a more prolonged intake of this level of salt is required to influence arteriolar oxygen responsiveness.

In rat cremaster muscle, oxygen-induced arteriolar constriction is mediated in large part by the CYP450 4A $\omega$-hydroxylase metabolite 20-HETE $(8,11,15,19,26)$. An 
increased contribution of 20-HETE to this constriction also appears to be at least partially responsible for the enhanced responsiveness of these arterioles to increased oxygen availability in hypertensive rat models $(8,20)$. Because less is known regarding the possible role of 20-HETE in the abnormal arteriolar responses in normotensive rats fed a high salt diet, the second aim of this study was to determine if oxygen-induced arteriolar constriction in the rat spinotrapezius muscle is also dependent on CYP450 4A $\omega$ hydroxylase activity, and if so, to determine if a high salt diet alters this pathway. The results of this study show that under normal conditions, the oxygen-induced constriction of spinotrapezius muscle arterioles is substantially reduced following inhibition of 20HETE formation with either 17-ODYA or DDMS. This is consistent with earlier findings in rat and hamster cremaster muscle $(8,11,15,19,26)$ and hamster retractor muscle (26), and strongly suggests that 20-HETE may play a universal role in mediating arteriolar oxygen responsiveness across different muscle types and species. Our Western analysis suggests that CYP450 4A $\omega$-hydroxylase is expressed in the arterioles (data not shown) as well as skeletal muscle fibers (Figure 3) of both dietary groups, suggesting that the arteriolar response to increased oxygen can be mediated via 20-HETE from CYP450 4A $\omega$-hydroxylase in the arterioles themselves and/or the surrounding skeletal muscle fibers. These results are also consistent with previous findings in the rat cremaster muscle (19).

In contrast, neither 17-ODYA nor DDMS had any effect on oxygen-induced arteriolar constriction or the accompanying flow reduction in rats fed high salt (Figure 2), suggesting a loss of 20-HETE's constriction to these responses. This effect could be due to: (1) a decrease in CYP450 4A $\omega$-hydroxylase enzyme expression and/or activity, 
leading to decreased 20-HETE formation, and/or (2) a reduction in vascular smooth muscle sensitivity to the 20-HETE that is formed. With respect to the first possibility, we did not detect differences between the dietary groups in overall skeletal muscle expression of CYP450 4A $\omega$-hydroxylase, but we are not able to rule out the possibility of salt-dependent differences in enzyme expression within the microvessels themselves. However, our findings clearly support the second possibility, in that compared to arterioles in normal salt rats, the constriction in response to exogenous 20-HETE was greatly reduced (Figure 4). To our knowledge this effect of a high salt diet on arteriolar smooth muscle responsiveness to 20 -HETE has not been previously evaluated. In contrast, Frisbee et al. (2000) did not find a reduced contribution of 20-HETE to oxygeninduced constriction of skeletal muscle arterioles in rats fed a high salt diet for 3 days. Therefore, as with the overall responsiveness to oxygen, a more chronic HS diet is necessary to induce this effect. 20-HETE influences vascular tone in part by inhibiting the activity of large-conductance $\mathrm{K}_{\mathrm{Ca}}$ channels in vascular smooth muscle leading to membrane depolarization and subsequent influx of calcium via L-type voltage-sensitive calcium channels $(2,14,40)$. In the current study, we found that blockade of large conductance $\mathrm{K}_{\mathrm{Ca}}$ channels with TEA decreased resting arteriolar diameters by a similar amount in both dietary groups, indicating a similar contribution of these channels to resting vascular tone. However, whereas TEA dramatically reduced the vasoconstrictor responses to exogenous 20-HETE in rats fed normal salt, it had no effect of the responses to 20-HETE in rats fed high salt (Figure 5). This lack of an effect of TEA in high salt rats suggests that the reduced vasoconstriction to exogenous 20-HETE in these animals is due to a loss of the $\mathrm{K}_{\mathrm{Ca}}$ channel-dependent component of the response. It is unlikely that 
the absence of this component is due to a general resistance of $\mathrm{K}_{\mathrm{Ca}}$ channels to inhibition in high salt rats; previous studies have documented that $\mathrm{K}^{+}$channel function and resting vascular smooth muscle membrane potential are not altered by high salt intake in normotensive rats $(12,27)$, and we found no difference between groups in the effect of TEA on resting arteriolar tone. Therefore, high salt intake must lead to a disruption of some 20 -HETE signaling event subsequent to $\mathrm{K}_{\mathrm{Ca}}$ channel inhibition and membrane depolarization.

Previous studies indicate that vascular smooth muscle responsiveness to ANG II is partly mediated via 20-HETE formation in rat renal interlobular arteries and afferent arterioles $(3,6,16)$ and rat cremaster muscle arterioles (8). In this study, ANG II-induced vasoconstriction was similar in both dietary groups (Fig 5). This is consistent with a previous report that cremaster muscle arterioles in rats fed $4 \%$ salt for the same duration as in the current study do not show a change in responsiveness to ANG II (36). However, gracilis muscle resistance arteries from these animals exhibit an enhanced responsiveness to ANG II, possibly due to an upregulation of ANG II receptors triggered by the saltdependent reduction in circulating ANG II (34). If this is truly the mechanism of this increased ANG II responsiveness, then the absence of such changes in the downstream arterioles could reflect a difference in the relative distribution of ANG II receptor subtypes between the microcirculation and the more proximal arteries (23). Whereas inhibition of 20-HETE formation with DDMS reduced arteriolar constriction to ANG II in both groups, this effect was less in the high salt rats (Figure 6). These data suggest that as in cremaster muscle and kidney, ANG II-induced arteriolar constriction in the 
spinotrapezius muscle is partly dependent on the 20-HETE pathway, although this component of the pathway is reduced in rats fed high salt.

The contractile effect of NE is also partly mediated by 20 -HETE formation in rat mesenteric resistance arteries (35) and rabbit aortic smooth muscle cells (18). However, inhibition of 20-HETE formation did not consistently affect NE-induced arteriolar constriction in the spinotrapezius muscle of rats on either diet (Figure 7), suggesting that there could be differences in the mechanism of adrenergic constriction between arterioles and upstream arteries and are thought to contribute to the reduced hypoxic dilation that is present in these rats .

In conclusion, the present study clearly demonstrates that 20-HETE plays an important role in the oxygen-induced constriction of rat spinotrapezius muscle arterioles and in contrast to previous findings after 3 days of high salt intake, a 4-5 week period of high salt intake leads to an attenuation of this response, largely through a reduction in the intrinsic responsiveness of arteriolar smooth muscle to 20-HETE. These findings raise the possibility that the reduced arteriolar dilation during skeletal muscle contraction may be due to the impaired arteriolar oxygen sensitivity in high salt-fed rats. 


\section{References}

\section{Alonso-Galicia M, Drummond HA, Reddy KK, Falck JR and Roman RJ.} Inhibition of 20-HETE production contributes to the vascular responses to nitric oxide. Hypertension 29: 320-325, 1997.

2. Alonso-Galicia M, Falck JR, Reddy KM and Roman RJ. 20-HETE agonists and antagonists in the renal circulation. Am J Physiol 277: F790-F796, 1999.

3. Alonso-Galicia M, Maier KG, Greene AS, Cowley AW, Jr. and Roman RJ. Role of 20-hydroxyeicosatetraenoic acid in the renal and vasoconstrictor actions of angiotensin II. Am J Physiol Regul Integr Comp Physiol 283: R60-R68, 2002.

4. Boegehold MA. Flow-dependent arteriolar dilation in normotensive rats fed lowor high-salt diets. Am J Physiol 269: H1407-H1414, 1995.

5. Boegehold MA and Bohlen HG. Arteriolar diameter and tissue oxygen tension during muscle contraction in hypertensive rats. Hypertension 12: 184-191, 1988.

6. Croft KD, McGiff JC, Sanchez-Mendoza A and Carroll MA. Angiotensin II releases 20-HETE from rat renal microvessels. Am J Physiol Renal Physiol 279: F544-F551, 2000.

7. Duling BR. Microvascular responses to alterations in oxygen tension. Circ Res 31: 481-489, 1972. 
8. Frisbee JC, Falck JR and Lombard JH. Contribution of cytochrome P-450 omega-hydroxylase to altered arteriolar reactivity with high-salt diet and hypertension. Am J Physiol Heart Circ Physiol 278: H1517-H1526, 2000.

9. Frisbee JC, Krishna UM, Falck JR and Lombard JH. Role of prostanoids and 20-HETE in mediating oxygen-induced constriction of skeletal muscle resistance arteries. Microvasc Res 62: 271-283, 2001.

10. Frisbee JC and Lombard JH. Reduced renal mass hypertension, but not high salt diet, alters skeletal muscle arteriolar distensibility and myogenic responses. Microvasc Res 59: 255-264, 2000.

11. Frisbee JC and Lombard JH. Parenchymal tissue cytochrome P450 4A enzymes contribute to oxygen-induced alterations in skeletal muscle arteriolar tone. Microvasc Res 63: 340-343, 2002.

12. Frisbee JC, Sylvester FA and Lombard JH. High-salt diet impairs hypoxiainduced cAMP production and hyperpolarization in rat skeletal muscle arteries. Am J Physiol Heart Circ Physiol 281: H1808-H1815, 2001.

13. Gorczynski RJ and Duling BR. Role of oxygen in arteriolar functional vasodilation in hamster striated muscle. Am J Physiol 235: H505-H515, 1978. 


\section{Harder DR, Gebremedhin D, Narayanan J, Jefcoat C, Falck JR, Campbell} WB and Roman R. Formation and action of a P-450 4A metabolite of arachidonic acid in cat cerebral microvessels. Am J Physiol 266: H2098-H2107, 1994.

15. Harder DR, Narayanan J, Birks EK, Liard JF, Imig JD, Lombard JH, Lange AR and Roman RJ. Identification of a putative microvascular oxygen sensor. Circ Res 79: 54-61, 1996.

16. Imig JD and Deichmann PC. Afferent arteriolar responses to ANG II involve activation of PLA2 and modulation by lipoxygenase and P-450 pathways. Am J Physiol 273: F274-F282, 1997.

17. Jackson WF and Duling BR. The oxygen sensitivity of hamster cheek pouch arterioles. In vitro and in situ studies. Circ Res 53: 515-525, 1983.

18. Kalyankrishna $\mathbf{S}$ and Malik KU. Norepinephrine-induced stimulation of p38 mitogen-activated protein kinase is mediated by arachidonic acid metabolites generated by activation of cytosolic phospholipase $\mathrm{A}(2)$ in vascular smooth muscle cells. J Pharmacol Exp Ther 304: 761-772, 2003.

\section{Kunert MP, Roman RJ, Alonso-Galicia M, Falck JR and Lombard JH.}

Cytochrome P-450 omega-hydroxylase: a potential $\mathrm{O}_{(2)}$ sensor in rat arterioles and skeletal muscle cells. Am J Physiol Heart Circ Physiol 280: H1840-H1845, 2001. 
20. Kunert MP, Roman RJ, Falck JR and Lombard JH. Differential effect of cytochrome $\mathrm{P}-450$ omega-hydroxylase inhibition on $\mathrm{O}_{2}$-induced constriction of arterioles in SHR with early and established hypertension. Microcirculation 8: 435-443, 2001.

21. Lash JM and Bohlen HG. Perivascular and tissue $\mathrm{PO}_{2}$ in contracting rat spinotrapezius muscle. Am J Physiol 252: H1192-H1202, 1987.

22. Linderman JR and Boegehold MA. Arteriolar network growth in rat striated muscle during juvenile maturation. Int J Microcirc Clin Exp 16: 232-239, 1996.

23. Linderman JR and Greene AS. Distribution of angiotensin II receptor expression in the microcirculation of striated muscle. Microcirculation 8: 275$281,2001$.

24. Liu Y, Fredricks KT, Roman RJ and Lombard JH. Response of resistance arteries to reduced $\mathrm{PO}_{2}$ and vasodilators during hypertension and elevated salt intake. Am J Physiol 273: H869-H877, 1997.

25. Lombard JH, Frisbee JC, Roman RJ and Falck JR. Evaluation of cytochrome P450-4A omega-hydroxylase and 20-hydroxyeicosatetraenoic acid as an $\mathrm{O}_{2}$ sensing mechanism in the microcirculation. Methods Enzymol 381: 140-165, 2004. 


\section{Lombard JH, Kunert MP, Roman RJ, Falck JR, Harder DR and Jackson}

WF. Cytochrome P-450 omega-hydroxylase senses $\mathrm{O}_{2}$ in hamster muscle, but not cheek pouch epithelium, microcirculation. Am J Physiol 276: H503-H508, 1999.

27. Lombard JH, Sylvester FA, Phillips SA and Frisbee JC. High-salt diet impairs vascular relaxation mechanisms in rat middle cerebral arteries. Am J Physiol Heart Circ Physiol 284: H1124-H1133, 2003.

28. Marvar PJ and Boegehold MA. Dietary salt reduces hydrogen peroxidedependent dilation in contracting muscle . FASEB J (Abstract) 20: A268, 2006.

29. Marvar PJ, Nurkiewicz TR and Boegehold MA. Reduced arteriolar responses to skeletal muscle contraction after ingestion of a high salt diet. J Vasc Res 42: 226-236, 2005.

30. Nelson MT and Quayle JM. Physiological roles and properties of potassium channels in arterial smooth muscle. Am J Physiol 268: C799-C822, 1995.

31. Nurkiewicz TR and Boegehold MA. High dietary salt alters arteriolar myogenic responsiveness in normotensive and hypertensive rats. Am J Physiol 275: H2095H2104, 1998. 
32. Proctor KG, Damon DN and Duling BR. Tissue $\mathrm{PO}_{2}$ and arteriolar responses to metabolic stimuli during maturation of striated muscle. Am J Physiol 241: H325H331, 1981.

33. Tominaga S, Suzuki T and Nakamura T. Evaluation of roles of potassium, inorganic phosphate, osmolarity, $\mathrm{pH}, \mathrm{pCO} 2, \mathrm{pO}_{2}$, and adenosine or AMP in exercise and reactive hyperemias in canine hindlimb muscles. Tohoku J Exp Med 109: 347-363, 1973.

34. Wang DH and Du Y. Regulation of vascular type 1 angiotensin II receptor in hypertension and sodium loading: role of angiotensin II. J Hypertens 16: 467-475, 1998.

35. Wang J, Roman RJ, Falck JR, de la CL and Lombard JH. Effects of high-salt diet on CYP450-4A omega-hydroxylase expression and active tone in mesenteric resistance arteries. Am J Physiol Heart Circ Physiol 288: H1557-H1565, 2005.

36. Weber DS, Frisbee JC and Lombard JH. Selective potentiation of angiotensininduced constriction of skeletal muscle resistance arteries by chronic elevations in dietary salt intake. Microvasc Res 57: 310-319, 1999.

37. Weber DS and Lombard JH. Elevated salt intake impairs dilation of rat skeletal muscle resistance arteries via ANG II suppression. Am J Physiol Heart Circ Physiol 278: H500-H506, 2000. 
38. Weber DS and Lombard JH. Angiotensin II AT1 receptors preserve vasodilator reactivity in skeletal muscle resistance arteries. Am J Physiol Heart Circ Physiol 280: H2196-H2202, 2001.

\section{Zhu D, Birks EK, Dawson CA, Patel M, Falck JR, Presberg K, Roman RJ} and Jacobs ER. Hypoxic pulmonary vasoconstriction is modified by P-450 metabolites. Am J Physiol Heart Circ Physiol 279: H1526-H1533, 2000.

40. Zou AP, Fleming JT, Falck JR, Jacobs ER, Gebremedhin D, Harder DR and Roman RJ. 20-HETE is an endogenous inhibitor of the large-conductance $\mathrm{Ca}(2+)$-activated $\mathrm{K}+$ channel in renal arterioles. Am J Physiol 270: R228-R237, 1996.

\section{Zou AP, Ma YH, Sui ZH, Ortiz de Montellano PR, Clark JE, Masters BS} and Roman RJ. Effects of 17-octadecynoic acid, a suicide-substrate inhibitor of cytochrome $\mathrm{P} 450$ fatty acid omega-hydroxylase, on renal function in rats. $J$ Pharmacol Exp Ther 268: 474-481, 1994.

42. Zweifach BW and Lipowsky HH. Pressure-flow relations in blood and lymph microcirculation. In: Handbook of Physiology, The Cardiovascular System: Microcirculation, edited by Renkin EM and Michel CC. Bethesda, MD: American Physiological Society, 1984, p. 251-308. 


\section{GENERAL DISCUSSION}

The overall goal of this dissertation project was to investigate the impact of dietary salt on mechanisms of local blood flow regulation in normotensive rats. This study was focused on examining the effects of dietary salt on functional hyperemia and oxygendependent control of arteriolar tone and was also undertaken to further elucidate the role(s) of reactive oxygen species (ROS) and 20-HETE in these processes.

Functional hyperemia is a complex hemodynamic phenomenon that is dependent on the integration of various mechanisms of local blood flow control serving to meet the metabolic needs of the tissue (Clifford \& Hellsten, 2004). A high salt (HS) diet has been previously shown to impair elements of microvascular function such as the dilation of skeletal muscle resistance arteries in response to a reduction in $\mathrm{PO}_{2}$ (Frisbee et al., 2001; Liu et al., 1997), myogenic stimuli (Nurkiewicz \& Boegehold, 1998), and increases in arteriolar wall shear stress (Boegehold, 1995). All of these mechanisms have been suggested to contribute to functional hyperemia to varying degrees (Lash, 1996; Laughlin et al., 1996; Laughlin \& Korzick, 2001) and therefore we hypothesized that a high salt diet would impair functional hyperemia. The specific aims of our first study were to (1) investigate the changes in arteriolar diameter and blood flow induced by different levels of muscle contraction in normotensive rats fed normal or high salt diets and (2) to determine if ROS and/or reduced NO bioavailability could contribute to any salt-linked deficit in the hyperemic response to muscle contraction.

Our first study determined that high dietary salt intake reduces the arteriolar dilation that accompanies functional hyperemia (which was confirmed in our second study), and 
that this blunted dilation is not due to the increased presence of reactive oxygen species (ROS) and/or a reduction in nitric oxide (NO) availability.

Previous reports from our laboratory have clearly demonstrated that a $7 \%$ high salt diet leads to a reduction in NO bioavailability (Boegehold, 1993; Boegehold, 1995) and a loss of endothelium-dependent dilation (Lenda et al., 2000) in rat spinotrapezius muscle. Additional studies confirmed there is an increased presence of ROS in the arteriolar walls as well as increased activity of ROS generating enzymes such as NAD(P)H oxdase (Lenda et al., 2000; Lenda \& Boegehold, 2002b). Furthermore, scavenging of ROS restores the endothelium-dependent dilation in these salt-fed rats, suggesting that ROS, most likely superoxide anion $\left(\mathrm{O}_{2}^{-}\right)$is inactivating the NO that is released from the endothelium (Harrison \& Cai, 2003). Based on these data, our experiments were designed to examine whether increased ROS are present in rats fed a lower HS diet (4\%), and to determine whether increased ROS, specifically $\mathrm{O}_{2}^{-}$, is involved in the destruction of vascular NO, thus contributing to the attenuated dilation that we observed during functional hyperemia.

Following inhibition of endothelial nitric oxide synthase (eNOS), there were similar increases in resting arteriolar tone in both dietary groups, and there was virtually no effect on the functional hyperemic response, with the exception of a slight reduction in the arteriolar diameter response at $4 \mathrm{~Hz}$ in the normal salt (NS) group. These data suggest that the impaired arteriolar dilation in the HS rats during functional hyperemia is most likely not due to reduced NO availability. This is not surprising given that NO has not been found to play a large role in functional hyperemia in this preparation (Boegehold, 1996). However, increased ROS may act via another mechanism to impair functional hyperemia and thus we sought to determine whether a $4 \%$ high salt diet results in increased 
ROS as observed with the 7\% HS diet (Lenda et al., 2000). We utilized two techniques to measure ROS in the arteriolar walls of the spinotrapezius muscle; tetranitrobluetetrazolium (TNBT) reduction assay, a general index of intra- and extracellular oxidant activity (Lenda et al., 2000) and the fluorescent probe, dihydroethidine (DHE), which is specific for intracellular $\mathrm{O}_{2}^{-}$detection (Tarpey \& Fridovich, 2001). Consistent with Lenda et al. (2000), we found that rats fed a $4 \% \mathrm{HS}$ diet for 4 weeks also exhibit increased arteriolar wall oxidant stress. However, contrary to what we predicted, there was no increase in DHE fluorescence in the high salt rats, suggesting that a ROS other than $\mathrm{O}_{2}{ }^{-}$is increased in the arteriolar wall of HS fed rats. Superoxide can either quickly react with NO to form the highly reactive species peroxynitrite $\left(\mathrm{ONOO}^{-}\right)$, or it can be dismutated by the $\mathrm{O}_{2}^{-}$scavenging enzyme superoxide dismutase (SOD) to its less reactive by-product hydrogen peroxide $\left(\mathrm{H}_{2} \mathrm{O}_{2}\right)$ (Halliwell \& Gutterman, 1989; Harrison, 1997). Both are potential ROS that could contribute to the increased TNBT signal in high salt rats. However, these increased ROS apparently do not contribute to the reduced functional dilation in HS rats, because in the presence of the SOD mimetic 2,2,6,6-tetramethylpiperidine-N-oxyl (Tempo) + the $\mathrm{H}_{2} \mathrm{O}_{2}$ scavenger catalase, the dilation and flow response during muscle contraction were reduced in both normal and high salt groups. Interestingly, these data suggest that ROS may actually contribute to skeletal muscle functional hyperemia rather than impair it as originally hypothesized.

The possibility that ROS may have a physiological role during functional hyperemia does not come as a complete surprise given the numerous lines of evidence suggesting ROS are important second messengers that participate in the regulation of 
vascular tone, oxygen sensing and receptor-mediated vascular responses (Droge, 2002). Given that other vasoactive metabolites (eg. adenosine, ATP, lactate) from surrounding extravascular tissue can influence resting vascular tone and functional hyperemia (Lash, 1996), it is feasible that ROS from extravascular sources can also have such an effect on the vasculature.

Study II (Chapter III) was undertaken to determine whether physiological levels of ROS released from the extravascular skeletal muscle contribute to functional hyperemia, and if so, whether high salt intake alters this role. $\mathrm{H}_{2} \mathrm{O}_{2}$, a highly diffusible ROS, has been shown to regulate vascular tone in numerous vascular beds as well as contribute to mechanisms of vascular function such as flow-mediated dilation and autoregulation (Koller \& Bagi, 2004; Miura et al., 2003; Yada et al., 2003). Furthermore, in vitro studies have shown that $\mathrm{H}_{2} \mathrm{O}_{2}$ production increases during skeletal muscle contraction (Silveira et al., 2003) and that ROS production contributes to force generation during contraction (Reid, 2001). Therefore in Study II we hypothesized that $\mathrm{H}_{2} \mathrm{O}_{2}$ released from the skeletal muscle fibers can contribute to the arteriolar dilation and blood flow response during skeletal muscle contraction in vivo.

To test this possibility, we used the fluorescent probe 2,7 dichlorodihydrofluorescein diacetate (DCFH-DA) as a means to detect intracellular $\mathrm{H}_{2} \mathrm{O}_{2}$ formation during skeletal muscle contraction (Miura et al., 2003; Silveira et al., 2003). Immediately following muscle contraction there was a significant increase in DCF fluorescence in the surrounding skeletal muscle fibers which was inhibited by the $\mathrm{H}_{2} \mathrm{O}_{2}$ scavenger catalase. These results suggest that $\mathrm{H}_{2} \mathrm{O}_{2}$ production is increased in contracting muscle fibers. It has been previously shown in skeletal muscle myotubes that 
production of $\mathrm{O}_{2}^{-}$and hydroxyl radical $\left(\mathrm{OH}^{-}\right)$, a by-product of $\mathrm{H}_{2} \mathrm{O}_{2}$ metabolism via the Fenton reaction, are increased in the extracellular space during contraction (Pattwell et al., 2004). This same group also used microdialysis probes in the intact mouse gastrocnemius muscle to demonstrate that $\mathrm{OH}^{-}$, most likely formed from $\mathrm{H}_{2} \mathrm{O}_{2}$ breakdown, is increased in the extracellular space during hindlimb contraction (Close et al., 2005). Given the close proximity of the skeletal muscle fibers to the vascular tissue, and the highly diffusible nature of $\mathrm{H}_{2} \mathrm{O}_{2}$, it is quite possible that $\mathrm{H}_{2} \mathrm{O}_{2}$ could have paracrine effects on the vasculature during skeletal muscle contraction.

In the presence of catalase, contraction-mediated arteriolar dilation and the increase in blood flow were significantly attenuated at the lower contraction frequencies $(0.5 \mathrm{~Hz}$ and $2.0 \mathrm{~Hz})$ in both dietary groups. In combination with the DCF results, these data strongly suggest that $\mathrm{H}_{2} \mathrm{O}_{2}$ contributes to functional hyperemia. However, compared to the NS rats, at $4 \mathrm{~Hz}$ stimulation, catalase had a significantly smaller effect on arteriolar dilation in HS rats, although its effect on the accompanying flow increase was not different from the NS rats. Another interesting observation from these studies was that the post-catalase arteriolar diameter change in NS rats was similar to the control diameter change in the HS rats. Overall, these data suggest that the reduced functional dilation in the $\mathrm{HS}$ rats is either due to a reduction in endogenous $\mathrm{H}_{2} \mathrm{O}_{2}$ production, reduced vascular smooth muscle sensitivity to $\mathrm{H}_{2} \mathrm{O}_{2}$ and/or a change in catalase activity or enzyme expression, leading to reduced $\mathrm{H}_{2} \mathrm{O}_{2}$ bioavailability. The latter possibility is unlikely given that it was previously shown that catalase activity and expression is unchanged in resting spinotrapezius muscle following a high salt diet (Lenda \& Boegehold, 2002a). In addition, reduced endogenous $\mathrm{H}_{2} \mathrm{O}_{2}$ is also not likely, given that catalase did not have a 
proportionally consistent reduced effect on both diameter and flow and the $\mathrm{H}_{2} \mathrm{O}_{2-}$ dependent mechanism was not affected by dietary salt (see below). Therefore we examined the effects of dietary salt on arteriolar sensitivity to exogenous $\mathrm{H}_{2} \mathrm{O}_{2}$ as well as its mechanism(s) of action.

Exogenous $\mathrm{H}_{2} \mathrm{O}_{2}$ elicited concentration-dependent arteriolar dilations in both NS and HS rats, but contrary to what we expected, the HS rats displayed an increased sensitivity to all three concentrations of $\mathrm{H}_{2} \mathrm{O}_{2}$. These results argue against the possibility that high salt rats have reduced vascular smooth muscle sensitivity to $\mathrm{H}_{2} \mathrm{O}_{2}$ as suggested above. Although speculative, the hypersensitivity to exogenous $\mathrm{H}_{2} \mathrm{O}_{2}$ in $\mathrm{HS}$ rats may reflect a secondary adaptation to the changes in pro-oxidant and anti-oxidant enzyme activities previously found in the spinotrapezius muscle of high salt fed rats (Lenda \& Boegehold, 2002b). The increased basal activity of NAD(P)H oxidase and reduced $\mathrm{CuZnSOD}$ activity in high salt fed rats (Lenda \& Boegehold, 2002b) could theoretically reduce overall basal levels $\mathrm{H}_{2} \mathrm{O}_{2}$ formation which may result in increased arteriolar sensitivity to exogenous $\mathrm{H}_{2} \mathrm{O}_{2}$. However, whether or not this observed hypersensitivity to $\mathrm{H}_{2} \mathrm{O}_{2}$ in high salt rats is related to some type of oxidative compensatory response is currently unknown and therefore may serve as an interesting future research question.

Several different mechanisms have been proposed to mediate $\mathrm{H}_{2} \mathrm{O}_{2}$-induced arteriolar dilation, including both direct and indirect effects on the vascular smooth muscle. These include an endothelium-dependent mechanism whereby $\mathrm{H}_{2} \mathrm{O}_{2}$ phosphorylates eNOS through the PI 3-kinase/Akt-dependent pathway (Cai et al., 2003) and a soluble-guanylate cyclase-dependent mechanism of $\mathrm{H}_{2} \mathrm{O}_{2}$ smooth muscle relaxation (Wolin \& Burke, 1987; Wolin et al., 2005). Because we have not found a convincing 
role for $\mathrm{NO}$ in functional hyperemia in spinotrapezius muscle, we reasoned that if $\mathrm{H}_{2} \mathrm{O}_{2}$ did contribute to functional hyperemia in this muscle, it would not be doing so via stimulating NO release, thus it is unlikely that $\mathrm{H}_{2} \mathrm{O}_{2}$-mediated dilation occurs through the PI3K/Akt/eNOS pathway in this tissue. Moreover, inhibition of soluble guanylate cyclase had no consistent effect in either group on responses to exogenous $\mathrm{H}_{2} \mathrm{O}_{2}$, suggesting that in the spinotrapezius muscle, $\mathrm{H}_{2} \mathrm{O}_{2}$-mediated dilation is not through the soluble guanylate cyclase pathway.

Other data suggest that $\mathrm{H}_{2} \mathrm{O}_{2}$ can directly activate various potassium channels, thus hyperpolarizing and relaxing the vascular smooth muscle (Barlow \& White, 1998; Barlow et al., 2000; Lacza et al., 2002; Matoba et al., 2000). Furthermore, previous data in skeletal muscle has suggested that $\mathrm{K}_{\mathrm{ATP}}$ channels contribute significantly to functional hyperemia (Hammer et al., 2001; Saito et al., 1996) and that $\mathrm{H}_{2} \mathrm{O}_{2}$-mediated dilation in rat gracilis arterioles is mediated by the combined activation of $\mathrm{K}_{\mathrm{Ca}}$ and $\mathrm{K}_{\mathrm{ATP}}$ channels (Cseko et al., 2004). Therefore we examined $\mathrm{K}^{+}$channel activation as a potential mechanism for $\mathrm{H}_{2} \mathrm{O}_{2}$-dependent dilation in spinotrapezius muscle. Following the inhibition of $\mathrm{K}_{\mathrm{Ca}}$ and $\mathrm{K}_{\mathrm{ATP}}$ channels, the arteriolar dilation to exogenous $\mathrm{H}_{2} \mathrm{O}_{2}$ was similarly reduced in both dietary groups and, inhibition of $\mathrm{K}_{\mathrm{ATP}}$ channels nearly abolished the functional hyperemic response in both groups. These results show that $\mathrm{H}_{2} \mathrm{O}_{2}$ mediates vasodilation via $\mathrm{K}^{+}$channels (predominantly $\mathrm{K}_{\mathrm{ATP}}$ ) and these data show that dietary salt does not alter this mechanism of $\mathrm{H}_{2} \mathrm{O}_{2}$-dependent arteriolar dilation. These results support previous studies demonstrating an important role for $\mathrm{K}^{+}$channels in functional hyperemia and $\mathrm{H}_{2} \mathrm{O}_{2}$ - dependent arteriolar dilation in skeletal muscle (Cseko et al., 2004; Hammer et al., 2001; Saito et al., 1996). 
While adding substantially to the current knowledge of the mechanisms of functional hyperemia, these results do not elucidate the functional significance of the increased ROS production shown in HS rats in Study I. This increased ROS production and the increased oxidant enzyme activity in HS rats (Lenda et al., 2000; Lenda \& Boegehold, 2002b) could be reflective of overall changes in local oxygen metabolism in high salt-fed rats. Because oxygen $\left(\mathrm{PO}_{2}\right)$ is an inherent component to the control and regulation of arteriolar tone and skeletal muscle blood flow during functional hyperemia (Boegehold \& Bohlen, 1988; Gorczynski \& Duling, 1978; Proctor et al., 1981), the main goal of our final study was to test the hypothesis that increased dietary salt impairs the arteriolar response to changes in oxygen availability, which ultimately could impact the arteriolar dilation in high salt-fed rats.

In the intravital microscopy model used in these studies, the control superfusate solution was equilibrated with $0 \%$ oxygen, therefore we examined an increase in oxygen availability to test our hypothesis. Consistent with our hypothesis, following an increase in superfusate $\mathrm{PO}_{2}$ the high salt rats displayed a reduced arteriolar constrictor response compared to the normal salt group. Previous studies in rat cremaster (Lombard et al., 1999) and isolated skeletal muscle gracilis arterioles (Frisbee et al., 2001) have demonstrated that during conditions of reduced oxygen availability there is an impaired dilator response in normotensive rats on a high salt diet. Taken together with the results from Study III, these data imply that the arteriolar oxygen sensing ability, to either an increase or decrease in oxygen, may be impaired in high salt-fed rats. In contrast, in the rat cremaster muscle, Frisbee et al., (2000) showed that a high salt diet does not affect the arteriolar constriction to an elevation in $\mathrm{PO}_{2}$. There are several potential explanations for 
these discrepancies. First, in the Frisbee et al (2000) study the animals were placed on a high salt diet for only three days, as opposed to the chronic 4-5 week diet in our studies. Second, the fiber type composition and citrate synthase activity (an indicator of mitochondrial oxygen consumption) are much different in the cremaster muscle compared to the spinotrapezius muscle (Delp \& Duan, 1996). Such differences could theoretically impact local oxygen metabolism and its role in the regulation of arteriolar tone and blood flow.

In skeletal muscle arterioles, some studies have attributed the mechanism(s) responsible for oxygen-induced constriction to a reduction in vasodilators such as NO (Pries et al., 1995) and or $\mathrm{PGI}_{2}$ (Messina et al., 1992). However, there are also several lines of evidence clearly demonstrating that a significant portion of the oxygen-induced constrictor response in skeletal muscle is mediated by the vasoconstrictor metabolite 20hydroxyeicosatetraenoic acid (20-HETE) (Lombard et al., 2004). CYP450 4A $\omega$ hydroxylase, the enzyme responsible for the synthesis and production of 20-HETE has been shown to be expressed in both skeletal muscle as well arteriolar vascular smooth muscle, suggesting that arteriolar changes in oxygen sensitivity could be mediated by the surrounding skeletal muscle and/or the arterioles themselves (Kunert et al., 2001). Frisbee et al. (2001) showed that arterioles isolated from the cremaster muscle constrict less to elevated oxygen compared to the same arterioles in an in vivo setting. These authors suggested that changes in 20-HETE production in both surrounding skeletal muscle as well as in the vascular smooth muscle of arterioles may be necessary for a complete oxygen-induced constrictor response. 
Following inhibition of 20-HETE formation, there was a significant reduction in the oxygen-induced constrictor response in our normal salt rats, suggesting that 20-HETE derived from CYP450 4A $\omega$-hydroxylase partly mediates the constrictor response.

Furthermore, exogenous 20-HETE elicited a concentration-dependent constriction in NS rats which was blocked by $\mathrm{K}_{\mathrm{Ca}}$ channel inhibition. These results are consistent with other authors who showed that 20-HETE exerts its effect via $\mathrm{K}_{\mathrm{Ca}}$ channel activation (AlonsoGalicia et al., 1999; Harder et al., 1994). In contrast, in the high salt rats, 20-HETE inhibition had no effect on the oxygen-induced constriction and the responsiveness of the arterioles to exogenous 20-HETE was reduced. In addition, $\mathrm{K}_{\mathrm{Ca}}$ channel inhibition had no effect on responses to 20-HETE in the HS rats. These data suggest that oxygeninduced constriction is mediated by 20-HETE formed by CYP4A $\omega$-hydroxylase and this mechanism appears to be reduced in normotensive rats fed a high salt diet.

20-HETE has been shown to have a modulatory role in responses to other vascoconstrictor agonists such as NE and ANG II (Frisbee et al., 2000; Zhang et al., 2001). Therefore, in Study III we also investigated whether ANG II and NE exhibited reduced arteriolar constrictions, similar to oxygen, following high salt intake. We were particularly interested in studying the effects of exogenous ANG II because in normotensive salt-fed rats, circulating levels of ANG II are reduced (Hernandez et al., 1992b; Nurkiewicz \& Boegehold, 2000). In the normal salt rats, 20-HETE inhibition, reduced the ANG II-induced constriction, suggesting that 20-HETE partially modulates this response. Although the high salt rats exhibited similar constrictor responses to ANG II, the effect of 20-HETE inhibition was less in these animals. This may be due to a reduction in circulating ANG II levels in high salt rats which may reduce 20-HETE 
synthesis and production (Roman, 2002). Unlike its effect on ANG II, 20-HETE

inhibition had no effect on the NE-induced constriction in either dietary group, suggesting that 20-HETE does not have a modulatory role in this response.

In contrast to these findings, Wang et al. (2004) showed that 20-HETE inhibition restored hypoxic dilation in normotensive rats fed a high salt diet. This was attributable to increased 20-HETE production, due in part to an increase in CYP450-4A enzyme expression in the mesenteric vasculature. In addition, these authors found a role for 20HETE in mediating NE-induced vasoconstriction. These results may differ from ours because Wang et al. (2004) used a non-skeletal muscle preparation (mesenteric vascular bed) and a shorter HS diet regime (3 days vs 4 weeks). Following high salt intake, CYP 4A $\omega$-hydroxylase protein expression and 20-HETE levels in the kidney have been found to decrease, thus promoting excretion of the excess sodium (Stec et al., 1996; Zhao et al., 2003). 20-HETE plays an important role in various aspects of renal function, such as inhibition of tubular sodium reabsorption (Nowicki et al., 1997; Ominato et al., 1996; Quigley et al., 2000), therefore the duration of the high salt diet could influence renal tubular sodium balance, thus potentially changing the levels of 20-HETE.

The results obtained in Study III show that oxygen-induced constriction is a 20HETE mediated event, and that this response and mechanism is altered in high salt rats. These data may present some insight into the mechanism(s) responsible for the impaired functional dilation during muscle contraction. Because 20-HETE production is linearly dependent on changes in oxygen availability (Harder et al., 1996) and both increases and decreases in oxygen occur during muscle contraction, an impaired 20-HETE system following high salt intake could affect the oxygen-dependent hemodynamics that occur 
with muscle contraction. This is only speculative and additional work needs to be done to determine whether 20-HETE plays a role functional hyperemia. However, other CYP 450 metabolites have been shown to play a role in the vascular response to skeletal muscle contraction (Hillig et al., 2003), thus this hypothesis is not beyond the realms of possibility.

Another possibility not investigated in this study is that the renin-angiotensin system (RAS) may contribute to the reduced functional dilation during muscle contraction, since high salt fed-rats exhibit reduced levels of circulating ANG II (Hernandez et al., 1992a; Weber \& Lombard, 2000). Because ANG II is a potent growth factor, the reduced ANG II levels in high salt rats are thought to contribute to changes in microvessel growth and wall structure (Wang \& Prewitt, 1990), thus contributing to dysfunctional vascular responsiveness. Several studies out of the Lombard laboratory have consistently shown that if circulating ANG II levels are maintained (via low-dose infusion) various impaired functional responses can be successfully restored in salt-fed rats (Lombard et al., 2003; Weber \& Lombard, 2000; Weber \& Lombard, 2001). Interestingly, it was recently shown that the angiogenic response following seven days of hindlimb muscle stimulation is completely blocked in normotensive high salt-fed rats. These authors concluded that this was attributable to suppression of ANG II levels, thus reducing ANG II-mediated stimulation of vascular endothelial growth factor (VEGF), an important trophic factor for angiogenesis (Petersen et al., 2006). In addition, other authors have demonstrated that either a high salt diet or pharmacological reductions in ANG II levels via angiotensin converting enzyme (ACE) inhibition with captopril, results in a reduced exercise capacity in normotensive rats (Minami et al., 2004). Taken 
together, these studies suggest that ANG II levels are intimately involved in maintaining normal vascular responses during conditions of increased metabolic demand. Whether or not the reduced functional dilation following skeletal muscle contraction in the current studies is can be explained by reductions in ANG II levels and impaired growth factor signaling and thus potentially affecting overall skeletal muscle performance and metabolic capacity, remains to be determined and would serve as an interesting topic of future research.

In summary, these studies have established that a high salt diet reduces the arteriolar dilation that accompanies muscle contraction and despite its important role in functional hyperemia, this attenuated response does not appear to be due changes in $\mathrm{H}_{2} \mathrm{O}_{2}$ levels. In addition, the increased oxidant stress and reduced NO availability that have been previously demonstrated in HS rats do not explain this impaired response. Oxygen sensing by arterioles is considered by some to be an important component of functional hyperemia. The CYP 4A $\omega$-hydroxylase metabolite 20-HETE is clearly involved in this process within skeletal muscle and our data show that this system is impaired in high saltfed rats. Further investigation is needed in order to determine the extent to which changes in arteriolar oxygen sensitivity are involved in the salt-induced impaired functional dilation and whether interventions such as maintenance of circulating ANG II levels can restore or improve this vascular dysfunction during skeletal muscle contraction. 
References for Literature Review and General Discussion

Abbracchio, M. P. \& Burnstock, G. (1994). Purinoceptors: are there families of P2X and P2Y purinoceptors? Pharmacol.Ther., 64, 445-475.

Adelstein, R. S., Conti, M. A., Hathaway, D. R., \& Klee, C. B. (1978). Phosphorylation of smooth muscle myosin light chain kinase by the catalytic subunit of adenosine 3': 5'-monophosphate-dependent protein kinase. J.Biol.Chem., 253, 8347-8350.

Afonso, S., Bandow, G. T., \& Rowe, G. G. (1974). Indomethacin and the prostaglandin hypothesis of coronary blood flow regulation. J.Physiol, 241, 299-308.

Allen, S. P., Wade, S. S., \& Prewitt, R. L. (1997). Myogenic tone attenuates pressure-induced gene expression in isolated small arteries. Hypertension, 30, 203208.

Alonso-Galicia, M., Falck, J. R., Reddy, K. M., \& Roman, R. J. (1999). 20HETE agonists and antagonists in the renal circulation. Am.J.Physiol, 277, F790F796.

Ardanaz, N. \& Pagano, P. J. (2006). Hydrogen peroxide as a paracrine vascular mediator: regulation and signaling leading to dysfunction. Exp.Biol.Med.(Maywood.), 231, 237-251.

Armstrong, R. B. \& Laughlin, M. H. (1985). Rat muscle blood flows during high-speed locomotion. J.Appl.Physiol, 59, 1322-1328.

Bagi, Z. \& Koller, A. (2003). Lack of nitric oxide mediation of flowdependent arteriolar dilation in type I diabetes is restored by sepiapterin. J.Vasc.Res., 40, 47-57.

Barlow, R. S., El Mowafy, A. M., \& White, R. E. (2000). H(2)O(2) opens BK(Ca) channels via the PLA(2)-arachidonic acid signaling cascade in coronary artery smooth muscle. Am.J.Physiol Heart Circ.Physiol, 279, H475-H483.

Barlow, R. S. \& White, R. E. (1998). Hydrogen peroxide relaxes porcine coronary arteries by stimulating BKCa channel activity. Am.J.Physiol, 275, H1283H1289.

Berg, B. R., Cohen, K. D., \& Sarelius, I. H. (1997). Direct coupling between blood flow and metabolism at the capillary level in striated muscle. Am.J.Physiol, 272, H2693-H2700. 
Bergfeld, G. R. \& Forrester, T. (1992). Release of ATP from human erythrocytes in response to a brief period of hypoxia and hypercapnia. Cardiovasc.Res., 26, 40-47.

Berne, R.M. \& Levy M.N. (1998). Physiology $4^{\text {th }}$ Ed. MOSBY, Inc, St. Louis, Missouri. pp. 721.

Blaustein, M. P., Zhang, J., Chen, L., \& Hamilton, B. P. (2006). How does salt retention raise blood pressure? Am.J.Physiol Regul.Integr.Comp Physiol, 290, R514-R523.

Boegehold, M. A. (1991). Effect of salt-induced hypertension on microvascular pressures in skeletal muscle of Dahl rats. Am.J.Physiol, 260, H1819H1825.

Boegehold, M. A. (1992). Reduced influence of nitric oxide on arteriolar tone in hypertensive Dahl rats. Hypertension, 19, 290-295.

Boegehold, M. A. (1993). Effect of dietary salt on arteriolar nitric oxide in striated muscle of normotensive rats. Am.J.Physiol, 264, H1810-H1816.

Boegehold, M. A. (1993a). Microvascular changes associated with high salt intake and hypertension in Dahl rats. Int J Microcirc, 12, 143-156.

Boegehold, M. A. (1995). Flow-dependent arteriolar dilation in normotensive rats fed low- or high-salt diets. Am.J.Physiol, 269, H1407-H1414.

Boegehold, M. A. (1996). Shear-dependent release of venular nitric oxide: effect on arteriolar tone in rat striated muscle. Am.J.Physiol, 271, H387-H395.

Boegehold, M. A. \& Bohlen, H. G. (1988). Arteriolar diameter and tissue oxygen tension during muscle contraction in hypertensive rats. Hypertension, 12, 184-191.

Boegehold, M. A. \& Johnson, P. C. (1988). Periarteriolar and tissue PO2 during sympathetic escape in skeletal muscle. Am.J.Physiol, 254, H929-H936.

Boegehold, M. A. \& Kotchen, T. A. (1990). Effect of dietary salt on the skeletal muscle microvasculature in Dahl rats. Hypertension, 15, 420-426.

Boushel, R. (2003). Metabolic control of muscle blood flow during exercise in humans. Can.J.Appl.Physiol, 28, 754-773.

Boushel, R., Langberg, H., Gemmer, C., Olesen, J., Crameri, R., Scheede, C., Sander, M., \& Kjaer, M. (2002). Combined inhibition of nitric oxide and prostaglandins reduces human skeletal muscle blood flow during exercise. J.Physiol, 543, 691-698. 
Burke, T. M. \& Wolin, M. S. (1987). Hydrogen peroxide elicits pulmonary arterial relaxation and guanylate cyclase activation. Am.J.Physiol, 252, H721-H732.

Burke-Wolin, T., Abate, C. J., Wolin, M. S., \& Gurtner, G. H. (1991). Hydrogen peroxide-induced pulmonary vasodilation: role of guanosine 3',5'-cyclic monophosphate. Am.J.Physiol, 261, L393-L398.

Busse, R., Forstermann, U., Matsuda, H., \& Pohl, U. (1984). The role of prostaglandins in the endothelium-mediated vasodilatory response to hypoxia. Pflugers Arch., 401, 77-83.

Cai, H., Li, Z., Davis, M. E., Kanner, W., Harrison, D. G., \& Dudley, S. C., Jr. (2003). Akt-dependent phosphorylation of serine 1179 and mitogen-activated protein kinase kinase/extracellular signal-regulated kinase 1/2 cooperatively mediate activation of the endothelial nitric-oxide synthase by hydrogen peroxide. Mol.Pharmacol., 63, 325-331.

Capdevila, J. H., Falck, J. R., \& Harris, R. C. (2000). Cytochrome P450 and arachidonic acid bioactivation. Molecular and functional properties of the arachidonate monooxygenase. J.Lipid Res., 41, 163-181.

Carroll, M. A., Balazy, M., Margiotta, P., Huang, D. D., Falck, J. R., \& McGiff, J. C. (1996). Cytochrome P-450-dependent HETEs: profile of biological activity and stimulation by vasoactive peptides. Am.J.Physiol, 271, R863-R869.

Chen, P. Y. \& Sanders, P. W. (1993). Role of nitric oxide synthesis in saltsensitive hypertension in Dahl/Rapp rats. Hypertension, 22, 812-818.

Clifford, P. S. \& Hellsten, Y. (2004). Vasodilatory mechanisms in contracting skeletal muscle. J.Appl.Physiol, 97, 393-403.

Close, G. L., Ashton, T., McArdle, A., \& Jackson, M. J. (2005). Microdialysis studies of extracellular reactive oxygen species in skeletal muscle: Factors influencing the reduction of cytochrome $c$ and hydroxylation of salicylate. Free Radic.Biol.Med., 39, 1460-1467.

Collins, D. M., McCullough, W. T., \& Ellsworth, M. L. (1998). Conducted vascular responses: communication across the capillary bed. Microvasc.Res., 56, 4353.

Cosentino, F., Barker, J. E., Brand, M. P., Heales, S. J., Werner, E. R., Tippins, J. R., West, N., Channon, K. M., Volpe, M., \& Luscher, T. F. (2001). Reactive oxygen species mediate endothelium-dependent relaxations in tetrahydrobiopterin-deficient mice. Arterioscler.Thromb.Vasc.Biol., 21, 496-502.

Cowley, A. W., Jr. (1991). Salt and hypertension--future directions. Hypertension, 17, I205-I210. 
Cowley, A. W., Jr., Roman, R. J., Kaldunski, M. L., Dumas, P., Dickhout, J. G., Greene, A. S., \& Jacob, H. J. (2001). Brown Norway chromosome 13 confers protection from high salt to consomic Dahl S rat. Hypertension, 37, 456-461.

Cowley, A. W., Jr., Skelton, M. M., Merrill, D. C., Quillen, E. W., Jr., \& Switzer, S. J. (1983). Influence of daily sodium intake on vasopressin secretion and drinking in dogs. Am.J.Physiol, 245, R860-R872.

Coyle, P. (1988). High NaCl predisposes Dahl rats to cerebral infarction after middle cerebral artery occlusion. Hypertension, 12, 96-101.

Cseko, C., Bagi, Z., \& Koller, A. (2004). Biphasic effect of hydrogen peroxide on skeletal muscle arteriolar tone via activation of endothelial and smooth muscle signaling pathways. J.Appl.Physiol, 97, 1130-1137.

Dahl, L.K., Heine, M., \& Tassinari, L. (1962). Role of genetic factors in susceptibility to experimental hypertension due to chronic excess salt ingestion. Nature, 194, 480-482.

Dahl, L. K., Heine, M., \& Thompson, K. (1972). Genetic influence of renal homografts on the blood pressure of rats from different strains. Proc.Soc.Exp.Biol.Med., 140, 852-856.

Dahl, L. K., Heine, M., \& Thompson, K. (1974). Genetic influence of the kidneys on blood pressure. Evidence from chronic renal homografts in rats with opposite predispositions to hypertension. Circ.Res., 40, 94-101. 238.

Dawes, G.S. (1941). The vasodilator action of potassium. J Physiol, 99, 224-

Delp, M. D. \& Duan, C. (1996). Composition and size of type I, IIA, IID/X, and IIB fibers and citrate synthase activity of rat muscle. J.Appl.Physiol, 80, 261270.

Deng, X., Welch, W. J., \& Wilcox, C. S. (1994). Renal vasoconstriction during inhibition of NO synthase: effects of dietary salt. Kidney Int., 46, 639-646.

Dietrich, H. H., Ellsworth, M. L., Sprague, R. S., \& Dacey, R. G., Jr. (2000). Red blood cell regulation of microvascular tone through adenosine triphosphate. Am.J.Physiol Heart Circ.Physiol, 278, H1294-H1298.

Drenjancevic-Peric, I., Frisbee, J. C., \& Lombard, J. H. (2003). Skeletal muscle arteriolar reactivity in SS.BN13 consomic rats and Dahl salt-sensitive rats. Hypertension, 41, 1012-1015.

Drenjancevic-Peric, I., Phillips, S. A., Falck, J. R., \& Lombard, J. H. (2005). Restoration of normal vascular relaxation mechanisms in cerebral arteries by 
chromosomal substitution in consomic SS.13BN rats. Am.J.Physiol Heart Circ.Physiol, 289, H188-H195.

Droge, W. (2002). Free radicals in the physiological control of cell function. Physiol Rev., 82, 47-95.

Duling, B. R. (1972). Microvascular responses to alterations in oxygen tension. Circ.Res., 31, 481-489.

Duling, B. R. (1974). Oxygen sensitivity of vascular smooth muscle. II. In vivo studies. Am.J.Physiol, 227, 42-49.

Ellsworth, M. L., Forrester, T., Ellis, C. G., \& Dietrich, H. H. (1995). The erythrocyte as a regulator of vascular tone. Am.J.Physiol, 269, H2155-H2161.

Emerson, G. G. \& Segal, S. S. (2000). Electrical coupling between endothelial cells and smooth muscle cells in hamster feed arteries: role in vasomotor control. Circ.Res., 87, 474-479.

Escalante, B., Erlij, D., Falck, J. R., \& McGiff, J. C. (1991). Ion transport inhibition in the medullary thick ascending limb of Henle's loop by cytochrome P450-arachidonic acid metabolites. Adv.Prostaglandin Thromboxane Leukot.Res., 21A, 209-212.

Feletou, M. \& Vanhoutte, P. M. (2000). Endothelium-dependent hyperpolarization of vascular smooth muscle cells. Acta Pharmacol.Sin., 21, 1-18.

Fields, L. E., Burt, V. L., Cutler, J. A., Hughes, J., Roccella, E. J., \& Sorlie, P. (2004). The burden of adult hypertension in the United States 1999 to 2000: a rising tide. Hypertension, 44, 398-404.

Fredricks, K. T., Liu, Y., \& Lombard, J. H. (1994). Response of extraparenchymal resistance arteries of rat skeletal muscle to reduced PO2. Am.J.Physiol, 267, H706-H715.

Frisbee, J. C., Falck, J. R., \& Lombard, J. H. (2000). Contribution of cytochrome $\mathrm{P}-450$ omega-hydroxylase to altered arteriolar reactivity with high-salt diet and hypertension. Am.J.Physiol Heart Circ.Physiol, 278, H1517-H1526.

Frisbee, J. C., Krishna, U. M., Falck, J. R., \& Lombard, J. H. (2001a). Role of prostanoids and 20-HETE in mediating oxygen-induced constriction of skeletal muscle resistance arteries. Microvasc.Res., 62, 271-283.

Frisbee, J. C. \& Lombard, J. H. (1998). Chronic elevations in salt intake and reduced renal mass hypertension compromise mechanisms of arteriolar dilation. Microvasc.Res., 56, 218-227. 
Frisbee, J. C. \& Lombard, J. H. (1999a). Acute elevations in salt intake and reduced renal mass hypertension compromise arteriolar dilation in rat cremaster muscle. Microvasc.Res., 57, 273-283.

Frisbee, J. C. \& Lombard, J. H. (1999b). Development and reversibility of altered skeletal muscle arteriolar structure and reactivity with high salt diet and reduced renal mass hypertension. Microcirculation., 6, 215-225.

Frisbee, J. C. \& Lombard, J. H. (2002). Parenchymal tissue cytochrome P450 4A enzymes contribute to oxygen-induced alterations in skeletal muscle arteriolar tone. Microvasc.Res., 63, 340-343.

Frisbee, J. C., Roman, R. J., Falck, J. R., Krishna, U. M., \& Lombard, J. H. (2001b). 20-HETE contributes to myogenic activation of skeletal muscle resistance arteries in Brown Norway and Sprague-Dawley rats. Microcirculation., 8, 45-55.

Frisbee, J. C., Roman, R. J., Krishna, U. M., Falck, J. R., \& Lombard, J. H. (2001c). Relative contributions of cyclooxygenase- and cytochrome P450 omegahydroxylase-dependent pathways to hypoxic dilation of skeletal muscle resistance arteries. J.Vasc.Res., 38, 305-314.

Frisbee, J. C., Roman, R. J., Murali, K. U., Falck, J. R., \& Lombard, J. H. (2001d). Altered mechanisms underlying hypoxic dilation of skeletal muscle resistance arteries of hypertensive versus normotensive Dahl rats. Microcirculation., 8, 115-127.

Frisbee, J. C., Sylvester, F. A., \& Lombard, J. H. (2001e). High-salt diet impairs hypoxia-induced cAMP production and hyperpolarization in rat skeletal muscle arteries. Am.J.Physiol Heart Circ.Physiol, 281, H1808-H1815.

Fujimoto, S., Asano, T., Sakai, M., Sakurai, K., Takagi, D., Yoshimoto, N., \& Itoh, T. (2001). Mechanisms of hydrogen peroxide-induced relaxation in rabbit mesenteric small artery. Eur.J.Pharmacol., 412, 291-300.

Furchgott, R. F. \& Zawadzki, J. V. (1980). The obligatory role of endothelial cells in the relaxation of arterial smooth muscle by acetylcholine. Nature, 288, 373376.

Ganguli, M., Tobian, L., \& Iwai, J. (1979). Cardiac output and peripheral resistance in strains of rats sensitive and resistant to $\mathrm{NaCl}$ hypertension. Hypertension, 1, 3-7.

Gao, Y. J., Hirota, S., Zhang, D. W., Janssen, L. J., \& Lee, R. M. (2003). Mechanisms of hydrogen-peroxide-induced biphasic response in rat mesenteric artery. Br.J.Pharmacol., 138, 1085-1092. 
Gao, Y. J. \& Lee, R. M. (2001). Hydrogen peroxide induces a greater contraction in mesenteric arteries of spontaneously hypertensive rats through thromboxane A(2) production. Br.J.Pharmacol., 134, 1639-1646.

Gebremedhin, D., Lange, A. R., Lowry, T. F., Taheri, M. R., Birks, E. K., Hudetz, A. G., Narayanan, J., Falck, J. R., Okamoto, H., Roman, R. J., Nithipatikom, K., Campbell, W. B., \& Harder, D. R. (2000). Production of 20-HETE and its role in autoregulation of cerebral blood flow. Circ.Res., 87, 60-65.

Gebremedhin, D., Lange, A. R., Narayanan, J., Aebly, M. R., Jacobs, E. R., \& Harder, D. R. (1998). Cat cerebral arterial smooth muscle cells express cytochrome P450 4A2 enzyme and produce the vasoconstrictor 20-HETE which enhances L-type Ca2+ current. J.Physiol, 507 ( Pt 3), 771-781. 824-826.

Goligorsky, M. S. (2000). Making sense out of oxygen sensor. Circ.Res., 86,

Gorczynski, R. J. \& Duling, B. R. (1978). Role of oxygen in arteriolar functional vasodilation in hamster striated muscle. Am.J.Physiol, 235, H505-H515.

Gorren, A. C., Schrammel, A., Schmidt, K., \& Mayer, B. (1998). Effects of pH on the structure and function of neuronal nitric oxide synthase. Biochem.J., 331 ( Pt 3), 801-807.

Govers, R. \& Rabelink, T. J. (2001). Cellular regulation of endothelial nitric oxide synthase. Am.J.Physiol Renal Physiol, 280, F193-F206.

Granger, H. J., Goodman, A. H., \& Granger, D. N. (1976). Role of resistance and exchange vessels in local microvascular control of skeletal muscle oxygenation in the dog. Circ.Res., 38, 379-385.

Greene, A. S., Lombard, J. H., Cowley, A. W., Jr., \& Hansen-Smith, F. M. (1990). Microvessel changes in hypertension measured by Griffonia simplicifolia I lectin. Hypertension, 15, 779-783.

Griendling, K. K. \& FitzGerald, G. A. (2003). Oxidative stress and cardiovascular injury: Part II: animal and human studies. Circulation, 108, 20342040.

Gutterman, D. D., Miura, H., \& Liu, Y. (2005). Redox modulation of vascular tone: focus of potassium channel mechanisms of dilation. Arterioscler.Thromb.Vasc.Biol., 25, 671-678.

Guyton, A. C. (1987). Renal function curve--a key to understanding the pathogenesis of hypertension. Hypertension, 10, 1-6.

Haddy, F. J. \& Scott, J. B. (1975). Metabolic factors in peripheral circulatory regulation. Fed.Proc., 34, 2006-2011. 
Halliwell, B. \& Gutterman, J. M. C. (1989). Free Radical Biology and Medicine. In ( Oxford: Oxford University Press.

Hammer, L. W. \& Boegehold, M. A. (2005). Functional hyperemia is reduced in skeletal muscle of aged rats. Microcirculation., 12, 517-526.

Hammer, L. W., Ligon, A. L., \& Hester, R. L. (2001). Differential inhibition of functional dilation of small arterioles by indomethacin and glibenclamide. Hypertension, 37, 599-603.

Hansen-Smith, F., Greene, A. S., Cowley, A. W., Jr., \& Lombard, J. H. (1990). Structural changes during microvascular rarefaction in chronic hypertension. Hypertension, 15, 922-928.

Hansen-Smith, F. M., Morris, L. W., Greene, A. S., \& Lombard, J. H. (1996). Rapid microvessel rarefaction with elevated salt intake and reduced renal mass hypertension in rats. Circ.Res., 79, 324-330.

Harder, D. R., Alkayed, N. J., Lange, A. R., Gebremedhin, D., \& Roman, R. J. (1998). Functional hyperemia in the brain: hypothesis for astrocyte-derived vasodilator metabolites. Stroke, 29, 229-234.

Harder, D. R., Campbell, W. B., \& Roman, R. J. (1995). Role of cytochrome $P-450$ enzymes and metabolites of arachidonic acid in the control of vascular tone. J.Vasc.Res., 32, 79-92.

Harder, D. R., Gebremedhin, D., Narayanan, J., Jefcoat, C., Falck, J. R., Campbell, W. B., \& Roman, R. (1994). Formation and action of a P-450 4A metabolite of arachidonic acid in cat cerebral microvessels. Am.J.Physiol, 266, H2098-H2107.

Harder, D. R., Lange, A. R., Gebremedhin, D., Birks, E. K., \& Roman, R. J. (1997). Cytochrome $\mathbf{P 4 5 0}$ metabolites of arachidonic acid as intracellular signaling molecules in vascular tissue. J.Vasc.Res., 34, 237-243.

Harder, D. R., Narayanan, J., Birks, E. K., Liard, J. F., Imig, J. D., Lombard, J. H., Lange, A. R., \& Roman, R. J. (1996). Identification of a putative microvascular oxygen sensor. Circ.Res., 79, 54-61.

Harrison, D. G. (1997). Endothelial function and oxidant stress. Clin.Cardiol., 20, II-7.

Harrison, D. G. \& Cai, H. (2003). Endothelial control of vasomotion and nitric oxide production. Cardiol.Clin., 21, 289-302.

Hatoum, O. A., Binion, D. G., Miura, H., Telford, G., Otterson, M. F., \& Gutterman, D. D. (2005). Role of hydrogen peroxide in ACh-induced dilation of 
human submucosal intestinal microvessels. Am.J.Physiol Heart Circ.Physiol, 288, H48-H54.

Hellsten, Y., Maclean, D., Radegran, G., Saltin, B., \& Bangsbo, J. (1998). Adenosine concentrations in the interstitium of resting and contracting human skeletal muscle. Circulation, 98, 6-8.

Hernandez, I., Cowley, A. W., Jr., Lombard, J. H., \& Greene, A. S. (1992). Salt intake and angiotensin II alter microvessel density in the cremaster muscle of normal rats. Am.J.Physiol, 263, H664-H667.

Hester, R. L., Eraslan, A., \& Saito, Y. (1993). Differences in EDNO contribution to arteriolar diameters at rest and during functional dilation in striated muscle. Am.J.Physiol, 265, H146-H151.

Hester, R. L. \& Hammer, L. W. (2002). Venular-arteriolar communication in the regulation of blood flow. Am.J.Physiol Regul.Integr.Comp Physiol, 282, R1280R1285.

Hevel, J. M. \& Marletta, M. A. (1992). Macrophage nitric oxide synthase: relationship between enzyme-bound tetrahydrobiopterin and synthase activity. Biochemistry, 31, 7160-7165.

Hillig, T., Krustrup, P., Fleming, I., Osada, T., Saltin, B., \& Hellsten, Y. (2003). Cytochrome P450 2C9 plays an important role in the regulation of exerciseinduced skeletal muscle blood flow and oxygen uptake in humans. J.Physiol, 546, 307-314.

Hintze, T. H. \& Kaley, G. (1977). Prostaglandins and the control of blood flow in the canine myocardium. Circ.Res., 40, 313-320.

Hirai, T., Visneski, M. D., Kearns, K. J., Zelis, R., \& Musch, T. I. (1994). Effects of NO synthase inhibition on the muscular blood flow response to treadmill exercise in rats. J.Appl.Physiol, 77, 1288-1293.

Hnik, P., Holas, M., Krekule, I., Kuriz, N., Mejsnar, J., Smiesko, V., Ujec, E., \& Vyskocil, F. (1976). Work-induced potassium changes in skeletal muscle and effluent venous blood assessed by liquid ion-exchanger microelectrodes. Pflugers Arch., 362, 85-94.

Holtz, J., Giesler, M., \& Bassenge, E. (1983). Two dilatory mechanisms of anti-anginal drugs on epicardial coronary arteries in vivo: indirect, flow-dependent, endothelium-mediated dilation and direct smooth muscle relaxation. Z.Kardiol., 72 Suppl 3, 98-106.

Hu, L. \& Manning, R. D., Jr. (1995). Role of nitric oxide in regulation of long-term pressure-natriuresis relationship in Dahl rats. Am.J.Physiol, 268, H2375H2383. 
Hutchins, P. M., Bond, R. F., \& Green, H. D. (1974). Participation of oxygen in the local control of skeletal muscle microvasculature. Circ.Res., 40, 85-93.

Ichinari, K., Kakei, M., Matsuoka, T., Nakashima, H., \& Tanaka, H. (1996). Direct activation of the ATP-sensitive potassium channel by oxygen free radicals in guinea-pig ventricular cells: its potentiation by MgADP. J.Mol.Cell Cardiol., 28, 1867-1877.

Ignarro, L. J., Buga, G. M., Wood, K. S., Byrns, R. E., \& Chaudhuri, G. (1987). Endothelium-derived relaxing factor produced and released from artery and vein is nitric oxide. Proc.Natl.Acad.Sci.U.S.A, 84, 9265-9269.

Iida, Y. \& Katusic, Z. S. (2000). Mechanisms of cerebral arterial relaxations to hydrogen peroxide. Stroke, 31, 2224-2230.

Imig, J. D., Zou, A. P., Ortiz de Montellano, P. R., Sui, Z., \& Roman, R. J. (1994). Cytochrome $P-450$ inhibitors alter afferent arteriolar responses to elevations in pressure. Am.J.Physiol, 266, H1879-H1885.

Imig, J. D., Zou, A. P., Stec, D. E., Harder, D. R., Falck, J. R., \& Roman, R. J. (1996). Formation and actions of 20-hydroxyeicosatetraenoic acid in rat renal arterioles. Am.J.Physiol, 270, R217-R227.

Ito, O. \& Roman, R. J. (1999). Role of 20-HETE in elevating chloride transport in the thick ascending limb of Dahl SS/Jr rats. Hypertension, 33, 419-423.

Jackson, W. F. (1986). Prostaglandins do not mediate arteriolar oxygen reactivity. Am.J.Physiol, 250, H1102-H1108.

Jackson, W. F. (1988). Lipoxygenase inhibitors block $O 2$ responses of hamster cheek pouch arterioles. Am.J.Physiol, 255, H711-H716.

Jackson, W. F. (1989). Arteriolar oxygen reactivity is inhibited by leukotriene antagonists. Am.J.Physiol, 257, H1565-H1572.

Jackson, W. F. (1991). Nitric oxide does not mediate arteriolar oxygen reactivity. Microcirc.Endothelium Lymphatics, 7, 199-215.

Jackson, W. F. (2000). Ion channels and vascular tone. Hypertension, 35, 173178.

Jackson, W. F. \& Duling, B. R. (1983). The oxygen sensitivity of hamster cheek pouch arterioles. In vitro and in situ studies. Circ.Res., 53, 515-525.

Jiang, J., Valen, G., Tokuno, S., Thoren, P., \& Pernow, J. (2000). Endothelial dysfunction in atherosclerotic mice: improved relaxation by combined supplementation with L-arginine-tetrahydrobiopterin and enhanced vasoconstriction by endothelin. Br.J.Pharmacol., 131, 1255-1261. 
Jin, N. \& Rhoades, R. A. (1997). Activation of tyrosine kinases in H2O2induced contraction in pulmonary artery. Am.J.Physiol, 272, H2686-H2692.

Johnson, P. C. (1989). The myogenic response in the microcirculation and its interaction with other control systems. J.Hypertens.Suppl, 7, S33-S39.

Juel, C., Pilegaard, H., Nielsen, J. J., \& Bangsbo, J. (2000). Interstitial K(+) in human skeletal muscle during and after dynamic graded exercise determined by microdialysis. Am.J.Physiol Regul.Integr.Comp Physiol, 278, R400-R406.

Kalsner, S. (1978). Prostaglandin mediated relaxation of coronary artery strips under hypoxia. Prostaglandins Med., 1, 231-239.

Kerkhof, C. J., Bakker, E. N., \& Sipkema, P. (1999). Role of cytochrome P$4504 \mathrm{~A}$ in oxygen sensing and $\mathrm{NO}$ production in rat cremaster resistance arteries. Am.J.Physiol, 277, H1546-H1552.

Kilbom, A. \& Wennmalm, A. (1976). Endogenous prostaglandins as local regulators of blood flow in man: effect of indomethacin on reactive and functional hyperaemia. J.Physiol, 257, 109-121.

Kitiyakara, C., Chabrashvili, T., Chen, Y., Blau, J., Karber, A., Aslam, S., Welch, W. J., \& Wilcox, C. S. (2003). Salt intake, oxidative stress, and renal expression of NADPH oxidase and superoxide dismutase. J.Am.Soc.Nephrol., 14, 2775-2782.

Kitiyakara, C., Chabrashvili, T., Jose, P., Welch, W. J., \& Wilcox, C. S. (2001). Effects of dietary salt intake on plasma arginine. Am.J.Physiol Regul.Integr.Comp Physiol, 280, R1069-R1075.

Kjellmer, I. (1964). The effect of exercise on the vascular bed of skeletal muscle. Acta Physiol Scand., 62, 18-30.

Klabunde, R. E., Laughlin, M. H., \& Armstrong, R. B. (1988). Systemic adenosine deaminase administration does not reduce active hyperemia in running rats. J.Appl.Physiol, 64, 108-114.

Kobayashi, T. \& Kamata, K. (2002). Modulation by hydrogen peroxide of noradrenaline-induced contraction in aorta from streptozotocin-induced diabetic rat. Eur.J.Pharmacol., 441, 83-89.

Koch, L. G., Britton, S. L., \& Metting, P. J. (1990). Adenosine is not essential for exercise hyperaemia in the hindlimb in conscious dogs. J.Physiol, 429, 63-75.

Koller, A. \& Bagi, Z. (2004). Nitric oxide and $\mathrm{H} 2 \mathrm{O} 2$ contribute to reactive dilation of isolated coronary arterioles. Am.J.Physiol Heart Circ.Physiol, 287, H2461H2467. 
Koller, A. \& Huang, A. (1999). Development of nitric oxide and prostaglandin mediation of shear stress-induced arteriolar dilation with aging and hypertension. Hypertension, 34, 1073-1079.

Koller, A., Huang, A., Sun, D., \& Kaley, G. (1995). Exercise training augments flow-dependent dilation in rat skeletal muscle arterioles. Role of endothelial nitric oxide and prostaglandins. Circ.Res., 76, 544-550.

Koller, A. \& Kaley, G. (1990). Prostaglandins mediate arteriolar dilation to increased blood flow velocity in skeletal muscle microcirculation. Circ.Res., 67, 529534.

Koller, A., Sun, D., Huang, A., \& Kaley, G. (1994). Corelease of nitric oxide and prostaglandins mediates flow-dependent dilation of rat gracilis muscle arterioles. Am.J.Physiol, 267, H326-H332.

Kontos, H. A., Wei, E. P., Christman, C. W., Levasseur, J. E., Povlishock, J. T., \& Ellis, E. F. (1983). Free oxygen radicals in cerebral vascular responses. Physiologist, 26, 165-169.

Kourie, J. I. (1998). Interaction of reactive oxygen species with ion transport mechanisms. Am.J.Physiol, 275, C1-24.

Kroetz, D. L. \& Xu, F. (2005). Regulation and inhibition of arachidonic acid omega-hydroxylases and 20-HETE formation. Annu.Rev.Pharmacol.Toxicol., 45, 413-438.

Kunert, M. P., Roman, R. J., Alonso-Galicia, M., Falck, J. R., \& Lombard, J. H. (2001). Cytochrome P-450 omega-hydroxylase: a potential $O(2)$ sensor in rat arterioles and skeletal muscle cells. Am.J.Physiol Heart Circ.Physiol, 280, H1840H1845.

Kurjiaka, D. T. \& Segal, S. S. (1995). Conducted vasodilation elevates flow in arteriole networks of hamster striated muscle. Am.J.Physiol, 269, H1723-H1728.

Lacy, F., Kailasam, M. T., O'Connor, D. T., Schmid-Schonbein, G. W., \& Parmer, R. J. (2000). Plasma hydrogen peroxide production in human essential hypertension: role of heredity, gender, and ethnicity. Hypertension, 36, 878-884.

Lacza, Z., Puskar, M., Kis, B., Perciaccante, J. V., Miller, A. W., \& Busija, D. W. (2002). Hydrogen peroxide acts as an EDHF in the piglet pial vasculature in response to bradykinin. Am.J.Physiol Heart Circ.Physiol, 283, H406-H411.

Landmesser, U., Dikalov, S., Price, S. R., McCann, L., Fukai, T., Holland, S. M., Mitch, W. E., \& Harrison, D. G. (2003). Oxidation of tetrahydrobiopterin leads to uncoupling of endothelial cell nitric oxide synthase in hypertension. J.Clin.Invest, 111, 1201-1209. 
Landmesser, U., Harrison, D. G., \& Drexler, H. (2006). Oxidant stress-a major cause of reduced endothelial nitric oxide availability in cardiovascular disease. Eur.J.Clin.Pharmacol., 62 Suppl 13, 13-19.

Lange, A., Gebremedhin, D., Narayanan, J., \& Harder, D. (1997). 20Hydroxyeicosatetraenoic acid-induced vasoconstriction and inhibition of potassium current in cerebral vascular smooth muscle is dependent on activation of protein kinase C. J.Biol.Chem., 272, 27345-27352.

Laughlin, M. H., Korthuis, R. J., Dunker, D. J., \& Bache, R. J. (1996). Control of blood flow to cardiac and skeletal muscle during exercise. In Handbook of Physiology. Exercise: Regulation and Integration of Multiple Systems (pp. 705-769). Oxford University Press .

Lash, J. M. (1994). Contribution of arterial feed vessels to skeletal muscle functional hyperemia. J.Appl.Physiol, 76, 1512-1519.

Lash, J. M. \& Bohlen, H. G. (1987). Perivascular and tissue PO2 in contracting rat spinotrapezius muscle. Am.J.Physiol, 252, H1192-H1202.

Lau, K. S., Grange, R. W., Isotani, E., Sarelius, I. H., Kamm, K. E., Huang, P. L., \& Stull, J. T. (2000). nNOS and eNOS modulate cGMP formation and vascular response in contracting fast-twitch skeletal muscle. Physiol Genomics, 2, 21-27.

Laughlin, M. H. \& Korzick, D. H. (2001). Vascular smooth muscle: integrator of vasoactive signals during exercise hyperemia. Med.Sci.Sports Exerc., 33, 81-91.

Laursen, J. B., Rajagopalan, S., Galis, Z., Tarpey, M., Freeman, B. A., \& Harrison, D. G. (1997). Role of superoxide in angiotensin II-induced but not catecholamine-induced hypertension. Circulation, 95, 588-593.

Lenda, D. M. \& Boegehold, M. A. (2002a). Effect of a high salt diet on microvascular antioxidant enzymes. J.Vasc.Res., 39, 41-50.

Lenda, D. M. \& Boegehold, M. A. (2002b). Effect of a high-salt diet on oxidant enzyme activity in skeletal muscle microcirculation. Am.J.Physiol Heart Circ.Physiol, 282, H395-H402.

Lenda, D. M., Sauls, B. A., \& Boegehold, M. A. (2000). Reactive oxygen species may contribute to reduced endothelium-dependent dilation in rats fed high salt. Am.J.Physiol Heart Circ.Physiol, 279, H7-H14.

Liu, Y., Fredricks, K. T., Roman, R. J., \& Lombard, J. H. (1997). Response of resistance arteries to reduced $\mathrm{PO} 2$ and vasodilators during hypertension and elevated salt intake. Am.J.Physiol, 273, H869-H877. 
Liu, Y. \& Gutterman, D. D. (2002). Oxidative stress and potassium channel function. Clin.Exp.Pharmacol.Physiol, 29, 305-311.

Liu, Y., Rusch, N. J., \& Lombard, J. H. (1999). Loss of endothelium and receptor-mediated dilation in pial arterioles of rats fed a short-term high salt diet. Hypertension, 33, 686-688.

Lombard, J. H. \& Duling, B. R. (1981). Multiple mechanisms of reactive hyperemia in arterioles of the hamster cheek pouch. Am.J.Physiol, 241, H748-H755.

Lombard, J. H., Sylvester, F. A., Phillips, S. A., \& Frisbee, J. C. (2003). Highsalt diet impairs vascular relaxation mechanisms in rat middle cerebral arteries. Am.J.Physiol Heart Circ.Physiol, 284, H1124-H1133.

Lombard, J. H., Frisbee, J. C., Roman, R. J., \& Falck, J. R. (2004). Evaluation of cytochrome P450-4A omega-hydroxylase and 20hydroxyeicosatetraenoic acid as an 02 sensing mechanism in the microcirculation. Methods Enzymol., 381, 140-165.

Lucchesi, P. A., Belmadani, S., \& Matrougui, K. (2005). Hydrogen peroxide acts as both vasodilator and vasoconstrictor in the control of perfused mouse mesenteric resistance arteries. J.Hypertens., 23, 571-579.

Mackie, B. G. \& Terjung, R. L. (1983). Blood flow to different skeletal muscle fiber types during contraction. Am.J.Physiol, 245, H265-H275.

Makita, K., Falck, J. R., \& Capdevila, J. H. (1996). Cytochrome P450, the arachidonic acid cascade, and hypertension: new vistas for an old enzyme system. FASEB J., 10, 1456-1463.

Marshall, J. M. \& Tandon, H. C. (1984). Direct observations of muscle arterioles and venules following contraction of skeletal muscle fibres in the rat. J.Physiol, 350, 447-459.

Matoba, T., Shimokawa, H., Kubota, H., Morikawa, K., Fujiki, T., Kunihiro, I., Mukai, Y., Hirakawa, Y., \& Takeshita, A. (2002). Hydrogen peroxide is an endothelium-derived hyperpolarizing factor in human mesenteric arteries. Biochem.Biophys.Res.Commun., 290, 909-913.

Matoba, T., Shimokawa, H., Nakashima, M., Hirakawa, Y., Mukai, Y., Hirano, K., Kanaide, H., \& Takeshita, A. (2000). Hydrogen peroxide is an endothelium-derived hyperpolarizing factor in mice. J.Clin.Invest, 106, 1521-1530.

Matsuguchi, H., Schmid, P. G., Van Orden, D., \& Mark, A. L. (1981). Does vasopressin contribute to salt-induced hypertension in the Dahl strain? Hypertension, 3, 174-181. 
Matsuoka, H., Itoh, S., Kimoto, M., Kohno, K., Tamai, O., Wada, Y., Yasukawa, H., Iwami, G., Okuda, S., \& Imaizumi, T. (1997). Asymmetrical dimethylarginine, an endogenous nitric oxide synthase inhibitor, in experimental hypertension. Hypertension, 29, 242-247.

Mayer, B. \& Werner, E. R. (1995). In search of a function for tetrahydrobiopterin in the biosynthesis of nitric oxide. Naunyn Schmiedebergs Arch.Pharmacol., 351, 453-463.

McArdle, A., Pattwell, D., Vasilaki, A., Griffiths, R. D., \& Jackson, M. J. (2001). Contractile activity-induced oxidative stress: cellular origin and adaptive responses. Am.J.Physiol Cell Physiol, 280, C621-C627.

McArdle, A., van der, M. J., Close, G. L., Pattwell, D., Van Remmen, H., Huang, T. T., Richardson, A. G., Epstein, C. J., Faulkner, J. A., \& Jackson, M. J. (2004). Role of mitochondrial superoxide dismutase in contraction-induced generation of reactive oxygen species in skeletal muscle extracellular space. Am.J.Physiol Cell Physiol, 286, C1152-C1158.

McDonald, K. S., Delp, M. D., \& Fitts, R. H. (1992). Effect of hindlimb unweighting on tissue blood flow in the rat. J.Appl.Physiol, 72, 2210-2218.

McGiff, J. C. \& Quilley, J. (1999). 20-HETE and the kidney: resolution of old problems and new beginnings. Am.J.Physiol, 277, R607-R623.

McKay, M. K., Gardner, A. L., Boyd, D., \& Hester, R. L. (1998). Influence of venular prostaglandin release on arteriolar diameter during functional hyperemia. Hypertension, 31, 213-217.

Messina, E. J., Sun, D., Koller, A., Wolin, M. S., \& Kaley, G. (1992). Role of endothelium-derived prostaglandins in hypoxia-elicited arteriolar dilation in rat skeletal muscle. Circ.Res., 71, 790-796.

Messina, E. J., Weiner, R., \& Kaley, G. (1976). Prostaglandins and local circulatory control. Fed.Proc., 35, 2367-2375.

Miseta, A., Bogner, P., Berenyi, E., Kellermayer, M., Galambos, C., Wheatley, D. N., \& Cameron, I. L. (1993). Relationship between cellular ATP, potassium, sodium and magnesium concentrations in mammalian and avian erythrocytes. Biochim.Biophys.Acta, 1175, 133-139.

Minami, N., Mori, N., Nagasaka, M., Harada, T., Kurosawa, H., Kanazawa, M., \& Kohzuki, M. (2004). Effect of high-salt diet or chronic captopril treatment on exercise capacity in normotensive rats. Clin.Exp.Pharmacol.Physiol, 31, 197-201.

Miura, H., Bosnjak, J. J., Ning, G., Saito, T., Miura, M., \& Gutterman, D. D. (2003). Role for hydrogen peroxide in flow-induced dilation of human coronary arterioles. Circ.Res., 92, e31-e40. 
Miyata, N. \& Cowley, A. W., Jr. (1999). Renal intramedullary infusion of Larginine prevents reduction of medullary blood flow and hypertension in Dahl saltsensitive rats. Hypertension, 33, 446-450.

Miyata, N. \& Roman, R. J. (2005). Role of 20-hydroxyeicosatetraenoic acid (20-HETE) in vascular system. J.Smooth Muscle Res., 41, 175-193.

Mohazzab, K. M. \& Wolin, M. S. (1994). Properties of a superoxide aniongenerating microsomal NADH oxidoreductase, a potential pulmonary artery PO2 sensor. Am.J.Physiol, 267, L823-L831.

Mohrman, D. E. (1982). Lack of influence of potassium or osmolality on steady-state exercise hyperemia. Am.J.Physiol, 242, H949-H954.

Mohrman, D. E. \& Regal, R. R. (1988). Relation of blood flow to VO2, PO2, and PCO2 in dog gastrocnemius muscle. Am.J.Physiol, 255, H1004-H1010.

Morgan, D. A., DiBona, G. F., \& Mark, A. L. (1990). Effects of interstrain renal transplantation on $\mathrm{NaCl}$-induced hypertension in Dahl rats. Hypertension, 15, 436-442.

Morrison, A. R. \& Pascoe, N. (1981). Metabolism of arachidonate through NADPH-dependent oxygenase of renal cortex. Proc.Natl.Acad.Sci.U.S.A, 78, 73757378.

Mugge, A., Elwell, J. H., Peterson, T. E., Hofmeyer, T. G., Heistad, D. D., \& Harrison, D. G. (1991). Chronic treatment with polyethylene-glycolated superoxide dismutase partially restores endothelium-dependent vascular relaxations in cholesterol-fed rabbits. Circ.Res., 69, 1293-1300.

Murrant, C. L. \& Sarelius, I. H. (2000). Local and remote arteriolar dilations initiated by skeletal muscle contraction. Am.J.Physiol Heart Circ.Physiol, 279, H2285-H2294.

Murrant, C. L. \& Sarelius, I. H. (2002). Multiple dilator pathways in skeletal muscle contraction-induced arteriolar dilations. Am.J.Physiol Regul.Integr.Comp Physiol, 282, R969-R978.

Musch, T. I., McAllister, R. M., Symons, J. D., Stebbins, C. L., Hirai, T., Hageman, K. S., \& Poole, D. C. (2001). Effects of nitric oxide synthase inhibition on vascular conductance during high speed treadmill exercise in rats. Exp.Physiol, 86, 749-757.

Nakamura, K. \& Cowley, A. W., Jr. (1989). Sequential changes of cerebrospinal fluid sodium during the development of hypertension in Dahl rats. Hypertension, 13, 243-249. 
Nase, G. P., Tuttle, J., \& Bohlen, H. G. (2003). Reduced perivascular PO2 increases nitric oxide release from endothelial cells. Am.J.Physiol Heart Circ.Physiol, 285, H507-H515.

Nowicki, S., Chen, S. L., Aizman, O., Cheng, X. J., Li, D., Nowicki, C., Nairn, A., Greengard, P., \& Aperia, A. (1997). 20-Hydroxyeicosa-tetraenoic acid (20 HETE) activates protein kinase $\mathrm{C}$. Role in regulation of rat renal $\mathrm{Na}+\mathrm{K}+-\mathrm{ATPase}$. J.Clin.Invest, 99, 1224-1230.

Nurkiewicz, T. R. \& Boegehold, M. A. (1998). High dietary salt alters arteriolar myogenic responsiveness in normotensive and hypertensive rats. Am.J.Physiol, 275, H2095-H2104.

Nurkiewicz, T. R. \& Boegehold, M. A. (1999). Limitation of arteriolar myogenic activity by local nitric oxide: segment-specific effect of dietary salt. Am.J.Physiol, 277, H1946-H1955.

Nurkiewicz, T. R. \& Boegehold, M. A. (2000). Reinforcement of arteriolar myogenic activity by endogenous ANG II: susceptibility to dietary salt. Am.J.Physiol Heart Circ.Physiol, 279, H269-H278.

Nuttle, L. C., Ligon, A. L., Farrell, K. R., \& Hester, R. L. (1999). Inhibition of phospholipase $\mathrm{A} 2$ attenuates functional hyperemia in the hamster cremaster muscle. Am.J.Physiol, 276, H1289-H1294.

O'Leary, D. S., Dunlap, R. C., \& Glover, K. W. (1994). Role of endotheliumderived relaxing factor in hindlimb reactive and active hyperemia in conscious dogs. Am.J.Physiol, 266, R1213-R1219.

Oltman, C. L., Kane, N. L., Miller, F. J., Jr., Spector, A. A., Weintraub, N. L., \& Dellsperger, K. C. (2003). Reactive oxygen species mediate arachidonic acidinduced dilation in porcine coronary microvessels. Am.J.Physiol Heart Circ.Physiol, 285, H2309-H2315.

Omar, H. A., Mohazzab, K. M., Mortelliti, M. P., \& Wolin, M. S. (1993). O2dependent modulation of calf pulmonary artery tone by lactate: potential role of H2O2 and cGMP. Am.J.Physiol, 264, L141-L145.

Ominato, M., Satoh, T., \& Katz, A. I. (1996). Regulation of Na-K-ATPase activity in the proximal tubule: role of the protein kinase $\mathrm{C}$ pathway and of eicosanoids. J.Membr.Biol., 152, 235-243.

Osborn, J.L. (1991). Relation between sodium intake, renal function, and the regulation of arterial pressure. Hypertension, 17;I-9-I-96.

Pattwell, D. M., McArdle, A., Morgan, J. E., Patridge, T. A., \& Jackson, M. J. (2004). Release of reactive oxygen and nitrogen species from contracting skeletal muscle cells. Free Radic.Biol.Med., 37, 1064-1072. 
Petersen, M. C., Munzenmaier, D. H., \& Greene, A. S. (2006). Angiotensin II Infusion Restores Stimulated Angiogenesis in the Skeletal Muscle of Rats on a High Salt Diet. Am.J.Physiol Heart Circ.Physiol.

Pohl, U. \& Busse, R. (1989). Hypoxia stimulates release of endotheliumderived relaxant factor. Am.J.Physiol, 256, H1595-H1600.

Pries, A. R., Heide, J., Ley, K., Klotz, K. F., \& Gaehtgens, P. (1995). Effect of oxygen tension on regulation of arteriolar diameter in skeletal muscle in situ. Microvasc.Res., 49, 289-299.

Proctor, K. G. (1984). Reduction of contraction-induced arteriolar vasodilation by adenosine deaminase or theophylline. Am.J.Physiol, 247, H195H205.

Proctor, K. G., Damon, D. N., \& Duling, B. R. (1981). Tissue PO2 and arteriolar responses to metabolic stimuli during maturation of striated muscle. Am.J.Physiol, 241, H325-H331.

Proctor, K. G. \& Duling, B. R. (1982). Adenosine and free-flow functional hyperemia in striated muscle. Am.J.Physiol, 242, H688-H697.

Quigley, R., Baum, M., Reddy, K. M., Griener, J. C., \& Falck, J. R. (2000). Effects of 20-HETE and 19(S)-HETE on rabbit proximal straight tubule volume transport. Am.J.Physiol Renal Physiol, 278, F949-F953.

Radak, Z. (2000). Free Radicals in Exercise and Aging. Human Kinetics, Champaign, IL pp. 35-64.

Radawski, D. P., Hoppe, W., \& Haddy, F. J. (1975). Role of vasoactive substances in active hyperemia in skeletal muscle (38520). Proc.Soc.Exp.Biol.Med., 148, 270-276.

Radegran, G. \& Calbet, J. A. (2001). Role of adenosine in exercise-induced human skeletal muscle vasodilatation. Acta Physiol Scand., 171, 177-185.

Rafi, J. A. \& Boegehold, M. A. (1993). Microvascular responses to oxygen and muscle contraction in hypertensive Dahl rats. Int.J.Microcirc.Clin.Exp., 13, 8397.

Ralevic, V. \& Burnstock, G. (1998). Receptors for purines and pyrimidines. Pharmacol.Rev., 50, 413-492.

Rapp, J. P. (1982). Dahl salt-susceptible and salt-resistant rats. A review. Hypertension, 4, 753-763. 
Rathaus, M. \& Bernheim, J. (2002). Oxygen species in the microvascular environment: regulation of vascular tone and the development of hypertension. Nephrol.Dial.Transplant., 17, 216-221.

Reid, M. B., Haack, K. E., Franchek, K. M., Valberg, P. A., Kobzik, L., \& West, M. S. (1992a). Reactive oxygen in skeletal muscle. I. Intracellular oxidant kinetics and fatigue in vitro. J.Appl.Physiol, 73, 1797-1804.

Reid, M. B. (2001). Invited Review: redox modulation of skeletal muscle contraction: what we know and what we don't. J.Appl.Physiol, 90, 724-731.

Reid, M. B., Shoji, T., Moody, M. R., \& Entman, M. L. (1992b). Reactive oxygen in skeletal muscle. II. Extracellular release of free radicals. J.Appl.Physiol, $73,1805-1809$.

Roberts, A. M., Messina, E. J., \& Kaley, G. (1981). Prostacyclin (PGI2) mediates hypoxic relaxation of bovine coronary arterial strips. Prostaglandins, 21, 555-569.

Rodriguez-Martinez, M. A., Garcia-Cohen, E. C., Baena, A. B., Gonzalez, R., Salaices, M., \& Marin, J. (1998). Contractile responses elicited by hydrogen peroxide in aorta from normotensive and hypertensive rats. Endothelial modulation and mechanism involved. Br.J.Pharmacol., 125, 1329-1335.

Roman, R. J. (2002). P-450 metabolites of arachidonic acid in the control of cardiovascular function. Physiol Rev., 82, 131-185.

Saito, Y., Eraslan, A., Lockard, V., \& Hester, R. L. (1994). Role of venular endothelium in control of arteriolar diameter during functional hyperemia. Am.J.Physiol, 267, H1227-H1231.

Sato, A., Sakuma, I., \& Gutterman, D. D. (2003). Mechanism of dilation to reactive oxygen species in human coronary arterioles. Am.J.Physiol Heart Circ.Physiol, 285, H2345-H2354.

Schnackenberg, C. G., Tabor, B. L., Strong, M. H., \& Granger, J. P. (1997). Inhibition of intrarenal NO stimulates renin secretion through a macula densamediated mechanism. Am.J.Physiol, 272, R879-R886.

Scott, J. B., Rudko, M., Radawski, D., \& Haddy, F. J. (1970). Role of osmolarity, $\mathrm{K}+, \mathrm{H}+, \mathrm{Mg}++$, and $\mathrm{O} 2$ in local blood flow regulation. Am.J.Physiol, 218, 338-345.

Segal, S. S. (1991). Microvascular recruitment in hamster striated muscle: role for conducted vasodilation. Am.J.Physiol, 261, H181-H189. 
Segal, S. S. \& Duling, B. R. (1986). Communication between feed arteries and microvessels in hamster striated muscle: segmental vascular responses are functionally coordinated. Circ.Res., 59, 283-290.

Segal, S. S. \& Duling, B. R. (1987). Propagation of vasodilation in resistance vessels of the hamster: development and review of a working hypothesis. Circ.Res., 61, II20-II25.

Shoemaker, J. K., Naylor, H. L., Pozeg, Z. I., \& Hughson, R. L. (1996). Failure of prostaglandins to modulate the time course of blood flow during dynamic forearm exercise in humans. J.Appl.Physiol, 81, 1516-1521.

Shultz, P. J. \& Tolins, J. P. (1993). Adaptation to increased dietary salt intake in the rat. Role of endogenous nitric oxide. J.Clin.Invest, 91, 642-650.

Silveira, L. R., Pereira-Da-Silva, L., Juel, C., \& Hellsten, Y. (2003). Formation of hydrogen peroxide and nitric oxide in rat skeletal muscle cells during contractions. Free Radic.Biol.Med., 35, 455-464.

Simon, G., Jaeckel, M., \& Illyes, G. (2003). Development of structural vascular changes in salt-fed rats. Am.J.Hypertens., 16, 488-493.

Skinner, N. S., Jr. \& Costin, J. C. (1971). Interactions between oxygen, potassium, and osmolality in regulation of skeletal muscle blood flow. Circ.Res., 28, Suppl-85.

Sobey, C. G. \& Faraci, F. M. (2000). Knockout blow for channel identity crisis : vasodilation to potassium is mediated via Kir2.1. Circ.Res., 87, 83-84.

Sobey, C. G., Heistad, D. D., \& Faraci, F. M. (1997). Mechanisms of bradykinin-induced cerebral vasodilatation in rats. Evidence that reactive oxygen species activate K+ channels. Stroke, 28, 2290-2294.

Somers, M. J., Mavromatis, K., Galis, Z. S., \& Harrison, D. G. (2000). Vascular superoxide production and vasomotor function in hypertension induced by deoxycorticosterone acetate-salt. Circulation, 101, 1722-1728.

Sparks, H.V. Effects of local metabolic factors on vascular smooth muscle. In: Handbook of Physiology, The Cardiovascular System II, D.F. Bohr, A.P. Somlyo and H.V. Sparks (eds.). Bethesda, MD: American Physiological Society pp. 475-513 (1980).

Sullivan, S. M. \& Johnson, P. C. (1981). Effect of oxygen on blood flow autoregulation in cat sartorius muscle. Am.J.Physiol, 241, H807-H815.

Sun, D., Huang, A., Koller, A., \& Kaley, G. (1995). Flow-dependent dilation and myogenic constriction interact to establish the resistance of skeletal muscle arterioles. Microcirculation., 2, 289-295. 
Swei, A., Lacy, F., DeLano, F. A., Parks, D. A., \& Schmid-Schonbein, G. W. (1999). A mechanism of oxygen free radical production in the Dahl hypertensive rat. Microcirculation., 6, 179-187.

Swei, A., Lacy, F., DeLano, F. A., \& Schmid-Schonbein, G. W. (1997). Oxidative stress in the Dahl hypertensive rat. Hypertension, 30, 1628-1633.

Sydow, K. \& Munzel, T. (2003). ADMA and oxidative stress. Atheroscler.Suppl, 4, 41-51.

Takenaka, T., Forster, H., De Micheli, A., \& Epstein, M. (1992). Impaired myogenic responsiveness of renal microvessels in Dahl salt-sensitive rats. Circ.Res., 71, 471-480.

Tan, D. Y., Meng, S., Cason, G. W., \& Manning, R. D., Jr. (2000). Mechanisms of salt-sensitive hypertension: role of inducible nitric oxide synthase. Am.J.Physiol Regul.Integr.Comp Physiol, 279, R2297-R2303.

Thengchaisri, N. \& Kuo, L. (2003). Hydrogen peroxide induces endotheliumdependent and -independent coronary arteriolar dilation: role of cyclooxygenase and potassium channels. Am.J.Physiol Heart Circ.Physiol, 285, H2255-H2263.

Thomas, S. R., Chen, K., \& Keaney, J. F., Jr. (2002). Hydrogen peroxide activates endothelial nitric-oxide synthase through coordinated phosphorylation and dephosphorylation via a phosphoinositide 3-kinase-dependent signaling pathway. J.Biol.Chem., 277, 6017-6024.

Tolins, J. P. \& Shultz, P. J. (1994). Endogenous nitric oxide synthesis determines sensitivity to the pressor effect of salt. Kidney Int., 46, 230-236.

Tominaga, S., Suzuki, T., \& Nakamura, T. (1973). Evaluation of roles of potassium, inorganic phosphate, osmolarity, $\mathrm{pH}, \mathrm{pCO2,} \mathrm{p} 2$, and adenosine or AMP in exercise and reactive hyperemias in canine hindlimb muscles. Tohoku J.Exp.Med., 109, 347-363.

Vasquez-Vivar, J., Kalyanaraman, B., Martasek, P., Hogg, N., Masters, B. S., Karoui, H., Tordo, P., \& Pritchard, K. A., Jr. (1998). Superoxide generation by endothelial nitric oxide synthase: the influence of cofactors.

Proc.Natl.Acad.Sci.U.S.A, 95, 9220-9225.

Wang, D. H. \& Prewitt, R. L. (1990). Captopril reduces aortic and microvascular growth in hypertensive and normotensive rats. Hypertension, 15, 6877.

Wang, D. H. \& Prewitt, R. L. (1993). Alterations of mature arterioles associated with chronically reduced blood flow. Am.J.Physiol, 264, H40-H44. 
Wang, J., Roman, R. J., Falck, J. R., de la, C. L., \& Lombard, J. H. (2005). Effects of high-salt diet on CYP450-4A omega-hydroxylase expression and active tone in mesenteric resistance arteries. Am.J.Physiol Heart Circ.Physiol, 288, H1557H1565.

Wang, J., Maier, K. G., Roman, R. J., de la, C. L., Zhu, J., Henderson, L., \& Lombard, J. H. (2004). Expression of cytochrome P450-4A isoforms in the rat cremaster muscle microcirculation. Microcirculation., 11, 89-96.

Wang, M. H., Zhang, F., Marji, J., Zand, B. A., Nasjletti, A., \& LaniadoSchwartzman, M. (2001). CYP4A1 antisense oligonucleotide reduces mesenteric vascular reactivity and blood pressure in SHR. Am.J.Physiol Regul.Integr.Comp Physiol, 280, R255-R261.

Weber, D. S., Frisbee, J. C., \& Lombard, J. H. (1999). Selective potentiation of angiotensin-induced constriction of skeletal muscle resistance arteries by chronic elevations in dietary salt intake. Microvasc.Res., 57, 310-319.

Weber, D. S. \& Lombard, J. H. (2000). Elevated salt intake impairs dilation of rat skeletal muscle resistance arteries via ANG II suppression. Am.J.Physiol Heart Circ.Physiol, 278, H500-H506.

Weber, D. S. \& Lombard, J. H. (2001). Angiotensin II AT1 receptors preserve vasodilator reactivity in skeletal muscle resistance arteries. Am.J.Physiol Heart Circ.Physiol, 280, H2196-H2202.

Wei, E. P., Ellis, E. F., \& Kontos, H. A. (1980). Role of prostaglandins in pial arteriolar response to $\mathrm{CO} 2$ and hypoxia. Am.J.Physiol, 238, H226-H230.

Wei, E. P., Kontos, H. A., \& Beckman, J. S. (1996). Mechanisms of cerebral vasodilation by superoxide, hydrogen peroxide, and peroxynitrite. Am.J.Physiol, 271, H1262-H1266.

Welsh, D. G. \& Segal, S. S. (1997). Coactivation of resistance vessels and muscle fibers with acetylcholine release from motor nerves. Am.J.Physiol, 273, H156-H163.

Welsh, D. G. \& Segal, S. S. (1998). Endothelial and smooth muscle cell conduction in arterioles controlling blood flow. Am.J.Physiol, 274, H178-H186.

Widimsky, J., Kuchel, O., Debinski, W., \& Du, S. P. (1991). High salt intakeinduced changes in atrial natriuretic factor kinetics are mediated by clearance receptors. Proc.Soc.Exp.Biol.Med., 198, 555-560.

Wilson, J. R. \& Kapoor, S. C. (1993). Contribution of prostaglandins to exercise-induced vasodilation in humans. Am.J.Physiol, 265, H171-H175. 
Wolin, M. S. \& Burke, T. M. (1987). Hydrogen peroxide elicits activation of bovine pulmonary arterial soluble guanylate cyclase by a mechanism associated with its metabolism by catalase. Biochem.Biophys.Res.Commun., 143, 20-25

Wolin, M. S. (1996). Reactive oxygen species and vascular signal transduction mechanisms. Microcirculation., 3, 1-17.

Wolin, M. S. (2000). Interactions of oxidants with vascular signaling systems. Arterioscler.Thromb.Vasc.Biol., 20, 1430-1442.

Wolin, M. S., Ahmad, M., \& Gupte, S. A. (2005). Oxidant and redox signaling in vascular oxygen sensing mechanisms: basic concepts, current controversies, and potential importance of cytosolic NADPH. Am.J.Physiol Lung Cell Mol.Physiol, 289, L159-L173.

Wolin, M. S., Burke-Wolin, T. M., \& Mohazzab, H. (1999). Roles for $\mathrm{NAD}(\mathbf{P}) \mathrm{H}$ oxidases and reactive oxygen species in vascular oxygen sensing mechanisms. Respir.Physiol, 115, 229-238.

Wood, P. A., Hamm, D. A., Chen, P. Y., \& Sanders, P. W. (1998). Studies of arginine metabolism and salt sensitivity in the Dahl/Rapp rat models of hypertension. Mol.Genet.Metab, 64, 80-83.

Yada, T., Shimokawa, H., Hiramatsu, O., Kajita, T., Shigeto, F., Goto, M., Ogasawara, Y., \& Kajiya, F. (2003). Hydrogen peroxide, an endogenous endothelium-derived hyperpolarizing factor, plays an important role in coronary autoregulation in vivo. Circulation, 107, 1040-1045.

Yang, Z., Zhang, A., Altura, B. T., \& Altura, B. M. (1999). Hydrogen peroxide-induced endothelium-dependent relaxation of rat aorta involvement of Ca2+ and other cellular metabolites. Gen.Pharmacol., 33, 325-336.

Yang, Z. W., Zheng, T., Zhang, A., Altura, B. T., \& Altura, B. M. (1998). Mechanisms of hydrogen peroxide-induced contraction of rat aorta. Eur.J.Pharmacol., 344, 169-181.

Young, E. W. \& Sparks, H. V. (1980). Prostaglandins and exercise hyperemia of dog skeletal muscle. Am.J.Physiol, 238, H191-H195.

Zhang, F., Wang, M. H., Krishna, U. M., Falck, J. R., Laniado-Schwartzman, M., \& Nasjletti, A. (2001). Modulation by 20-HETE of phenylephrine-induced mesenteric artery contraction in spontaneously hypertensive and Wistar-Kyoto rats. Hypertension, 38, 1311-1315.

Zhao, X., Pollock, D. M., Inscho, E. W., Zeldin, D. C., \& Imig, J. D. (2003). Decreased renal cytochrome $\mathbf{P 4 5 0} 2 \mathrm{C}$ enzymes and impaired vasodilation are associated with angiotensin salt-sensitive hypertension. Hypertension, 41, 709-714 
Zhu, D., Birks, E. K., Dawson, C. A., Patel, M., Falck, J. R., Presberg, K., Roman, R. J., \& Jacobs, E. R. (2000). Hypoxic pulmonary vasoconstriction is modified by P-450 metabolites. Am.J.Physiol Heart Circ.Physiol, 279, H1526-H1533.

Zhu, J., Drenjancevic-Peric, I., McEwen, S. T., Friesema, J., Schulta, D. R., Yu, M., Roman, R. J., \& Lombard, J. H. (2006). Role of Superoxide and Angiotensin II Suppression In Salt-Induced Changes in Endothelial Ca2+ Signaling and NO Production in Rat Aorta. Am.J.Physiol Heart Circ.Physiol.

Zhu, J., Mori, T., Huang, T., \& Lombard, J. H. (2004). Effect of high-salt diet on NO release and superoxide production in rat aorta. Am.J.Physiol Heart Circ.Physiol, 286, H575-H583.

Zou, A. P., Fleming, J. T., Falck, J. R., Jacobs, E. R., Gebremedhin, D., Harder, D. R., \& Roman, R. J. (1996). 20-HETE is an endogenous inhibitor of the large-conductance $\mathrm{Ca}(2+)$-activated $\mathrm{K}+$ channel in renal arterioles. Am.J.Physiol, 270, R228-R237.

Zou, M. H., Shi, C., \& Cohen, R. A. (2002). Oxidation of the zinc-thiolate complex and uncoupling of endothelial nitric oxide synthase by peroxynitrite. J.Clin.Invest, 109, 817-826. 


\section{CURRICULUM VITAE}

\section{PERSONAL DETAILS}

\begin{tabular}{|c|c|}
\hline Name & Paul J. Marvar \\
\hline \multicolumn{2}{|l|}{ Current } \\
\hline Position & Graduate Research Assistant /Doctoral Candidate \\
\hline \multirow[t]{4}{*}{ Address } & Department of Physiology and Pharmacology \\
\hline & West Virginia University School of Medicine \\
\hline & Center for Interdisciplinary Research in Cardiovascular Sciences \\
\hline & Morgantown, WV 26506-9229 \\
\hline e-mail & pmarvar@mix.wvu.edu \\
\hline Telephone & (304) 293-7813 (w); (304) 685-9687 (cell) \\
\hline $\begin{array}{l}\text { Birth Place } \\
\text { \& Date }\end{array}$ & Cleveland, Ohio \\
\hline
\end{tabular}

\section{EDUCATION}

1993-1997

1999-2001

2001-present
Canisius College, Buffalo, NY Northern Illinois University

West Virginia University

Anticipated completion: May 2006 $\begin{array}{ll}\text { BS } & \text { Athletic Training } \\ \text { MSEd } & \text { Exercise Physiology } \\ \text { PhD } & \text { Physiology \& Pharmacology }\end{array}$

\section{PROFESSIONAL EXPERIENCE}

2001-present Graduate Research Assistant, West Virginia University School of Medicine Center for Interdisciplinary Research in Cardiovascular Sciences

2000 Student Researcher Program, American Sports Medicine Institute, Birmingham, AL

1999-2001 Graduate Assistant in Athletic Training, Northern Illinois University Department of Kinesiology \& Physical Education

1998-1999 Assistant Athletic Trainer, Buffalo State College Department of Intercollegiate Athletics

1998-1999 Student Research Assistant, Canisius College, Buffalo, NY

Department of Sports Medicine, Health and Human Performance

\section{HONORS AND AWARDS}

2005 Finalist-Van Liere Memorial Research Convocation, West Virginia University

2001 Outstanding Graduate Student Award, Northern Illinois University

2000 Stroup-Dunn Scholarship Award, Northern Illinois University

1997 Deans Academic Merit List, Canisius College

1993 National Scholar Athlete, United States Army Reserve 


\title{
PROFESSIONAL MEMBERSHIPS
}

\author{
2004-present Society for Experimental Biology and Medicine \\ 2003-present Microcirculatory Society \\ 2003-present Society for Free Radical Biology and Medicine \\ 2003-present The American Physiological Society \\ 2001-present American College of Sports Medicine \\ 1996-present National Athletic Trainers' Association
}

\section{RESEARCH INTERESTS}

Understanding the roles and interactions of nitric oxide (NO), reactive oxygen species (ROS) and antioxidants in cardiovascular health and disease as well as a long-standing interest in the effects of exercise in the prevention and treatment of cardiovascular diseases.

\section{PUBLICATIONS}

1. Marvar, P.J. and Boegehold, M.A. Reduced arteriolar responses to skeletal muscle contraction after ingestion of a high salt diet. J Vasc Res. 42(3), 226-236, 2005

2. Nurkiewicz, T.R., Porter, D.W., Barger, M., Marvar, P.J., Hubbs, A., Millecchia, L.,Castranova, V., and Boegehold, M.A. Systemic microvascular dysfunction after pulmonary particulate matter exposure. Environ Health Perspect. (in press), 2006

3. Marvar, P.J., Hammer, L.W., and Boegehold, M.A. Hydrogen peroxide-dependent arteriolar dilation in contracting muscle of rats fed normal and high salt diets. Am J Physiol Heart Circ Physiol. (submitted), 2006

\section{ABSTRACTS PRESENTED AT SCIENTIFIC MEETINGS}

1. Dolan, M.G., Mendel, F.M., Teprovich, J.M., Marvar, P.J. and Bibi K.W. Effects of dependent positioning and cold water immersions on non-traumatized ankle volumes. J Athl Train. 34, 2, S-17, 1999

2. Marvar, P.J., Ragan, B.G., Dolan, M.G., Teprovich, J.M. and Bibi, K.W. Effects of focal and circumferential compression on non-traumatized ankle volumes. J Athl Train. 35, 2, S-50, 2000

3. Ragan, B.G., Marvar, P.J., Dolan, M.G. and Bibi, K.W. Effects of magnesium sulfate and warm baths on non-traumatized ankle volumes. J Athl Train. 35, 2, S-43, 2000

4. Marvar, P.J., Plowman, S.A. and Mestek, R. An evaluation of selected claims of liquid creatine. Med Sci Sports Exerc. 33, S-204, 2001

5. Yeater, R.A., Marvar, P.J. and Hornsby, W.G. Chronotropic response during graded exercise predicts exercise adherence in a high-risk rural population. Med Sci Sports Exerc. 34, S-64, 2002 
6. Zheng, N., Ragan, B.G., Marvar, P.J., Fleisig, G. and Barrentine, S. Normalization of surface emg signals-comparison among effort, joint position and processing method. Proceedings of the Fourth World Congress of Biomechanics, Calgary, Alberta, Canada, 2002

7. Marvar, P.J., Schlabach, G.A., Nelson, R.E. and Looney, M.A. Effects of ice application on nitric oxide levels following rhythmic handgrip contractions. Med Sci Sports Exerc. 34, S-100, 2002

8. Marvar, P.J. and Boegehold, M.A. Reduced arteriolar responses in rats fed high salt are not due to altered nitric oxide (NO) activity. FASEB J. A543, 346.26, 2003

9. Marvar, P.J., Balch-Samora, J. and Boegehold, M.A. Reduced arteriolar responses to increased oxygen tension $\left(\mathrm{PO}_{2}\right)$ in rats fed high salt. FASEB J. A1247, 688.25, 2005

10. Marvar, P.J. and Boegehold, M.A. High salt intake may reduce the contribution of hydrogen peroxide to functional hyperemia in skeletal muscle. FASEB J. A1247, 688.26, 2005

11. Nurkiewicz, T.R., Porter, D.W., Barger, M., Marvar, P.J., Hubbs, A., Millecchia, L.,Castranova, V., and Boegehold, M.A. Systemic microvascular dysfunction after pulmonary particulate matter exposure. FASEB J. A1263, 691.10, 2005

12. Marvar, P.J. and Boegehold, M.A. Dietary salt reduces hydrogen peroxide-dependent dilation in contracting muscle. FASEB J. (in press), 2006 Abstract \# 6799

\section{RESEARCH PRESENTATIONS}

1. "Clinical Implications in the Management of Ankle Edema", Canisius College Athletic Training Education Program, Buffalo, NY, June 1999.

2. "Effects of Ice Application on Nitric Oxide Levels Following Rhythmic Handgrip Contractions", Masters Thesis Defense, Northern Illinois University Department of Kinesiology \& Physical Education, May 2001.

3. "Effect of Dietary Salt on Arteriolar Responses to Muscle Contraction", Annual Julie Betschart Research Symposium, West Virginia University Department of Physiology \& Pharmacology, April 2003.

4. "Effect of Dietary Salt in the Microcirculation: The Role of Reactive Oxygen Species", Summer Seminar Series, West Virginia University Department of Physiology \& Pharmacology, August 2003.

5. "The Role of Reactive Oxygen Species in the Control of Oxygen Dependent Arteriolar Tone", American Heart Association, Pre-doctoral fellowship grant, West Virginia University Department of Physiology \& Pharmacology faculty, August 2004.

6. "Reduced Metabolic Responses in the Microvasculature Following a High Salt Diet", Summer Seminar Series, West Virginia University Department of Physiology \& Pharmacology, August 2004. 
7. "Reduced Arteriolar Responses to Increased Oxygen Tension $\left(\mathrm{PO}_{2}\right)$ in Rats Fed High Salt", Van Liere Memorial Research Convocation, West Virginia University School of Medicine, April 2005.

8. "Reduced Arteriolar Responses to Increased Oxygen Tension $\left(\mathrm{PO}_{2}\right)$ in Rats Fed High Salt. Annual Julie Betschart Research Symposium, West Virginia University Department of Physiology \& Pharmacology, April 2005.

\section{INVITED LECTURES}

1. "An Evaluation of Selected Claims of Liquid Creatine", Sports Nutrition Conference, Coronado, CA, June 25-26, 2002.

2. Participant in Panel Discussion on "Ephedra and Creatine", Sports Nutrition Conference, Coronado, CA, June 25-26, 2002.

\section{RESEARCH AND TRAVEL SUPPORT}

2005 - West Virginia University School of Medicine, Graduate Student Travel Award (\$400)

2003 - West Virginia University Department of Physiology, Travel Grant (\$250)

2001 - Northern Illinois University, Graduate School Travel Grant (\$250)

2000 - Northern Illinois University, Graduate School Research Project Funding (\$150)

2000 - Northern Illinois University, Graduate School Travel Grant (\$325)

\section{TEACHING EXPERIENCE}

2004-present Lecturer, Physiology 441 - Cardiovascular Physiology, 5 lecture Hours (300+ undergraduate students), West Virginia University School of Medicine, Dept. of Physiology \& Pharmacology

2004-present Tutorial Assistant, Physiology 441, West Virginia University School of Medicine, Dept. of Physiology \& Pharmacology

2003-2004 Small Group Facilitator, Human Function course (14 medical students) West Virginia University School of Medicine, Dept. of Physiology \& Pharmacology

\section{COMMITTEES AND SERVICE}

2005-present Guest Reviewer- Environmental Health Perspectives

2004-present Guest Reviewer- Journal of Athletic Training

2004-present Guest Reviewer- Athletic Therapy Today

2005-present PhD Student Leader Representative, West Virginia University, School of Medicine

2003-present Senate Committee Member, Graduate Student Organization, West Virginia University

2004-2005 Curriculum Committee, Graduate Student Organization, West Virginia University

1999-2001 Athletic Training Committee, Northern Illinois University 